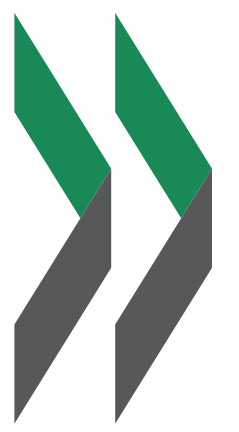

\title{
Equity in Education
}

\section{BREAKING DOWN BARRIERS TO SOCIAL MOBILITY}

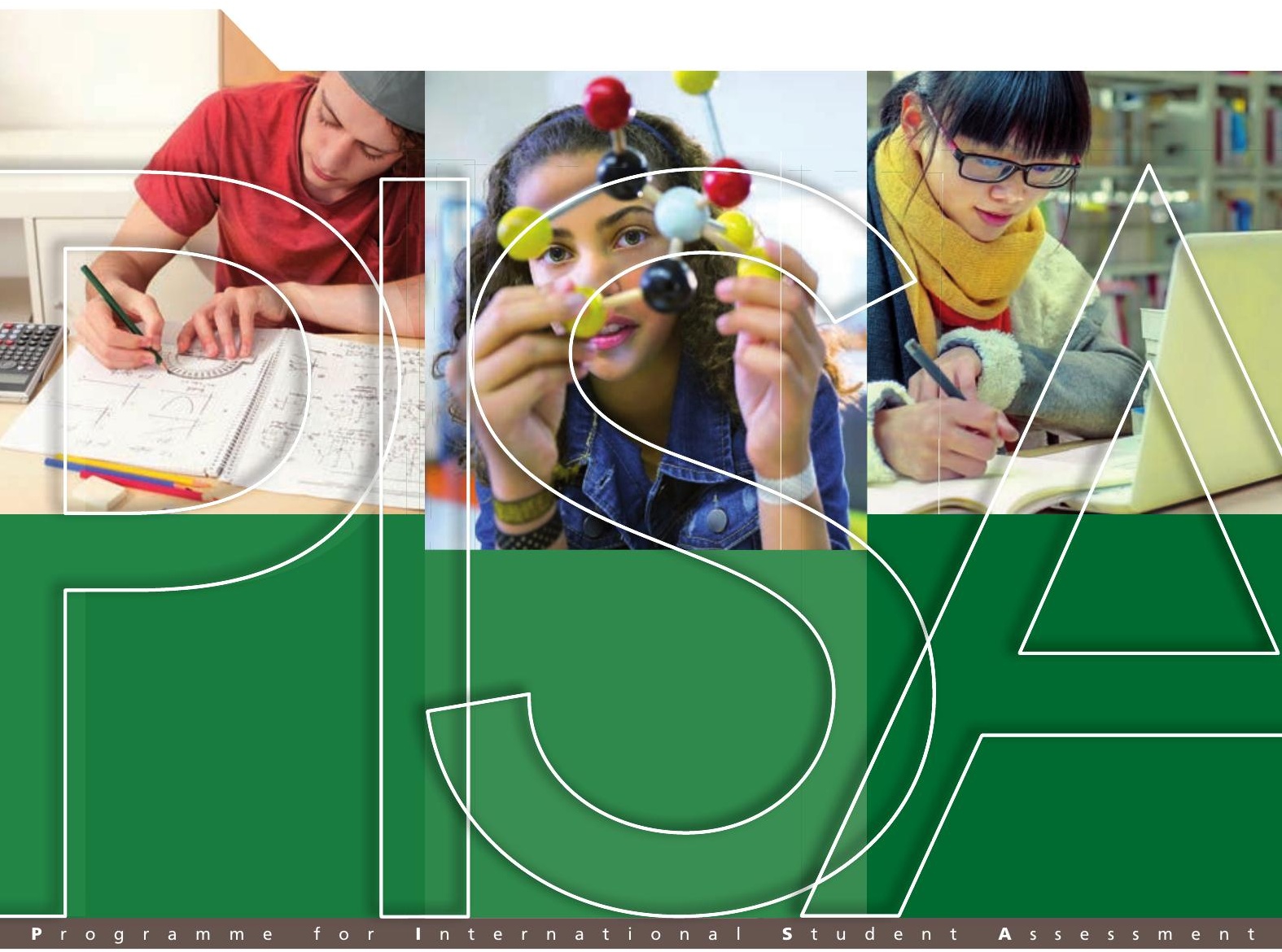

O $\gg$ OECD 



\author{
PISA
}

\title{
Equity in Education
}

BREAKING DOWN BARRIERS TO SOCIAL MOBILITY 
This work is published under the responsibility of the Secretary-General of the OECD. The opinions expressed and arguments employed herein do not necessarily reflect the official views of the OECD member countries.

This document, as well as any data and any map included herein, are without prejudice to the status of or sovereignty over any territory, to the delimitation of international frontiers and boundaries and to the name of any territory, city or area.

Please cite this publication as:

OECD (2018), Equity in Education: Breaking Down Barriers to Social Mobility, PISA, OECD Publishing, Paris. https://doi.org/10.1787/9789264073234-en

ISBN 978-92-64-05673-2 (print)

ISBN 978-92-64-07323-4 (PDF)

ISBN 978-92-64-30696-7 (HTML)

ISBN 978-92-64-30695-0 (epub)

Series: PISA

ISSN: $1990-8539$ (print)

ISSN: 1996-3777 (online)

The statistical data for Israel are supplied by and under the responsibility of the relevant Israeli authorities. The use of such data by the OECD is without prejudice to the status of the Golan Heights, East Jerusalem and Israeli settlements in the West Bank under the terms of international law.

\section{Photo credits:}

๑) RelaXimages/Corbis

(c) Hero Images Inc./Getty Images

(c) LIUSHENGFILM/Shutterstock

(c) Tyler Olsen/Shutterstock

(c) Flying Colours Ltd/Getty Images

(c) Jacobs Stock Photography/Getty Images

(c) Geostock/GO Premium/GraphicObsesion

Corrigenda to OECD publications may be found on line at: www.oecd.org/publishing/corrigenda.

(c) OECD 2018

This work is available under the Creative Commons Attribution-NonCommercial-ShareAlike 3.0 IGO (CC BY-NC-SA 3.0 IGO). For specific information regarding the scope and terms of the licence as well as possible commercial use of this work or the use of PISA data please consult Terms and Conditions on www.oecd.org. 


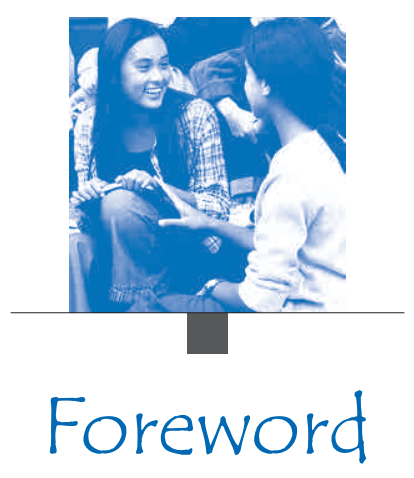

What wise parents want for their children is what the government should want for all children. Children from wealthier families will find many open doors to a successful life. But children from poor families often have just one chance in life, and that is a good school that gives them an opportunity to develop their potential. Those who miss that boat rarely catch up; in fact, this report provides compelling data on how subsequent education opportunities tend to reinforce social disparities that appear early in life.

All of this is well known, and yet in many countries, a student's or school's postal code is still the best predictor for the quality of the education that students acquire. It is particularly disappointing that surprisingly little headway has been made towards giving all children an equal chance to succeed. However, the fact that the impact of social background on educational success varies greatly across countries shows there is nothing inevitable about disadvantaged students performing worse than more advantaged students. Results from education systems as different as Estonia, Hong Kong, Shanghai and Viet Nam show that the poorest students in one region might score higher than the wealthiest students in another country. Within countries too, there are many students who succeed despite predicted failure. On average across OECD countries, more than one in ten disadvantaged students are among the top quarter of achievers in science.

This report looks at these issues in greater depth, and provides valuable lessons for policy that can be gleaned from the world's most equitable school systems. A first lesson is to start early, and promote access to the kind of childhood education and care that can help children acquire essential social and emotional skills, particularly children from disadvantaged families. Countries also need to set ambitious goals for and monitor the progress of disadvantaged students, target additional resources towards disadvantaged students and schools, and reduce the concentration of disadvantaged students in schools.

The more difficult but no less important policy levers revolve around human resources. This is about developing teachers' capacity to identify students' needs and to manage diversity in classrooms, to build strong links with parents, and to encourage parents to be more involved in their child's education. Teachers can also foster students' well-being and create a positive learning environment for all students by emphasising the importance of persistence, investing effort and using appropriate learning strategies, and by encouraging students to support each other, such as through peer-mentoring programmes. 
Clearly, the most impressive outcome of world-class school systems is that they deliver high-quality education across the entire school system so that every student benefits from excellent teaching. Achieving greater equity in education is not only a social-justice imperative, it is also a way to use resources more efficiently, and to increase the supply of knowledge and skills that fuel economic growth and promote social cohesion. Not least, how we treat the most vulnerable students shows who we are as a society.

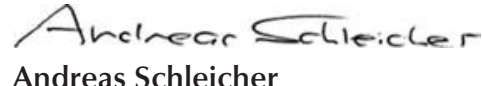

Director for Education and Skills 


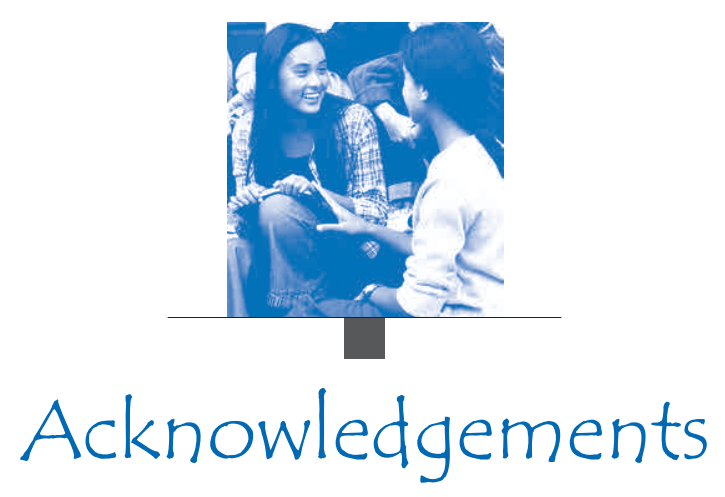

This report is the product of a joint effort between the countries participating in PISA and the OECD Secretariat. The report was prepared by Daniel Salinas, with contributions from Mario Piacentini, Pauline Givord, Ariel Gruver, Gwénaël Jacotin, Juan León (Grupo de Análisis para el Desarrollo [GRADE]), Camille Marec, Jeffrey Mo, Bonaventura Pacileo and Giannina Rech. Mario Piacentini, Bonaventura Pacileo and Ariel Gruver drafted Chapter 5. Marilyn Achiron edited the report. Statistical and analytical support was co-ordinated by Giannina Rech and provided by Gwénaël Jacotin with the help of Hélène Guillou. Andreas Schleicher, Yuri Belfali, Miyako Ikeda, Marco Paccagnella, William Thorn and Rodrigo Torres provided valuable feedback at various stages of the report. Rebecca Tessier co-ordinated production and JOUVE designed the publication. Administrative support was provided by Juliet Evans, Thomas Marwood, Lesley O'Sullivan and Hanna Varkki. The development of the report was steered by the PISA Governing Board, chaired by Michele Bruniges (Australia), with Peggy Carr (United States), Jimin Cho (Korea), Maria Helena Guimarães de Castro (Brazil) and Carmen Tovar Sánchez (Spain) as vice-chairs. 



\section{Table of Contents}

EXECUTIVE SUMMARY

READER'S GUIDE.

CHAPTER 1 OVERVIEW AND POLICY IMPLICATIONS

Equity in education and social mobility.

Key findings.

What the results imply for policy

CHAPTER 2 HOW IS EQUITY IN EDUCATION CHANGING?

Equity in education: A framework

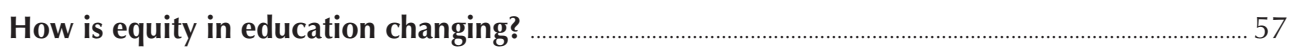

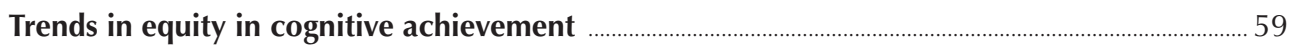

- Socio-economic disparities in student achievement ....................................................................... 59

- Genesis and growth of the achievement gap during students' lives .................................................... 66

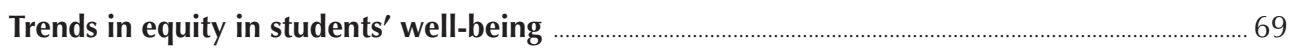

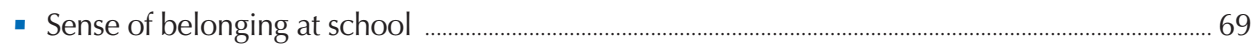

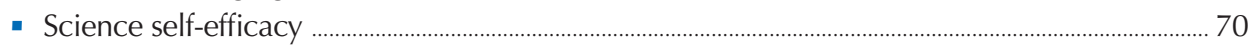

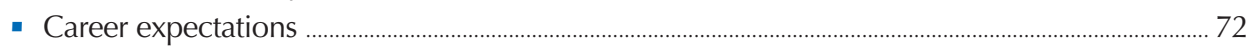

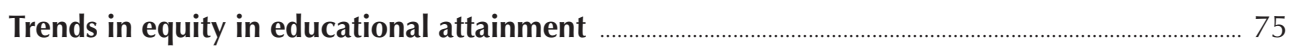

- Equity among countries in average years of schooling …………………………………………........... 76

- Equity in the attainment of upper secondary and tertiary education ................................................. 77

\section{CHAPTER 3 ACADEMIC AND SOCIO-EMOTIONAL RESILIENCE AMONG}

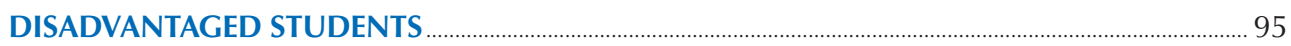

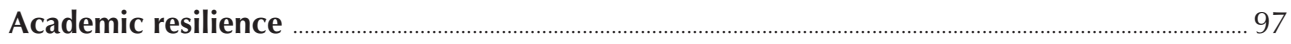

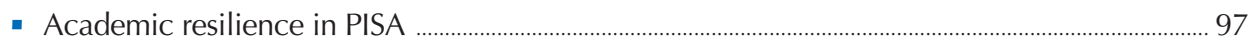

- Academic resilience across countries ................................................................................................ 101

- Student and school characteristics related to academic resilience ................................................. 106

Social and emotional resilience …….................................................................................................................. 111

- Academic and social and emotional resilience .............................................................................. 115 
CHAPTER 4 ARE DISADVANTAGED STUDENTS AFFECTED

BY THE SOCIO-ECONOMIC PROFILE OF THEIR SCHOOL?.

Socio-economic segregation of disadvantaged students in schools

- Why is the segregation of disadvantaged students in schools more frequently

observed in some countries than in others?

How the performance of disadvantaged students may be affected

by a school's socio-economic profile

- Why does a school's socio-economic profile matter for student performance?

- The performance of disadvantaged students and schools' socio-economic profile

- Factors that may mediate the relationship between school socio-economic profile and performance among disadvantaged students

- The relationship between socio-economic diversity in school and student performance

\section{CHAPTER 5 EDUCATIONAL MOBILITY AND SCHOOL-TO-WORK TRANSITIONS}

AMONG DISADVANTAGED STUDENTS

Defining social and educational mobility

Progression into higher education and PISA performance at age 15

Early career outcomes and PISA performance.

Understanding the forces behind educational mobility and school-to-work transitions

- Differences in 15-year-old students' attitudes and behaviour

- Differences in family background

- Differences in school characteristics

ANNEX A TECHNICAL NOTES ON ANALYSES IN THIS REPORT.

ANNEX B LIST OF TABLES AVAILABLE ON LINE

BOX

Box 2.1 How PISA measures socio-economic status

Box 2.2 The socio-economic gradient: Measuring socio-economic inequalities in cognitive achievement.

Box 2.3 Measuring trends in educational attainment.

Box 3.1 Are measures of social and emotional well-being internationally comparable?

Box $5.1 \quad$ Longitudinal country data

Box 5.2 The Danish case: Linking PISA to PIAAC 


\section{FIGURES}

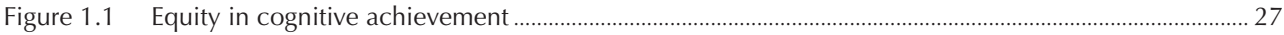

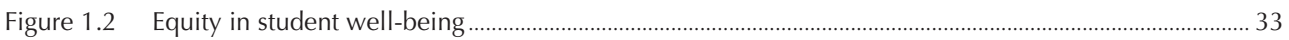

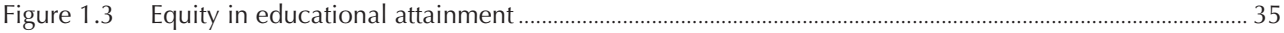

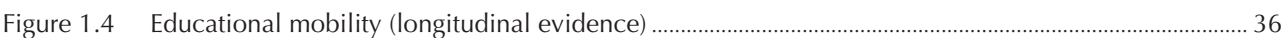

Figure 1.5 School-to-work transitions (longitudinal evidence) …..................................................................... 37

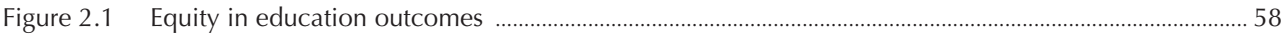

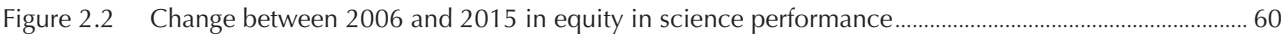

Figure 2.3 Students' socio-economic status and average performance across OECD countries .............................61

Figure 2.4 Change between 2000 and 2015 in equity in reading performance .................................................64

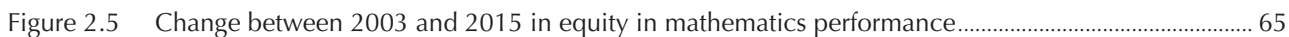

Figure 2.6 Socio-economic disparities in mathematics performance over students' lifetime .................................67

Figure 2.7 Change between 2003 and 2015 in sense of belonging at school,

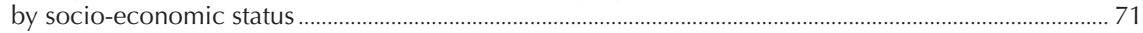

Figure 2.8 Change between 2006 and 2015 in science self-efficacy, by socio-economic status........................... 73

Figure 2.9 Change between 2006 and 2015 in career expectations, by socio-economic status .......................... 74

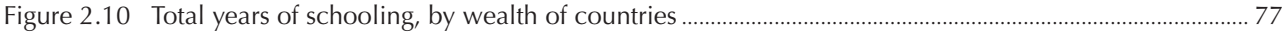

Figure 2.11 Highest level of education completed, by parents' education .................................................................... 78

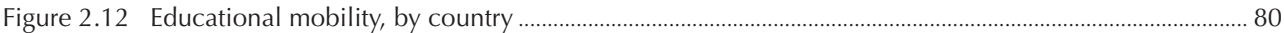

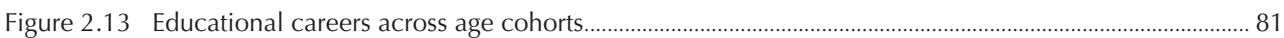

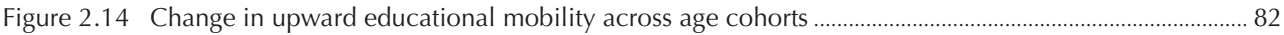

Figure 2.15 Likelihood of attaining tertiary education, by parents' education ........................................................ 85

Figure 2.16 Trends in likelihood of completing tertiary education, by parents' education .........................................8 86

Figure 2.17 National trends in likelihood of completing tertiary education, by parents' education

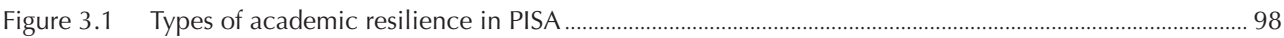

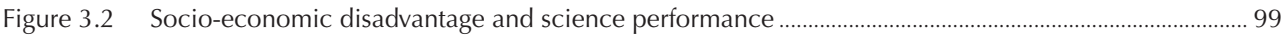

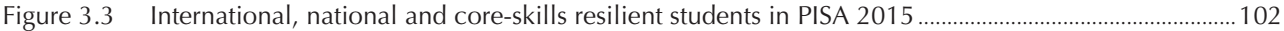

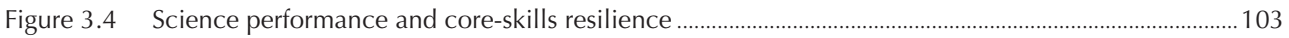

Figure 3.5 Equity in science achievement and national resilience …................................................................... 105

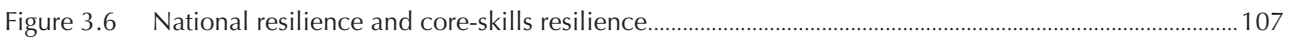

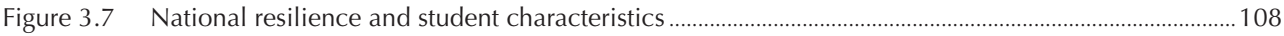

Figure 3.8 Core-skills resilience and student characteristics ......................................................................... 110

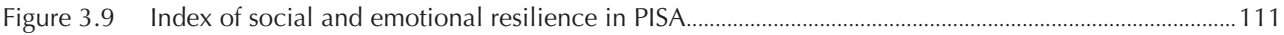

Figure 3.10 Social and emotional resilience, and its components .......................................................................... 113

Figure 3.11 Academic resilience, and the likelihood of social and emotional resilience...................................... 116 
Figure 4.1 Disadvantaged students in disadvantaged schools

Figure 4.2 Evolution since 2006 of the percentage of disadvantaged students in schools, by school socio-economic profile

Figure 4.3 Science performance, by student and school socio-economic profile............................................... 127

Figure 4.4 Change in student performance associated with school socio-economic profile.....

Figure 4.5 School policies, practices and characteristics, and the impact of socio-economic status on science performance

Figure 4.6 Student truancy and the impact of socio-economic status on science performance............................133

Figure 4.7 Socio-economic diversity in school and student performance

Figure 5.1 Description of longitudinal data sets

Figure 5.2 Highest level of education completed, by socio-economic status

Figure 5.3 University completion, by quarter of PISA reading performance

Figure 5.4 Completed university education at age 25, by PISA reading performance and parents' education

Figure 5.5 Employment status at age 25, by socio-economic background

Figure 5.6 Skilled employment, by parents' education and PISA reading performance 151

Figure 5.7 Variation in numeracy proficiency explained by student characteristics and educational attainment (Denmark)

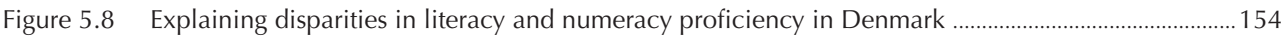

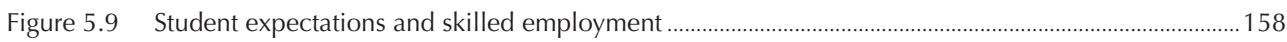

Figure 5.10 University completion rates, by effort and perseverance ........................................................................159

Figure 5.11 University completion rates, by frequency of cultural activity, parents' education and PISA reading performance

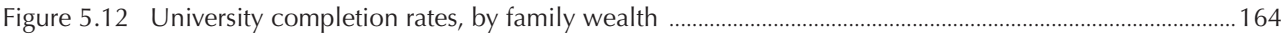

Figure 5.13 University completion rates among advantaged students, by school composition and student performance

Figure 5.14 University completion rates among disadvantaged students, by school composition and student performance

Figure 5.15 University completion rates, by peer expectations and school performance 168 


\section{Follow OECD Publications on:}

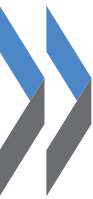

$\square$

http://twitter.com/OECD_Pubs

f http://www.facebook.com/OECDPublications

in. http://www.linkedin.com/groups/OECD-Publications-4645871

Your

http://www.youtube.com/oecdilibrary

Alerts

http://www.oecd.org/oecddirect/

This book has...

StatLinks ज्ञाजम

A service that delivers Excel $^{\oplus}$ files from the printed page!

Look for the StatLinks ants at the bottom of the tables or graphs in this book. To download the matching Excel® spreadsheet, just type the link into your Internet browser, starting with the http://dx.doi.org prefix, or click on the link from the e-book edition. 



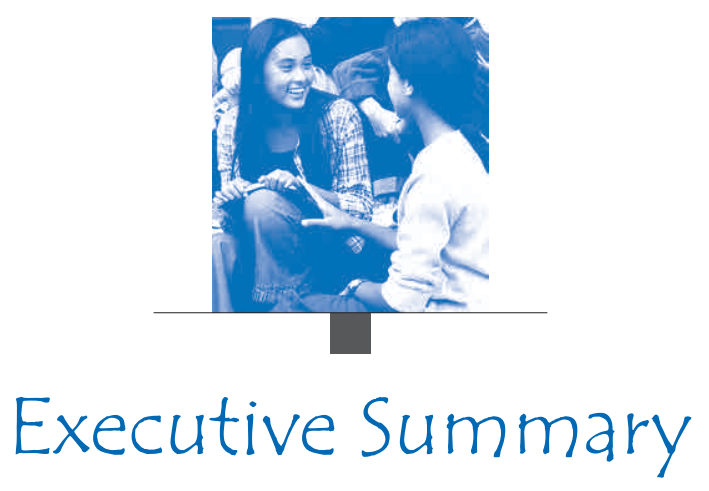

Equity in education means that schools and education systems provide equal learning opportunities to all students. As a result, during their education, students of different socio-economic status, gender or immigrant and family background achieve similar levels of academic performance in key cognitive domains, such as reading, mathematics and science, and similar levels of social and emotional well-being in areas such as life satisfaction, self-confidence and social integration. Equity does not mean that all students obtain equal education outcomes, but rather that differences in students' outcomes are unrelated to their background or to economic and social circumstances over which students have no control.

As this report shows, there is no country in the world that can yet claim to have entirely eliminated socio-economic inequalities in education. While some countries and economies that participate in PISA have managed to build education systems where socio-economic status makes less of a difference in students' learning, well-being and post-secondary educational attainment, every country can do more to improve equity in education.

The report shows that an expansion of access to education, particularly tertiary education, does not automatically result in greater equity in educational attainment. For that to happen, disadvantaged students need to benefit as much as or more than advantaged students. In recent decades, some $41 \%$ of adults attained a higher level of education than their parents did, on average across countries that participated in the Survey of Adult Skills (PIAAC). However, the children of families with higher levels of education were more likely than the children of families with lower levels of education to benefit from the expansion of tertiary education.

\section{CONSEQUENCES OF DISADVANTAGE OVER TIME}

In all countries and economies that participated in PISA 2015, socio-economic status has a large influence on students' performance in science, reading and mathematics. For example, the mean science score among disadvantaged students was 88 points lower than the mean score among advantaged students, on average across OECD countries. This gap is equivalent to about three full years of schooling. However, performance differences between advantaged and disadvantaged students have narrowed over past PISA cycles, on average across OECD countries and in many individual countries and economies. This implies that equity, or the lack of it, is not a fixed feature 
of education systems. All countries can reduce the impact of socio-economic status on student performance, given the right education policies and practices.

An analysis of data for a single cohort of students who participated in the Trends in International Mathematics and Science Study (TIMSS), PISA and the Survey of Adult Skills (PIAAC) finds that disparities in performance related to socio-economic status develop early - even among pupils as young as 10 - and widen throughout students' lives. On average across 11 OECD countries with comparable data, about two-thirds of the achievement gap observed at age 15 (PISA) and more than half of the achievement gap observed among 25-29 year-olds (PIAAC) was already seen among 10-year-olds (TIMSS).

Longitudinal data for individual students in five countries show that student performance in PISA is strongly correlated with outcomes in early adulthood. Fifteen-year-old students who scored in the top quarter in reading are between 38 and 53 percentage points more likely to complete university than students who scored in the bottom quarter; and students who scored in the top quarter of reading performance are between 24 and 47 percentage points more likely than students in the bottom quarter of performance to be working in a job that requires tertiary education by the age of 25. Furthermore, differences in 15-year-olds' reading performance explain between $27 \%$ and $43 \%$ of the difference in university completion rates between students with and those without tertiary-educated parents. This suggests that reducing the gaps related to socio-economic status in what students learn during compulsory schooling could increase upward educational mobility.

Less household wealth often translates into fewer educational resources, such as books, games and interactive learning materials in the home. In addition, families with limited income may not have access to early education if it is not publicly funded. Many disadvantaged students are concentrated in lower-quality schools. Disadvantaged students attending advantaged schools score 78 points higher than those attending disadvantaged schools, on average across OECD countries; disadvantaged students attending schools with an average socio-economic profile (schools that are neither advantaged nor disadvantaged) score 36 points higher in science than those attending disadvantaged schools.

But the report also finds that, on average across OECD countries, $11 \%$ of disadvantaged students across OECD countries score in the top quarter of science performance in their own countries (these students are considered to be "nationally resilient"), 25\% score at PISA proficiency Level 3 or above in science, reading and mathematics ("core-skills resilient"), and $26 \%$ are satisfied with their life, feel socially integrated at school and do not suffer from test anxiety ("socially and emotionally resilient"). Disadvantaged students who are socially and emotionally resilient also tend to do better academically. This implies that helping disadvantaged students develop positive attitudes towards their education can also benefit these students' academic development. Academic resilience can also promote social and emotional resilience, creating a cycle of positive reinforcement.

\section{WHAT THE RESULTS IMPLY FOR POLICY}

Countries need to consider creating and strengthening policies and programmes that support disadvantaged students. For example, countries can promote greater access to early childhood 
education and care, particularly among disadvantaged families, as these programmes both provide more equitable learning environments and help children acquire essential social and emotional skills.

Countries can also set ambitious goals for and monitor the progress of disadvantaged students, target additional resources towards disadvantaged students and schools, and reduce the concentration of disadvantaged students in particular schools. They can also develop teachers' capacity to identify students' needs and manage diverse classrooms, promote better communication between parents and teachers, and encourage parents to be more involved in their child's education. Teachers and schools can foster students' well-being and create a positive learning environment for all students by emphasising the importance of persistence, investing effort and using appropriate learning strategies, and by encouraging students to support each other, such as through peer-mentoring programmes. 



\section{Reader's Guide}

\section{Data underlying the figures}

The data referred to in this report are presented in tables available on line and listed in Annex B.

Three symbols are used to denote missing data:

c There are too few observations or no observation to provide reliable estimates (i.e. there are fewer than 30 students or fewer than 5 schools with valid data).

$\mathrm{m}$ Data are not available. These data were not submitted by the country or were collected but subsequently removed from the publication for technical reasons.

w Data have been withdrawn or have not been collected at the request of the country concerned.

\section{Country coverage}

This publication features data on 72 countries and economies, including all 36 OECD countries and 36 partner countries and economies.

Lithuania acceded to the OECD on 5 July 2018 and was not an OECD member at the time this publication was prepared. Accordingly, Lithuania is shown as a partner country and is not included in the OECD average.

The statistical data for Israel are supplied by and under the responsibility of the relevant Israeli authorities. The use of such data by the OECD is without prejudice to the status of the Golan Heights, East Jerusalem and Israeli settlements in the West Bank under the terms of international law.

Two notes were added to the statistical data related to Cyprus:

Note by Turkey: The information in this document with reference to "Cyprus" relates to the southern part of the Island. There is no single authority representing both Turkish and Greek Cypriot people on the Island. Turkey recognises the Turkish Republic of Northern Cyprus (TRNC). Until a lasting and equitable solution is found within the context of the United Nations, Turkey shall preserve its position concerning the "Cyprus issue".

Note by all the European Union Member States of the OECD and the European Union: The Republic of Cyprus is recognised by all members of the United Nations with the exception of Turkey. The information in this document relates to the area under the effective control of the Government of the Republic of Cyprus. 
B-S-J-G (China) refers to the four PISA-participating Chinese provinces of Beijing, Shanghai, Jiangsu and Guangdong.

FYROM refers to the Former Yugoslav Republic of Macedonia.

For the countries below, when results are based on students' or school principals' responses (see Annex A4 of Volume I [OECD, 2016 $6_{[1]}$ for more information):

Argentina: Only data for the adjudicated region of Ciudad Autónoma de Buenos Aires $(\mathrm{CABA})$ are reported in figures and in the text. Results for Argentina are reported in tables only.

Kazakhstan: Results for Kazakhstan are reported in tables only.

Malaysia: Results for Malaysia are reported in tables only.

\section{International averages}

The OECD average corresponds to the arithmetic mean of the respective country estimates. It was calculated for most indicators presented in this report. For some indicators, data may not be available for all countries, or specific categories may not apply. Readers should, therefore, keep in mind that the term "OECD average" refers to the OECD countries included in the respective comparisons. In cases where data are not available or do not apply to all sub-categories of a given population or indicator, the "OECD average" may be consistent within each column of a table but not necessarily across all columns of a table.

In analyses involving data from multiple years, the OECD average is reported on consistent sets of OECD countries, and several averages may be reported in the same table. For instance, the "OECD average-35" refers to the average across all 35 OECD countries, and is reported as missing if fewer than 35 OECD countries have comparable data; the "OECD average-34" includes only 34 OECD countries that have non-missing values across all the assessments for which this average itself is calculated. This restriction allows for valid comparisons of the OECD average across the same countries over time. As noted previously, Lithuania was not an OECD member at the time this publication was prepared. Accordingly, Lithuania is not included in the OECD average.

\section{Rounding figures}

Because of rounding, some figures in tables may not add up exactly to the expected totals. Totals, differences and averages are always calculated on the basis of exact numbers and are rounded only after calculation.

All standard errors in this publication have been rounded to one or two decimal places. Where the value 0.0 or 0.00 is shown, this does not imply that the standard error is zero, but that it is smaller than 0.05 or 0.005 , respectively. 


\section{Reporting student data}

The report uses "15-year-olds" as shorthand for the PISA target population. PISA covers students who are aged between 15 years 3 months and 16 years 2 months at the time of assessment and who are enrolled in school and have completed at least 6 years of formal schooling, regardless of the type of institution in which they are enrolled, whether they are in full-time or part-time education, whether they attend academic or vocational programmes, and whether they attend public or private schools or foreign schools within the country.

\section{Reporting school data}

The principals of the schools in which students were assessed provided information on their schools' characteristics by completing a school questionnaire. Where responses from school principals are presented in this publication, they are weighted so that they are proportionate to the number of 15 -year-olds enrolled in the school.

\section{Focusing on statistically significant differences}

This report discusses only statistically significant differences or changes (at the $5 \%$ level of significance), unless explicitly stated. These are denoted in darker colours in figures and in bold font in tables.

\section{Abbreviations used in this report}

\begin{tabular}{ll}
\hline Dif. & Difference \\
\hline$\%$ dif. & Percentage-point difference \\
\hline$\%$ pts & Percentage points \\
\hline Score dif. & Score-point difference \\
\hline S.D. & Standard deviation \\
\hline S.E. & Standard error \\
\hline ESCS & PISA index of economic, social and cultural status \\
\hline ISCED & International Standard Classification of Education \\
\hline ISCO & International Standard Classification of Occupations \\
\hline ISEI & International Socio-Economic Index of Occupational Status \\
\hline
\end{tabular}

\section{Categorising students and schools according to their socio-economic profile}

PISA classifies students into several categories according to their socio-economic status. For the purpose of the analyses in this report two different definitions were used. The first definition (used in Chapters 2 to 4 ) identifies:

- Socio-economically disadvantaged students as those whose value on the PISA index of economic, social and cultural status (ESCS) is among the bottom $25 \%$ of students within their country or economy.

- Socio-economically advantaged students as those whose ESCS is among the top 25\% of students within their country or economy. 
The same logic is employed for the socio-economic profile of schools:

- Socio-economically disadvantaged schools are schools in the bottom $25 \%$ of the national distribution of the school-level ESCS index, which is calculated as the average ESCS index among students in a school.

- Socio-economically advantaged schools are schools in the top $25 \%$ of the national distribution of the school-level ESCS index.

In some analyses included in this report (as in the sections "Genesis and growth of the achievement gap during students' lives" and "Equity in the attainment of upper secondary and tertiary education" in Chapter 2; and throughout Chapter 5), alternative definitions were used to identify advantaged and disadvantaged students. Socio-economic status in these analyses is measured by parents' education or by the number of books at home:

- Socio-economically disadvantaged students are those with fewer than 100 books in their home/whose parents did not complete tertiary education.

- Socio-economically advantaged students are those with more than 100 books in their home/with at least one parent who completed tertiary education.

The definitions of the socio-economic profiles of schools in Chapter 5 are related to the socio-economic status of students:

- Disadvantaged schools are those where the share of students with tertiary-educated parents is in the bottom quarter of the national distribution.

- Advantaged schools are those where the share of students with tertiary-educated parents is in the top quarter of the national distribution.

\section{Further documentation}

For further information on the PISA assessment instruments and the methods used in PISA, see the PISA 2015 Technical Report (OECD, 2017 ${ }_{[2]}$ ).

\section{Statlinks}

This report uses the OECD StatLinks service. Below each table and chart is a URL leading to a corresponding Exce ${ }^{\mathrm{TM}}$ workbook containing the underlying data. These urls are stable and will remain unchanged over time. In addition, readers of the e-books will be able to click directly on these links and the workbook will open in a separate window, if their Internet browser is open and running.

\section{Reference}

OECD (2017), PISA 2015 Technical Report, OECD Publishing, Paris, 


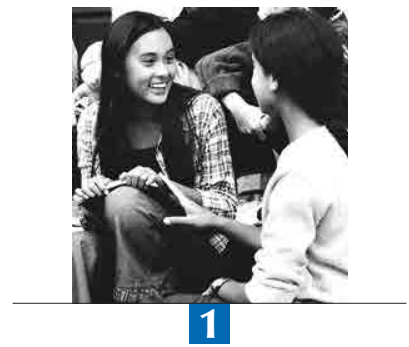

\section{Overview and policy implications}

This chapter provides the context and purpose of the report, a summary of the key findings, and implications for the design and implementation of policies and practices aimed at improving equity in education.

\section{Notes regarding Cyprus}

Note by Turkey: The information in this document with reference to "Cyprus" relates to the southern part of the Island. There is no single authority representing both Turkish and Greek Cypriot people on the Island. Turkey recognises the Turkish Republic of Northern Cyprus (TRNC). Until a lasting and equitable solution is found within the context of the United Nations, Turkey shall preserve its position concerning the "Cyprus issue".

Note by all the European Union Member States of the OECD and the European Union: The Republic of Cyprus is recognized by all members of the United Nations with the exception of Turkey. The information in this document relates to the area under the effective control of the Government of the Republic of Cyprus.

\section{A note regarding the Russian Federation concerning Survey of Adult Skills (PIAAC) data}

Readers should note that the sample for the Russian Federation does not include the population of the Moscow municipal area. The data published, therefore, do not represent the entire resident population aged 16-65 in Russia but rather the population of Russia excluding the population residing in the Moscow municipal area.

More detailed information regarding the data from the Russian Federation as well as that of other countries can be found in the Technical Report of the Survey of Adult Skills (OECD, 2016 $\left.{ }_{[1]}\right)$.

\section{A note regarding Israel}

The statistical data for Israel are supplied by and under the responsibility of the relevant Israeli authorities. The use of such data by the OECD is without prejudice to the status of the Golan Heights, East Jerusalem and Israeli settlements in the West Bank under the terms of international law.

\section{A note regarding Lithuania}

Lithuania was not an OECD member at the time of preparation of this publication. Accordingly, Lithuania is shown as a partner country and is not included in the OECD average.

This document, as well as any data and map included herein, are without prejudice to the status of or sovereignty over any territory, to the delimitation of international frontiers and boundaries and to the name of any territory, city or area. 


\section{EQUITY IN EDUCATION AND SOCIAL MOBILITY}

Equity in education means that schools and education systems provide equal learning opportunities to all students. As a result, students of different socio-economic status, gender or immigrant and family background achieve similar levels of academic performance in key cognitive domains, such as reading, mathematics and science, and similar levels of social and emotional well-being in areas such as life satisfaction, self-confidence and social integration, during their education. Equity does not mean that all students obtain equal education outcomes, but rather that differences in students' outcomes are unrelated to their background or to economic and social circumstances over which the students have no control. Equity in education also demands that students from different backgrounds are equally likely to earn desirable post-secondary education credentials, such as university degrees, that will make it easier for them to succeed in the labour market and to realise their goals as adult members of society.

Equity is a fundamental value and guiding principle of education policy, but it is not necessarily actualised in education systems around the world. A strong normative commitment to equity was already evident in the origins of modern education in the 19th century, when early advocates of public schooling imagined that public education would become society's "great equaliser" of opportunities and conditions (Mann, 1957 ${ }_{[2]}$ ). Today, the international community is committed to the right to education, which was first established in Article 26 of the Universal Declaration of Human Rights of 1948 and is now mandated in national legislation (UNESCO, 2000 200). Equity in education is also a specific target of the Sustainable Development Goals set by the United Nations in 2015 (UNESCO, 2015 $5_{[4]}$ ).

However, as this report shows, there is no country in the world that can yet claim to have entirely eliminated socio-economic inequalities in education. While some countries and economies that participate in PISA have managed to build education systems where socio-economic status makes less of a difference in students' learning, well-being and post-secondary educational attainment, every country can do more to improve equity in education.

Given the sharp increase in economic inequality in recent years, improving equity in education is even more urgent today than in previous decades. Income inequality among OECD countries today is at its highest level since the 1980s (OECD, 2015 $5_{[5]}$; OECD, 2011 $1_{[6]}$ ), and the economic recovery observed since 2010 has not reversed this trend (OECD, 2016 $\left.6_{[7]}\right)$. As a result, countries are increasingly concerned about the potentially harmful consequences of growing economic inequality for social and educational mobility.

Indeed, much empirical research finds that countries with higher levels of income inequality tend to show lower levels of social mobility across generations, with more egalitarian Scandinavian countries having higher levels of social mobility than more unequal countries, such as Italy, the United Kingdom and the United States (Corak, 2013 [8]; Blanden, 2013 [9]; Solon, 2002 $2_{[10] ;}$ Torche, 2015 $\left.[11]\right)$. In Latin American countries, income inequality is considerably greater, and social mobility is considerably less prevalent than in most OECD countries (Torche, 2014 $4_{[12]}$ ). These studies, which are based on cross-sectional measures or on historical data, are descriptive in nature and do not establish causal effects; still, the results they provide are troubling. 
Research on the mechanisms through which income inequality influences social mobility reveals that greater income inequality limits education opportunities for talented yet underprivileged individuals (Lee and Lee, $2018_{[13]}$ ). In societies with higher income inequality, socio-economically disadvantaged youth tend to perceive smaller-than-actual returns to investing in further education (Kearney and Levine, 2016 $\left.{ }_{[14]}\right)$. In addition, the actual increase in earnings associated with a fouryear university degree (relative to a high school degree) is found to be significantly smaller for disadvantaged than for advantaged youth in such circumstances (Bartik and Hershbein, 2018 ${ }_{[15]}$ ). Therefore, rising inequality might not only affect social mobility, but also equity in education.

Social and educational mobility are important because they indicate the equality of opportunity in a society. Social mobility refers to a change in the economic, social or cultural status of individuals between their childhood (when this status is determined, largely, by their parents' background) and their adult life (Torche, 2015 $5_{[11]}$; Hout and DiPrete, 2006 $6_{[16]}$ ). Upward social mobility occurs when students born into socio-economically disadvantaged families end up, as adults, in positions of higher status than those of their parents. Social mobility is more prevalent when the socio-economic status of parents is weakly associated with that of their adult children. Inversely, mobility is less prevalent when adults' socio-economic status is more related to their parents' position in society and less to individual talent and effort.

The principle that everybody has a fair chance at improving his or her life is at the heart of democratic political and economic institutions. In this context, schools and education systems can offer more opportunities for children and young people born into disadvantaged families to move up the socio-economic ladder. Better education outcomes correlate strongly with higher socio-economic status in adulthood (Hout, 2012 ${ }_{[17]}$ ). In particular, the economic returns to earning a university degree are high, even as access to tertiary education is expanding $\left(\mathrm{OECD}, 2017_{[18]}\right)$. As this report shows, high performance and well-being among disadvantaged 15 -year-old students is a strong predictor of success in higher education and work later on.

However, the extent to which education promotes social mobility varies across countries. In contexts where success in education remains strongly linked to family background rather than to students' own talent and attitudes, education may not promote socio-economic mobility; rather, it may simply reproduce pre-existing inequalities across generations, as critical theories of education would predict (Bourdieu, 2018 ${ }_{[19]}$; Bowles and Gintis, 2002 $2_{[20]}$ ). In contrast, education policies that focus on equity can be among the most potent levers to reduce income disparities and foster upward social mobility over the long term (Brueckner, Dabla-Norris and Gradstein, 2014 $4_{[21]}$ ).

There are some signs that countries are moving in the direction of greater equity. For example, the level of educational attainment increased worldwide during the past few decades (Barro and Lee, $\left.2013_{[22]}\right)$. Among OECD countries, the expansion of access to tertiary education has been particularly significant. However, participation in education continues to be related to socio-economic background (Pfeffer, 2008 ${ }_{[23]}$; Hout and DiPrete, 2006 ${ }_{[16]}$ ), and improvements in educational attainment have ambiguous effects on income inequality if not accompanied by improvements in equity in education (Lee and Lee, 2018 $8_{[13]}$; World Bank, 2018 $8_{[24]}$ ). At the same time, PISA results show that many school systems became more equitable over the past ten years and, in many countries, progress in equity was a reflection of improvements in performance among the most disadvantaged students (OECD, 2017 $\left.{ }_{[25]}\right)$. 
This report examines how successful today's schools are at counterbalancing the forces that perpetuate existing inequalities in society. It identifies the education policies and practices that promote educational equity and social mobility. The report finds that improving equity in education is consistent with, and a necessary step towards, the goal of enhancing social mobility.

\section{KEY FINDINGS}

\section{Overall educational attainment is rising, but inequity in the completion of tertiary education persists over time within countries.}

An analysis of education trends reveals that, around the world, educational attainment and access to education have greatly improved over the past half-century. Regardless of their average level of income, most countries can celebrate the fact that younger people are attaining higher levels of education than their parents and grandparents, on average. Yet, while it was hoped that such an achievement would translate into more equitable societies, this has not necessarily been the case. Disparities in educational attainment persist between adults from different countries and socio-economic backgrounds. Education has expanded faster in wealthier countries, resulting in larger absolute gaps in attainment between adults living in the richest countries (where the average number of years of schooling completed is 12) and those in the poorest countries (where the average number of years of schooling completed is 5). Less of a difference is observed between high-income and upper-middle-income countries; the gap of about two years of schooling completed between these two groups of countries has remained more or less stable over time (Figure 2.10).

Inequalities in attainment trends, related to socio-economic status, are also observed within countries. Data from the countries that participated in the Survey of Adult Skills, a product of the OECD Programme for the International Assessment of Adult Competencies (PIAAC), reveal that the probability of completing tertiary education among adults with low-educated parents (i.e. those who did not complete upper secondary education) grew from $18 \%$ to $24 \%$ between the generation born in the mid-1940s to 1950s, and that born in the mid-1970s to 1980s. For adults with highly educated parents (i.e. those who completed tertiary education), this probability grew from $61 \%$ to $69 \%$ (Figure 2.16 ). This suggests that equity in attainment has decreased moderately or remained stable over time, as the difference in the probability of completing tertiary education between adults with highly educated parents and those with low-educated parents grew from 43 to 45 percentage points over the past half-century, on average across the 33 countries that participated in PIAAC.

However, certain countries show notable gains in equity over the same period. In Singapore, equity has improved markedly over time. Among the oldest cohort, those with highly educated parents were 55 percentage points more likely to complete tertiary education than those with low-educated parents; yet among the youngest cohort, those with highly educated parents were only 36 percentage points more likely than those with low-educated parents to complete that level of education. The United States and Germany also showed moderate improvements over the period. In the United States, the difference in the probability of completing tertiary education between these two groups fell from 50 to 48 percentage points; in Germany, the difference dropped from 45 to 43 percentage points (Figure 2.17). 
Yet there are also a number of countries where equity has declined over time. In the Czech Republic, the disparity in the attainment of tertiary education between adults with highly educated parents and those with low-educated parents increased from 47 to 57 percentage points over the period; in Italy, the difference increased from 52 to 60 percentage points; and in Chile, the difference increased from 49 to 54 percentage points (Figure 2.17).

Some $41 \%$ of adults between the ages of 26 and 65 experienced upward mobility, meaning that they attained a higher level of education than their parents, on average across countries that participated in the Survey of Adult Skills (PIAAC) (Figure 1.3). In most PIAAC-participating countries, upward educational mobility was less prevalent among members of younger cohorts than of older cohorts (Figure 1.3). Most countries follow an inverted U-shaped trajectory of upward mobility, which is largely dependent on the timing of the country's expansion of education. Significant expansion often results in substantial absolute upward mobility, as average education levels within a population rise, and large shares of the population more easily surpass their parents' educational attainment. However, as the average level of education within a population increases, upward educational mobility becomes less prevalent. This is observed in many developed nations, where larger shares of the population are now secondary- and tertiaryeducated, and therefore smaller shares of subsequent generations can be considered as upwardly mobile. If these trends continue, future generations will be less likely to experience upward mobility than today's adults.

These findings show that expansion of access to education does not automatically result in greater equity in educational attainment. Educational expansion opens opportunities for education to more students. Who these new students are, however, can determine whether expansion improves equity. For expansion to result in greater equity, disadvantaged students need to benefit as much as or more than advantaged students. Findings show that, in recent decades, the children of families with higher levels of education were more likely than the children of families with lower levels of education to benefit from educational expansion. Previous studies suggest that, unless special policies are put into place to assist disadvantaged students in accessing tertiary education, wealthy and middle-class families will maintain their relative advantage (Raftery and Hout, $1993_{[26]}$ ). It remains to be seen whether, once the proportion of socio-economically advantaged students completing tertiary education plateaus, disadvantaged students will enrol in tertiary education in larger numbers. It will also be important to monitor whether new kinds of inequalities in post-secondary education become more prominent (Bar Haim and Shavit, $2013_{[27] ;}$ Gerber and Cheung, 2008 $\left.{ }_{[28]}\right)$.

These findings also suggest that countries cannot rely solely on expanding access to increase educational mobility or to improve equity in the completion of tertiary education. Because gaps related to socio-economic status appear early, countries must consider ways to equalise learning opportunities during early childhood and adolescence in order to see greater improvements in educational and social mobility. Disparities in tertiary attainment build upon earlier disparities in learning, which stem from differences in school quality throughout compulsory education. In other words, equality of opportunities in education should not be measured just by the level of education people reach, but by the quality of education that students receive, and ultimately by what students learn and are able to do with what they learn in real-life contexts. 
In addition to comparing educational attainment across different generations measured at a single point in time, this report also uses longitudinal data to analyse how disadvantaged and advantaged students who sat the PISA test progress in their education and transition into the labour market. The report shows that, among the five high-income OECD countries with available longitudinal data, adults with tertiary-educated parents are between 17 and 30 percentage points more likely to complete university, and between 7 and 20 percentage points more likely to obtain a skilled job than their peers whose parents had not attained a tertiary education (Figures 1.4 and 1.5). It also shows that differences in 15-year-olds' reading performance explain between $27 \%$ and $43 \%$ of the difference in university completion rates between advantaged and disadvantaged students (Figure 5.4), which suggests that reducing the socio-economic gaps in what students learn during compulsory schooling could increase educational mobility.

Thus the relationship between equity in education and social mobility must be better understood, particularly in a time of increasing income inequality. Unequal access to quality education can severely limit opportunities for disadvantaged students to move up the social ladder. More inclusive education - with equitable education opportunities for all - could be the basis of inclusive growth (UNICEF, 2015 $\left.{ }_{[29]}\right)$.

\section{Performance gaps related to students' socio-economic status narrowed across PISA cycles in certain countries.}

In all countries and economies that participated in PISA 2015, socio-economic status has a large influence on students' performance in science, reading and mathematics. On average across OECD countries, the mean PISA science score among disadvantaged students was 452 points, while among advantaged students it was 540 points (Table 2.1). This gap of 88 points represents the equivalent of about three full years of schooling.

Equity in education can also be measured by the so-called "socio-economic gradient", which describes how well students' performance can be predicted based solely on their socio-economic status. In PISA 2015, about 13\% of the variation in students' science performance was accounted for by students' socio-economic status, on average across OECD countries. In the countries and economies with the highest levels of equity in science performance, such as Algeria, Hong Kong (China), Iceland, Macao (China), Qatar and the United Arab Emirates, less than 5\% of the variation in science performance is so accounted for, but in Ciudad Autónoma de Buenos Aires (Argentina) (hereafter "CABA [Argentina]"), France, Hungary, Luxembourg and Peru, 20\% or more of students' achievement can be accounted for by students' socio-economic status alone (Figure 1.1). The strength of the relationship between socio-economic status and performance in reading and mathematics is similar to that observed in science.

If education systems around the world were to deliver truly equitable opportunities for all students to succeed in school, no differences in student performance related to socio-economic status would be found.

The good news, however, is that these differences have narrowed over PISA cycles, on average, across OECD countries and in many individual countries and economies. 
Figure $1.1[1 / 2]$ - Equity in cognitive achievement

\begin{tabular}{|c|c|c|c|c|c|c|c|c|c|}
\hline & & \multicolumn{8}{|c|}{$\begin{array}{l}\text { Countries/economies with higher values than the OECD average } \\
\text { Countries/economies with values not statistically different from the OECD average } \\
\text { Countries/economies with lower values than the OECD average }\end{array}$} \\
\hline & \multicolumn{2}{|c|}{$\begin{array}{l}\text { Variation in } \\
\text { science performance } \\
\text { explained by student's } \\
\text { socio-economic status }\end{array}$} & \multicolumn{2}{|c|}{$\begin{array}{l}\text { Academic } \\
\text { resilience among } \\
\text { disadvantaged } \\
\text { students }^{1}\end{array}$} & \multicolumn{2}{|c|}{$\begin{array}{l}\text { Double socio- } \\
\text { economic } \\
\text { disadvantage }\end{array}$} & \multicolumn{3}{|c|}{$\begin{array}{c}\text { Difference in mathematics } \\
\text { achievement between individuals who } \\
\text { had more and individuals who had } \\
\text { fewer than } 100 \text { books in their home... }\end{array}$} \\
\hline & $\sum_{\substack{1 \\
\frac{1}{2}}}^{\frac{10}{2}}$ & 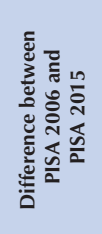 & 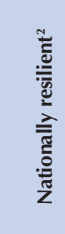 & 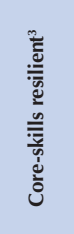 & 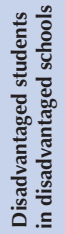 & 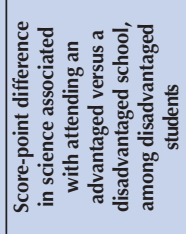 & 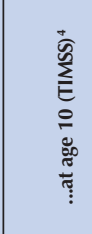 & 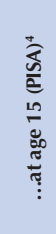 & 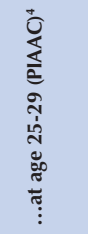 \\
\hline & $\%$ & $\%$ dif. & $\%$ & $\%$ & $\%$ & Score dif. & Dif. & Dif. & Dif. \\
\hline OECD average & 12.9 & -1.4 & 11.3 & 25.2 & 48.0 & 78 & $\mathrm{~m}$ & $\mathrm{~m}$ & $\mathrm{~m}$ \\
\hline Australia & 11.7 & -0.4 & 12.7 & 28.7 & 51.2 & 86 & 0.31 & 0.49 & 0.54 \\
\hline Austria & 15.9 & 0.1 & 9.2 & 23.2 & 48.1 & 93 & 0.44 & 0.56 & 0.66 \\
\hline Belgium & 19.3 & -0.7 & 9.2 & 26.6 & 50.2 & 131 & $\mathrm{~m}$ & $\mathrm{~m}$ & $\mathrm{~m}$ \\
\hline Canada & 8.8 & 0.3 & 13.1 & 39.7 & 45.4 & 46 & 0.17 & 0.40 & 0.54 \\
\hline \begin{tabular}{|l|} 
Chile \\
\end{tabular} & 16.9 & -6.4 & 8.9 & 7.1 & 54.9 & 93 & $\mathrm{~m}$ & $\mathrm{~m}$ & $\mathrm{~m}$ \\
\hline \begin{tabular}{|l} 
Czech Republic \\
\end{tabular} & 18.8 & 2.7 & 9.1 & 20.4 & 50.7 & 128 & 0.45 & 0.69 & 0.74 \\
\hline Denmark & 10.4 & -3.6 & 12.1 & 31.1 & 45.7 & 45 & $\mathrm{~m}$ & $\mathrm{~m}$ & $\mathrm{~m}$ \\
\hline Estonia & 7.8 & -1.0 & 14.2 & 41.5 & 47.8 & 37 & $\mathrm{~m}$ & $\mathrm{~m}$ & $\mathrm{~m}$ \\
\hline Finland & 10.0 & 1.8 & 14.1 & 39.5 & 40.2 & -9 & $\mathrm{~m}$ & $\mathrm{~m}$ & $\mathrm{~m}$ \\
\hline \begin{tabular}{|l|} 
France \\
\end{tabular} & 20.3 & $\begin{array}{l}-1.9 \\
\end{array}$ & 9.3 & 23.8 & 50.0 & 134 & $\mathrm{~m}$ & $\mathrm{~m}$ & $\mathrm{~m}$ \\
\hline Germany & 15.8 & -4.0 & 10.4 & 32.0 & 46.1 & 122 & $\mathrm{~m}$ & $\mathrm{~m}$ & $\mathrm{~m}$ \\
\hline Greece & 12.5 & -2.1 & 12.3 & 14.8 & 47.7 & 85 & 0.28 & 0.54 & 0.55 \\
\hline \begin{tabular}{|l|} 
Hungary \\
\end{tabular} & 21.4 & 0.3 & 7.5 & 14.0 & 55.3 & 138 & $\mathrm{~m}$ & $\mathrm{~m}$ & $\mathrm{~m}$ \\
\hline Iceland & 4.9 & -2.6 & 15.5 & 23.5 & 44.8 & -3 & $\mathrm{~m}$ & $\mathrm{~m}$ & $\mathrm{~m}$ \\
\hline Ireland & 12.7 & -0.5 & 12.4 & 32.3 & 43.6 & 49 & 0.40 & 0.55 & 0.58 \\
\hline Israel & 11.2 & 0.9 & 8.4 & 16.0 & 51.1 & 89 & $\mathrm{~m}$ & $\mathrm{~m}$ & $\mathrm{~m}$ \\
\hline Italy & 9.6 & -0.6 & 12.1 & 20.8 & 49.2 & 95 & $\mathrm{~m}$ & $\mathrm{~m}$ & $\mathrm{~m}$ \\
\hline Japan & 10.1 & 1.6 & 11.6 & 40.6 & 49.0 & 125 & $\mathrm{~m}$ & $\mathrm{~m}$ & $\mathrm{~m}$ \\
\hline Korea & 10.1 & 3.1 & 13.1 & 36.5 & 45.6 & 59 & 0.51 & 0.56 & 0.42 \\
\hline \begin{tabular}{|l} 
Latvia \\
\end{tabular} & 8.7 & -0.5 & 12.0 & 22.2 & 46.6 & 50 & $\mathrm{~m}$ & $\mathrm{~m}$ & $\mathrm{~m}$ \\
\hline Luxembourg & 20.8 & -1.7 & 6.1 & 17.1 & 47.4 & 99 & $\mathrm{~m}$ & $\mathrm{~m}$ & $\mathrm{~m}$ \\
\hline Mexico & 10.9 & -5.2 & 11.9 & 3.4 & 59.8 & 71 & $\mathrm{~m}$ & $\mathrm{~m}$ & $\mathrm{~m}$ \\
\hline \begin{tabular}{|l|} 
Netherlands \\
\end{tabular} & 12.5 & -3.8 & 11.5 & 32.8 & 46.5 & 154 & 0.39 & 0.69 & 0.77 \\
\hline New Zealand & 13.6 & -2.0 & 9.9 & 25.4 & 45.1 & 75 & 0.54 & 0.58 & 0.62 \\
\hline Norway & 8.2 & -0.4 & 13.6 & 31.6 & 42.4 & 10 & 0.45 & 0.57 & 0.72 \\
\hline \begin{tabular}{|l|} 
Poland \\
\end{tabular} & 13.4 & -1.4 & 11.1 & 30.3 & 46.3 & 13 & $\mathrm{~m}$ & $\mathrm{~m}$ & $\mathrm{~m}$ \\
\hline \begin{tabular}{|l|} 
Portugal \\
\end{tabular} & 14.9 & -1.4 & 11.0 & 25.6 & 48.6 & 52 & $\mathrm{~m}$ & $\mathrm{~m}$ & $\mathrm{~m}$ \\
\hline Slovak Republic & 16.0 & -3.6 & 11.4 & 15.7 & 50.3 & 151 & $\mathrm{~m}$ & $\mathrm{~m}$ & $\mathrm{~m}$ \\
\hline Slovenia & 13.5 & -4.0 & 11.5 & 32.2 & 48.2 & 140 & $\mathrm{~m}$ & $\mathrm{~m}$ & $\mathrm{~m}$ \\
\hline Spain & 13.4 & 1.0 & 11.9 & 24.4 & 50.5 & 43 & $\mathrm{~m}$ & $\mathrm{~m}$ & $\mathrm{~m}$ \\
\hline \begin{tabular}{|l|} 
Sweden \\
\end{tabular} & 12.2 & 1.2 & 10.7 & 24.8 & 41.6 & 21 & $\mathrm{~m}$ & $\mathrm{~m}$ & $\mathrm{~m}$ \\
\hline \begin{tabular}{|l|} 
Switzerland \\
\end{tabular} & 15.6 & -0.7 & 9.3 & 27.1 & 44.0 & 88 & $\mathrm{~m}$ & $\mathrm{~m}$ & $\mathrm{~m}$ \\
\hline Turkey & 9.0 & -6.1 & 13.9 & 7.3 & 48.9 & 98 & $\mathrm{~m}$ & $\mathrm{~m}$ & $\mathrm{~m}$ \\
\hline United Kingdom $^{5}$ & 10.5 & -2.9 & 12.6 & 28.6 & 45.5 & 77 & 0.51 & 0.61 & 0.85 \\
\hline United States & 11.4 & -6.0 & 11.3 & 22.5 & 50.9 & 41 & 0.51 & 0.69 & 0.70 \\
\hline
\end{tabular}

1. Socio-economically disadvantaged students are those whose values on the PISA index of economic, social and cultural status are among the bottom $25 \%$ within their country or economy.

2. Refers to disadvantaged students who score in the top quarter of science performance in their own country/economy.

3. Refers to disadvantaged students who score at proficiency Level 3 or above in science, reading and mathematics.

4. Standardised scores in TIMSS 1995, PISA 2000 and PIAAC. To allow for comparability among the studies, the scores of each study were transformed into standardised scores using the means and standard deviations for each country in each study.

5. Only England is considered for the analysis of disparities in numeracy at age 25-29 (PIAAC) (last two columns).

6. See notes at the beginning of the chapter.

Note: Values that are statistically significant are indicated in bold.

Sources: IEA, TIMSS dataset. OECD, PIAAC dataset. OECD, PISA 2000, 2006 and 2015 Databases, Tables 2.2, 2.5, 3.3, 3.5, 4.1, and 4.5 .

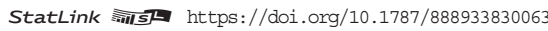




\section{Figure $1.1[2 / 2]$ - Equity in cognitive achievement}

\begin{tabular}{|c|c|c|c|c|c|c|c|c|c|c|}
\hline & & \multicolumn{8}{|c|}{$\begin{array}{l}\text { Countries/economies with higher values than the OECD average } \\
\text { Countries/economies with values not statistically different from the OECD average } \\
\text { Countries/economies with lower values than the OECD average }\end{array}$} \\
\hline & & \multicolumn{2}{|c|}{$\begin{array}{l}\text { Variation in } \\
\text { science performance } \\
\text { explained by student's } \\
\text { socio-economic status }\end{array}$} & \multicolumn{2}{|c|}{\begin{tabular}{|c|} 
Academic \\
resilience among \\
disadvantaged \\
students $^{1}$
\end{tabular}} & \multicolumn{2}{|c|}{$\begin{array}{l}\text { Double socio- } \\
\text { economic } \\
\text { disadvantage }\end{array}$} & \multicolumn{3}{|c|}{$\begin{array}{c}\text { Difference in mathematics } \\
\text { achievement between individuals who } \\
\text { had more and individuals who had } \\
\text { fewer than } 100 \text { books in their home... }\end{array}$} \\
\hline & & $\sum_{\substack{10 \\
\frac{10}{2}}}^{\frac{10}{2}}$ & 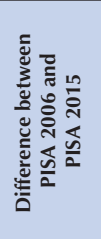 & 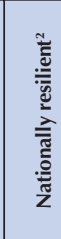 & 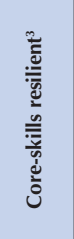 & 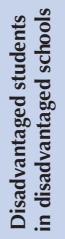 & 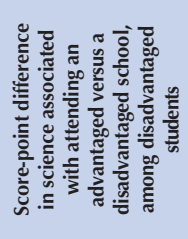 & 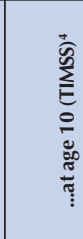 & 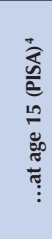 & 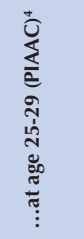 \\
\hline & & $\%$ & $\%$ dif. & $\%$ & $\%$ & $\%$ & Score dif. & Dif. & Dif. & Dif. \\
\hline & OECD average & 12.9 & -1.4 & 11.3 & 25.2 & 48.0 & 78 & $\mathrm{~m}$ & $\mathrm{~m}$ & $\mathrm{~m}$ \\
\hline \multirow{35}{*}{ 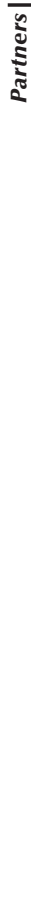 } & Albania & $\mathrm{m}$ & $\mathrm{m}$ & $\mathrm{m}$ & $\mathrm{m}$ & 41.7 & -3 & $\mathrm{~m}$ & $\mathrm{~m}$ & $\mathrm{~m}$ \\
\hline & \begin{tabular}{|l|} 
Algeria \\
\end{tabular} & 1.4 & $\mathrm{~m}$ & 20.7 & 0.4 & 42.8 & 31 & $\mathrm{~m}$ & $\mathrm{~m}$ & $\mathrm{~m}$ \\
\hline & \begin{tabular}{|l|} 
Brazil \\
\end{tabular} & 12.5 & -4.5 & 11.2 & 2.1 & 51.8 & 67 & $\mathrm{~m}$ & $\mathrm{~m}$ & $\mathrm{~m}$ \\
\hline & B-S-J-G (China) & 18.5 & $\mathrm{~m}$ & 8.7 & 25.9 & 56.6 & 131 & $\mathrm{~m}$ & $\mathrm{~m}$ & $\mathrm{~m}$ \\
\hline & \begin{tabular}{|l|} 
Bulgaria \\
\end{tabular} & 16.4 & -6.3 & 9.5 & 9.3 & 52.4 & 146 & $\mathrm{~m}$ & $\mathrm{~m}$ & $\mathrm{~m}$ \\
\hline & CABA (Argentina) & 25.6 & $\mathrm{~m}$ & 5.2 & 7.5 & 63.5 & 134 & $\mathrm{~m}$ & $\mathrm{~m}$ & $\mathrm{~m}$ \\
\hline & Colombia & 13.7 & 3.1 & 10.5 & 2.8 & 53.6 & 52 & $\mathrm{~m}$ & $\mathrm{~m}$ & $\mathrm{~m}$ \\
\hline & Costa Rica & 15.6 & $\mathrm{~m}$ & 10.9 & 2.4 & 52.0 & 42 & $\mathrm{~m}$ & $\mathrm{~m}$ & $\mathrm{~m}$ \\
\hline & \begin{tabular}{|l|} 
Croatia \\
\end{tabular} & 12.1 & -0.1 & 13.3 & 20.3 & 43.0 & 86 & $\mathrm{~m}$ & $\mathrm{~m}$ & $\mathrm{~m}$ \\
\hline & \begin{tabular}{|l|} 
Cyprus $^{6}$ \\
\end{tabular} & 9.4 & $\mathrm{~m}$ & 12.1 & 8.8 & 48.7 & 47 & $\mathrm{~m}$ & $\mathrm{~m}$ & $\mathrm{~m}$ \\
\hline & Dominican Republic & 12.9 & $\mathrm{~m}$ & 10.2 & 0 & 50.0 & 45 & $\mathrm{~m}$ & $\mathrm{~m}$ & $\mathrm{~m}$ \\
\hline & FYROM & 6.9 & $\mathrm{~m}$ & 15.4 & 1.7 & 42.9 & 60 & $\mathrm{~m}$ & $\mathrm{~m}$ & $\mathrm{~m}$ \\
\hline & Georgia & 11.1 & $\mathrm{~m}$ & 11.7 & 2.6 & 50.9 & 48 & $\mathrm{~m}$ & $\mathrm{~m}$ & $\mathrm{~m}$ \\
\hline & Hong Kong (China) & 4.9 & -1.5 & 18.2 & 53.2 & 45.2 & 75 & $\mathrm{~m}$ & $\mathrm{~m}$ & $\mathrm{~m}$ \\
\hline & Indonesia & 13.2 & 3.5 & 12.1 & 1.1 & 55.2 & 50 & $\mathrm{~m}$ & $\mathrm{~m}$ & $\mathrm{~m}$ \\
\hline & \begin{tabular}{|l|} 
Jordan \\
\end{tabular} & 9.4 & -1.6 & 11.9 & 1.7 & 46.7 & 38 & $\mathrm{~m}$ & $\mathrm{~m}$ & $\mathrm{~m}$ \\
\hline & Kosovo & 5.1 & $\mathrm{~m}$ & 16.9 & 0.4 & 41.6 & 53 & $\mathrm{~m}$ & $\mathrm{~m}$ & $\mathrm{~m}$ \\
\hline & Lebanon & 9.7 & $\mathrm{~m}$ & 11.5 & 1.7 & 56.3 & 63 & $\mathrm{~m}$ & $\mathrm{~m}$ & $\mathrm{~m}$ \\
\hline & \begin{tabular}{|l} 
Lithuania \\
\end{tabular} & 11.6 & -2.6 & 11.6 & 19.4 & 50.1 & 74 & $\mathrm{~m}$ & $\mathrm{~m}$ & $\mathrm{~m}$ \\
\hline & Macao (China) & 1.7 & -0.1 & 20.4 & 51.4 & 48.8 & 11 & $\mathrm{~m}$ & $\mathrm{~m}$ & $\mathrm{~m}$ \\
\hline & Malta & 14.5 & $\mathrm{~m}$ & 11.4 & 17.5 & 46.9 & 109 & $\mathrm{~m}$ & $\mathrm{~m}$ & $\mathrm{~m}$ \\
\hline & Moldova & 11.6 & $\mathrm{~m}$ & 12.8 & 4.9 & 51.6 & 28 & $\mathrm{~m}$ & $\mathrm{~m}$ & $\mathrm{~m}$ \\
\hline & Montenegro & 5.0 & -2.6 & 16.1 & 7.3 & 44.8 & 80 & $\mathrm{~m}$ & $\mathrm{~m}$ & $\mathrm{~m}$ \\
\hline & Peru & 21.6 & $\mathrm{~m}$ & 5.6 & 0.6 & 67.7 & 66 & $\mathrm{~m}$ & $\mathrm{~m}$ & $\mathrm{~m}$ \\
\hline & Qatar & 4.4 & 2.4 & 12.1 & 6.0 & 54.3 & 46 & $\mathrm{~m}$ & $\mathrm{~m}$ & $\mathrm{~m}$ \\
\hline & Romania & 13.8 & -1.5 & 11.8 & 5.3 & 49.9 & 81 & $\mathrm{~m}$ & $\mathrm{~m}$ & $\mathrm{~m}$ \\
\hline & Russia & 6.7 & -0.9 & 13.3 & 24.0 & 50.4 & 52 & $\mathrm{~m}$ & $\mathrm{~m}$ & $\mathrm{~m}$ \\
\hline & Singapore & 16.8 & $\mathrm{~m}$ & 9.5 & 43.2 & 46.3 & 127 & $\mathrm{~m}$ & $\mathrm{~m}$ & $\mathrm{~m}$ \\
\hline & Chinese Taipei & 14.1 & 1.0 & 10.7 & 37.1 & 48.0 & 115 & $\mathrm{~m}$ & $\mathrm{~m}$ & $\mathrm{~m}$ \\
\hline & Thailand & 9.0 & -6.5 & 15.4 & 4.5 & 49.0 & 57 & $\mathrm{~m}$ & $\mathrm{~m}$ & $\mathrm{~m}$ \\
\hline & \begin{tabular}{|l|} 
Trinidad and Tobago \\
\end{tabular} & 10.0 & $\mathrm{~m}$ & 13.9 & 7.9 & 44.3 & 129 & $\mathrm{~m}$ & $\mathrm{~m}$ & $\mathrm{~m}$ \\
\hline & Tunisia & 9.0 & 0.1 & 14.7 & 0.7 & 50.4 & 55 & $\mathrm{~m}$ & $\mathrm{~m}$ & $\mathrm{~m}$ \\
\hline & \begin{tabular}{|l|} 
United Arab Emirates \\
\end{tabular} & 4.9 & $\mathrm{~m}$ & 10.9 & 8.4 & 48.1 & 48 & $\mathrm{~m}$ & $\mathrm{~m}$ & $\mathrm{~m}$ \\
\hline & \begin{tabular}{|l|} 
Uruguay \\
\end{tabular} & 16.1 & -1.6 & 9.2 & 4.6 & 47.5 & 45 & $\mathrm{~m}$ & $\mathrm{~m}$ & $\mathrm{~m}$ \\
\hline & Viet Nam & 10.8 & $\mathrm{~m}$ & 15.5 & 29.8 & 53.5 & 68 & $\mathrm{~m}$ & $\mathrm{~m}$ & $\mathrm{~m}$ \\
\hline
\end{tabular}

1. Socio-economically disadvantaged students are those whose values on the PISA index of economic, social and cultural status are among the bottom $25 \%$ within their country or economy.

2. Refers to disadvantaged students who score in the top quarter of science performance in their own country/economy.

3. Refers to disadvantaged students who score at proficiency Level 3 or above in science, reading and mathematics.

4. Standardised scores in TIMSS 1995, PISA 2000 and PIAAC. To allow for comparability among the studies, the scores of each study were transformed into standardised scores using the means and standard deviations for each country in each study.

5. Only England is considered for the analysis of disparities in numeracy at age 25-29 (PIAAC) (last two columns).

6. See notes at the beginning of the chapter.

Note: Values that are statistically significant are indicated in bold.

Sources: IEA, TIMSS dataset. OECD, PIAAC dataset. OECD, PISA 2000, 2006 and 2015 Databases, Tables 2.2, 2.5, 3.3, 3.5, 4.1 , and 4.5 .

StatLink 赫西 https://doi.org/10.1787/888933830063 
Between 2006 and 2015, equity related to science performance improved in 11 countries and economies that participated in PISA in both of those years: Brazil, Bulgaria, Chile, Denmark, Germany, Iceland, Mexico, Montenegro, Slovenia, Thailand and the United States. On average across OECD countries, in 2006, $14.4 \%$ of the variation in students' science performance was explained by students' socio-economic status, whereas in PISA 2015, 12.9\% of the variation was so explained (Figure 1.1).

Similarly, between 2000 and 2015, equity related to reading performance improved in 11 out of 35 countries and economies with comparable data: Australia, Brazil, Canada, Chile, Denmark, the Former Yugoslav Republic of Macedonia (hereafter "FYROM"), Germany, Israel, Mexico, Switzerland and the United States. On average across OECD countries, in PISA 2000, 14.3\% of the variation in student performance in reading was accounted for by differences in students' socio-economic status; in PISA 2015, 11.9\% of the variation was so explained (Figure 2.4).

Equity related to mathematics achievement also improved over PISA cycles. On average across OECD countries, between 2003 and 2015 the percentage of variation in mathematics performance accounted for by socio-economic status decreased by 3.7 percentage points (from $16.9 \%$ in 2003 to $13.1 \%$ in 2015). During this period, 15 out of 38 countries with comparable data improved equity related to mathematics performance: Belgium, Denmark, Germany, Greece, Italy, Mexico, the Netherlands, New Zealand, Poland, Portugal, the Russian Federation (hereafter "Russia"), the Slovak Republic, Switzerland, Turkey and the United States (Figure 2.5).

The fact that equity related to student performance has improved shows that equity is not a fixed feature of education systems. Equity can improve, and over relatively short periods of time. Countries as diverse as Chile, Denmark, Germany, Mexico, Montenegro, Slovenia and the United States have improved equity in education in all three cognitive domains assessed in PISA (science, reading and mathematics). This diversity suggests that all countries can reduce the influence of socio-economic status on student performance, given the right education policies and practices.

These findings do not imply that all inequalities in student performance have narrowed. Gender and immigrant background, for example, are also significant sources of inequality in education opportunities, and the strength of their association with performance over time has been studied separately (OECD, 2016 $\left.{ }_{[30]}\right)$.

Trends in equity in performance may offer insights into what can be expected for future generations. In education systems with greater equity in student performance, more disadvantaged students perform among the best students in their own country (national resilience). According to the findings on transition to higher education in this report, this might allow larger shares of disadvantaged students to enter and complete tertiary education. For this reason, improvements in equity in performance observed among students born between 1985 (in PISA 2000) and 2000 (in PISA 2015) may well translate into more equitable tertiary education attainment. However, in this report, the analysis of trends in attainment is based on PIAAC data for adults born between 1945 and 1989, which captures an earlier cohort than the analysis measuring trends in equity in performance.

\section{In some countries the association between socio-economic status and academic performance did not weaken over the past decade.}

Equity related to science performance decreased only in Qatar between PISA 2006 and PISA 2015, and no changes were observed in 40 countries and economies that participated in both PISA cycles (Figure 1.1). 
Equity related to reading performance decreased in Belgium between PISA 2000 and PISA 2015, and no changes were observed in 23 countries that participated in both cycles (Figure 2.4).

Equity related to mathematics performance decreased in Indonesia, where the variation in performance accounted for by students' socio-economic status increased by 9.8 percentage points, from $6.3 \%$ in 2003 to $16.1 \%$ in 2015. In 22 countries that participated in both cycles (PISA 2003 and 2015), no changes were observed (Figure 2.5).

\section{Disparities in performance related to socio-economic status develop early and widen throughout students' lives.}

Based on data from the Trends in International Mathematics and Science Study (TIMSS), PISA and PIAAC, the analysis shows that differences in performance related to socio-economic status not only take root at an early age, but also are significant by the age of 10. On average among 15 year-olds across the 12 OECD countries with comparable data, more than two-thirds of the gap in mathematics scores associated with having more books at home was already observed at age 10. About half of this achievement gap among 25-29 year-olds was seen even among 10-year-olds (Figure 1.1, Figure 2.6).

The socio-economic gap in mathematics performance among 10-year-olds (as measured by TIMSS), was largest in England, Korea, New Zealand and the United States; it was about average in Australia, Austria, the Czech Republic, Ireland, Norway and the Netherlands; and it was smallest in Canada and Greece (Figure 1.1, Figure 2.6).

PISA results revealed that the achievement gap had grown, relative to that observed in the TIMSS assessment, in 7 out of the 12 countries under study. The gap in mathematics achievement among 15-year-old students (as measured by PISA) grew the most in Canada, the Czech Republic, Greece and the Netherlands; and it grew an average amount in Australia, Ireland and the United States (Figure 1.1, Figure 2.6).

By early adulthood (ages 25 to 29), inequity in mathematics achievement had become even greater. The standardised socio-economic gap in numeracy, as measured by the Survey of Adult Skills (PIAAC), grew, relative to the gap observed in TIMSS, in five out of the 12 countries. Growth in the gap was largest in Canada, England and the Netherlands, and smallest in Australia and Norway (Figure 1.1, Figure 2.6).

The evolution of disparities in performance from childhood to early adulthood offers three key lessons. First, evidence of large differences early on suggests that initial learning and development are largely influenced by factors related to family background and early environments, including early education and primary schooling. Second, the evolution of these inequalities, particularly between primary and secondary school, underscores the crucial role that schools, teachers, and education policies and practices can play in narrowing the gaps and equalising opportunities for all students. Third, a number of countries have unique profiles that do not fit into the average patterns. Notable trends are found in Korea, for example, where inequalities in achievement narrow considerably between adolescence and early adulthood; in Canada, where performance inequalities during childhood (at age 10) are smaller than those observed in other countries; and in England, where inequalities in performance grow markedly between adolescence and early adulthood. Further research into these cases might provide greater insights into the mechanisms through which inequalities in education take root and evolve, and help in the development of more effective policies. 


\section{Performance at age 15 is a strong predictor of higher education and early career outcomes.}

Across the five countries included in the longitudinal analyses, student performance in PISA is strongly correlated with outcomes in early adulthood. Fifteen-year-old students who score in the top quarter in reading are between 38 and 53 percentage points more likely to complete university than students who score in the bottom quarter. Differences in 15-year-olds' reading performance explain between $27 \%$ and $43 \%$ of the difference in university completion rates between advantaged and disadvantaged students, suggesting that reducing socio-economic differences in what students learn during compulsory schooling could increase educational mobility (Figure 1.4).

In addition to furthering education, performance at age 15 is also linked to opportunities for skilled employment. Students who score in the top quarter of reading performance are between 24 and 47 percentage points more likely than students in the bottom quarter of performance to be working in a job that requires tertiary education by the age of 25 . These results imply that performance during secondary school matters not only for later educational attainment, but also for shaping opportunities in the labour market during early adulthood (Figure 1.5).

\section{Some disadvantaged students perform as well as their top-performing national peers or reach good levels of performance in core subjects.}

Academic resilience, as defined in PISA, is the capacity of disadvantaged students to achieve higher levels of performance than would be predicted by their family background. This report distinguishes between different types of academic resilience to capture the notion that resilience goes beyond excellence in a single subject as measured in international comparisons. Resilience is considered using a national perspective, by comparing disadvantaged students with the best-performing students in their own countries, and also using a "core-skills" perspective, by considering the achievement of good levels of performance in science, reading and mathematics.

Some $11 \%$ of disadvantaged students across OECD countries are "nationally resilient" - meaning that they score in the top quarter of science performance in their own countries. National resilience is more prevalent in countries and economies with greater equity in education. Algeria, Hong Kong (China), Iceland, Kosovo, Macao (China) and Montenegro have the largest shares of nationally resilient students, while top-performing countries and economies Singapore and Beijing-Shanghai-Jiangsu-Guangdong (China) (hereafter "B-S-J-G [China]") have some of the smallest shares of nationally resilient students (Figure 1.1).

On average across OECD countries, 25\% of disadvantaged students are "core-skills resilient", meaning that they score at PISA proficiency Level 3 or above in science, reading and mathematics. This type of academic resilience is more prevalent in countries with higher average performance. In Hong Kong (China) and Macao (China), more than half of all disadvantaged students are core-skills resilient.

School characteristics and students' attitudes and behaviours towards school tend to be more strongly associated with academic resilience than students' demographic background. The share of nationally and core-skills resilient students is greater in schools with a better disciplinary climate, and among students who do not skip school and who have greater motivation to achieve, on average across OECD countries. 


\section{Disadvantaged students express less psychological well-being than advantaged students, even when they perform similarly in PISA.}

Disadvantaged students tend to express less psychological well-being than advantaged students. One indicator of psychological well-being measured in PISA is students' self-efficacy in science: how much students believe in their own capacity to perform tasks similar to those included in the PISA science assessment. The level of science self-efficacy was higher among more advantaged students in each of the 53 countries and economies that participated in both PISA 2006 and PISA 2015 (Figure 1.2). Furthermore, in nearly every country and economy that participated in PISA 2015, advantaged students were more confident in their ability to solve science problems than disadvantaged students, even when comparing students whose science knowledge and skills are demonstrably similar (Table 2.9).

On average across OECD countries and in 33 countries and economies with comparable data, the disparities in students' science self-efficacy related to socio-economic status did not change in magnitude between PISA 2006 and PISA 2015 (Figure 2.8).

Students' career expectations reflect their psychological well-being. Positive expectations for the future signal high self-esteem and effective coping mechanisms. In every country and economy that participated in PISA 2015, socio-economically advantaged students expected to be employed in occupations of higher social status than disadvantaged students (as measured by the International Socio-economic Index of Occupational Status [Ganzeboom and Treiman, 2003 $\left.{ }_{[31]}\right]$ ) (Figure 1.2). In all OECD countries, differences in career expectations related to socio-economic status were significant, even after accounting for students' performance in science (in Israel, the difference is not significant after accounting for performance) (Table 2.11).

These differences in career expectations were larger in PISA 2006 than in PISA 2015, on average across OECD countries and in 18 of the 51 countries and economies with comparable data. Disparities in career expectations related to socio-economic status have narrowed over time as the share of disadvantaged students who expect to work in a high-status career grew by more than the share of advantaged students with similar career expectations. By contrast, the gap in expectations related to socio-economic status was wider in 2015 than in 2006 in 14 countries (Figure 2.9).

\section{Socio-economic disparities in students' social well-being are small.}

Students' social well-being is measured by examining students' sense of belonging at school: the extent to which students feel accepted by and connected to their peers, and part of the school community. Students from socio-economically advantaged families enjoy a stronger sense of belonging at school than disadvantaged students (Figure 1.2). However, the disparity between the two groups of students is not large because most disadvantaged students feel they belong at school. In PISA 2015, on average across OECD countries, $77 \%$ of advantaged students and $69 \%$ of disadvantaged students reported that they feel they belong at school (Table 2.6). In most countries, differences in sense of belonging at school related to socio-economic status disappear once student performance is taken into account (Table 2.7). 
Figure $1.2[1 / 2]$ - Equity in student well-being

\begin{tabular}{|c|c|c|c|c|c|}
\hline & & $\begin{array}{l}\square \text { Countries/ecc } \\
\text { Countries/ecc } \\
\square \text { Countries/ecc }\end{array}$ & $\begin{array}{l}\text { nies with higher } \\
\text { nies with values } \\
\text { nies with lower }\end{array}$ & $\begin{array}{l}\text { ues than the OECD aver } \\
\text { statistically different fror } \\
\text { ues than the OECD avera }\end{array}$ & e OECD average \\
\hline & & $\begin{array}{l}\text { Differen } \\
\text { advantage }\end{array}$ & $\begin{array}{l}\text { d disadvantage } \\
\text { d }\end{array}$ & $\begin{array}{l}\text { nomically } \\
\text { tudents in... }\end{array}$ & $\begin{array}{l}\text { Socially and } \\
\text { emotionally }\end{array}$ \\
\hline & & $\begin{array}{c}\text {... index of science } \\
\text { self-efficacy }\end{array}$ & $\begin{array}{c}\text {...career } \\
\text { expectations }^{2}\end{array}$ & $\begin{array}{c}\text {...sense of belonging } \\
\text { at school }{ }^{3}\end{array}$ & $\begin{array}{l}\text { resilient } \\
\text { students }^{4}\end{array}$ \\
\hline & & Index dif. & Index dif. & $\%$ dif. & $\%$ \\
\hline & OECD average & 0.60 & 50.2 & 7.7 & 26.2 \\
\hline 0 & Australia & 0.73 & 50.6 & 13.2 & $\mathrm{~m}$ \\
\hline ن & Austria & 0.84 & 55.4 & 7.5 & 27.9 \\
\hline 0 & Belgium & 0.72 & 53.0 & 13.2 & 26.3 \\
\hline & Canada & 0.72 & 46.3 & 15.0 & $\mathrm{~m}$ \\
\hline & Chile & 0.49 & 41.0 & 3.9 & 22.8 \\
\hline & Czech Republic & 0.52 & 58.1 & 10.2 & 29.8 \\
\hline & Denmark & 0.77 & 51.4 & 13.6 & $\mathrm{~m}$ \\
\hline & Estonia & 0.54 & 51.3 & 9.3 & 29.4 \\
\hline & Finland & 0.63 & 58.9 & 7.2 & 38.6 \\
\hline & France & 0.75 & 55.6 & 12.9 & 30.8 \\
\hline & Germany & 0.56 & 55.5 & 5.7 & 36.0 \\
\hline & Greece & 0.51 & 46.3 & 2.9 & 20.3 \\
\hline & Hungary & 0.39 & 57.2 & 8.5 & 24.6 \\
\hline & Iceland & 0.80 & 45.9 & 7.5 & 30.4 \\
\hline & Ireland & 0.75 & 47.2 & 8.2 & 24.8 \\
\hline & Israel & 0.46 & 41.8 & $\mathrm{~m}$ & $\mathrm{~m}$ \\
\hline & Italy & 0.46 & 52.8 & 4.2 & 15.6 \\
\hline & Japan & 0.58 & 49.9 & 6.1 & 19.6 \\
\hline & Korea & 0.69 & 44.0 & 12.8 & 25.5 \\
\hline & Latvia & 0.47 & 54.0 & 3.2 & 32.6 \\
\hline & Luxembourg & 0.76 & 54.7 & 17.4 & 25.8 \\
\hline & Mexico & 0.23 & 37.2 & 1.6 & 21.8 \\
\hline & Netherlands & 0.53 & 53.7 & 5.3 & 50.2 \\
\hline & New Zealand & 0.74 & 47.3 & 13.1 & $\mathrm{~m}$ \\
\hline & Norway & 0.63 & 49.5 & 8.6 & $\mathrm{~m}$ \\
\hline & Poland & 0.53 & 56.3 & 7.2 & 27.4 \\
\hline & Portugal & 0.66 & 46.6 & 1.6 & 16.5 \\
\hline & Slovak Republic & 0.60 & 56.3 & 7.7 & 25.7 \\
\hline & Slovenia & 0.60 & 51.3 & 0.8 & 22.2 \\
\hline & Spain & 0.64 & 47.3 & 2.4 & 19.7 \\
\hline & Sweden & 0.69 & 54.4 & 8.3 & $\mathrm{~m}$ \\
\hline & Switzerland & 0.56 & 54.7 & 4.1 & 43.2 \\
\hline & Turkey & 0.26 & 42.5 & 1.5 & 13.1 \\
\hline & United Kingdom & 0.61 & 44.8 & 9.3 & 15.3 \\
\hline & United States & 0.65 & 43.3 & 8.3 & 18.3 \\
\hline
\end{tabular}

1. In PISA 2015, students were asked to rate how they would perform on different science tasks, using a four-point scale with the answers: "I could do this easily"; "I could do this with a bit of effort"; "I would struggle to do this on my own"; and "I couldn't do this". This index was scaled using the IRT scaling model. The higher the value, the greater the level of science self-efficacy.

2. In PISA 2015, students were asked "What kind of job do you expect to have when you are about 30 years old?" This was an open question and responses were coded to four-digit ISCO (International Standard Classification of Occupations) codes, and then mapped to the ISEI (International Socio-Economic Index of occupational status) index (Ganzeboom and Treiman, 2003). Higher scores in the ISEI index indicate higher occupational status.

3. Refers to the percentage of students who feel they belong at school.

4. Refers to disadvantaged students who are satisfied with their life, feel socially integrated at school and do not suffer from test anxiety.

5. See notes at the beginning of the chapter.

Note: Values that are statistically significant are indicated in bold.

Source: OECD, PISA 2015 Database, Tables 2.6, 2.8, 2.10 and 3.9a.

StatLink त्ताज https://doi.org/10.1787/888933830082 
Figure $1.2[2 / 2]$ - Equity in student well-being

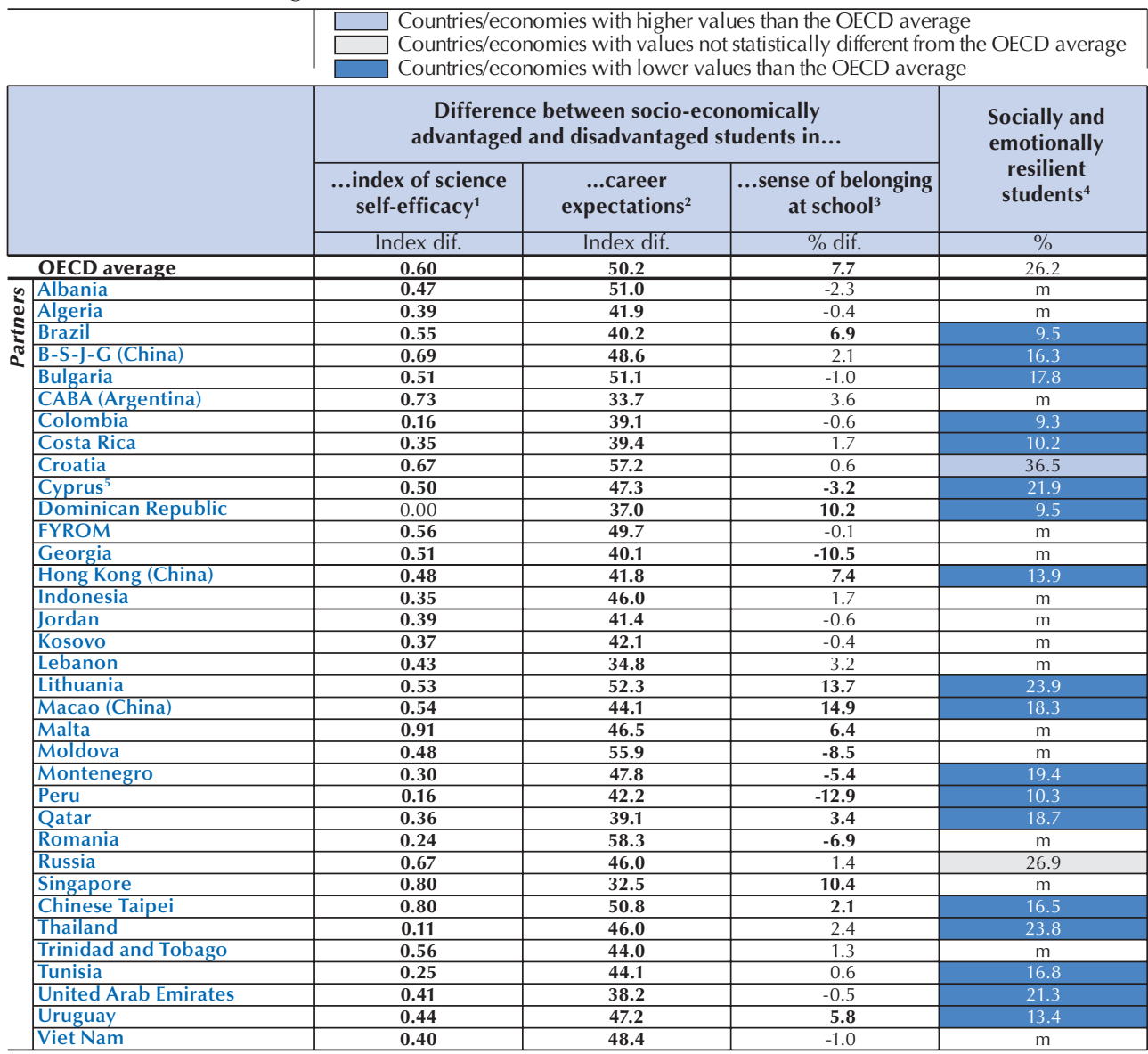

1. In PISA 2015, students were asked to rate how they would perform on different science tasks, using a four-point scale with the answers: "I could do this easily"; "I could do this with a bit of effort"; "I would struggle to do this on my own"; and "I couldn't do this". This index was scaled using the IRT scaling model. The higher the value, the greater the level of science self-efficacy.

2. In PISA 2015, students were asked "What kind of job do you expect to have when you are about 30 years old?" This was an open question and responses were coded to four-digit ISCO (International Standard Classification of Occupations) codes, and then mapped to the ISEI (International Socio-Economic Index of occupational status) index (Ganzeboom and Treiman, 2003). Higher scores in the ISEI index indicate higher occupational status.

3. Refers to the percentage of students who feel they belong at school.

4. Refers to disadvantaged students who are satisfied with their life, feel socially integrated at school and do not suffer from test anxiety.

5. See notes at the beginning of the chapter.

Note: Values that are statistically significant are indicated in bold.

Source: OECD, PISA 2015 Database, Tables 2.6, 2.8, 2.10 and 3.9a.

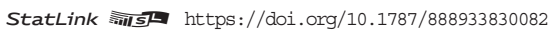


Figure 1.3 - Equity in educational attainment

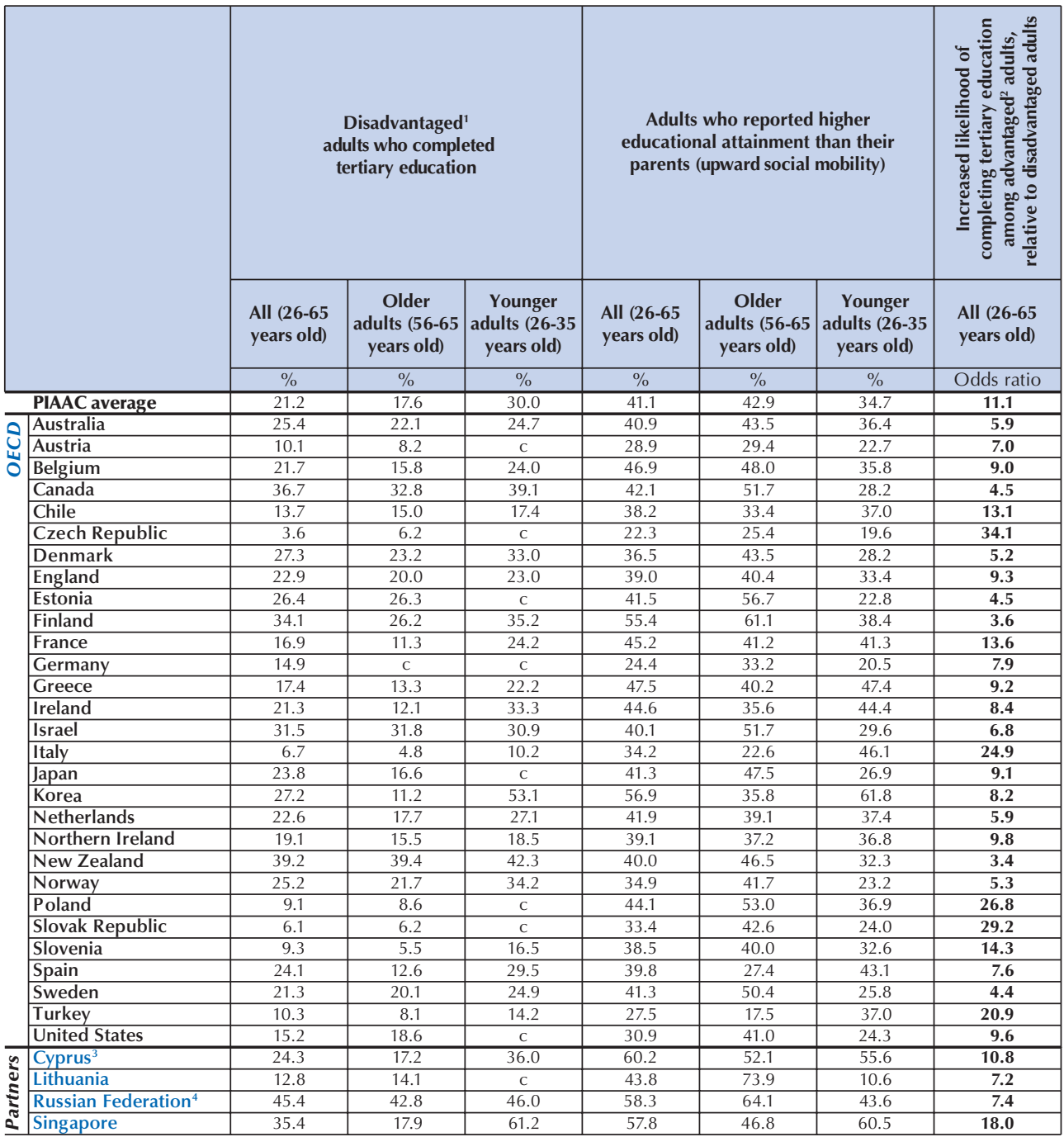

1. Adults with parents who did not complete lower secondary education.

2. Adults with at least one parent who completed tertiary education.

3. See notes at the beginning of the chapter.

4. See note at the beginning of the chapter.

Note: Values that are statistically significant are indicated in bold.

Source: OECD, PIAAC Dataset, Tables 2.18, 2.19, 2.22, 2.23 and 2.24.

StatLink 需西 https://doi.org/10.1787/888933830101 
Figure 1.4 - Educational mobility (longitudinal evidence)

\begin{tabular}{|c|c|c|c|c|c|c|c|c|}
\hline & & & & Univer & complet & d by age 25 & & \\
\hline & 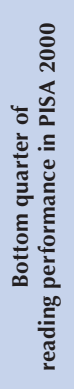 & 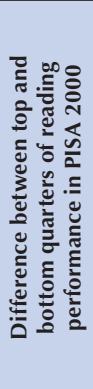 & 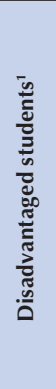 & 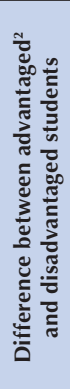 & 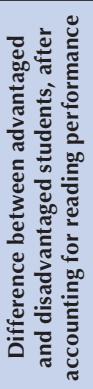 & 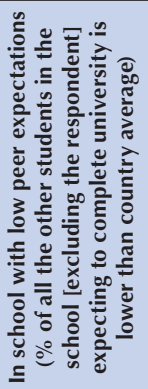 & 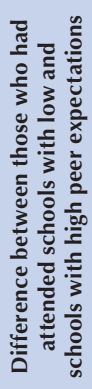 & 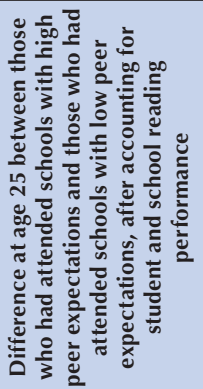 \\
\hline & $\%$ & $\%$ dif. & $\%$ & $\%$ dif. & $\%$ dif. & $\%$ & $\%$ dif. & $\%$ dif. \\
\hline Australia & 15.1 & 50.8 & 29.3 & 21.1 & 14.7 & 25.9 & 27.3 & 20.0 \\
\hline Canada & 9.3 & 53.2 & 24.3 & 17.0 & 10.8 & 27.8 & 13.6 & 7.1 \\
\hline Denmark & 7.3 & 44.3 & 14.3 & 19.1 & 11.0 & 24.0 & 6.9 & 0.6 \\
\hline Switzerland & 1.3 & 37.9 & 11.1 & 16.5 & 10.2 & 8.6 & 22.2 & 10.0 \\
\hline United States & 9.2 & 50.8 & 21.9 & 29.7 & 21.7 & $m$ & $\mathrm{~m}$ & $\mathrm{~m}$ \\
\hline
\end{tabular}

1. Disadvantaged students are those without a tertiary-educated parent.

2. Advantaged students are those with a tertiary-educated parent.

Note: Values that are statistically significant are indicated in bold.

Sources: See Tables 5.3, 5.4 and 5.30 of this report.

OECD, PISA 2000 and 2003 databases.

For Australia: Longitudinal Surveys of Australian Youth (LSAY).

For Canada: Youth in Transition Survey (YITS).

For Denmark: OECD, PISA Database and PIAAC Dataset.

For Switzerland: Transitions from Education to Employment (TREE1) ${ }^{1}$.

For the United States: Educational Longitudinal Study of 2002 (ELS).

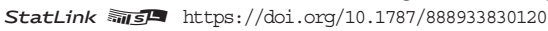

There has been little change over time in the gap in students' sense of belonging at school related to socio-economic status. Only in four countries did this gap shrink over PISA cycles (Bulgaria, Japan, the Netherlands and Portugal); in six countries the gap widened (Australia, Brazil, New Zealand, Singapore, the Slovak Republic and Sweden) (Figure 2.7).

\section{Social and emotional resilience has been shown to reinforce academic resilience.}

Student resilience is considered not only in terms of academic performance, as in previous PISA reports, but also in terms of social and emotional well-being. Student well-being is positively related to academic performance. Both dimensions are mutually reinforcing parts of a successful school experience.

Some $26 \%$ of disadvantaged students across OECD countries are "socially and emotionally resilient", meaning that they are satisfied with their life, feel socially integrated at school and do not suffer from test anxiety. In Croatia, the Czech Republic, Finland, France, Germany, Iceland, Latvia, the Netherlands and Switzerland, the share of socially and emotionally resilient students is among the largest (30\% or more) found across all countries; but in other European countries, including Bulgaria, Italy, Montenegro, Portugal and the United Kingdom, the share is 
comparatively small (less than 20\%). In top-performing Asian countries and economies, such as B-S-J-G (China), Hong Kong (China), Japan, Macao (China) and Chinese Taipei, the share is also small (20\% or less), but the Latin American countries of Brazil, Colombia, Costa Rica, the Dominican Republic, Peru and Uruguay, and also Turkey, have the smallest proportions of socially and emotionally resilient students overall (less than 15\%) (Figure 1.2).

Figure 1.5 - School-to-work transitions (longitudinal evidence)

\begin{tabular}{|c|c|c|c|c|c|c|c|c|}
\hline & & & & Employe & n a skillec & b at ag & & \\
\hline & 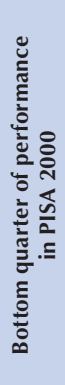 & 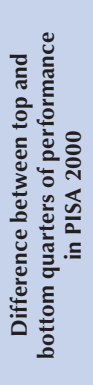 & 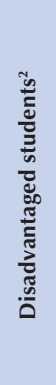 & 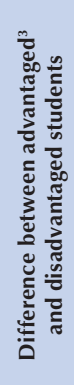 & 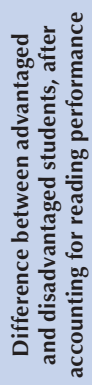 & 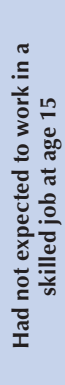 & 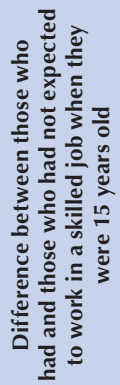 & 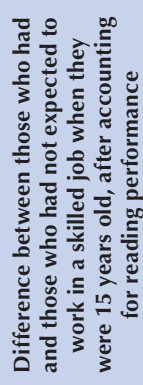 \\
\hline & $\%$ & $\%$ dif. & $\%$ & $\%$ dif. & $\%$ dif. & $\%$ & $\%$ dif. & $\%$ dif. \\
\hline Australia & 14.2 & 33.9 & 22.2 & 15.3 & 10.2 & 20.1 & 20.4 & 14.2 \\
\hline \begin{tabular}{|l} 
Canada \\
\end{tabular} & 18.2 & 24.0 & 26.6 & 7.2 & 3.7 & 25.4 & 11.4 & 7.2 \\
\hline \begin{tabular}{|l|} 
Denmark \\
\end{tabular} & 21.7 & 47.3 & 30.5 & 20.2 & 11.0 & 26.5 & 39.5 & 32.5 \\
\hline \begin{tabular}{|l|} 
Switzerland \\
\end{tabular} & 12.7 & 23.5 & 16.7 & 12.6 & 10.1 & 19.5 & 10.0 & 4.8 \\
\hline United States & 30.0 & 25.2 & 35.5 & 16.5 & 12.5 & $\mathrm{~m}$ & $\mathrm{~m}$ & $\mathrm{~m}$ \\
\hline
\end{tabular}

1. A skilled job means a job requiring tertiary education.

2. Disadvantaged students are those without a tertiary-educated parent.

3. Advantaged students are those with a tertiary-educated parent.

Note: Values that are statistically significant are indicated in bold.

Sources: See Tables 5.10, 5.19 and 5.20 of this report.

OECD, PISA 2000 and 2003 databases.

For Australia: Longitudinal Surveys of Australian Youth (LSAY).

For Canada: Youth in Transition Survey (YITS).

For Denmark: OECD, PISA Database and PIAAC Dataset.

For Switzerland: Transitions from Education to Employment (TREE1).

For the United States: Educational Longitudinal Study of 2002 (ELS).

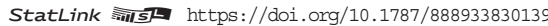

Disadvantaged students who are socially and emotionally resilient also tend to do better academically. This implies that helping disadvantaged students develop positive attitudes and behaviours towards themselves and their education can also benefit these students' academic development. Academic resilience can also promote social and emotional resilience, creating a cycle of positive reinforcement.

A positive relationship between national resilience (disadvantaged students who perform as well as the top performers in their own countries), and social and emotional resilience is significant in 30 out of the 48 countries and economies for which data is available. In Belgium and Bulgaria, nationally resilient students are almost three times more likely than disadvantaged students who are not nationally resilient to also be socially and emotionally resilient (Figure 3.11). 
Similarly, the positive relationship between core-skills resilience (disadvantaged students who score at proficiency Level 3 or above in science, reading and mathematics), and social and emotional resilience is significant in 28 countries and economies. In Brazil and Mexico, coreskills resilient students are almost three times more likely than disadvantaged students who are not core-skills resilient to be socially and emotionally resilient as well (Figure 3.11).

\section{Disadvantaged students face a variety of barriers to learning.}

Family background and early environments are strongly linked to student learning and performance. Research shows that students from low-income and single-parent households tend to have significantly lower performance during both primary and secondary schooling (Barajas, 2011 $1_{[32]}$; Ferguson, Bovaird and Mueller, 2007 $\left.{ }_{[33]}\right)$. This gap can still be observed in university completion rates at the age of 25 (Figure 5.12). Specifically, students from low-income and single-parent households are between 7 and 17 percentage points less likely to complete university (Tables 5.26 and 5.33). While this does not suggest a causal relationship, it highlights the potential effects that limited resources at home can have on education opportunities and attainment.

Less household wealth often translates into fewer educational resources, such as books, games and interactive learning materials in the home. In addition, families with limited income may not have access to early education if it is not publicly funded; and children from these families are shown to benefit the most from such opportunities. Single parents have to shoulder double the responsibilities as parents in a two-parent household, which may limit their time to engage and interact with their children.

These results emphasise the importance of identifying the specific inequities faced by disadvantaged children, both during early stages of development and outside the classroom during compulsory schooling. Not only do these factors contribute to academic performance and educational attainment, they are also likely to shape students' expectations, attitudes, and beliefs regarding education and opportunity.

\section{Many disadvantaged students are concentrated in lower-quality schools.}

There is a strong link between schools' socio-economic profile and students' performance: students who attend more socio-economically advantaged schools perform better in PISA. Hence, disadvantaged students attending disadvantaged schools are, a priori, doubly disadvantaged as they strive for academic achievement (Figure 1.1).

Countries that participated in the 2015 PISA assessment differ in the degree to which their school systems segregate disadvantaged students into certain schools. On average across OECD countries, $48 \%$ of disadvantaged students attended disadvantaged schools in PISA 2015; and there has been no significant change in the average level of segregation of disadvantaged students in most PISA-participating education systems.

On average across OECD countries, disadvantaged students attending advantaged schools score 78 points higher than those attending disadvantaged schools. Disadvantaged students attending schools with an average socio-economic profile (schools that are neither advantaged nor disadvantaged) score 36 points higher than those attending disadvantaged schools. 
A school's socio-economic profile is most strongly related to performance in Belgium, B-S-J-G (China), Bulgaria, CABA (Argentina), France, Hungary, the Slovak Republic, Slovenia and the Netherlands, where disadvantaged students attending advantaged schools score more than 130 points higher in science than those in disadvantaged schools. By contrast, in Albania, Finland, Iceland, Macao (China), Norway and Poland, there is no significant difference in the performance of disadvantaged students related to whether they attend advantaged or disadvantaged schools (Figure 1.1).

Several factors explain this relationship between a school's socio-economic profile and the performance of disadvantaged students. The academic level of peers in the school, the availability of science-specific resources and science competitions, the disciplinary climate, class size, student truancy, and the various pedagogical strategies used are all potential mediating factors between school socio-economic profile and the performance of disadvantaged students (Figures 4.5 and 4.6). In other words, the aforementioned are school characteristics that tend to be related to performance, and the more positive of these characteristics tend to be found more commonly in socio-economically advantaged schools. For example, clustering disadvantaged students in certain schools can affect performance because teachers may adapt their academic standards to the average level of their classes, resulting in less stimulating and demanding learning environments in schools with larger shares of disadvantaged students. Teachers might also be more attracted to schools with fewer disciplinary problems and more resources, which is more often the case in advantaged schools.

\section{WHAT THE RESULTS IMPLY FOR POLICY}

Policies and practices aimed at providing more equal education opportunities for all children can be implemented at the classroom, school and education-system levels. Such policies may have more success if they are implemented as early as possible, and if they dismantle the extensive barriers to learning that disadvantaged students face, focus on students' attitudes, and social and emotional well-being, and are coupled with education and social programmes that improve students' environments outside of school. This section offers a series of general policy recommendations, based on the results from this report, that countries can use to identify the most appropriate tools for improving equity in education and social mobility in their own specific contexts.

\section{Support disadvantaged children, adolescents and young adults in their education}

Findings in this report show that disparities in performance related to socio-economic status develop early and widen throughout students' lives. They also show that in different countries inequity increases more markedly during specific life stages (childhood, adolescence or young adulthood) than in others. For example, in England, Korea, New Zealand and the United States, inequity is comparatively large during childhood (as measured by TIMSS, when students are 10 years old), whereas in Australia, Canada and Greece inequities are smaller at this stage. But in the latter three countries, and also in the Czech Republic, Ireland, the Netherlands and the United States, inequity grows significantly during adolescence; and in Australia, Canada, England, the Netherlands and Norway, inequity increases significantly during early adulthood (as measured by the Survey of Adult Skills among 25-29 year-olds) (Figure 2.6). Therefore, 
each country needs to understand at what age inequity begins to affect individuals and how it deepens over a lifetime. This might require developing age-appropriate national assessments and conducting longitudinal studies. Countries need to consider creating and reinforcing policies and programmes that support disadvantaged students at the stages in which inequity is most prevalent, and during the periods immediately before these inequities arise. Such policies can help prevent inequities from developing and limit those that may have already taken root.

\section{Provide quality early-education programmes to disadvantaged children}

A finding common across countries is that inequity in education is already observed by age 10; this leads to the second policy implication of the report: the importance of early intervention. Early childhood education and care are critical vehicles for providing more equitable learning environments early on. Studies in the United States show that disadvantaged children benefit most from a wide range of means-tested and universal early childhood education programmes including Head Start, state preschool programmes and demonstration programmes, such as the Perry Preschool Program and the Carolina Abecedarian Project - and society earns higher returns from targeted investments (Heckman, 2016 $6_{[34]}$ ). Such studies have investigated the short- and long-term effects of providing high-quality early childhood education and care to impoverished, at-risk children, often while coupling these interventions with health, nutrition and parentinvolvement services. By conducting a series of follow-up interviews with people who had attended such programmes through adolescence and adulthood (up to ages 35-40), researchers were able to compare various life outcomes across treatment and control groups. Studies reveal that these programmes offer substantial lifelong benefits, including higher educational attainment and career achievement, reduced criminal activity, better health, and stronger family and personal relationships (Schweinhart et al., 2005 [35]; Conti, Heckman and Pinto, 2015 $5_{[36]}$ ).

In addition, quality early childhood education helps children acquire essential social and emotional skills. Yet in many countries, poor and minority families are less likely to enrol their children in such programmes. Countries should promote greater access to these programmes, particularly among disadvantaged families. In some countries, a first step is to fund the development of more quality early childhood education and care establishments in order to meet demand. If enrolment fees are required, policies that subsidise or reduce the costs for poor families may lead to considerable gains in attendance. In addition, sufficient resources must be allocated to improve the quality of these programmes, by assuring that teachers are qualified and well-trained, and that the environment is conducive to learning for all students.

\section{Set ambitious goals and monitor the progress of disadvantaged students}

Countries could set progressive benchmarking points to monitor their progress in equity in education. For example, when it comes to improving the academic performance of disadvantaged students, countries might want to distinguish between benchmarks based on national criteria, such as reaching a certain share of disadvantaged students who achieve excellence by national standards (i.e. national resilience), and benchmarks based on international or absolute criteria, such as reaching a certain share of disadvantaged students who achieve proficiency Level 3 in PISA in science, reading and mathematics (i.e. core-skills resilience). All countries might want to define ambitious national goals, such as ensuring that $20 \%$ of disadvantaged students are nationally resilient (the current share of national resilience is between $7 \%$ and $14 \%$ in most 
OECD members and partner countries [Figure 1.1]). If $25 \%$ of disadvantaged students scored among the top quarter of all students in a country, it would be as if performance was unrelated to socio-economic background (complete equity).

Top-performing and low-performing countries start from very different points. Top-performing countries might want to set a goal of ensuring that $75 \%$ of disadvantaged students are core-skills resilient; the current OECD average is $25 \%$ (Figure 1.1). In the lowest-performing countries, a small minority of students reaches proficiency Level 3 in reading, mathematics and science; therefore, ensuring that $25 \%$ of disadvantaged students are core-skills resilient (the current OECD standard) can be defined as a long-term goal for these countries, to be achieved as the education system improves its overall quality.

\section{Develop teachers' capacity to detect student needs and manage diverse classrooms}

Changing practices inside the classroom can help reduce cognitive and socio-emotional gaps related to socio-economic status. By providing schools with services such as specialised teacher support and training, teachers may be better equipped with the skills to identify and address learning difficulties, develop more customised and effective teaching methods, and foster selfesteem and positive attitudes among disadvantaged students. Often, programmes that conduct more frequent assessments and monitor individual performance help teachers identify struggling students and track student progress more effectively. These activities should be coupled with greater enthusiasm for personalised learning and the use of technologies that facilitate it.

In addition, schools that provide guidance and career counselling to students may be able to complement efforts in the classroom, and help students assess their progress and think strategically about goals and aspirations. While advantaged students tend to enjoy the benefits of stronger support networks and mentorship outside of the classroom, thus requiring less from their school environments, this is often not the case for disadvantaged students. When schools and teachers understand the barriers that disadvantaged students face, and allocate resources to initiatives that have been proven successful, they can help students overcome these obstacles.

By contrast, the risks of managing student heterogeneity by implementing rigid stratification policies are well-documented (Dupriez, Dumay and Vause, $\left.2008_{[37]}\right)$. Tracking has been shown to increase inequality in education, particularly within systems that track students into different schools at early ages (Hanushek and Wossmann, 2006 ${ }_{[38]}$; Van de Werfhorst and Mijs, $2010_{[39]}$ ). Grade repetition tends to stigmatise repeaters, undermining their self-esteem and sense of belonging at school, and reinforcing their disengagement from the learning process (Jimerson, $2001_{[40] ;}$ Jimerson, Anderson and Whipple, 2002 $\left.{ }_{[41]}\right)$.

Socio-economically disadvantaged and minority students tend to perform worse during initial years of school due to differences in early education, family and home environments; in some cases, these students are also learning in a non-native language. As a result, they tend to repeat grades more often and to be sorted into education programmes that provide them with fewer learning opportunities and less-demanding content. Though managing classrooms with students of different levels and backgrounds may require the adoption of new tools and teaching practices, such settings prove to be the most beneficial for disadvantaged students. 


\section{Target additional resources towards disadvantaged students and schools}

More often than not, disadvantaged students are clustered in schools where a lack of financial, material and human resources hinders student learning. Schools with more disadvantaged students tend to receive more teachers (quantity) but not necessarily more experienced and skilled teachers (quality) (OECD, 2018 $\left.8_{[42]}\right)$. Achievement may suffer if a student's classmates include a large proportion of low-achieving peers (Hanushek et al., 2003 ${ }_{[43]}$; Lavy, Silva and Weinhardt,

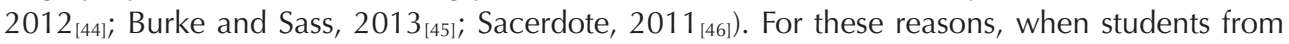
disadvantaged families attend disadvantaged schools, they face a double disadvantage that puts them at serious risk of not performing academically at adequate levels. Education systems must acknowledge this issue and provide special support for these students and their schools.

It is essential that disadvantaged students in all schools have the resources they needed to succeed. This means that funding must be targeted in a way that equalises opportunities for learning and achievement. Schools with larger shares of disadvantaged students therefore will require additional investments in human and material resources, such as improvements to school infrastructure, teacher training and support, language-development programmes for minority students, tutoring and homework-assistance services, extracurricular activities, and customised instructional programmes to address the learning challenges particular to disadvantaged and minority students. Equally important, schools with large shares of disadvantaged students must ensure that the supply of available resources is sufficient to meet the demand of all students. Disadvantaged students, even those in more advantaged schools, must be informed of and encouraged to use these services.

In countries where there is a higher concentration of disadvantaged students in certain schools, targeting resources to disadvantaged schools can be an effective strategy. In countries where disadvantaged students are less concentrated, targeting individual students and their families can be more effective.

\section{Reduce the concentration of disadvantaged students in particular schools}

Another way to address double disadvantage is to reduce the number of students suffering from it by reducing the concentration of disadvantaged students in particular schools.

Residential segregation may explain why large groups of disadvantaged students are found in the same schools. However, policies used to assign students to schools can provide opportunities to improve the level of social diversity in schools. This can happen by reshaping school catchment areas or school districts to include neighbourhoods with different social characteristics. However, these policies may, in turn, reinforce residential segregation in the long run. Black and Machin $\left(2011_{[47]}\right)$ review a broad range of evidence that parents may pay significantly more for housing in areas where the perceived quality of schooling is higher. Trying to achieve more diverse school enrolment in some districts may eventually lead to greater stratification between schools by outcome and ability, as more educated and wealthy parents may choose to relocate in order to have access to schools with the most favourable socio-economic status (Epple and Romano, $\left.2003_{[48]}\right)$.

Providing more opportunities for school choice is another mechanism that may alter the social mix in schools (Musset, 2012 ${ }_{[49]}$ ). In theory, school choice may benefit disadvantaged students 
by allowing them to leave low-performing schools when school assignment is mainly residencebased. However, most empirical evidence in countries as diverse as Chile, New Zealand, Sweden, the United Kingdom and the United States suggests that reforms introducing greater school choice also tend to increase academic and socio-economic sorting because more advantaged, highly educated families are more likely to make better-informed choices (Levin, 1998 ${ }_{[50] ;}$; Burgess and Briggs, 2010 [51]; Ladd and Fiske, 2001 [52]; Söderström and Uusitalo, 2010 [53]; Schneider, Elacqua and Buckley, 2006 ${ }_{[54]}$; Mizala and Torche, 2012 $\left.{ }_{[55]}\right)$.

Yet the sorting effect of school choice may be either mitigated or intensified, depending on the design of the policy (Epple, Romano and Urquiola, 2017 $\left.{ }_{[56]}\right)$. As the OECD suggests $\left(2017_{[57]}\right)$, school choice can be regulated in order to promote social diversity in schools. This could be accomplished, for instance, by improving disadvantaged families' access to information about schools, and also by restricting the possibilities for schools to skim off the best students through selective admissions criteria. Local authorities may also control enrolments in order to mitigate imbalances in schools' social composition.

Some countries provide good examples of policies and tools aimed at creating more socio-

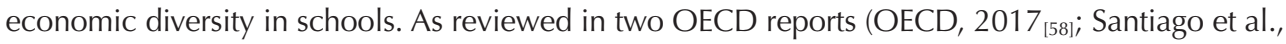
$\left.2017_{[59]}\right)$, Chile introduced a series of recent reforms with the aim of reducing social segregation in schools and ensuring that school choice is not contingent on families' ability to pay, student achievement or other potentially discriminatory factors. The reforms regulate student admissions by forbidding the use of economic, social, ethnic, religious or academic criteria; eliminating shared funding (financiamiento compartido, the existence of tuition fees in parallel with public subsidies in a single school); providing greater public resources to the Preferential School Subsidy (Subvención Escolar Preferencial); making it impossible for schools to receive public funding to make a profit; and forbidding the expulsion of students for academic, political, ideological or other reasons.

\section{Foster student well-being}

The findings reveal that student expectations are a key factor in their future success. There are significant disparities in expectations for future education and careers between 15-year-old advantaged and disadvantaged students, and these gaps help to explain differences in educational and occupational attainment among young adults, independent of performance in PISA. Similar relationships are observed for a range of socio-emotional outcomes, including student selfefficacy, sense of belonging at school, and attitudes towards schooling. Therefore, policies aimed at promoting equity in education and educational mobility need to be multi-pronged. They need to ensure that students are given adequate educational resources that are allocated fairly at the school level, and also supply teachers with the tools to help nurture positive attitudes and aspirations among students from disadvantaged backgrounds.

While more attention has been devoted to research regarding student well-being in recent years, this is not necessarily the case for classroom pedagogy. Because student well-being is less evident and harder to measure, it can often be overlooked. Teachers may more easily interpret poor performance as a lack of effort, and fail to investigate further. This is much more likely to occur in schools with large shares of disadvantaged students, where less-experienced teachers face greater time and resource constraints, and where students tend to perform worse and have less positive 
attitudes towards schooling. Yet teachers' understanding of student perceptions, favourable relationships between teachers and students, and better classroom dynamics have been shown to improve academic performance, discipline and cognitive engagement (willingness and ability to take on and learn the tasks at hand) among disadvantaged students (Whitehead, 2006 [60]; Archambault, Janosz and Chouinard, 2012 $[61])$.

Just as formative assessments can be important for monitoring students' academic progress (OECD, 2013 $3_{[62]}$ ), teachers should have tools in place for observing and promoting student well-being. Research shows that teachers can foster a stronger sense of belonging for all students with activities that ask students to identify similarities among one another, to consider reasons why some students may feel that they do not belong in a particular class or school setting, or to reflect on times where they may have felt they did not belong and how those feelings changed over time (O'Reilly et al., 2017 $\left.{ }_{[63]}\right)$.

The same study suggests that teachers may also take part in counteracting negative self-perceptions through class exercises that affirm values. For example, asking students to consider their values and explain why these values are important to them may be particularly effective when students are going through periods of transition.

Another way teachers can support student well-being is by helping students think deeply and see the relevance of what they are learning. Encouraging students to consider how new topics could apply directly to their lives, and reflect on how this information could help others, are ways that may help students to find more value in and develop greater motivation for learning (O'Reilly et al., 2017 ${ }_{[63]}$ ).

Students are more likely to be resilient when they are taught that intellectual abilities are qualities that can be developed, rather than qualities that are fixed (Yeager and Dweck, 2012 ${ }_{[64]}$ ). Teachers should thus emphasise the importance of persistence, effort and learning strategies as a way to advance. A series of studies revealed that teachers' praise of students' intellect led students to view their intelligence as being fixed and thus respond with less resilience following academic setbacks. By comparison, when teachers praise process and effort, student performance improves and students respond positively to more challenging tasks in the future (Mueller and Dweck, 1998 ${ }_{[65]}$ ).

The process through which negative feedback is delivered can have similar effects. Parents and teachers may try to comfort students who perform poorly by suggesting that the subject is simply not their strength and encouraging them to focus on their successes in other domains. This form of feedback can create low confidence, low expectations and poor resilience in students (Yeager and Dweck, 2012 $\left.2_{[64]}\right)$. A better way to provide feedback is by helping students see that they need better strategies to improve (Good, Rattan and Dweck, $2012_{[66]}$ ). Again, this method focuses more on the process than on ability and can put students in a mindset that improves their resilience to challenges.

Conducting such activities in class, in addition to developing awareness of individual students' backgrounds can help teachers anticipate and understand students' behaviour and perspectives. Using this approach, teachers may be able to more quickly identify students facing particular social and emotional challenges, and can engage student counselling services and family members for additional support. 


\section{Create a climate that favours learning and well-being}

While teachers can help promote well-being in their classrooms, all school actors - staff and students - should work together to prioritise well-being in schools. Schools can give students more opportunities to engage in such efforts by encouraging students to voice their opinions on the subject, offering leadership roles through student organisations and governments, and allowing for more student-led approaches to learning and decision making. The school community can collaborate to implement targeted programmes and interventions, develop supportive policies, and design strategic approaches to address specific behaviours, including bullying and violence, and other anti-social behaviours, and psychological states, including low self-esteem, depression and grief. A growing number of both private and public organisations are developing extensive school frameworks that encourage schools and teachers to foster well-being and mental health (Stirling and Emery, 2016 $6_{[67]}$; NSW Department of Education and Communities, 2015 $5_{[68]}$ ).

Some schools are experimenting with various forms of peer-mentoring programmes, where student mentors are matched with their peers in order to provide an additional source of guidance and support. Several studies indicate positive self-reported outcomes for supported students, including a greater sense of happiness or well-being, improved self-esteem and confidence,

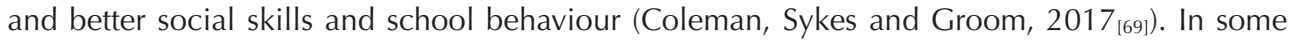
cases, peer mentors also report positive effects from participating in the programme, including (self-reported) improvements in skills, self-confidence and relationships. Studies have also shown that projects can benefit the school environment overall by fostering valuable student relationships. Students and schools benefit most from peer-mentoring programmes that are wellrun, and that have a clear focus, strong leadership and school-wide support. The most effective programmes also have high-quality student mentors who are enthusiastic and committed, and have strong communication and interpersonal skills (Coleman, Sykes and Groom, 2017 $7_{[69]}$ ).

\section{Encourage parent-teacher communication and parental engagement}

For in-class methods to succeed, schools and teachers need to improve communication with parents in the most disadvantaged homes and help develop home environments that are more conducive to learning. Teachers can use various forms of communication to keep parents up to date on student progress and to collaboratively address any difficulties the student might be having at school. Parent-teacher communication can also provide a platform for discussing with parents the various ways they can become more involved in their child's studies.

Parental engagement has been shown to boost achievement among disadvantaged children, improve student health and well-being, and even increase representation of minorities and female students in certain subjects, such as science, technology, engineering and mathematics (STEM) (Liu and Wang, 2008 ${ }_{[70]}$; Parker, 2013 ${ }_{[71]}$ ). Messages encouraging parental involvement from teachers and school communities have proven to significantly influence parents' behaviour (Avvisati et al., 2014 ${ }_{[72]}$; Kohl et al., 2000 $[73]$ ). Such communication not only helps parents understand that participation in their child's education is welcome, valuable and expected, but may be particularly significant for parents whose role is otherwise passive and whose sense of self-efficacy in helping their child succeed at school is relatively weak (Hoover-Dempsey and Sandler, $1997_{[74]}$; Hoover-Dempsey et al., 2005 $\left.{ }_{[75]}\right)$. Parents from disadvantaged families often face greater obstacles (such as time constraints, lack of information, language barriers, etc.) to 
becoming more involved in their child's learning. It is thus essential that schools take a proactive approach in encouraging parents, especially disadvantaged parents, to be part of their child's education and express positive attitudes towards learning at home.

Teacher-parent communication may also be a way to provide information regarding available extracurricular activities. Disadvantaged and minority students are much less likely to participate in after-school programmes, yet research shows that these types of activities can improve students' academic performance and boost social skills (Chanfreau et al., 2016 $6_{[76]}$ ). With the known benefits of participating in activities, including sports, music, language, tutoring and the arts, schools should promote school-based clubs as an affordable alternative for poorer children, and ensure that this information is shared with students' families to encourage participation.

\section{Note}

1. The Swiss panel study TREE (Transitions from Education to Employment) is a social science data infrastructure mainly funded by the Swiss National Science Foundation (SNF) and located at the University of Bern.

\section{References}

Archambault, I., M. Janosz and R. Chouinard (2012), "Teacher Beliefs as Predictors of Adolescents' Cognitive Engagement and Achievement in Mathematics", The Journal of Educational Research, Vol. 105/5, pp. 319-328, http://dx.doi.org/10.1080/00220671.2011.629694.

Avvisati, F. et al. (2014), "Getting Parents Involved: A Field Experiment in Deprived Schools", The Review of Economic Studies, Vol. 81/1, pp. 57-83, http://dx.doi.org/10.1093/restud/rdt027.

Bar Haim, E. and Y. Shavit (2013), "Expansion and inequality of educational opportunity: A comparative study", Research in Social Stratification and Mobility, Vol. 31, pp. 22-31, http://dx.doi.org/10.1016//.RSSM.2012.10.001.

Barajas, M. (2011), "Academic Achievement of Children in Single Parent Homes: A Critical Review", The Hilltop Review, Vol. 5/1, pp. 13-21, http://scholarworks.wmich.edu/hilltopreview (accessed on 25 June 2018).

Barro, R. and J. Lee (2013), "A new data set of educational attainment in the world, 1950-2010", Journal [22] of Development Economics, Vol. 104, pp. 184-198, http://dx.doi.org/10.1016/J.JDEVECO.2012.10.001.

Bartik, T. and B. Hershbein (2018), "Degrees of Poverty: The Relationship between Family Income [15] Background and the Returns to Education", Upjohn Institute Working Paper, No. 18, W.E. Upjohn Institute for Employment Research, http://dx.doi.org/10.17848/wp18-284.

Black, S. and S. Machin (2011), "Housing Valuations of School Performance", Handbook of the [47] Economics of Education, Vol. 3, pp. 485-519, http://dx.doi.org/10.1016/B978-0-444-53429-3.00010-7.

Blanden, J. (2013), "Cross-country rankings in intergenerational mobility: a comparison of [9] approaches from economics and sociology", Journal of Economic Surveys, Vol. 27/1, pp. 38-73, http://dx.doi.org/10.1111/j.1467-6419.2011.00690.x. 
Bourdieu, P. (2018), "Cultural reproduction and social reproduction", in Knowledge, Education, and Cultural Change: Papers in the Sociology of Education, Routledge, London.

Bowles, S. and H. Gintis (2002), "Schooling in Capitalist America Revisited", Sociology of Education, Vol. 75/1, pp. 1-18, http://dx.doi.org/10.2307/3090251.

Brueckner, M., E. Dabla-Norris and M. Gradstein (2014), "National Income and Its Distribution", IMF Working Paper, Vol. 14/101, http://www.imf.org/external/pubs/ft/wp/2014/wp14101.pdf (accessed on 01 June 2018).

Burgess, S. and A. Briggs (2010), "School assignment, school choice and social mobility", Economics of Education Review, Vol. 29/4, pp. 639-649, http://dx.doi.org/10.1016/I.ECONEDUREV.2009.10.011.

Burke, M. and T. Sass (2013), "Classroom Peer Effects and Student Achievement", Journal of Labor Economics, Vol. 31/1, pp. 51-82, http://dx.doi.org/10.1086/666653.

Chanfreau, J. et al. (2016), "Out of school activities during primary school and KS2 attainment", Working paper 2016/1, Centre for Longitudinal Studies, UCL Institute of Education, London, http://www.natcen.ac.uk/media/1135440/CLS-WP-2016-Out-of-school-activities-during-primaryschool-and-KS2-attainment.pdf (accessed on 11 June 2018).

Coleman, N., W. Sykes and C. Groom (2017), Peer support and children and young people's [69] mental health, UK Government Department for Education, https://assets.publishing.service.gov.uk/ government/uploads/system/uploads/attachment_data/file/603107/Children and_young people_s mental health peer support.pdf (accessed on 22 June 2018).

Conti, G., J. Heckman and R. Pinto (2015), "The Effects of Two Influential Early Childhood [36] Interventions on Health and Healthy Behaviors", Working Paper No. 21454, National Bureau of Economic Research, Cambridge, MA, http://dx.doi.org/10.3386/w21454.

Corak, M. (2013), "Income Inequality, Equality of Opportunity, and Intergenerational Mobility", Journal of Economic Perspectives, Vol. 27/3, pp. 79-102, http://dx.doi.org/10.1257/jep.27.3.79.

Dupriez, V., X. Dumay and A. Vause (2008), "How Do School Systems Manage Pupils' Heterogeneity?", Comparative Education Review, Vol. 52/2, pp. 245-273, http://dx.doi.org/10.1086/528764.

Epple, D. and R. Romano (2003), "Neighborhood Schools, Choice, and the Distribution of Educational [48] Benefits", The Economics of School Choice, National Bureau of Economic Research, Cambridge, MA, https://ideas.repec.org/h/nbr/nberch/10090.html (accessed on 21 May 2018), pp. 227-286.

Epple, D., R. Romano and M. Urquiola (2017), "School Vouchers: A Survey of the Economics Literature", [56] Journal of Economic Literature, Vol. 55/2, pp. 441-492, http://dx.doi.org/10.1257/jel.20150679.

Ferguson, H., S. Bovaird and M. Mueller (2007), "The impact of poverty on educational outcomes for [33] children.", Paediatrics \& child health, Vol. 12/8, pp. 701-6,

http://www.ncbi.nlm.nih.gov/pubmed/19030450 (accessed on 25 June 2018).

Ganzeboom, H. and D. Treiman (2003), "Three Internationally Standardised Measures for Comparative [31] Research on Occupational Status", in Advances in Cross-National Comparison, Springer US, Boston, MA, http://dx.doi.org/10.1007/978-1-4419-9186-7_9.

Gerber, T. and S. Cheung (2008), "Horizontal Stratification in Postsecondary Education: Forms, [28] Explanations, and Implications", Annual Review of Sociology, Vol. 34/1, pp. 299-318,

http://dx.doi.org/10.1146/annurev.soc.34.040507.134604. 
Good, C., A. Rattan and C. Dweck (2012), "Why do women opt out? Sense of belonging and women's [66] representation in mathematics", Journal of Personality and Social Psychology, Vol. 102/4, pp. 700-717, http://dx.doi.org/10.1037/a0026659.

Hanushek, E. et al. (2003), "Does peer ability affect student achievement?", Journal of Applied Economics, Vol. 18/5, pp. 527-544, http://dx.doi.org/10.1002/jae.741.

Hanushek, E. and L. Wossmann (2006), "Does Educational Tracking Affect Performance and Inequality? Differences-in-Differences Evidence Across Countries", The Economic Journal, Vol. 116/510, pp. C63-C76, http://dx.doi.org/10.1111/j.1468-0297.2006.01076.x.

Heckman, J. (2016), Early Childhood Education: Quality and Access Pay off, University of Chicago, Chicago, http://www.heckmanequation.org (accessed on 22 May 2018).

Hoover-Dempsey, K. and H. Sandler (1997), "Why Do Parents Become Involved in Their Children's Education?", Review of Educational Research, Vol. 67/1, pp. 3-42, http://dx.doi.org/10.3102/00346543067001003.

Hoover-Dempsey, K. et al. (2005), "Why Do Parents Become Involved? Research Findings and Implications", The Elementary School Journal, Vol. 106/2, pp. 105-130, http://dx.doi.org/10.1086/499194.

Hout, M. (2012), "Social and Economic Returns to College Education in the United States", Annual [17] Review of Sociology, Vol. 38/1, pp. 379-400, http://dx.doi.org/10.1146/annurev.soc.012809.102503.

Hout, M. and T. DiPrete (2006), "What we have learned: RC28's contributions to knowledge about [16] social stratification", Research in Social Stratification and Mobility, Vol. 24/1, pp. 1-20, http://dx.doi.org/10.1016//.RSSM.2005.10.001.

Jimerson, S. (2001), "Meta-analysis of grade retention research: Implications for practice in the 21st [40] century", School Psychology Review, Vol. 30/3, pp. 420-437, https://search.proquest.com/openview/8 3f3300ef82a658dae4bbf41d346dcbc/1?pq-origsite=gscholar\&cbl=48217 (accessed on 17 May 2018).

Jimerson, S., G. Anderson and A. Whipple (2002), "Winning the battle and losing the war: Examining [41] the relation between grade retention and dropping out of high school", Psychology in the Schools, Vol. 39/4, pp. 441-457, http://dx.doi.org/10.1002/pits.10046.

Kearney, M. and P. Levine (2016), "Income Inequality, Social Mobility, and the Decision to Drop Out of High School", in Brookings Papers on Economic Activity, The Brookings Institution, https://www.brookings.edu/wp-content/uploads/2016/03/kearneytextspring16bpea.pdf (accessed on 01 June 2018).

Kohl, G. et al. (2000), "Parent Involvement in School Conceptualizing Multiple Dimensions and [73] Their Relations with Family and Demographic Risk Factors", Journal of School Psychology, Vol. 38/6, pp. 501-523, http://dx.doi.org/10.1016/S0022-4405(00)00050-9.

Ladd, H. and E. Fiske (2001), "The uneven playing field of school choice: Evidence from New Zealand", [52] Journal of Policy Analysis and Management, Vol. 20/1, pp. 43-64, http://dx.doi.org/10.1002/1520-6688(200124)20:1<43::AID-PAM1003>3.0.CO;2-4.

Lavy, V., O. Silva and F. Weinhardt (2012), "The Good, the Bad, and the Average: Evidence [44] on Ability Peer Effects in Schools", Journal of Labor Economics, Vol. 30/2, pp. 367-414, http://dx.doi.org/10.1086/663592.

Lee, J. and H. Lee (2018), "Human Capital and Income Inequality", Working Paper No. 810, Asian [13] Development Bank Institute, https://www.adb.org/sites/default/files/publication/401466/adbi-wp810.pdf (accessed on 01 June 2018). 
Levin, H. (1998), "Educational vouchers: Effectiveness, choice, and costs", Journal of Policy Analysis and [50] Management, Vol. 17/3, pp. 373-392, http://dx.doi.org/10.1002/(SICI)1520-6688(199822)17:3<373::AID-PAM1>3.0.CO;2-D.

Liu, W. and C. Wang (2008), "Home Environment and Classroom Climate: An Investigation of their [70] Relation to Students' Academic Self-Concept in a Streamed Setting", Current Psychology, Vol. 27, pp. 242-256, http://dx.doi.org/10.1007/s12144-008-9037-7.

Mann, H. (1957), The Republic and the School: Horace Mann on the Education of Free Men, Teachers College, Columbia University.

Mizala, A. and F. Torche (2012), "Bringing the schools back in: the stratification of educational [55] achievement in the Chilean voucher system", International Journal of Educational Development, Vol. 32/1, pp. 132-144, http://dx.doi.org/10.1016/J.IJEDUDEV.2010.09.004.

Mueller, C. and C. Dweck (1998), "Praise for Intelligence Can Undermine Children's Motivation [65] and Performance", Journal of Personality and Social Psychology, Vol. 75/1, pp. 33-52, http://citeseerx.ist.psu.edu/viewdoc/download?doi=10.1.1.477.4297\&rep=rep $1 \& t y p e=p d f$ (accessed on 22 May 2018).

Musset, P. (2012), "School Choice and Equity: Current Policies in OECD Countries and a Literature [49] Review", OECD Education Working Papers, No. 66, OECD Publishing, Paris,

http://dx.doi.org/10.1787/5k9fq23507vc-en.

NSW Department of Education and Communities (2015), The Well Being Framework for Schools, NSW Department of Education and Communities, Sydney, https://www.det.nsw.edu.au/wellbeing/about/16531_Wellbeing-Framework-for-schools_Acessible.pdf (accessed on 22 May 2018).

OECD (2018), Effective Teacher Policies: Insights from PISA, PISA, OECD Publishing, Paris, http://dx.doi.org/10.1787/9789264301603-en.

OECD (2017), Education at a Glance 2017: OECD Indicators, OECD Publishing, Paris, http://dx.doi.org/10.1787/eag-2017-en.

OECD (2017), Education in Chile, Reviews of National Policies for Education, OECD Publishing, [58] Paris, http://dx.doi.org/10.1787/9789264284425-en.

OECD (2017), School choice and school vouchers: An OECD perspective, OECD, Paris, http://www.oecd.org/education/School-choice-and-school-vouchers-an-OECD-perspective.pdf.

OECD (2017), "Where did equity in education improve over the past decade?", PISA in Focus, No. 68, [25] OECD Publishing, Paris, http://dx.doi.org/10.1787/33602e45-en.

OECD (2016), Technical Report of the Survey of Adult Skills (PIAAC), OECD, Paris,

http://www.oecd.org/skills/piaac/PIAAC Technical Report 2nd Edition Full Report.pdf (accessed on 16 January 2018).

OECD (2016), Income Inequality Update: Income Inequality Remains High In The Face Of Weak Recovery, http://www.oecd.org/social/OECD2016-Income-Inequality-Update.pdf.

OECD (2016), PISA 2015 Results (Volume I): Excellence and Equity in Education, PISA, OECD [30] Publishing, Paris, http://dx.doi.org/10.1787/9789264266490-en.

OECD (2015), In It Together: Why Less Inequality Benefits All, OECD Publishing, Paris, http://dx.doi.org/10.1787/9789264235120-en. 
OECD (2013), Synergies for Better Learning: An International Perspective on Evaluation and [62] Assessment, OECD Reviews of Evaluation and Assessment in Education, OECD Publishing, Paris, http://dx.doi.org/10.1787/9789264190658-en.

OECD (2011), Divided We Stand: Why Inequality Keeps Rising, OECD Publishing, Paris, http://dx.doi.org/10.1787/9789264119536-en.

O'Reilly, F. et al. (2017), Behavioural Insights for Education: A practical guide for parents, teachers and school leaders, Pearson, London, http://38r8om2xjhhl25mw24492dir.wpengine.netdna-cdn.com/ wp-content/uploads/2017/06/BI-for-Education-A-Practical-Guide-for-Parents-Teachers-and-SchoolLeaders.pdf (accessed on 22 May 2018).

Parker, A. (2013), "Family matters: familial support and science identity formation for African American [71] female STEM majors", ProQuest LLC, https://eric.ed.gov/?id=ED560384 (accessed on 22 May 2018).

Pfeffer, F. (2008), "Persistent Inequality in Educational Attainment and its Institutional Context", European Sociological Review, Vol. 24/5, pp. 543-565, http://dx.doi.org/10.1093/esr/jcn026.

Raftery, A. and M. Hout (1993), "Maximally Maintained Inequality: Expansion, Reform, and Opportunity in Irish Education, 1921-75", Sociology of Education, Vol. 66/1, p. 41, http://dx.doi.org/10.2307/2112784.

Sacerdote, B. (2011), Peer Effects in Education: How Might They Work, How Big Are They and How Much Do We Know Thus Far?, http://dx.doi.org/10.1016/B978-0-444-53429-3.00004-1.

Santiago, P. et al. (2017), OECD Reviews of School Resources: Chile 2017, OECD Reviews of School [59] Resources, OECD Publishing, Paris, http://dx.doi.org/10.1787/9789264285637-en.

Schneider, M., G. Elacqua and J. Buckley (2006), "School choice in Chile: Is it class or the classroom?", Journal of Policy Analysis and Management, Vol. 25/3, pp. 577-601, http://dx.doi.org/10.1002/pam.20192.

Schweinhart, L. et al. (2005), The High/Scope Perry Preschool Study Through Age 40: Summary, Conclusions, and Frequently Asked Questions, High/Scope ${ }^{\circledR}$ Educational Research Foundation, Ypsilanti, http://nieer.org/wp-content/uploads/2014/09/specialsummary rev2011 02 2.pdf (accessed on 22 May 2018).

Söderström, M. and R. Uusitalo (2010), "School Choice and Segregation: Evidence from an Admission [53] Reform", Scandinavian Journal of Economics, Vol. 112/1, pp. 55-76,

http://dx.doi.org/10.1111/j.1467-9442.2009.01594.x.

Solon, G. (2002), "Cross-Country Differences in Intergenerational Earnings Mobility", Journal of [10] Economic Perspectives, Vol. 16/3, pp. 59-66, http://dx.doi.org/10.1257/089533002760278712.

Stirling, S. and H. Emery (2016), A Whole School Framework for Emotional Well-being and Mental [67] Health, National Children's Bureau, London, https://www.ncb.org.uk/sites/default/files/field/ attachment/NCB\%20School\%20Well\%20Being\%20Framework\%20Leaders $\% 20$ Resources $\% 20$ FINAL.pdf (accessed on 22 May 2018).

Torche, F. (2015), "Analyses of Intergenerational Mobility", The ANNALS of the American Academy [11] of Political and Social Science, Vol. 657/1, pp. 37-62, http://dx.doi.org/10.1177/0002716214547476.

Torche, F. (2014), "Intergenerational Mobility and Inequality: The Latin American Case", Annual [12] Review of Sociology, Vol. 40/1, pp. 619-642, http://dx.doi.org/10.1146/annurev-soc-071811-145521. 
UNESCO (2015), Incheon Declaration. Education 2030: Towards Inclusive and Equitable Quality

Education and Lifelong Learning for All, http://unesdoc.unesco.org/images/0023/002338/233813m.pdf (accessed on 05 April 2018)

UNESCO (2000), World education report 2000. The right to education: Towards education for all

throughout life, UNESCO Publishing, Paris, http://unesdoc.unesco.org/images/0011/001197/119720e.pdf (accessed on 30 January 2018).

UNICEF (2015), The Investment Case for Education and Equity, Unicef, New York, [29] https://www.unicef.org/publications/files/Investment Case for Education and Equity FINAL.pdf (accessed on 05 April 2018).

Van de Werfhorst, H. and J. Mijs (2010), "Achievement Inequality and the Institutional Structure of [39] Educational Systems: A Comparative Perspective", Annual Review of Sociology, Vol. 36/1, pp. 407-428, http://dx.doi.org/10.1146/annurev.soc.012809.102538.

Whitehead, U. (2006), "African-American Students' Perceptions of Teacher Attitudes On Academic [60] Achievement and Discipline Sanctions", Aquila Dissertation Archive, Vol. 954,

https://aquila.usm.edu/theses dissertations/954 (accessed on 22 May 2018).

World Bank (2018), World Development Report 2018: Learning to Realize Education's Promise, [24] http://www.worldbank.org/en/publication/wdr2018 (accessed on 22 June 2018).

Yeager, D. and C. Dweck (2012), "Mindsets That Promote Resilience: When Students Believe That [64] Personal Characteristics Can Be Developed", Educational Psychologist, Vol. 47/4, pp. 302-314, http://dx.doi.org/10.1080/00461520.2012.722805. 



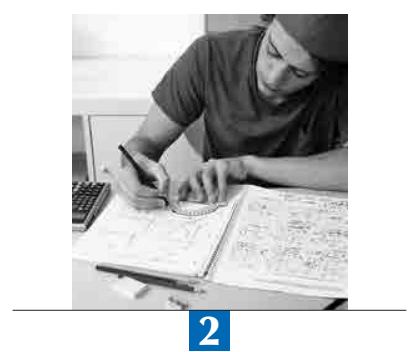

\section{How is equity in education changing?}

This chapter examines trends in equity in education. It focuses on three areas: cognitive achievement, socio-emotional well-being and educational attainment. The chapter discusses disparities in student performance related to socio-economic status and how those differences evolve over time. It also explores students' sense of belonging at school, their beliefs about their own academic abilities, and their expectations for their future. The chapter considers how educational attainment in countries has changed over recent decades and what that means for social (educational) mobility across generations.

\section{Notes regarding Cyprus}

Note by Turkey: The information in this document with reference to "Cyprus" relates to the southern part of the Island. There is no single authority representing both Turkish and Greek Cypriot people on the Island. Turkey recognises the Turkish Republic of Northern Cyprus (TRNC). Until a lasting and equitable solution is found within the context of the United Nations, Turkey shall preserve its position concerning the "Cyprus issue".

Note by all the European Union Member States of the OECD and the European Union: The Republic of Cyprus is recognized by all members of the United Nations with the exception of Turkey. The information in this document relates to the area under the effective control of the Government of the Republic of Cyprus.

\section{A note regarding the Russian Federation concerning Survey of Adult Skills (PIAAC) data}

Readers should note that the sample for the Russian Federation does not include the population of the Moscow municipal area. The data published, therefore, do not represent the entire resident population aged 16-65 in Russia but rather the population of Russia excluding the population residing in the Moscow municipal area.

More detailed information regarding the data from the Russian Federation as well as that of other countries can be found in the Technical Report of the Survey of Adult Skills (OECD, 2016 $[11]$ ).

\section{A note regarding Israel}

The statistical data for Israel are supplied by and under the responsibility of the relevant Israeli authorities. The use of such data by the OECD is without prejudice to the status of the Golan Heights, East Jerusalem and Israeli settlements in the West Bank under the terms of international law.

\section{A note regarding Lithuania}

Lithuania was not an OECD member at the time of preparation of this publication. Accordingly, Lithuania is shown as a partner country and is not included in the OECD average.

This document, as well as any data and map included herein, are without prejudice to the status of or sovereignty over any territory, to the delimitation of international frontiers and boundaries and to the name of any territory, city or area. 


\section{What the data tell us}

- Equity in science, reading and mathematics performance has improved across PISA cycles, on average across OECD countries. In seven countries (Chile, Denmark, Germany, Mexico, Montenegro, Slovenia and the United States) equity in achievement improved in all three core subjects; but in 14 countries equity did not improve in any subject.

- Differences in achievement related to socio-economic status grow over students' lives. On average across 11 OECD countries with comparable data, the magnitude of the achievement gap during childhood is about two-thirds as large as the gap observed during adolescence. Inequalities also grow, although less markedly, between adolescence and early adulthood.

- Disparities related to socio-economic status in students' psychological well-being, as measured by students' science self-efficacy and career expectations, are large even when comparing students with the same cognitive achievement. Disparities in social well-being, as measured by students' sense of belonging at school, are smaller and tend to disappear once performance differences are taken into account.

- On average across countries that participated in the Survey of Adult Skills (PIAAC), $41 \%$ of adults completed a higher level of education than their parents did (upward educational mobility), $48 \%$ attained the same highest level of education as their parents (no mobility), and $11 \%$ attained a lower level of education than their parents (downward mobility).

- The probability of completing tertiary education among adults with low-educated parents was $18 \%$ among older adults (those born in the mid-1940s and 1950s) and $24 \%$ among younger adults (those born in the mid-1970s and 1980s). For adults with highly educated parents, the probability of completing tertiary education was $61 \%$ among older adults and $69 \%$ among younger adults.

\section{EQUITY IN EDUCATION: A FRAMEWORK}

Equity in education is examined in this report by looking at socio-economic disparities in students' education outcomes. Equity is greater when the relationship between students' outcomes and socio-economic status is weaker. This does not mean that all students have equal outcomes; indeed, some degree of inequality in education outcomes is to be expected in any school system. Equity means that whatever inequality exists between students in a school system, it is not related to students' socio-economic status (Willms, 2006 ${ }_{[2]}$; Downey and Condron, 2016 [3]; Roemer and Trannoy, 2015 $\left.5_{[4]}\right)$.

The terms "equity" and "equality" are often confused but they do not mean the same thing. Equity in education is synonymous with equality of education opportunities, thus inequity implies a lack of fairness. Inequality is not necessarily unfair, as differences in student outcomes might be due to differences in students' efforts, interests, talents or even luck. However, as this report shows, in 
practice, a large part of the inequality in students' outcomes is indeed related to socio-economic status, and is thus an equity issue that calls for better education policies and practices. Policies that improve equity in education are those that level the playing field among students of different socio-economic status, so that all students get a fair chance to succeed in school and in their future life.

This report considers socio-economic disparities in three kinds of education outcomes: cognitive achievement, social and emotional well-being, and educational attainment.

Students' cognitive achievement (also referred to as "performance") is measured by PISA scores in science, reading and mathematics. Students participate in PISA when they are 15 years old. However, in certain sections of the report, cognitive achievement is also considered at earlier and later ages. This is important because social inequities in performance develop early and continue to grow during later stages of life. Data from international studies other than PISA notably the Trends in International Mathematics and Science Study (TIMSS), for data on $4^{\text {th }}$-grade students, and the Survey of Adult Skills, a product of the OECD Programme for the International Assessment of Adult Competencies (PIAAC), for data on adults aged 25 to 29 - are used in these analyses. Analyses explore how equity in performance has evolved over time in PISAparticipating countries; how disparities in performance between advantaged and disadvantaged students develop and widen through students' lives; what factors make it more likely for disadvantaged students to perform as well as the best students in their own countries and attain good levels of performance in core subjects; and how a school's socio-economic profile relates to the performance of disadvantaged students.

Students' social and emotional outcomes (also referred to as "well-being") are measured using PISA data. PISA's student questionnaires collect information on variables such as students' selfefficacy, career expectations, and sense of belonging and social integration at school. Analyses explore how equity in students' well-being has evolved over time, and the extent to which disadvantaged students are socially and emotionally resilient. The report looks at students' well-being because socio-economically disadvantaged students not only tend to perform worse, academically, than advantaged students, but they are also less likely to enjoy a sense of belonging at school and to feel confident when faced with challenging evaluations and tasks (OECD, 2017 $7_{[5]}$ ).

Disparities in a third kind of outcome, educational attainment, are also considered in the report. While cognitive achievement and well-being matter in themselves, they are also important because they influence student outcomes in post-secondary education and the labour market. Data from PISA are insufficient to determine educational attainment because the assessment measures proficiency among 15-year-old students, and many people continue their education well beyond this age. Differences between countries in average years of schooling completed are examined using data compiled by R. J. Barro and J. W. Lee (Barro and Lee, 2013 $3_{[6]}$ ). The analyses also look at the highest level of education completed by adults in different countries, and whether or not this level is higher than the level attained by their parents (i.e. upward educational mobility). The analyses also consider whether differences in the attainment of tertiary education are related to differences in socio-economic status. These analyses are based on data from PIAAC, which surveys adults aged 26 to 65 . The report also explores cross-national 
differences in social mobility based on student-level longitudinal data in five countries. It looks at disparities in the probability of earning a university degree and obtaining a skilled job by the age of 25, accounting for students' academic performance at 15 .

Students' socio-economic status is measured using the PISA index of economic, social and cultural status (ESCS; Box 2.1). But in some cases, socio-economic status is measured by parents' education or by the number of books at home.

\section{Box 2.1 How PISA measures socio-economic status}

Socio-economic status is a broad concept that summarises many different aspects of a student, school or school system. In PISA, a student's socio-economic status is typically measured by the PISA index of economic, social and cultural status (ESCS).

ESCS is a composite score built by the indicators of three components via principal component analysis:

- Parents' highest level of education (PARED index ${ }^{1}$ )

- Parents' highest occupational status (HISEI index ${ }^{1}$ )

- Home possessions (HOMEPOS index ${ }^{1}$ ), a proxy measure for family wealth that includes the following items:

- availability of country-specific household items, such as a subscription to a daily newspaper, an MP3 player, high-speed Internet connection or other

- the number of books at home

- other educational resources available in the home, such as a computer that can be used for school work or specific educational software.

Information about PARED, HISEI and HOMEPOS for each student was collected through the student questionnaire, a survey that students answered after completing the PISA cognitive assessment.

The rationale for using these three components is that socio-economic status is usually regarded as being based on education, occupational status and income. As no direct income measure is available from the PISA data, the availability of household items is used as a proxy for family wealth.

The ESCS is constructed to be internationally comparable. The values of the ESCS scale are standardised to have a mean of zero and a standard deviation of one for the population of students in OECD countries, with each country given equal weight (for a more technical description of how the index is computed, please see PISA 2015 Technical Report [OECD, $\left.\left.2017_{[7]}\right]\right)$.

The ESCS index makes it possible to draw comparisons between students and schools with different socio-economic profiles. The higher the value of ESCS, the higher the socioeconomic status. 
For the purposes of this report, ESCS is used in the analysis to distinguish among students who are:

- socio-economically advantaged: those who are among the $25 \%$ of students with the highest values on the ESCS index in their country or economy

- socio-economically disadvantaged: those whose values on the ESCS index are among the bottom $25 \%$ within their country or economy

- socio-economically average: those whose values on the ESCS index are in the middle $50 \%$ within their country or economy.

Following the same logic, schools are classified as socio-economically advantaged, disadvantaged or average within each country or economy based on their students' mean values on the ESCS index.

An index of economic, cultural and social status has been used since the first PISA assessment (PISA 2000). However, the components of ESCS and the scaling model have changed over cycles, meaning that values on the ESCS index are not directly comparable across cycles. In order to allow for trend analyses, in PISA 2015, the ESCS was computed for the current cycle and also recomputed for earlier cycles using a similar methodology (see PISA 2015 Technical Report [OECD, 2017 $[7]]$ ).

This measure of socio-economic status captures multiple relevant dimensions of an individual's economic and social position relative to others in society, and can be easily compared within and between countries for various PISA cycles. In addition, with the rescaling of ESCS from previous cycles in 2015, valid comparisons can be made across time. However, differences in results between PISA analyses and national research for specific countries may still be observed for a number of reasons, including discrepancies in sampling, weighting, measurement, variable construction and estimation methods.

1. Please refer to the PISA 2015 Technical Report (OECD, 2017) for detailed information on these components.

Source: OECD (2017), PISA 2015 Technical Report, OECD Publishing, Paris.

\section{HOW IS EQUITY IN EDUCATION CHANGING?}

Has equity in education increased, decreased or remained stable over the past few decades? This chapter examines the evolution of socio-economic inequalities in education. It contains three sections, each describing equity in a different education outcome: cognitive achievement, socio-emotional well-being and educational attainment. These outcomes are examined using the measures shown in Figure 2.1.

Trends in cognitive achievement are examined in the first section. Education matters in the labour market, and in other domains of life, partly because it leads to the acquisition of more, and more advanced, knowledge and cognitive skills. Socio-economic gaps in cognitive achievement are evident among 15-year-old students, as PISA results show, but the size of these gaps differs 
greatly among countries and, as shown here, they are not fixed over time. Furthermore, socioeconomic inequalities in student achievement are observed much earlier than age 15, and they continue to evolve throughout later stages of students' lives. The emergence and evolution of achievement gaps is examined in this chapter by comparing disparities during childhood, adolescence and young adulthood, using data from the Trends in International Mathematics and Science Study (TIMSS), the OECD Programme for International Student Assessment (PISA) and the OECD Programme for the International Assessment of Adult Competencies (PIAAC).

Figure 2.1 - Equity in education outcomes

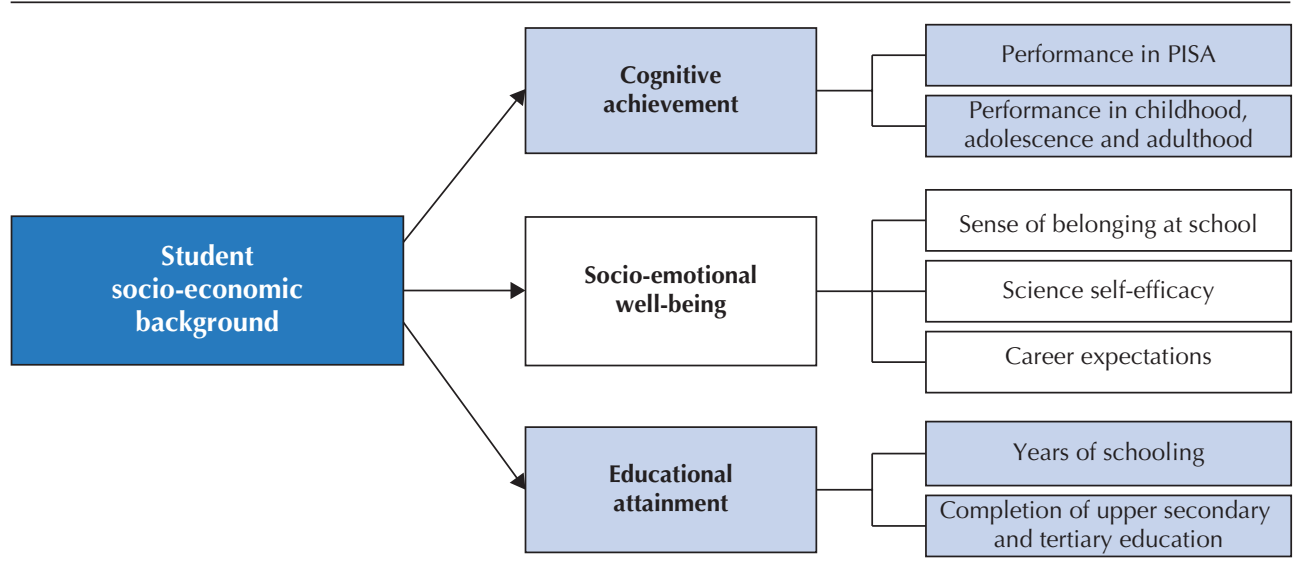

Student well-being is a more recent focus of research in international studies of education. A quality educational experience also involves the acquisition of social and emotional competencies. PISA conducted a review of student well-being in 2015 (OECD, 2017 ${ }_{[7]}$ ), but earlier PISA cycles included indicators of some aspects of well-being, particularly students' psychological and social health, thus allowing for an analysis of trends in equity in these outcomes. The fourth section of the chapter examines disparities related to socio-economic status in sense of belonging at school, students' self-efficacy and career expectations.

Equity in educational attainment is the focus of the fifth section of the chapter. The expansion of access to primary, secondary and tertiary education that has occurred around the world since the middle of the 20th century suggests that more education opportunities are available today than were available in the past. But are these new opportunities allocated more equitably among students from different backgrounds? The literature is inconclusive about this, with some studies finding "persistent inequality" over time (Shavit and Blossfeld, 1993 ${ }_{[8]}$; Pfeffer, 2008 ${ }_{[9]}$ ), while other studies find signs of equalisation in educational attainment (Breen et al., 2009 [10]; Dorius, $\left.2013_{[11]}\right)$. This chapter examines whether there has been a change over time in the extent to which students from wealthier countries and socio-economically advantaged families are more likely than students from developing countries and disadvantaged families to progress in school and attain higher academic degrees. 
Findings in this chapter show that, on average across OECD countries, equity in education is increasing in some dimensions but not in others. Socio-economic disparities in science, reading and mathematics achievement have declined over PISA cycles, albeit by small margins, on average across OECD countries. In terms of students' psychological well-being, inequities in students' science self-efficacy are large and have remained so over the years, but inequities in students' career expectations have narrowed. Inequities in students' sense of belonging at school are small and have not changed much over the PISA cycles. Finally, large socio-economic differences in educational attainment, for example, in the completion of tertiary degrees, have not narrowed over the past few decades, despite the expansion of education observed during this period.

Average trends do not necessarily reflect the reality of individual countries. Providing a detailed explanation for the trends observed in different countries and economies goes beyond the scope of this report. A number of different factors are surely at play, such as changes in education policy and practice (particularly those aimed at compensating for differences in students' socio-economic status) or broader changes in society, such as trends in income inequality and immigration, among others. Additional information on five countries (Australia, Canada, Denmark, Switzerland and the United States) for which longitudinal data exist is provided in Chapter 5. Further research is needed in order to contextualise these findings and develop possible explanations for the trends observed.

\section{TRENDS IN EQUITY IN COGNITIVE ACHIEVEMENT}

In all countries and economies that participated in PISA 2015, and in the three core cognitive domains assessed in PISA (science, reading and mathematics), students of higher socio-economic status scored better than students of lower socio-economic status. However, in some countries and economies student performance can be predicted solely by students' socio-economic status more accurately than in other countries. There are also large differences among countries in the size of the gap in achievement between advantaged and disadvantaged students. Furthermore, the size of this gap varies over the course of students' lives, as students complete the transitions from childhood (primary school) to adolescence (secondary school) to young adulthood (tertiary education and the labour market). Last but not least, levels of equity in student achievement have changed over the past 15 years in many countries that participated in PISA. In other words, the influence of socio-economic background on student achievement, although strong everywhere, is far from deterministic and fixed. There is much that teachers and educators, school communities, policy makers, families and students themselves can do to compensate for and overcome the inequity in education opportunities that socio-economically disadvantaged students often face (see Chapter 1 on policy implications).

\section{Socio-economic disparities in student achievement}

Science was the main domain of assessment in PISA 2015 and in PISA 2006. Over this period, equity in science achievement, as measured by the strength of the socio-economic gradient (see Box 2.2), improves slightly. In 2006, on average across OECD countries, $14.4 \%$ of the variation in students' science performance was explained by students' socio-economic status, whereas in PISA 2015, 12.9\% was - a small, but statistically significant, change of 1.4 percentage points in the direction of greater equity. 
Figure 2.2 - Change between 2006 and 2015 in equity in science performance Percentage of variation in science performance explained by students' socio-economic status

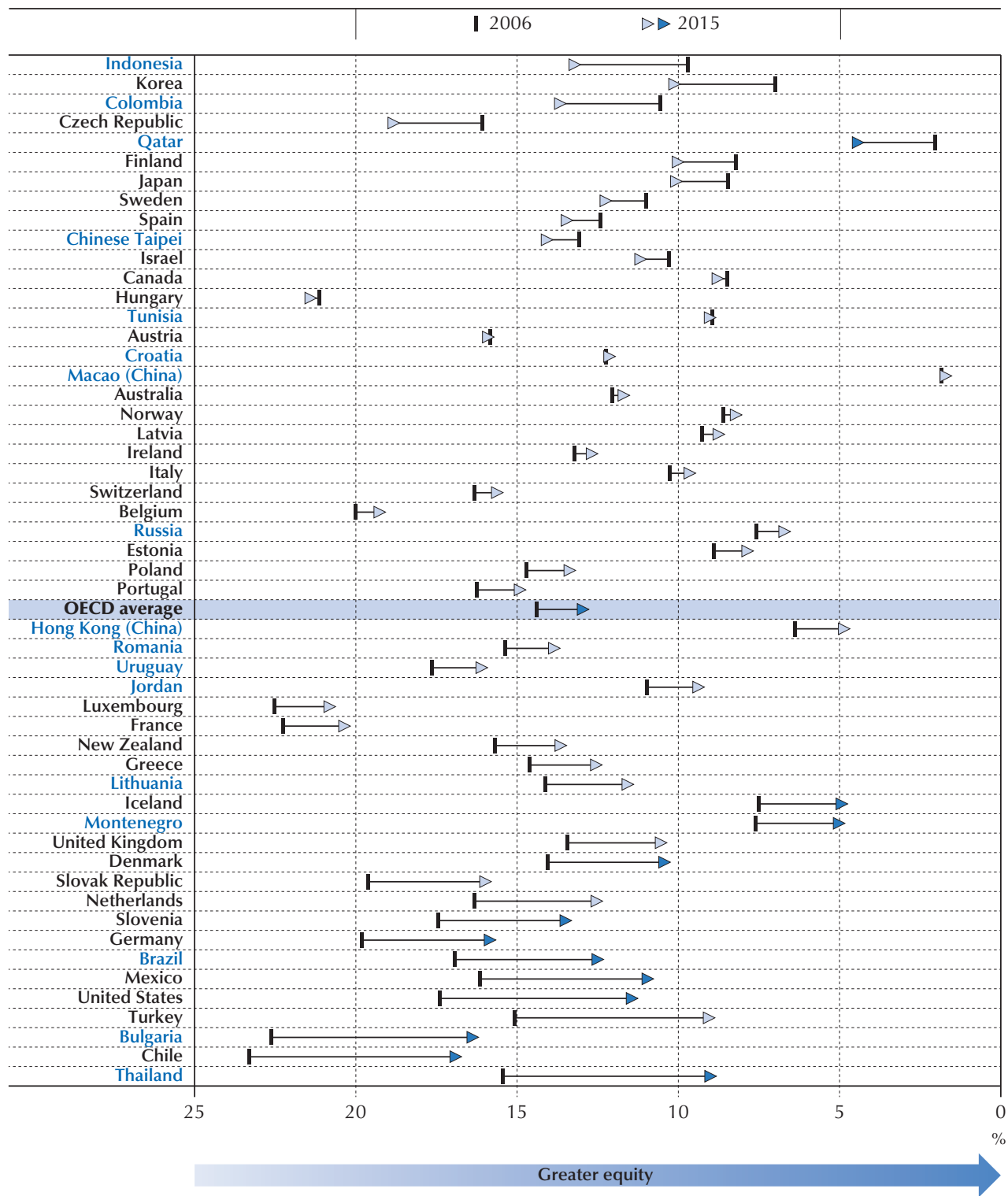

Notes: Socio-economic status is measured by the PISA index of economic, social and cultural status of students. Statistically significant differences between 2006 and 2015 are shown in dark blue.

Countries and economies are ranked in descending order of difference between 2006 and 2015 in the percentage of variation in science performance explained by students' socio-economic status.

Source: OECD, PISA 2006 and PISA 2015 Databases, Table 2.2.

StatLink 需S https://doi.org/10.1787/888933830158 


\section{Box 2.2 The socio-economic gradient: Measuring socio-economic inequalities in cognitive achievement}

A common measure used in PISA reports to examine the level of equity of education systems is the so-called "socio-economic gradient". The socio-economic gradient captures the average association between students' scores in PISA assessments and students' socio-economic status, as measured by the PISA index of economic, social and cultural status, or ESCS (Box 2.1 describes how the ESCS index is computed). This gradient can be represented graphically, as in Figure 2.3, as the straight line that best fits the heterogeneous combinations of scores and socio-economic status among students.

Figure 2.3 - Students' socio-economic status and average performance across OECD countries

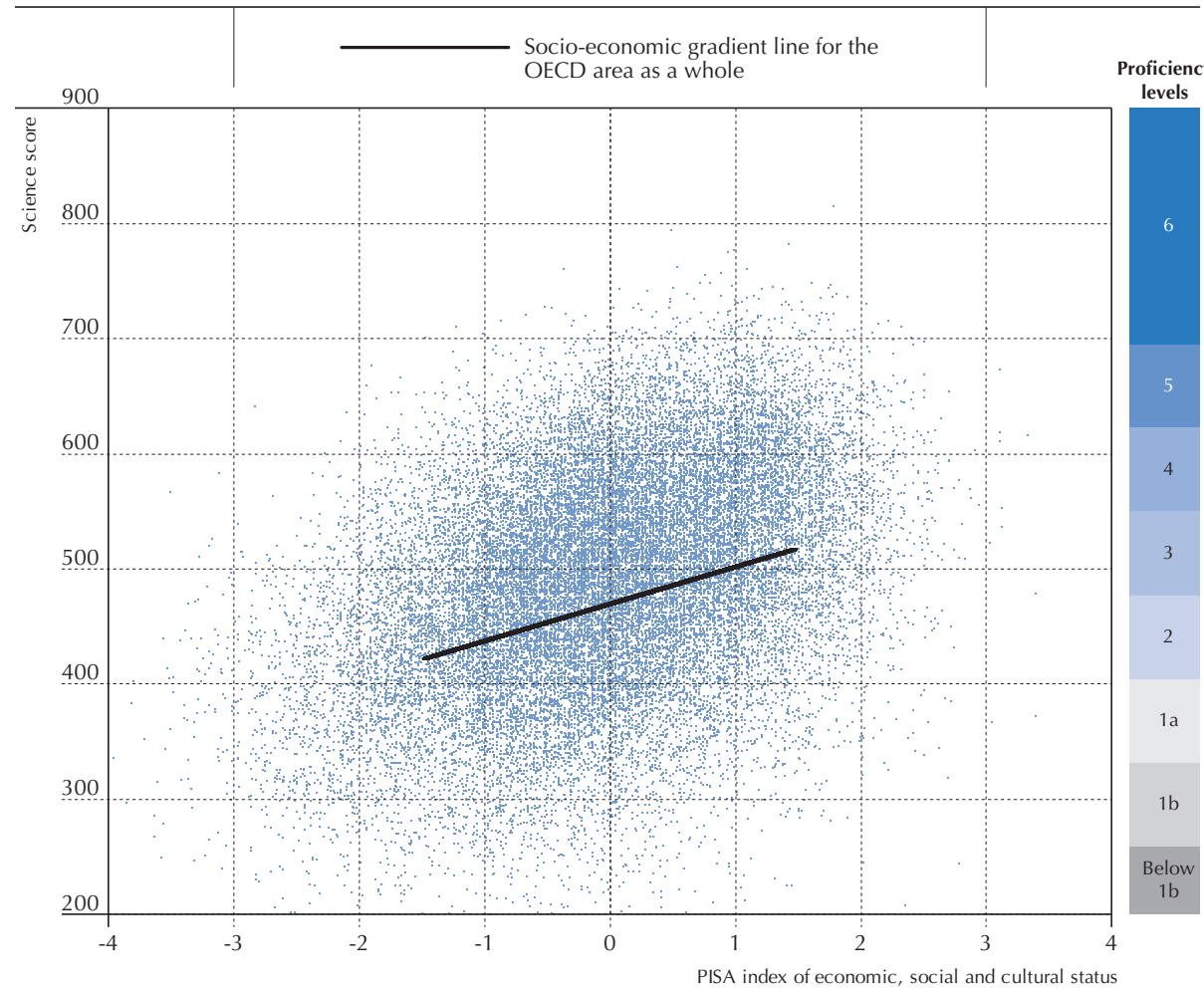

Note: Each dot represents an OECD student picked at random out of ten OECD students.

Source: OECD, PISA 2015 Database.

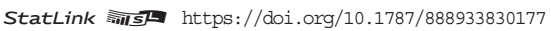

The socio-economic gradient provides two key pieces of information: the slope and the strength of the relationship between student achievement and the ESCS index. 
The slope of the gradient line indicates how many score points in a PISA assessment are associated with a one-unit increase in the ESCS index. On average across OECD countries in PISA 2015, one point in the ESCS index was associated with 38 score points in the science assessment - more or less equivalent to one year of school instruction (see Box I.2.1 in OECD, 2016 $6_{[12]}$ ). The slope of the gradient was much steeper than average meaning that the extent of inequality attributable to socio-economic status was greater - in the Czech Republic and France, where the score difference was greater than 50 points. Countries and economies where the slope of the gradient was flatter than average meaning that there was greater equity - include Algeria, Hong Kong (China), Kosovo, Macao (China), Mexico and Tunisia, where the difference associated with socio-economic status was less than 20 score points (Table 2.1).

The strength of the socio-economic gradient is the percentage of variation in student performance accounted for by students' socio-economic status (a.k.a. coefficient of determination or "R squared"). This measure describes the extent to which student performance can be predicted based solely on the family's socio-economic status. If a larger percentage of the variation in performance is related to students' socio-economic status, it means that students' success in school depends more on family factors and other "accidents of birth" over which students have no control, and less on students' own actions, talents and effort.

On average across OECD countries in 2015, students' socio-economic status accounted for $13 \%$ of the variation in science performance (Table 2.2) (OECD, 2016 $6_{[12]}$ ). In the countries with the least equity in student achievement, socio-economic status accounted for about $20 \%$ of the variation in science scores; in Ciudad Autónoma de Buenos Aires (Argentina) (hereafter "CABA [Argentina]"), 26\% of the variation was related to socio-economic status. In the countries and economies with greater equity, socio-economic status accounted for about $5 \%$ of the variation in student performance. In Macao (China), socio-economic status accounted for $2 \%$ of the variation, and in Algeria it accounted for only $1 \%$ of the variation.

Source: OECD (2016), PISA 2015 Results (Volume I): Excellence and Equity in Education, http:// dx.doi.org/10.1787/9789264266490-en.

Between 2006 and 2015, equity in science performance improved in 11 countries and economies that participated in both PISA cycles: Brazil, Bulgaria, Chile, Denmark, Germany, Iceland, Mexico, Montenegro, Slovenia, Thailand and the United States. In nine of these countries, no drop in mean science performance or in the percentage of top-performing students was observed during the period. This shows that equity in student achievement can be improved without damaging the quality of the system or penalising more advanced students. However, this is not always the case. In Iceland, the mean science score dropped by 18 points during the period while in Slovenia the share of top performers in science shrank by 2.3 percentage points. 
Only in Qatar did equity in science performance worsen during the period. No changes were observed in 40 countries and economies that participated in the two PISA cycles.

Equity in reading achievement has also improved. The percentage of variance in reading scores accounted for by differences in students' socio-economic status decreased by 2.4 percentage points between 2000 and 2015, on average across OECD countries with comparable data ${ }^{1}$ (see Figure 2.4). In PISA 2000, $14.3 \%$ of the variation in student performance was related to socioeconomic status. Between 2000 and 2009, the two cycles when reading was the main domain of assessment in PISA, the level of equity in reading remained about the same. But in PISA 2015, $11.9 \%$ of the variation in reading scores was accounted for by differences in students' socioeconomic status, less than in 2009 and 2000.

Between 2000 and 2015, equity in reading performance improved in 11 out of 35 countries and economies with comparable data. The largest improvements were observed in Germany and the United States, where the relationship between socio-economic status and reading performance weakened by 10 percentage points or more. In Chile, Germany and Israel, equity in reading performance and the average level of reading performance improved during this period; in Australia equity improved while average reading performance declined. Inversely, in Belgium the influence of socio-economic status on performance strengthened during this period.

Equity in mathematics achievement also improved over PISA cycles, as shown in Figure 2.5. Between 2003 and 2012, the two PISA cycles in which mathematics was the main domain assessed, the percentage of variation in mathematics performance accounted for by socioeconomic status decreased by 2.2 percentage points (it was $16.9 \%$ in 2003 and $14.7 \%$ in 2012), on average across OECD countries with comparable data. This average trend towards equity in mathematics performance continued in PISA 2015, when differences in students' socioeconomic status accounted for only $13.1 \%$ of the variation in mathematics scores, on average across OECD countries with comparable data.

Between 2003 and 2015, 15 out of 38 countries with comparable data improved equity in mathematics performance. In Turkey, the improvement in equity in mathematics performance was the largest (a change of 14.7 percentage points); in Germany too the change was large (10 percentage points). In some countries (e.g. Italy, Mexico), improvements in equity were accompanied by improvements in mathematics performance, while in others (e.g. Belgium, the Netherlands, New Zealand, the Slovak Republic) performance declined as equity improved. By contrast, equity worsened in Indonesia, where the variation accounted for by socio-economic status increased by 9.8 percentage points between 2003 and 2015 - from $6.3 \%$ to $16.1 \%$.

In seven countries - Chile, Denmark, Germany, Mexico, Montenegro, Slovenia and the United States - equity in achievement improved over PISA cycles in all three domains (science, reading and mathematics).

In 14 countries and economies - Estonia, Finland, France, Hong Kong (China), Hungary, Ireland, Japan, Lithuania, Luxembourg, Macao (China), Romania, Spain, Sweden and Tunisia - equity did not improve over PISA cycles in any of the cognitive domains assessed. 
Figure 2.4 - Change between 2000 and 2015 in equity in reading performance Percentage of variation in reading performance explained by students'socio-economic status

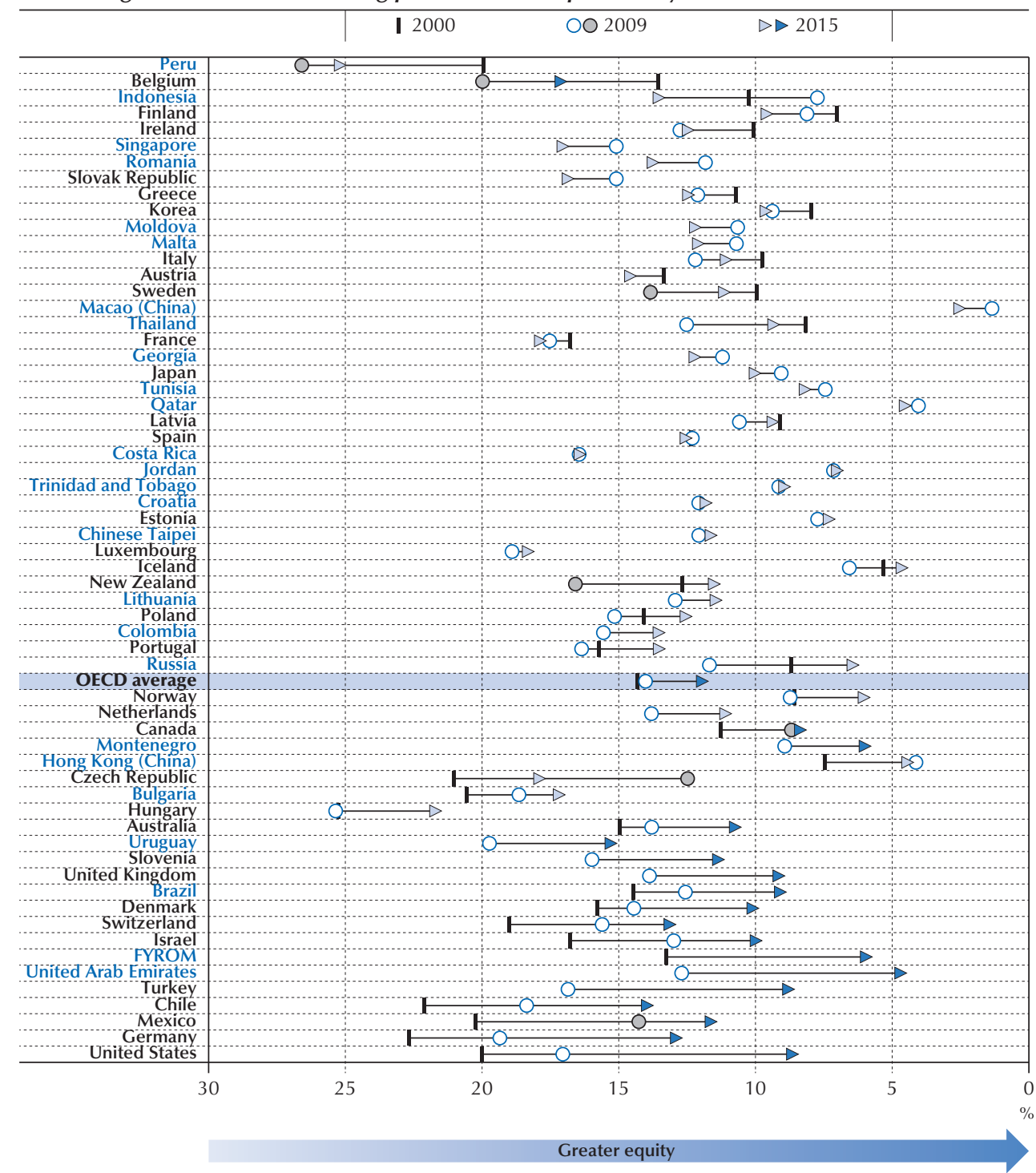

Notes: Socio-economic status is measured by the PISA index of economic, social and cultural status of students.

Statistically significant differences between 2000 and 2009 are shown in grey.

Statistically significant differences between 2000 and 2015 are shown in dark blue.

For countries/economies that did not participate in 2000, statistically significant differences between 2009 and 2015 are shown in dark blue.

Countries and economies are ranked in descending order of difference between 2000 and 2015 (or between 2009 and 2015 if 2000 is missing) in the percentage of variation in reading performance explained by students' socio-economic status. Source: OECD, PISA 2000, PISA 2009 and PISA 2015 Databases, Table 2.4.

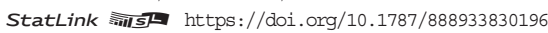


Figure 2.5 - Change between 2003 and 2015 in equity in mathematics performance

Percentage of variation in mathematics performance explained by students' socio-economic status

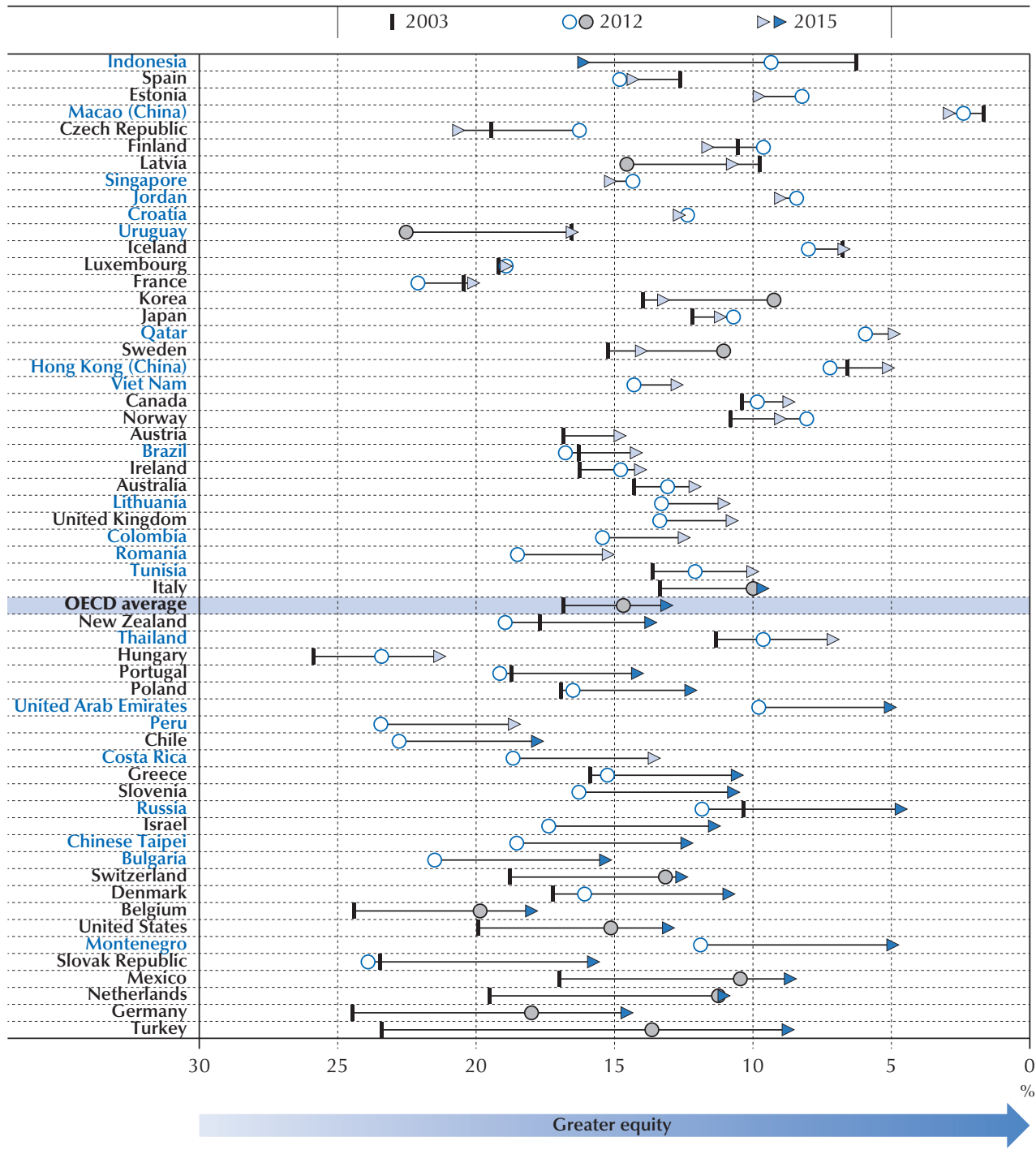

Notes: Socio-economic status is measured by the PISA index of economic, social and cultural status of students.

Statistically significant differences between 2003 and 2012 are shown in grey.

Statistically significant differences between 2003 and 2015 are shown in dark blue.

For countries that did not participate in 2003, statistically significant differences between 2012 and 2015 are shown in dark blue. Countries and economies are ranked in descending order of difference between 2003 and 2015 (or between 2012 and 2015 if 2003 is missing) in the percentage of variation in mathematics performance explained by students' socio-economic status. Source: OECD, PISA 2003, PISA 2012 and PISA 2015 Databases, Table 2.3.

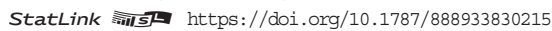




\section{Genesis and growth of the achievement gap during students' lives}

When do socio-economic inequalities in student performance first appear, and how do they evolve over students' lives?

Fifteen-year-old students' performance, as measured by PISA, is the result of a combination and accumulation of multiple factors and experiences. Differences in PISA scores are influenced mainly by characteristics of students and their families, by the learning environment in schools, and by the policies and institutional characteristics of school systems.

What happens at early stages of students' lives affects what happens at later stages, as research on life learning has extensively shown (DiPrete and Eirich, 2006 ${ }_{[13]}$; Entwisle, Alexander and Olson, 2005 $\left.{ }_{[14]}\right)$. Whereas the previous section focused on differences in performance over time (for different cohorts), this section focuses on the evolution over students' lives (for a single cohort). This is done by comparing the size of the socio-economic gap in cognitive achievement for the proxy of a single cohort of students, born in or around 1985, that took part in three different international studies: the Trends in International Mathematics and Science Study (TIMSS) in 1995, when these students were in grade 4 of primary school and were around 10 years old; PISA 2000, when these students were around 15 years old and in secondary school; and the Programme for the International Assessment of Adult Competencies (PIAAC), when members of this cohort were young adults between the ages of 25 and 29 (the PIAAC data collection occurred between 2011 and 2015). ${ }^{2}$ Although the same individual students were not necessarily sampled in each of the three studies, the data compiled through these studies is representative of this birth cohort at the level of the population for the countries that took part in these three studies. ${ }^{3}$

Data to conduct this analysis is available for 12 countries, all of them OECD countries. Cognitive achievement and socio-economic background are the two variables of interest in the analysis. To measure cognitive achievement, TIMSS and PISA provide scores (plausible values) for their mathematics assessments and PIAAC provides scores (plausible values) for its numeracy assessment. The scores of these studies are not directly comparable because each study uses its own scoring scale. To allow for comparability among the studies, the scores of each study were transformed into standardised scores using the means and standard deviations for each country in each study. The number of books present in the student's or respondent's home was used to measure socio-economic status - a measure common to all three studies (none of the other components of socio-economic status [see Box 2.1 for details] is available in the three studies). In the Survey of Adult Skills (PIAAC), adult respondents were asked to estimate the number of books that were available in their home when they were 16 years old.

Results can be found in Figure 2.6. The figure presents the difference in mathematics achievement between individuals who had more and individuals who had fewer than 100 books in their home (i.e. the socio-economic gap). For each country in the analysis, the figure shows the socioeconomic gap (in standardised scores) when students were about 10 years old (as measured in TIMSS 1995), ${ }^{4}$ when students were around 15 years old (as measured in PISA 2000) and when students were 25-29 years old (as measured in PIAAC). 


\section{Figure 2.6 - Socio-economic disparities in mathematics performance over students' lifetime}

Difference in mathematics achievement between individuals who had more and those who had fewer than 100 books in their home

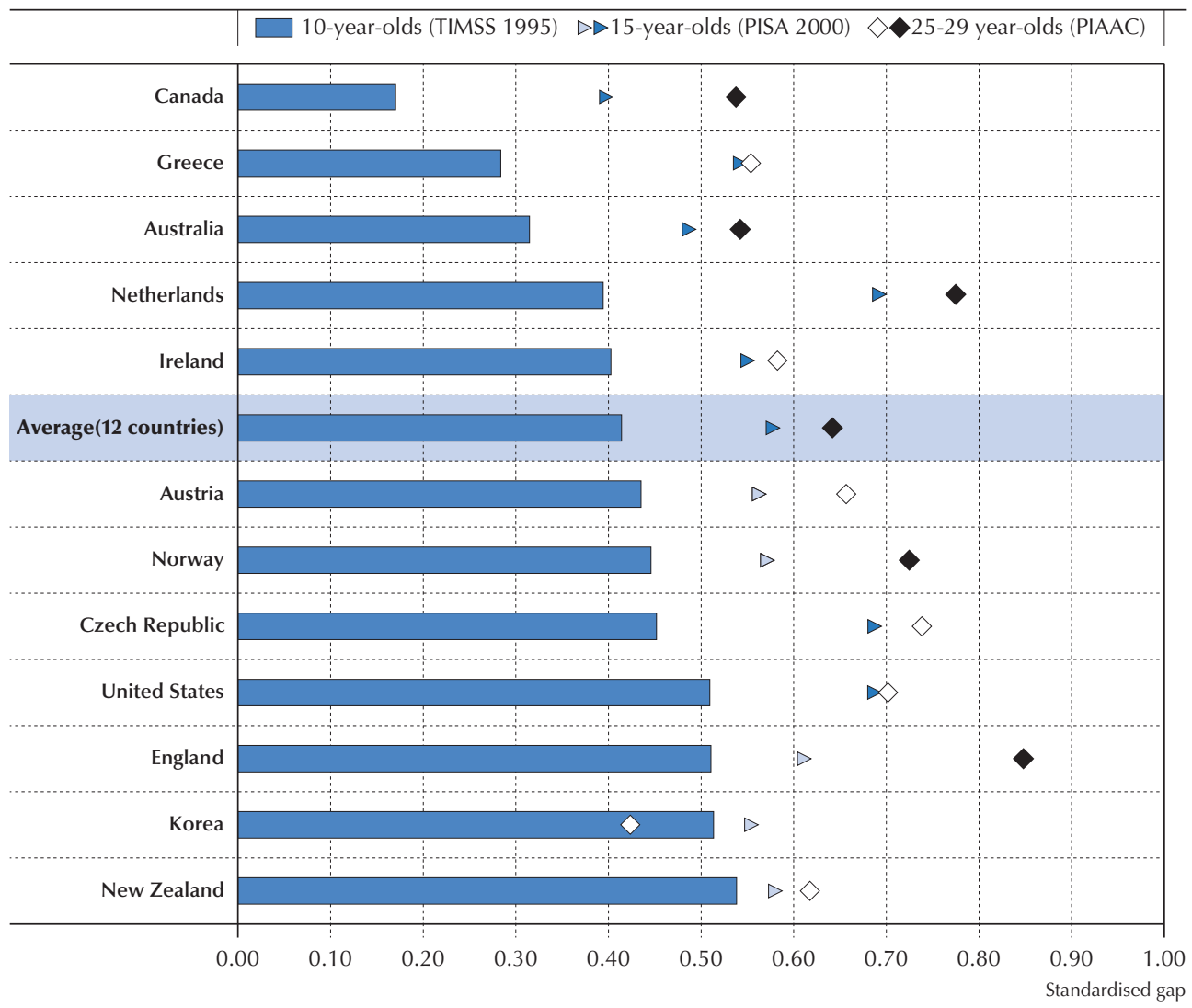

Notes: The standardised gap refers to the difference in the mean scores of individuals with more than 100 books in the home and individuals with fewer than 100 books, divided by the pooled standard deviation.

Statistically significant differences between 15-year-olds (PISA) and 10-year-olds (TIMSS) are shown by the dark blue triangles. Statistically significant differences between 25-29 year-olds (PIAAC) and 10-year-olds (TIMSS) are shown by the black diamonds.

There are no statistically significant differences between 25-29 year-olds (PIAAC) and 15-year-olds (PISA).

Only countries with available data are included.

Countries are ranked in ascending order of the gap in TIMSS.

Source: IEA, TIMSS 1995 dataset. OECD, PISA 2000 database and PIAAC dataset (Rounds 1 and 2), Table 2.5.

StatLink 需s https://doi.org/10.1787/888933830234

The size of the socio-economic gap in mathematics achievement is already large by the time students are in primary school, and it grows substantially in later years. On average across the 12 OECD countries with comparable data, the standardised gap in mathematics scores associated with having more books at home was 0.41 around the age of 10 . It increased to 0.58 
age 15, and then it grew further to reach 0.64 between the ages of 25 and 29 . The socioeconomic gap grew by a larger margin between TIMSS and PISA (the average difference between the two assessments is 0.16 standardised score point), than between PISA and PIAAC (average difference is 0.06 point). In other words, more than two-thirds of the achievement gap observed at age 15, and about two thirds of the achievement gap observed among 25-29 year-olds was already seen among 10-year-olds.

The socio-economic gap in mathematics performance among 10-year-olds (as measured by TIMSS; the blue bars in Figure 2.6) was largest in England, Korea, New Zealand and the United States (standardised gap greater than 0.5 point); it was smallest (less than 0.3 point) in Canada and Greece.

By the time this cohort of students reached age 15 and was assessed by PISA, the achievement gap had grown, relative to that observed in the TIMSS assessment, in 7 out of the 12 countries under study. The standardised gap in mathematics achievement among 15-year-old students (as measured by PISA; the white diamonds in Figure 2.6) grew the most (more than 0.2 point) in Canada, the Czech Republic, Greece and the Netherlands; and it grew an average amount in Australia, Ireland and the United States.

When the cohort members were young adults (aged 25-29), inequity in mathematics achievement among them had become even greater. The standardised socio-economic gap in numeracy, as measured by PIAAC, grew, relative to the gap observed in TIMSS, in five out of the 12 countries. Growth in the gap was largest (greater than 0.3 point) in Canada, England and the Netherlands, and smallest (less than 0.3 point) in Australia and Norway.

In Austria, the Czech Republic, Greece, Ireland, Korea, New Zealand and the United States, changes are observed that suggest larger inequities in mathematics achievement at later periods of students' lives (with the exception of a seemingly narrower gap among young adults in Korea). However, in these countries, none of the differences is statistically significant, thus it is unclear whether the observed changes are real or are the result of measurement errors.

These results provide evidence for at least three conclusions with implications for policy makers and educators. First, the fact that socio-economic differences in performance are so prominent early on, when students are only 10 years old, underscores the impact of family background, early childhood education, and primary schools in the genesis of the large socio-economic inequalities in achievement that PISA finds among adolescents and PIAAC finds among young adults.

Second, in most countries, inequalities in achievement grow by a much larger margin between primary and secondary school than between secondary school and young adulthood. This underscores the importance of policies and practices that affect students' performance during adolescence. OECD and PISA reports examining the policies and practices used in successful schools offer suggestions about what can be done to address the inequalities that seem to become more entrenched during primary and secondary school (OECD, 2016 ${ }_{[15] ;}$ OECD, 2012 $2_{[16]}$ ). For example, targeting professional resources, such as qualified teachers, in schools that have large proportions of low-performing and socio-economically disadvantaged students, or limiting stratification practices, such as early tracking, ability grouping or grade repetition in favour of more inclusive approaches to address classroom heterogeneity, could improve equity in student performance. 
Third, a number of countries have unique profiles that are not adequately captured by the average patterns. In-depth research into these cases might provide further insights into the mechanisms through which inequality in achievement emerges and develops. Evidence acquired through this research could inform the design of effective policies. These unique patterns are found in Korea, for example, where inequalities in achievement narrow considerably between adolescence and early adulthood. They are also found in Canada, where performance inequalities in childhood are smaller than those observed in other countries, and in England, where inequality in performance grows markedly between adolescence and adulthood.

\section{TRENDS IN EQUITY IN STUDENTS' WELL-BEING}

Students' well-being, as defined and measured in PISA, has four main dimensions: social, psychological, physical and cognitive (OECD, 2017 $[7]$ ). A large part of PISA information about students' well-being was collected for the first time in 2015, during the most recent cycle of PISA. Because the purpose of this chapter is to understand trends in inequalities in students' wellbeing related to socio-economic status, only a handful of measures for which there are data from more than one PISA cycle are included here. This section focuses on two dimensions: students' psychological and social well-being.

Students' social well-being refers to the quality of students' social lives. It includes students' relationships with their family, their peers and their teachers, and how they perceive their social life in school (Pollard and Lee, $2003_{[17]}$ ). In this section, students' social well-being is examined by looking at students' sense of belonging at school.

Students' psychological well-being refers to students' views about life, their engagement at school, and the goals and ambitions they have for their future. In this section, two measures of students' psychological well-being are considered: science self-efficacy and career expectations.

\section{Sense of belonging at school}

Students' sense of belonging at school is the extent to which students feel accepted by and connected to their peers, and part of the school community. A sense of belonging gives students feelings of security, identity and community which, in turn, support academic, psychological and social development. A lack of connectedness can adversely affect students' perceptions of themselves, their satisfaction with life, and their willingness to learn and put effort into their studies (Baumeister and Leary, 1995 $[18]$; Ma, 2003 ${ }_{[19]}$ ).

In 2015, as in 2012 and 2003, PISA measured sense of belonging directly by asking students to report whether they "strongly agree", "agree", "disagree" or "strongly disagree" that they feel they belong at school. On average across 28 OECD countries with comparable data, the share of students who reported that they feel they belong at school was $81 \%$ in PISA 2003 and PISA 2012, but 73\% in PISA 2015 - a significant drop (Table 2.6). In Australia, Brazil, Hungary, Italy, Mexico, the Russian Federation (hereafter "Russia"), the Slovak Republic, Thailand and Uruguay, the share of students who reported that they feel they belong at school dropped by 15 percentage points or more between 2003 and 2015. By contrast, in Indonesia, the share of students who reported feeling a sense of belonging at school increased by about 24 percentage points during the same period; in Belgium, Hong Kong (China), Korea, the Netherlands and Spain, the share also grew, but by smaller margins. 
Students from socio-economically advantaged families enjoy a stronger sense of belonging at school than disadvantaged students. However, the disparity is not large because most disadvantaged students feel they belong at school. In PISA 2015, on average across OECD countries, $77 \%$ of advantaged students reported that they feel they belong at school, whereas some $69 \%$ of disadvantaged students so reported. Thus, the socio-economic gap in sense of belonging at school was 8 percentage points, on average across OECD countries (Table 2.6).

In most countries, there has been little change over time in the socio-economic gap in students' sense of belonging, as shown in Figure 2.7. On average across OECD countries, in PISA 2003 the socio-economic gap in students' sense of belonging at school was 7 percentage points ( $76 \%$ of disadvantaged students and $83 \%$ of advantaged students reported feeling a relatively strong sense of belonging at school), roughly the same gap observed in PISA 2015. Between 2012 and 2015, the socio-economic gap in the sense of belonging at school widened by 2 percentage points, on average across OECD countries.

In Bulgaria, Japan, the Netherlands and Portugal, the socio-economic gap in sense of belonging at school narrowed over PISA cycles, while in Australia, Brazil, New Zealand, Singapore, the Slovak Republic and Sweden the gap widened.

Interestingly, in most countries, socio-economic differences in sense of belonging at school disappear once student performance is taken into account (Table 2.7). This suggests that disadvantaged students who score higher enjoy a similarly strong sense of belonging at school as their more advantaged peers. It also shows that these differences in sense of belonging at school are relatively small.

\section{Science self-efficacy}

Self-efficacy describes the strength of students' belief that they can perform tasks similar to those tested in cognitive assessments. A student with a high level of self-efficacy believes that, through her or his own actions, she or he can achieve goals or produce desired effects. Selfefficacy is thus a powerful incentive to act and to persevere in the face of difficulties (Bandura, $1997_{[20]}$ ).

In 2006 and 2015, PISA measured students' self-efficacy in science by asking students to answer the following question: "How easy do you think it would be for you to perform the following tasks on your own?" Tasks included: "Explain why earthquakes occur more frequently in some areas than in others"; "Describe the role of antibiotics in the treatment of disease"; "Identify the science question associated with the disposal of garbage"; "Predict how changes to an environment will affect the survival of certain species"; "Interpret the scientific information provided on the labelling of food items"; "Discuss how new evidence can lead you to change your understanding about the possibility of life on Mars"; and "Identify the better of two explanations for the formation of acid rain". Students were not asked to solve any of these tasks; rather, they were asked to report whether: "[I] could do this easily"; "[I] could do this with a bit of effort"; "[I] would struggle to do this on my own"; or "[I] couldn't do this". Students' responses to these questions were used to build the index of science self-efficacy, a single measure of students' overall level of self-efficacy in science. ${ }^{5}$ 
Figure 2.7 - Change between 2003 and 2015 in sense of belonging at school, by socio-economic status

Difference between the percentage of socio-economically advantaged and disadvantaged students who feel they belong at school

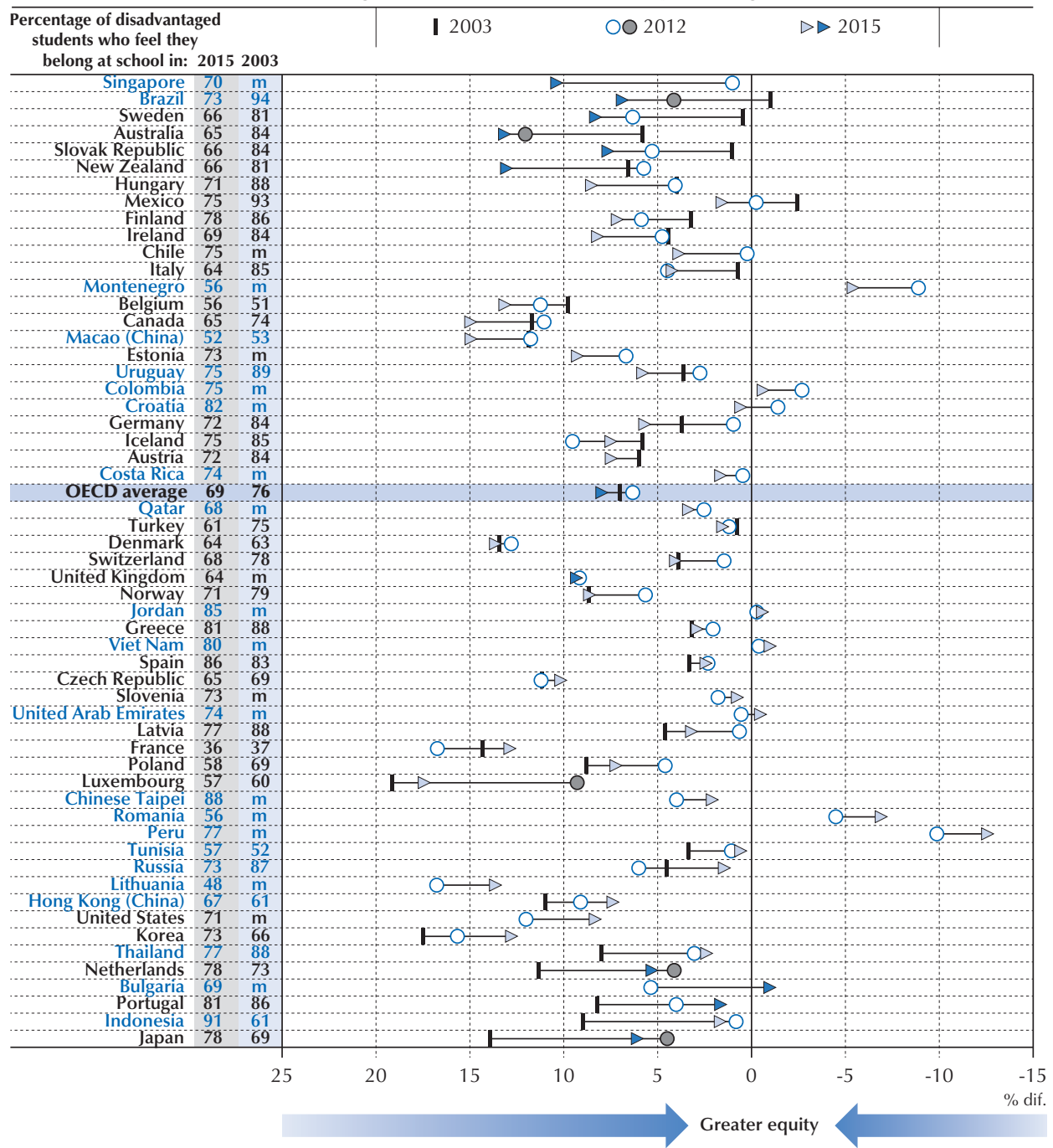

Notes: Socio-economic status is measured by the PISA index of economic, social and cultural status of students.

Statistically significant differences between 2003 and 2015 (or 2012 and 2015 for countries not included in 2003) are shown in dark blue.

Statistically significant differences between 2003 and 2012 are shown in grey.

The percentage of socio-economically disadvantaged students who feel they belong at school in PISA 2003 and PISA 2015 is shown next to the country/economy name.

Countries and economies are ranked in descending order of the difference between 2003 and 2015 (or between 2012 and 2015 if 2003 is missing) in the gap between advantaged and disadvantaged students.

Source: OECD, PISA 2003, PISA 2012 and PISA 2015 Databases, Table 2.6.

StatLink 尚is https://doi.org/10.1787/888933830253 
Socio-economic disparities in self-efficacy are large and widespread across countries. The level of science self-efficacy, as measured by the index of science self-efficacy, was higher among advantaged students than among disadvantaged students in each of the 52 countries and economies that participated in both PISA 2006 and PISA 2015 (see Figure 2.8).

In fact, in every country and economy that participated in PISA 2015, students from advantaged families reported higher levels of self-efficacy, even after science performance is taken into account (Table 2.9). In other words, even when comparing students whose science knowledge and skills are demonstrably similar, advantaged students are more confident in their ability to solve science problems than disadvantaged students.

Socio-economic disparities in science self-efficacy have remained relatively stable over PISA cycles. On average across OECD countries, the difference between advantaged and disadvantaged students in the index of science self-efficacy did not change between 2006 and 2015.

However, changes are observed in certain countries. In 15 countries (Bulgaria, Chile, Colombia, Germany, Hungary, Indonesia, Mexico, Montenegro, Poland, Qatar, Romania, Switzerland, Thailand, Turkey and the United Kingdom), equity in self-efficacy improved between 2006 and 2015, meaning that the socio-economic gap in the index of science self-efficacy narrowed.

Equity in science self-efficacy deteriorated in four countries and economies: Belgium, Croatia, Estonia and Chinese Taipei. In these education systems, the socio-economic gap in science selfefficacy widened between 2006 and 2015.

\section{Career expectations}

Students with more ambitious education and career expectations tend to put more effort into their studies and school experience. Moreover, defining career plans during adolescence motivates students into pursuing their goals (Marks, 2010 $0_{[21]}$; Saha and Sikora, 2008 ${ }_{[22]}$ ). Some studies also suggest that adolescents have become more ambitious in recent decades (Goyette, 2008 [23]; Reynolds et al., 2006 $[24]$ ).

In the PISA 2015 student questionnaire, as in the PISA 2006 questionnaire, students were asked: "What kind of job do you expect to have when you are about 30 years old?" This was an open question, meaning that no response categories were provided and students were able to answer freely using their own words. Responses were coded to four-digit ISCO (International Standard Classification of Occupations) codes and then mapped to the ISEI (International Socio-Economic Index of occupational status) index (Ganzeboom and Treiman, $2003_{[25]}$ ). Higher scores in the ISEI index indicate higher occupational status.

In every country and economy that participated in PISA 2015, socio-economically advantaged students expected to be employed in occupations of higher social status than disadvantaged students (a difference of 50.2 points in the ISEI index, on average across OECD countries). In all OECD countries except Israel, socio-economic differences in career expectations were significant, even after accounting for students' performance in science (Table 2.11).

The socio-economic gap in career expectations was marginally larger in PISA 2006 than in PISA 2015, as shown in Figure 2.9. This narrowing of the gap over the past decade reflects a greater increase among disadvantaged students than among advantaged students in OECD countries in expecting to work in a high-status career, although more students in both socioeconomic groups expected a high-status career in 2015 than did in 2006. 
Figure 2.8 - Change between 2006 and 2015 in science self-efficacy, by socio-economic status

Difference between socio-economically advantaged and disadvantaged students in the index of science self-efficacy

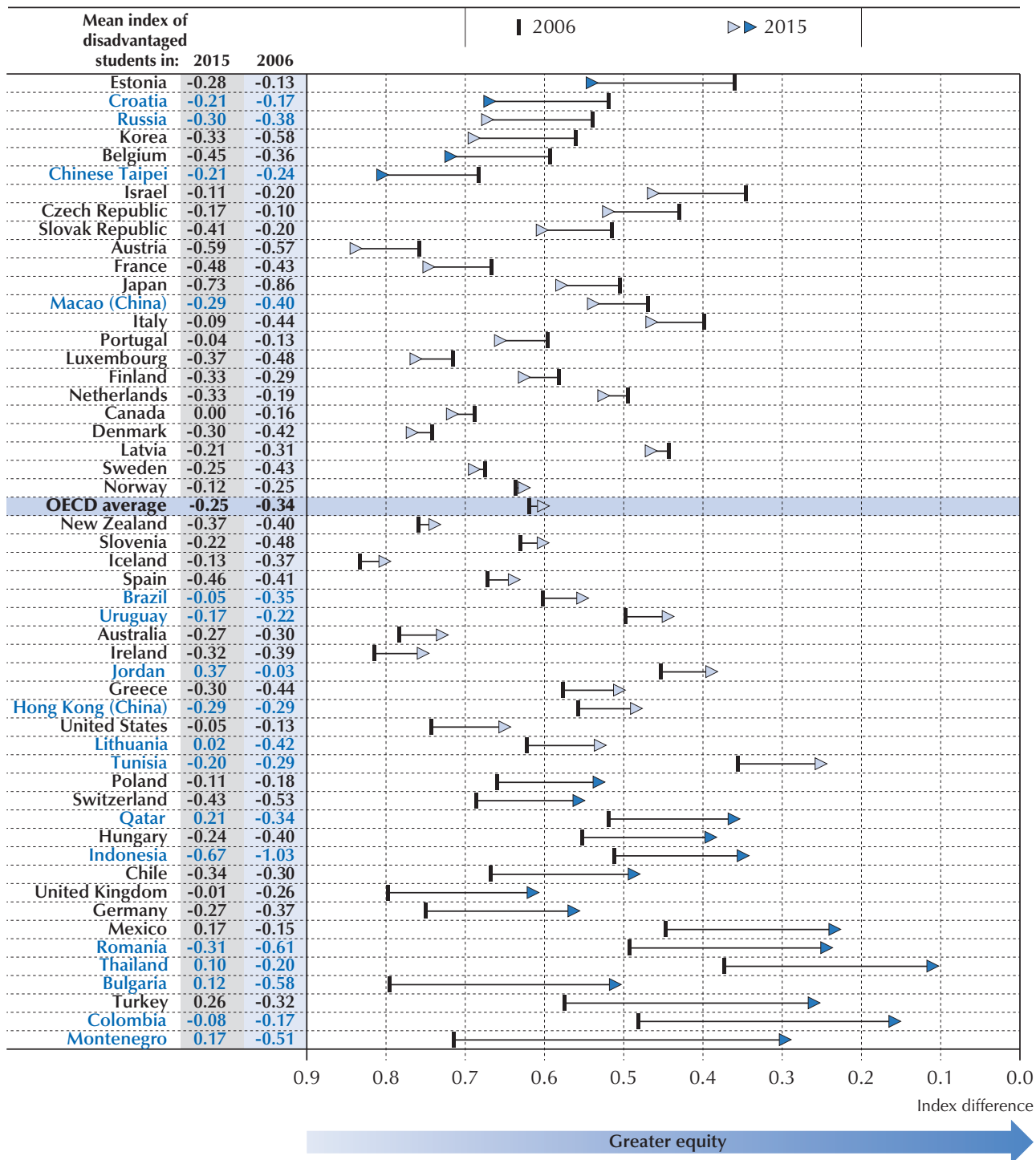

Notes: Socio-economic status is measured by the PISA index of economic, social and cultural status of students. Statistically significant differences between 2006 and 2015 are shown in dark blue.

The average value in the index of science self-efficacy for socio-economically disadvantaged students in PISA 2006 and PISA 2015 is shown next to the country/economy name.

Countries and economies are ranked in descending order of difference between 2006 and 2015 in the gap between advantaged and disadvantaged students.

Source: OECD, PISA 2006 and PISA 2015 Databases, Table 2.8.

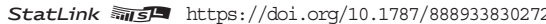


Figure 2.9 - Change between 2006 and 2015 in career expectations, by socio-economic status

Difference between socio-economically advantaged and disadvantaged students in the International Socio-Economic Index of occupational status (ISEI)

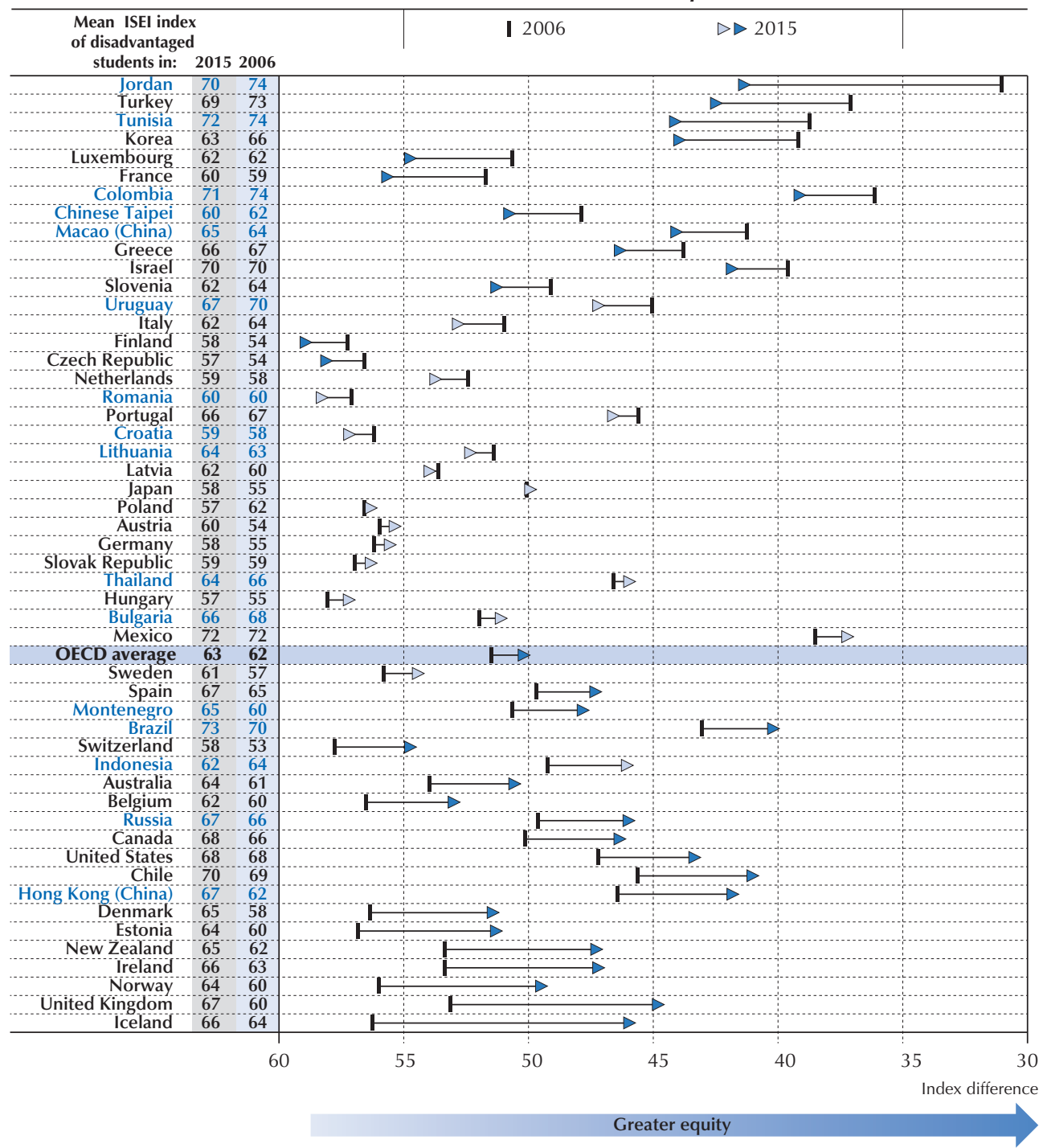

Notes: Socio-economic status is measured by the PISA index of economic, social and cultural status of students.

Statistically significant differences between 2006 and 2015 are shown in dark blue.

The average value in the ISEI index for socio-economically disadvantaged students in PISA 2006 and PISA 2015 is shown next to the country/economy name. Higher ISEI values indicate higher occupational status.

Countries and economies are ranked in descending order of the difference between 2006 and 2015 in the gap between advantaged and disadvantaged students.

Source: OECD, PISA 2006 and PISA 2015 Databases, Table 2.10.

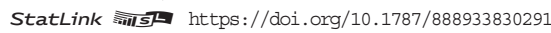


In addition to the average trends across OECD countries, different trends are observed between countries. The socio-economic gap in career expectations narrowed between 2006 and 2015 in 18 of the 51 countries and economies with comparable data. By contrast, the gap widened in 14 countries.

\section{TRENDS IN EQUITY IN EDUCATIONAL ATTAINMENT}

The analyses of trends in disparities in educational attainment related to socio-economic status tell two larger stories. The first is a story of expansion in access to education. During the past century, the average level of education increased steadily in countries all over the world, including both wealthier and developing countries. This has allowed a large share of individuals born in recent decades to attain higher levels of education than those attained by their parents, i.e. to experience upward educational mobility.

The second story, however, is one of inequities in attainment that persist over time despite the expansion of access to education. Even among younger cohorts, socio-economically advantaged people have greater chances of completing higher levels of education than disadvantaged people.

In other words, absolute levels of educational attainment have increased over time on average across populations and among different socio-economic groups. However, differences between people in high- and low-income countries, and between advantaged and disadvantaged people, in the likelihood of attaining higher levels of education have remained significant over time.

\section{Box 2.3 Measuring trends in educational attainment}

Data from PISA are insufficient to determine educational attainment because the assessment measures proficiency among 15-year-old students, and many people continue their education well beyond this age. Consequently, two additional sources of data are used to examine educational attainment in this chapter.

A standard way to measure attainment is to count the total number of years of schooling completed by an individual. Educational attainment is here understood as each progression to the next grade. Aggregating data on years of schooling at the national level allows for comparisons between countries. The most complete international dataset of historical trends in average years of schooling is the one compiled by R. J. Barro and J. W. Lee (Barro and Lee, 2013 ${ }_{[6]}$ ). This dataset is used in this section to examine trends in equity in educational attainment among countries.

In addition to being a continuous sequence of grades, schooling is organised in longer periods of time that group several grades and are certified with a diploma (e.g. primary, secondary, tertiary degrees). Measuring attainment by looking at the highest level of education an individual completed is important for two reasons: because it implies the skills students have acquired, and because the degrees earned at those levels are a prerequisite for further education and entry into certain occupations and professions (Bills, $\left.2003_{[26]}\right)$. The Survey of Adult Skills (PIAAC) (OECD, 2016 $\left.6_{[1]}\right)$ collects data on educational 
attainment in this way for survey respondents and respondents' parents. PIAAC data is used in this section to analyse trends in equity in educational attainment within countries.

Source: Barro, R. and J. Lee (2013), "A new data set of educational attainment in the world, 19502010", Journal of Development Economics, http://dx.doi.org/10.1016/J.JDEVECO.2012.10.001.

Bills, D. (2003), "Credentials, Signals, and Screens: Explaining the Relationship Between Schooling and Job Assignment", Review of Educational Research, http://dx.doi.org/10.3102/00346543073004441.

OECD (2016), Technical Report of the Survey of Adult Skills (PIAAC), OECD, Paris

http://www.oecd.org/skills/piaac/PIAAC_Technical_Report_2nd_Edition_Full_Report.pdf.

\section{Equity among countries in average years of schooling}

Average educational attainment has been increasing in countries in every region of the world and among people of all income levels for decades. However, the pace of growth has not been the same everywhere. Wealthier regions have generally seen faster increases in attainment than poorer regions, and thus gaps in average education levels among countries have persisted over time.

Figure 2.10 shows the evolution over the 20th century in the average years of schooling completed by adults (age 25 or over) in 128 countries. Countries are grouped according to their level of per-capita income (World Bank, 2017 $7_{[27]}$ ). All OECD countries are included in the high-income group, except Mexico and Turkey, which are part of the upper-middle-income group. Partner countries and economies that have participated in PISA are included either in the high-income, the upper-middle-income or the lower-middle-income group. ${ }^{6}$ Low-income economies include 20 countries that have not participated in PISA.

Up to the first decades of the 20th century, individuals attended school for only a few years. Adults born during the 1900s in high-income countries completed an average of about five years of schooling; in all other countries the average was less than three years. Towards the end of the century, adults in high-income countries completed an average of 12 years of schooling, those in upper-middle-income countries completed about 10 years, adults in lower-middle-income countries completed about 8 years, and those in low-income countries completed about 5 years of schooling, on average.

Even though educational expansion was a worldwide phenomenon over the past century, growth was faster in wealthier countries. As a result, the absolute gap in educational attainment between people living in the richest and those in the poorest countries increased. Earlier in the 20th century, individuals born in high-income countries had completed around four more years of school, on average, than those born in low-income countries. This gap widened slowly but steadily over time, so that for the generation born in the 1980s the gap had almost doubled.

Less of a difference is observed between high-income and upper-middle-income countries. The gap of about two years of schooling between these two groups of countries has remained more or less stable throughout the period. 
Figure 2.10 - Total years of schooling, by wealth of countries

Years of schooling completed by 25-74 year-olds, by year of birth

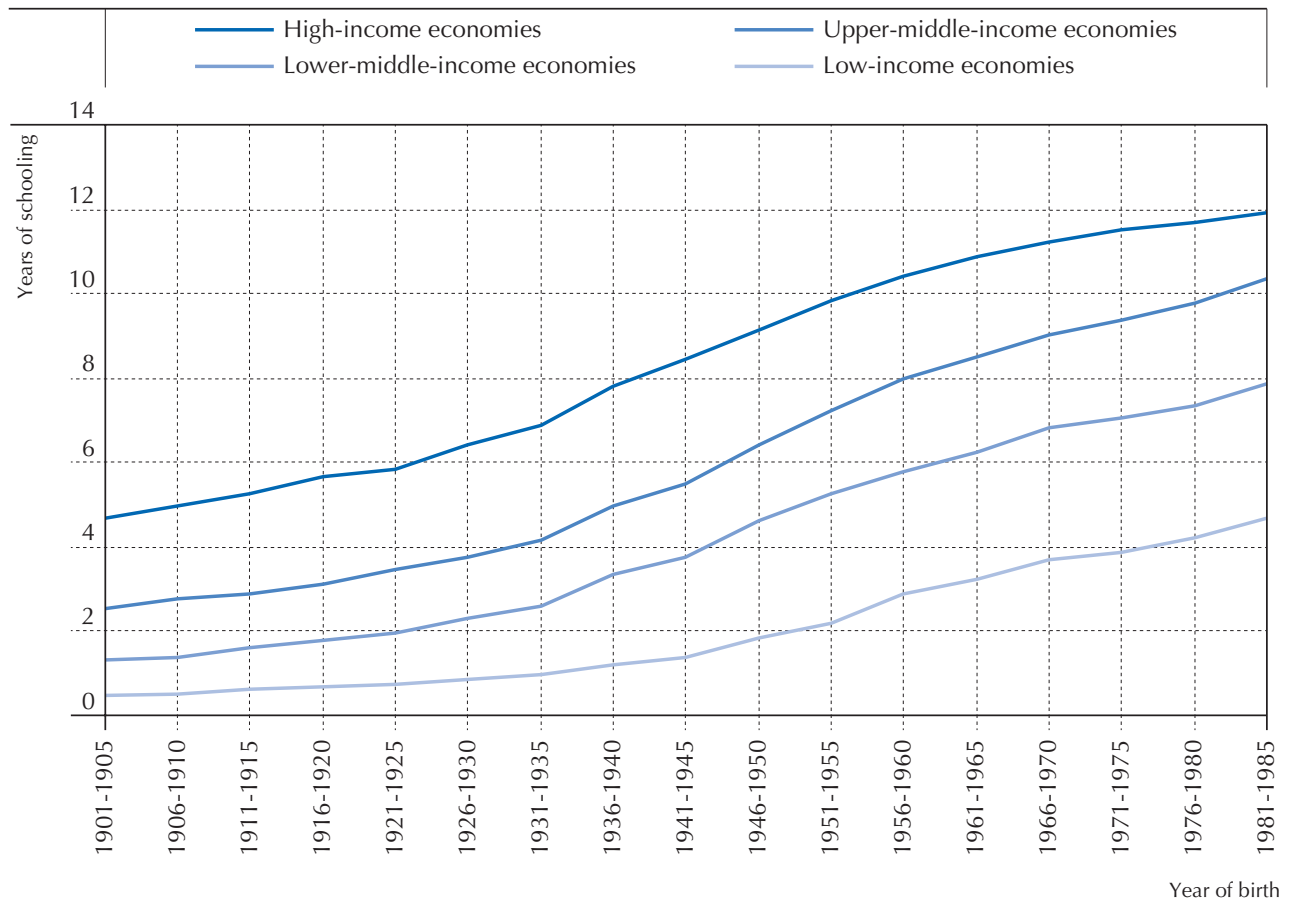

Notes: Low-income economies are defined as those with a GNI per capita of USD 1005 or less in 2016; lower-middleincome economies are those with a GNI per capita between USD 1006 and USD 3 955; upper-middle-income economies are those with a GNI per capita between USD 3956 and USD 12 235; high-income economies are those with a GNI per capita of USD 12236 or more (World Bank, 2017 2 [27] ).

Sources: Based on Barro-Lee educational attainment dataset (February 2016); and World Bank Country and Lending Groups (reviewed on October 2017). See Table 2.12 for national data.

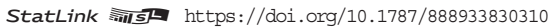

\section{Equity in the attainment of upper secondary and tertiary education}

As discussed above, average levels of educational attainment rose worldwide during the past few decades, but more so in OECD countries than in developing countries. This means that there are more education opportunities today than in the past. But what has happened within countries? Have these opportunities been distributed more equitably across socio-economic groups in more recent decades? Has the expansion of access to education translated into greater equity in education opportunities? For example, are adults from different socioeconomic backgrounds acquiring more, the same amount, or less education than their parents? Has the share of adults benefiting from upward educational mobility changed over the past decades?

In order to answer these questions, the analyses that follow use data from the Survey of Adult Skills (PIAAC). Survey respondents were between 26 and 65 years old at the time of the 
interview. $^{7}$ Some 33 countries participated in the survey between 2008 and 2016. Countries participating in PIAAC include OECD countries (except Hungary, Iceland, Luxembourg, Mexico, Portugal and Switzerland), and four partner countries (Cyprus, ${ }^{8}$ Lithuania, Russia $^{9}$ and Singapore).

In the analyses based on PIAAC data, socio-economic background is measured by parents' education. Adults from a socio-economically disadvantaged background are those whose parents completed less than upper secondary education; adults from a mid-level socio-economic background are those with at least one parent who had completed upper secondary education; and adults from an advantaged background are those with at least one parent who had completed tertiary education. Equity is the greatest when adults' educational "destinations" (i.e. their highest level of education) cannot be predicted based on their educational "origins" (i.e. their parents' education). By contrast, there is less equity in attainment when educational origins and destinations are more strongly related.

\section{Educational mobility across generations}

As shown in Figure 2.11, three types of educational mobility can be distinguished: individuals who attained higher levels of education than their parents (that is, who experienced upward educational mobility), lower levels of education than their parents (downward educational mobility), or the same level of education as their parents (no educational mobility).

Figure 2.11 - Highest level of education completed, by parents' education Percentage of adults 26 years or older, PIAAC average (33 countries)

\begin{tabular}{|c|c|c|c|c|c|}
\hline & & Upward m & $\square$ No mobi & $\square$ Dow & obility \\
\hline & & \multicolumn{4}{|c|}{ Respondents' education } \\
\hline & & $\begin{array}{l}\text { Less than upper } \\
\text { secondary }\end{array}$ & Upper secondary & Tertiary & Total \\
\hline \multirow{4}{*}{$\begin{array}{l}\text { Parents' } \\
\text { education }\end{array}$} & $\begin{array}{l}\text { Less than upper } \\
\text { secondary }\end{array}$ & 17 & 19 & 9 & 45 \\
\hline & Upper secondary & 4 & 17 & 13 & 34 \\
\hline & Tertiary & 1 & 6 & 14 & 22 \\
\hline & Total & 22 & 42 & 37 & 100 \\
\hline
\end{tabular}

Notes: Respondent's education is the highest level of education completed by the person responding to the Survey of Adult Skills (PIAAC).

Parents' education is the highest level of education completed by either the father or the mother of the respondent.

Tertiary education includes ISCED levels 5 (short-cycle tertiary education), 6 (bachelor's or equivalent level), 7 (master's or equivalent) and 8 (doctoral or equivalent).

Source: OECD, PIAAC dataset. See Table 2.17 for national data.

StatLink 需可 https://doi.org $/ 10.1787 / 888933830329$ 
On average across PIAAC-participating countries, $41 \%$ of adults achieved upward educational mobility. Individuals who attained higher levels of education than their parents can be categorised into three groups (the cells coloured in dark blue in Figure 2.11): respondents who completed upper secondary education and neither of whose parent had completed upper secondary school (19\%); respondents who completed tertiary education and at least one of whose parent had completed upper secondary education $(13 \%)$; or respondents who completed tertiary education and neither of whose parent had completed upper secondary education (9\%). The latter group, although the smallest, is the most remarkable because it involves moving from the most disadvantaged educational origins (parents with less than upper secondary education) to the most advantaged educational destination (completing tertiary education).

However, the most frequently observed pattern of educational mobility is not upward mobility but no mobility: almost half of the respondents (48\%; the white cells in Figure 2.11) attained the same highest level of education as their parents. This group includes adults with less than upper secondary education whose parents also did not complete upper secondary education (17\%); adults who completed upper secondary education and have at least one parent who attained that level of education (17\%); and adults who completed a tertiary degree and at least one of whose parents had also attained a tertiary degree (14\%).

The share of respondents contending with downward educational mobility is considerably smaller (11\%). The largest group is composed of adults with tertiary-educated parents who completed only upper secondary education themselves $(6 \%)$, and adults who did not complete upper secondary education even though at least one of their parents had (4\%). Rare are the adults with highly educated parents who did not complete upper secondary education.

Levels of educational mobility vary across countries, as shown in Figure 2.12. In Finland, Korea, Russia and Singapore, more than one in two adults experienced upward educational mobility, according to PIAAC data. By contrast, in Austria, the Czech Republic, Germany and Turkey, fewer than one in three adults did so. Shares of downwardly mobile adults are larger (17\% or more) in Germany, Lithuania, Norway and Sweden, and smaller (less than 5\%) in Italy, Korea, Singapore and Turkey.

The share of upwardly mobile adults is larger than the share of downwardly mobile adults in all PIAAC-participating countries, even in those where upward educational mobility is comparatively rare and where downward mobility is comparatively common. This reflects the expansion in access to education across generations, or "educational upgrading", made evident by looking at populations' average years of schooling.

In Figure 2.11 above, the levels of education of PIAAC respondents and those of their parents are presented in the "Total" cells coloured in grey. Education levels are higher among respondents than among their parents: $22 \%$ of respondents attained less than upper secondary education as their highest level of attainment compared to $45 \%$ of parents who did so. Completion of upper secondary and tertiary education is far more frequent among respondents than among their parents. 
Figure 2.12 - Educational mobility, by country

Percentage of adults 26 years or older who reported lower, the same or higher educational attainment than/as their parents

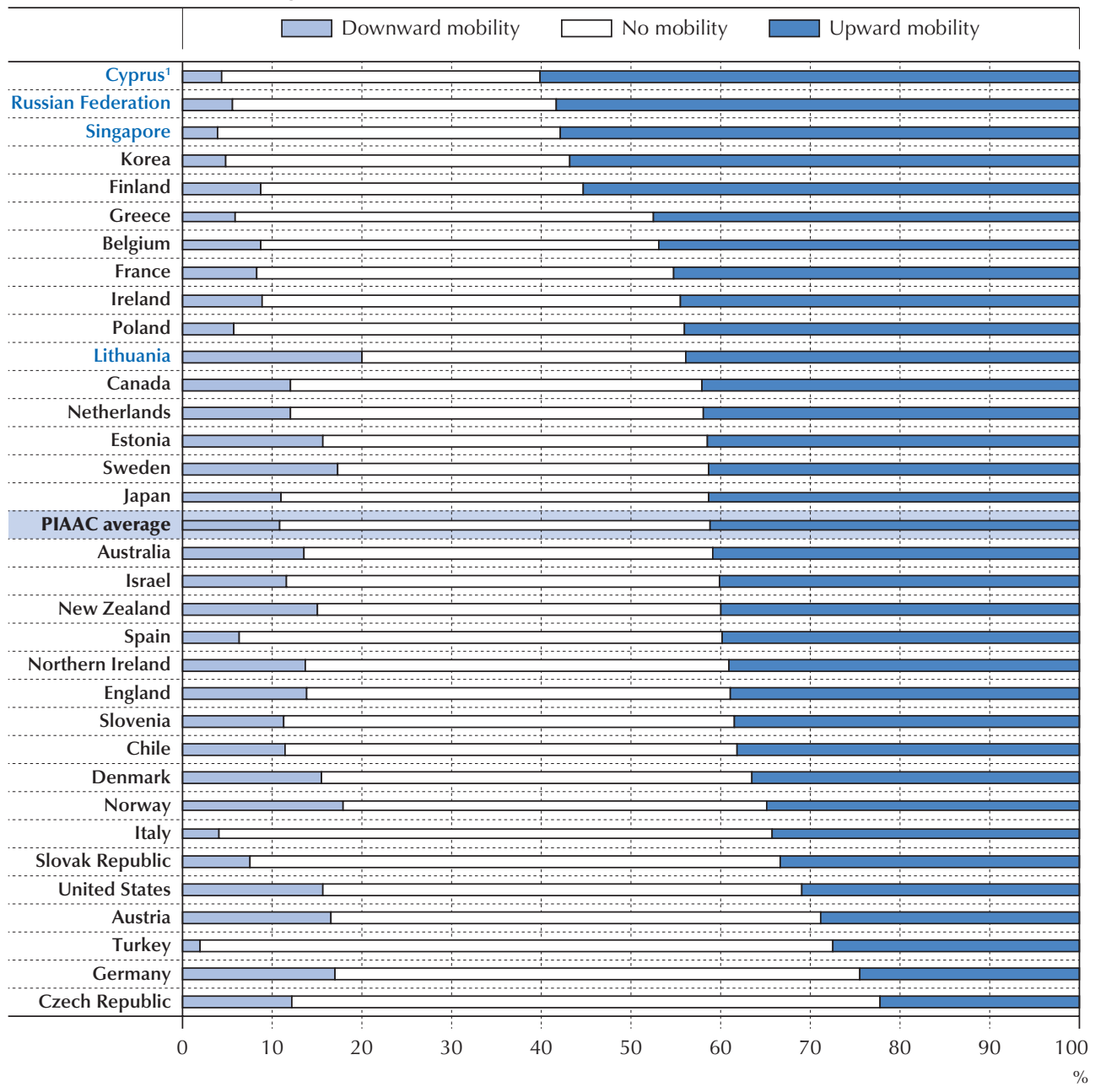

1. See notes at the beginning of this chapter.

Countries and economies are ranked in descending order of the percentage of respondents who experienced upward educational mobility.

Source: OECD, PIAAC dataset, Table 2.18.

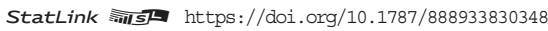

Has educational mobility changed over time? A way to answer this question using PIAAC data is to compare educational mobility rates across respondents from different age cohorts (Figure 2.13). The oldest PIAAC respondents, those who were between 56 and 65 years old at the time of data collection (which occurred between 2011 and 2015, depending on the country ${ }^{10}$ ), were born during the late 1940s and throughout the 1950s, and typically entered primary school during the 
1950 s and early 1960s. Those who continued studying completed tertiary education during the 1970s. At the other extreme, the youngest PIAAC respondents in the analysis, those who were around 26 years old at the time of the survey, were born between the second half of the 1970s and the end of the 1980s, and attended and completed tertiary education in the 2000s. Thus, Figures 2.13 to 2.17 , about trends in equity in attainment, cover a period of several decades, and adults who were born and completed their education in the immediate aftermath of World War II to the present.

Figure 2.13 - Educational careers across age cohorts

\begin{tabular}{|c|c|c|c|c|c|}
\hline Cohort & Age & Year of birth & $\begin{array}{c}\text { Entered } \\
\text { primary }\end{array}$ & $\begin{array}{c}\text { Completed } \\
\text { upper secondary }\end{array}$ & $\begin{array}{c}\text { Completed } \\
\text { tertiary }\end{array}$ \\
\hline 1 & $56-65$ & $1946-59$ & 1950 -early $60 \mathrm{~s}$ & Late 1960s-early 70s & 1970 s \\
\hline 2 & $46-55$ & $1956-69$ & 1960 s-early 70s & Late 1970s-early 80s & 1980 s \\
\hline 3 & $36-45$ & $1966-79$ & 1970 s-early $80 \mathrm{~s}$ & Late 1980s-early 90s & $1990 \mathrm{~s}$ \\
\hline 4 & $26-35$ & $1976-89$ & 1980 s-early 90s & Late 1990s-early 2000s & $2000 \mathrm{~s}$ \\
\hline
\end{tabular}

Note: Respondents younger than 26 at the time of data collection are not included in the analysis. A first round of data collection in 25 countries occurred between August 2011 and March 2012. A second round of data collection in eight countries occurred between August 2014 and January 2015.

Source: OECD, PIAAC dataset.

There has been considerable variation over the past few decades in the rates of upward educational mobility, as shown in Figure 2.14. On average across PIAAC-participating countries, the percentage of upwardly mobile adults was higher among older respondents $(43 \%$ in oldest Cohort 1, 45\% in Cohort 2) than among younger respondents (41\% in Cohort 3, 35\% in youngest Cohort 4). Upward educational mobility reached a peak in previous decades, among individuals born between the 1950s and 1960s (Cohorts 1 and 2), before a sharp decline began among individuals born in the 1970s and 1980s. If these average trends continue at the same pace, students who are completing their education today will be less likely to be upwardly mobile than the youngest adult respondents in PIAAC. This means that less than a third of the members of current and future generations would be expected to attain an educational level higher than that of their parents. ${ }^{11}$

Declining upward educational mobility is observed in 21 countries (see Figure 2.14). These are countries where the percentage of upwardly mobile adults was higher among the oldest cohort than among the youngest cohort in the study. In 11 of these countries (Canada, Denmark, Estonia, Israel, Lithuania, New Zealand, Norway, Poland, the Slovak Republic, Sweden and the United States) the share of upwardly mobile adults shrank gradually with each new cohort. In seven other countries (Austria, Belgium, England, Finland, Japan, Slovenia and Russia), as on 
average for all PIAAC-participating countries, an increase in upward mobility between the first and the second cohorts was followed by a stronger decline among younger cohorts.

Figure 2.14 - Change in upward educational mobility across age cohorts Percentage of 26-65 year-olds who attained a higher level of education than their parents did, by cohort

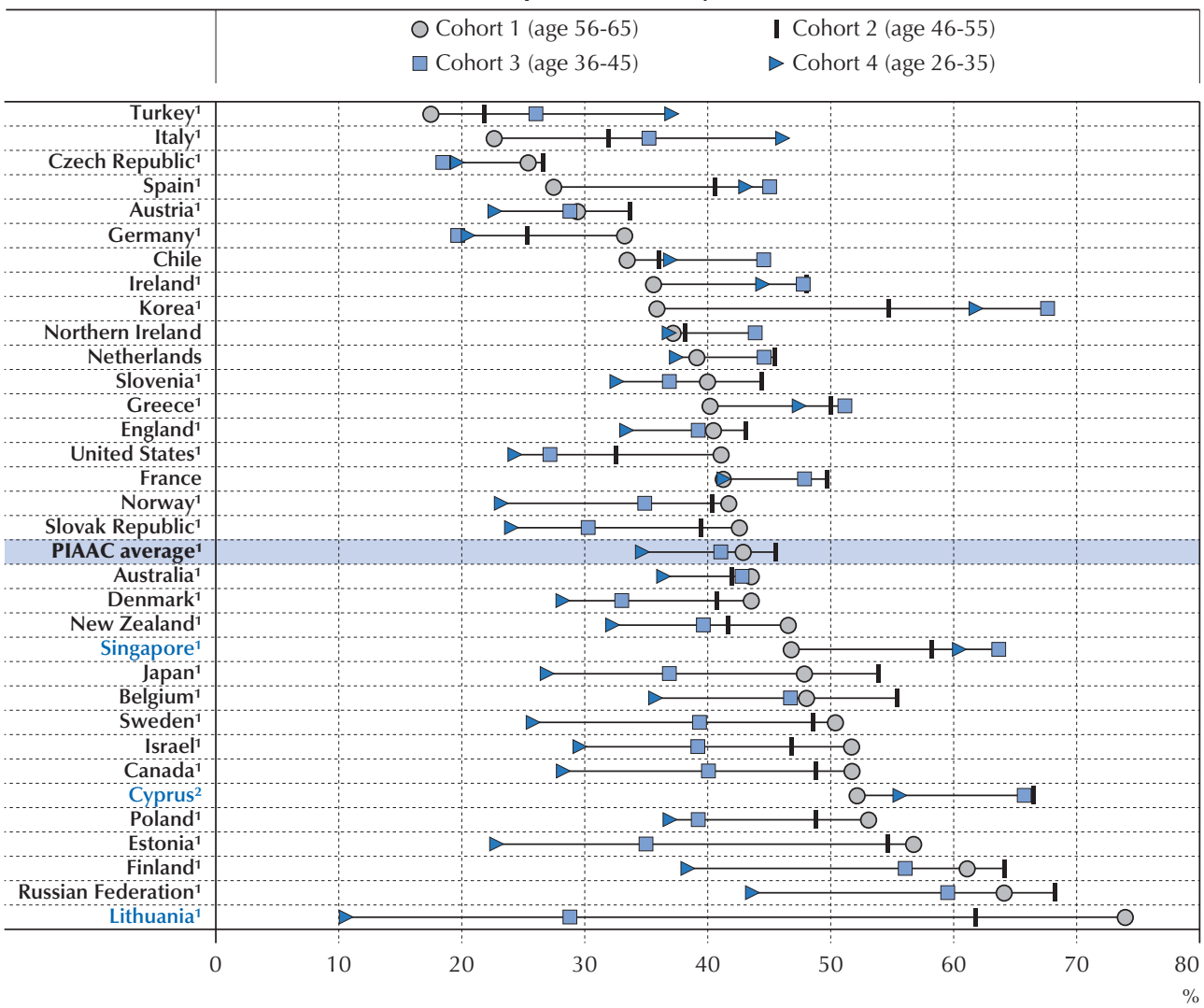

1. The difference between the oldest and youngest cohorts is statistically significant.

2. See notes at the beginning of this chapter.

Countries and economies are ranked in ascending order of the percentage of 56-65 year-olds (Cohort 1) who attained a higher level of education than their parents had.

Source: OECD, PIAAC dataset, Table 2.19.

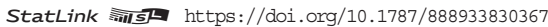

By contrast, in seven countries the share of upwardly mobile adults increased over time. In Italy, Singapore, Spain and Turkey, each successive cohort was generally more upwardly mobile than the preceding cohort. In Greece, Ireland and Korea, upward mobility increased over the first two or three cohorts then stabilised or declined slightly in the last cohort, but the trend for the period is positive. 
Why do trends in upward educational mobility vary over time and across countries? The key explanatory factor is the timing of educational expansion. As discussed above, upward mobility occurs when an adult attains an education level higher than that of her or his parents. In this analysis, tertiary education is the highest education level under consideration; thus, individuals with tertiary-educated parents cannot experience upward educational mobility. This is partly an artefact of the way education categories were defined in this analysis; but it also reflects the real organisation of the education system and the fact that even the best-performing students do not continue studying indefinitely. Therefore, as a result of what could be called a "ceiling effect", countries in which upper secondary and tertiary education expanded earlier would be expected to have smaller or declining rates of upward mobility. By contrast, countries with lower levels of educational attainment among older cohorts will have more room to upgrade their populations' education level.

Take, for example, the seven countries with a positive trend in upward mobility mentioned in the paragraph above. These are countries where the massification of upper secondary education occurred more recently. In Greece, Ireland, Italy, Korea, Spain and Turkey, more than one in two adults born between the mid-1940s and late 1950s (members of Cohort 1, the oldest under study) attained only less than upper secondary education; in Italy and Turkey as few as about one in four did (Table 2.14). By comparison, in Germany and the United States, two countries that led the way in providing schooling for the masses, only about $10 \%$ of adults born in the mid-1940s to late 1950s completed their education before entering upper secondary school.

Another source of cross-national variation in upward mobility trends during the past few decades is the timing of the expansion of tertiary education. In Korea and Singapore, two countries where upward mobility has increased over time, the growth over recent decades in the percentage of tertiary-educated adults was the largest among all countries participating in PIAAC. Among adults born between 1946 and 1959 (members of Cohort 1), 21\% in Singapore and 15\% in Korea completed tertiary education; among those born between 1976 and 1989 (members of Cohort 4), $74 \%$ in Singapore and 64\% in Korea completed that level of education. By contrast, on average across countries participating in PIAAC, the difference in the share of tertiary-educated adults between the youngest cohort (45\%) and the oldest cohort (26\%) was 19 percentage points, less than half of the increase in the share of tertiary-educated adults in the two Asian countries (see Table 2.14).

Similarly, in Greece, Italy, Korea, Singapore, Spain and Turkey, parents' education was very low among adults born between 1946 and 1959 (members of Cohort 1). More than three in four of these parents had completed less than upper secondary education; in Italy (92\%) and Turkey $(98 \%)$, more than nine in ten respondents had parents who had not completed upper secondary education (Table 2.16). This relative delay in securing access to and completing upper secondary education meant that a large part of the population in these countries was eligible to experience upward mobility in the following decades.

In countries where there is a decline in upward educational mobility, access to and attainment of upper secondary education expanded earlier. In Canada, Estonia, Germany, Israel, Lithuania, Poland, Russia and the United States, upper secondary schooling was nearly universal by the middle of the 20th century (i.e. at least $80 \%$ of respondents in these countries had completed 
upper secondary school or attained higher levels of education; see Table 2.14). Similarly, parents' educational attainment was higher in these countries, among the oldest cohort, than on average in PIAAC-participating countries (Table 2.16).

\section{Disparities in completing tertiary education related to parents' education}

Analyses of educational mobility across generations can capture how much educational attainment has changed between one generation and the next (also known as "absolute" mobility), but it cannot determine whether all socio-economic groups are affected in the same way (a.k.a. "relative" mobility). For example, socio-economically disadvantaged adults who are upwardly mobile compared with their parents might, or might not, attain similar levels of educational attainment as advantaged adults.

Research suggests that inequity in attainment might persist despite educational expansion because individuals who are more socio-economically advantaged progress through the levels of education faster than or as fast as individuals from disadvantaged groups, thus retaining their relative advantage (Raftery and Hout, 1993 ${ }_{[28]}$; Breen and Jonsson, 2000 ${ }_{[29]}$ ). In this hypothesis, disadvantaged groups could gain access only once advantaged groups reached a level of "saturation" (access for all of their group members).

Yet, some countries might be more efficient than others in promoting access for disadvantaged students (Breen et al., 2009 ${ }_{[10]}$ ). Furthermore, universal access is by definition a source of equity (and also of equality) in education opportunities. The universalisation of primary and secondary education is a reality in most OECD countries, but universal tertiary education is not. Also, "horizontal" disparities in the quality of education can persist in those levels of education that have become universal (Lucas, 2001 [30]; Marteleto et al., 2012 [31]; Gerber and Cheung, $\left.2008_{[32]}\right)$. Thus, compensating for the early effects of family background on students' academic performance and behaviours that influence attainment remains the fundamental equity challenge (Erikson et al., 2005 $\left.{ }_{[33]}\right)$.

In all 33 countries that participated in the Survey of Adult Skills (PIAAC), adults with moreeducated parents have considerably greater chances of completing tertiary education than adults with less-educated parents (Figure 2.15). On average across PIAAC-participating countries, adults with at least one tertiary-educated parent were 11 times more likely to complete tertiary education than adults whose parents had not completed upper secondary school.

Relative disparities in attaining tertiary education are even more pronounced, in ascending order of magnitude, in Singapore, Turkey, Italy, Poland, the Slovak Republic and the Czech Republic. In these countries, adults with tertiary-educated parents were between 18 and 34 times more likely to complete tertiary education than adults with low-educated parents. Disparities are smaller, but still statistically significant, in Canada, Estonia, Finland, New Zealand and Sweden, where the odds of completing tertiary education were between three and five times greater among adults with highly educated parents than among adults with low-educated parents.

Adults with at least one parent who had completed upper secondary education were also more likely to complete tertiary education than those from families where neither parent had completed upper secondary school. On average across PIAAC-participating countries, adults with at least 
one parent who had completed upper secondary education were three times more likely to complete tertiary education than adults with low-educated parents. In the Czech Republic, these adults were six times more likely to complete tertiary education; in Italy, they were seven times more likely, and in Turkey they were eight times more likely than adults with low-educated parents to complete tertiary education.

\section{Figure 2.15 - Likelihood of attaining tertiary education, by parents' education Increased likelihood of completing tertiary education among adults 26 years or older whose parents had attained a high or middle level of education, relative to adults with low-educated parents}

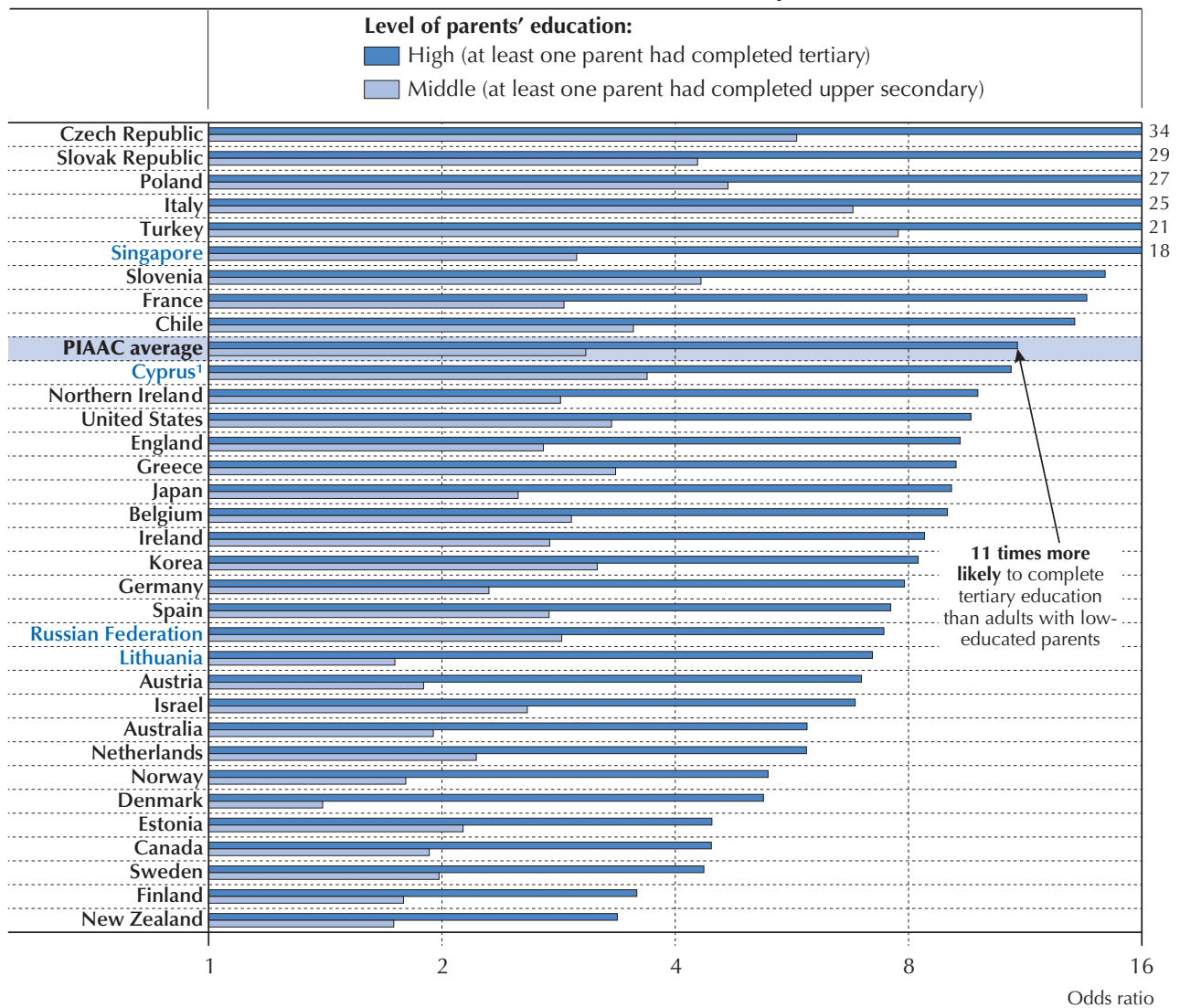

1. See notes at the beginning of this chapter.

Note: All odds ratios are statistically significant.

Countries and economies are ranked in descending order of the increased likelihood of completing tertiary education among adults whose parents are highly educated, relative to adults with low-educated parents (neither parent completed upper secondary education).

Source: OECD, PIAAC dataset, Table 2.24.

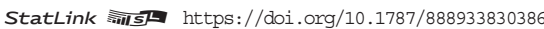


However, this does not mean that opportunities to attend and complete tertiary education did not improve over time for people from disadvantaged families. Education opportunities expanded for all socio-economic groups, on average across PIAAC-participating countries; but people with more-educated parents were more likely to seize those opportunities. To illustrate this point, Figure 2.16 presents the predicted probability of completing tertiary education among individuals with highly, middle- and low-educated parents among members of different age cohorts. $^{12}$

On average across PIAAC-participating countries, the probability of completing tertiary education among adults with highly educated parents evolved from about $61 \%$ among the oldest cohort to $69 \%$ among the youngest cohort (Figure 2.16). Among adults with low-educated parents, the probability of attaining tertiary education was $18 \%$ among members of the oldest cohort, and $24 \%$ among those in the youngest cohort (an increase of 6 percentage points).

Because gains were larger among those with highly educated parents, the gap in tertiary attainment between adults with highly educated parents and those with low-educated parents grew over time. In the oldest cohort, the gap was 43 percentage-points wide, while in the youngest cohort, the gap was 45 percentage-points wide. Even if this difference is not very large, it suggests inequity in tertiary attainment increased moderately (or remained stable) over time.

\section{Figure 2.16 - Trends in likelihood of completing tertiary education, by parents' education}

Predicted probability of completing tertiary education among adults 26 years or older, PIAAC average (33 countries)

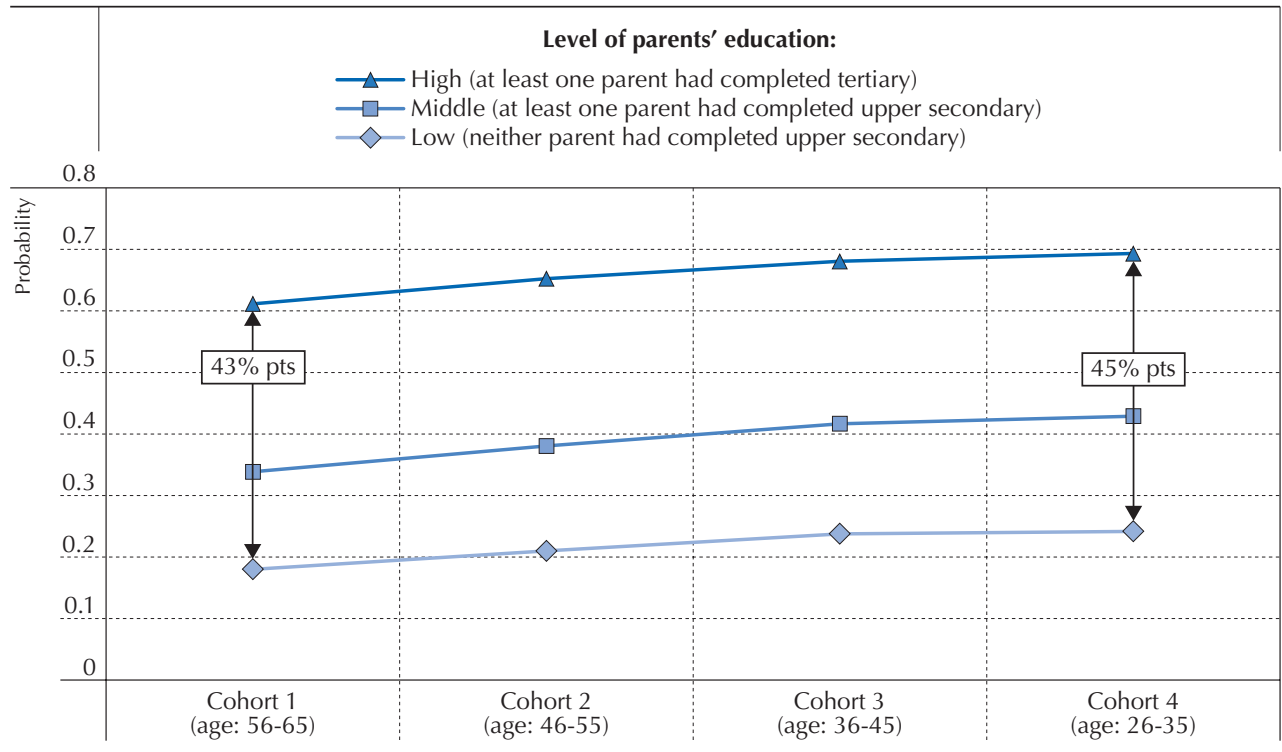

Note: Predicted probabilities are estimated based on a multivariate logistic regression with completing tertiary education as the outcome and parents' education and age-cohort as predictors.

Source: OECD, PIAAC dataset, Table 2.26.

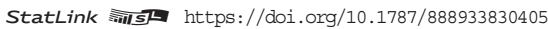


Adults whose parents had attained a middle level of education showed significant gains. Among adults with at least one parent who had completed upper secondary education, the predicted probability of completing tertiary education was 34\% among the oldest cohort, and $43 \%$ among the youngest cohort, an increase of 9 percentage points over time (Figure 2.16). This suggests that the disparity between adults with middle-educated parents and those with highly educated parents remained stable during the past few decades, while the disparity between those with middle-educated parents and those with low-educated parents widened, on average across PIAAC-participating countries.

Some countries deviate from these average trends, however. Inequity in attainment of tertiary education (predicted values) increased more markedly in Chile, the Czech Republic, Ireland, Italy, Poland, Slovenia, Spain and Turkey (Table 2.26). In these countries the gap between those respondents with highly educated parents and those with low-educated parents widened by six percentage points or more between the oldest and youngest cohorts.

The largest decline in equity was observed in the Czech Republic. The difference in the predicted probability of completing tertiary education between adults with highly educated parents and those with low-educated parents increased by 11 percentage points. As shown in Figure 2.17, this widening of the gap was mainly due to recent gains among young adults with highly educated parents, and also to the lack of gains among adults with low-educated parents over the period. In the Czech Republic, only $14 \%$ of older adults completed tertiary education, but almost $30 \%$ of younger adults did (Table 2.21). This expansion mostly involved those with highly educated parents who already had a much higher likelihood of completing tertiary education than the rest of the Czech population.

Italy and Chile provide two additional examples of how access to tertiary education can become more inequitable over time. In these countries inequity did not increase only among the youngest cohort, as in the Czech Republic, but started growing in older cohorts.

In Italy, the predicted probability of completing tertiary education improved over time among people of high and middle socio-economic status, and not as much among disadvantaged individuals (Figure 2.17). The average educational attainment in Italy is low by OECD standards: only $14 \%$ of Italian adults had earned a tertiary degree by the time of PIAAC data collection (Table 2.20). In previous decades, this share was even smaller: less than one in ten 56-65 year-olds in Italy completed tertiary education (Table 2.21). Younger Italians, those aged between 26 and 45 at the time of the survey, benefited from greater access to higher education.

In Chile, tertiary attainment rates improved with each successive cohort across all socio-economic groups, but the larger gains were observed among the middle and high socio-economic strata (Figure 2.17). Some 29\% of adults in Chile held a tertiary degree at the time of PIAAC data collection - a larger share than in Italy and the Czech Republic (Table 2.20). A recent OECD review of education in Chile identified strengthening equity in access to higher education as one the main challenges for education policy in that country (OECD, 2017 ${ }_{[34]}$ ). 


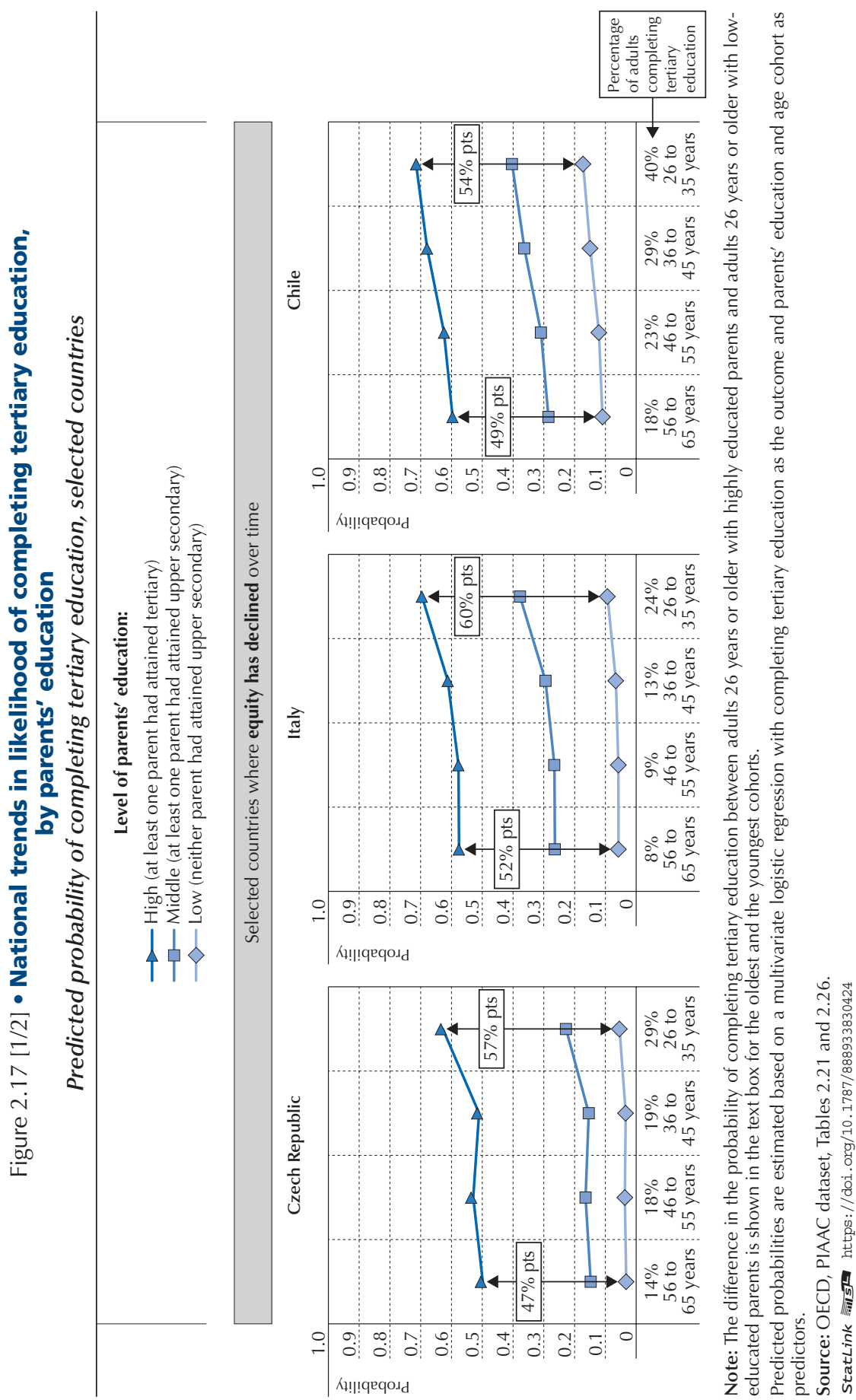




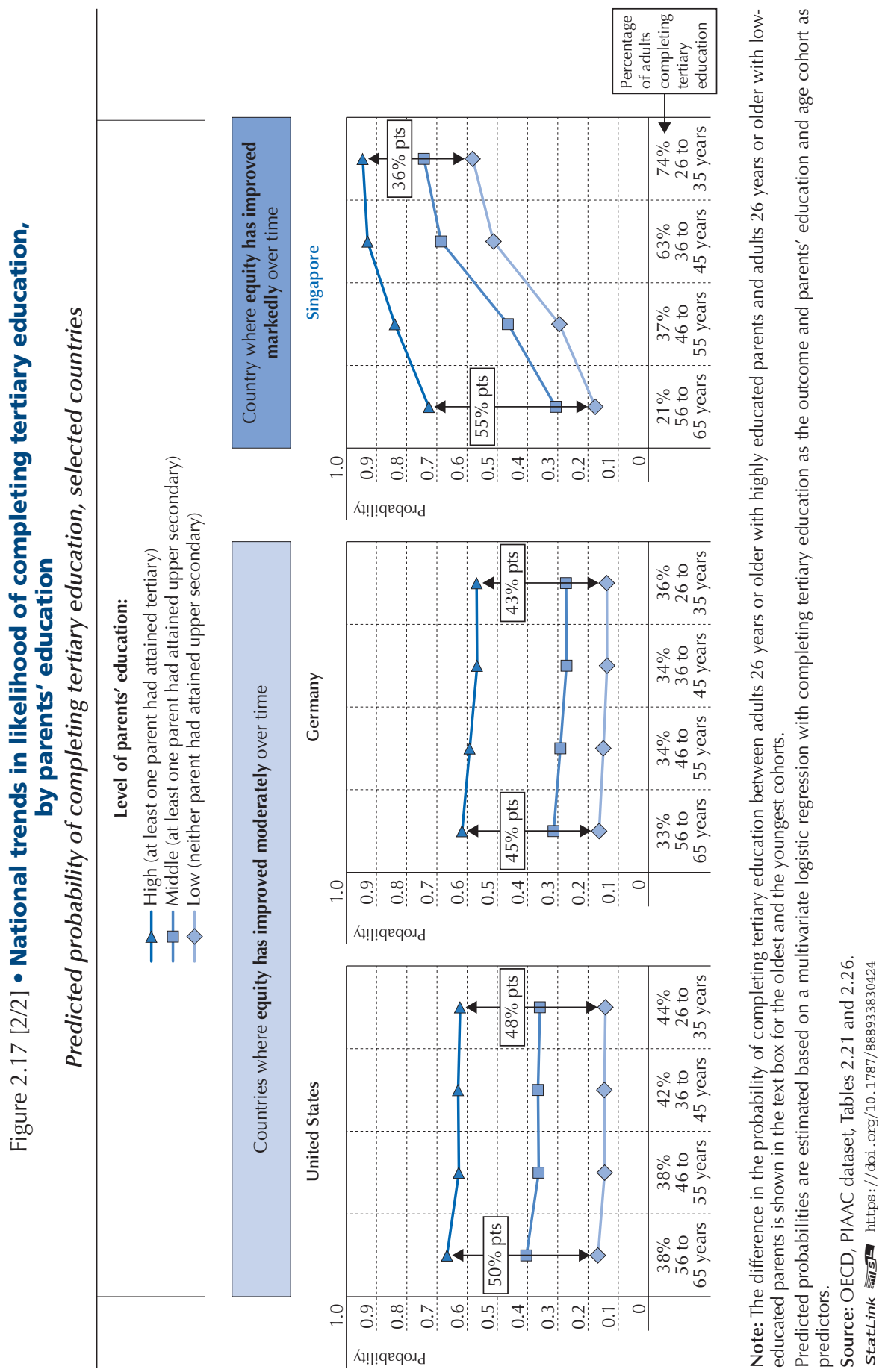


By contrast, Singapore is the only country where equity in the attainment of tertiary education improved markedly over time, as show in Figure 2.17. In Singapore, the difference in the likelihood of completing tertiary education related to parents' education narrowed by 19 percentage points between the oldest and youngest cohorts. What is unique about Singapore are the enormous strides made by adults with low-educated parents. In Singapore, even disadvantaged adults in the two youngest cohorts were more likely than not to complete tertiary education (i.e. among those with low-educated parents, the probability of completing tertiary education was $51 \%$ for adults aged 36-45 and 58\% for adults aged 26-35) (Figure 2.17). Arguably, this was possible because the stratum of socio-economically advantaged adults had already reached a "saturation" point in their access to tertiary education by the 1980 s, when $86 \%$ of adults with tertiary-educated parents also completed tertiary education (Table 2.23).

Germany and the United States also show some minor increases in equity in tertiary attainment. What is interesting about these cases is that the probability of completing tertiary education decreased for German and American adults regardless of their parents' level of education. Greater equity is achieved because the decrease in likelihood is slightly greater for adults with highly educated parents than for adults with low-educated parents.

Neither Germany nor the United States saw a great expansion in access to tertiary education in the four decades prior to the Survey of Adult Skills. In Germany, 34\% of respondents held a tertiary degree at the time of data collection (Table 2.20), and no difference in the share of the population with a tertiary degree is observed between the youngest and oldest cohorts (Table 2.21). In the United States, $40 \%$ of all respondents had completed tertiary education (Table 2.20), with a small increase between the older and younger respondents (Table 2.21). 


\section{Notes}

1. Reading was the main domain of assessment in PISA 2000 and PISA 2009. The analyses in Figure 2.4 consider, first, changes that occurred between PISA 2000 and PISA 2015, because the purpose of the analysis is to observe trends over the longest possible period of time. For particular countries that did not participate in PISA 2000, changes occurred between PISA 2009 and PISA 2015 are considered. Similarly, in Figure 2.5 changes between PISA 2003 (when mathematics was the main domain of assessment for the first time) and PISA 2015 are considered, and data for PISA 2012 is used only for countries that did not participate in PISA 2003.

2. PIAAC collects data for respondents aged 16 and older. For this analysis, the sample was limited to the first age group in 5-year intervals (25-29). This means that the PIAAC results reported in this analysis refer to a wider age group than TIMSS and PISA results, which use a sample of students of roughly similar age.

3. This methodological design is called a "pseudo-cohort" analysis. For a similar analytical approach, see Borgonovi et al. (2017 $[35])$.

4. TIMSS 1995 tested three separate populations. So-called "Population 1" included students enrolled in two adjacent grades that contained the largest proportion of 9-year-old students at the time of testing - third- and fourth-grade students (IEA, $1997_{[36]}$ ). In this analysis, the sample was restricted to students attending grade 4 of primary school, to capture more 10-year-old students. The average age of students in the sample for each country was the following (in years; standard errors in parenthesis): Australia: 10.25 (0.015); Austria: 10.46 (0.014); Canada: 10.02 (0.011); the Czech Republic: 10.42 (0.011); England: 10.04 (0.011); Greece: 9.61 (0.008); Ireland: 10.34 (0.016); Korea: 10.28 (0.009); the Netherlands: 10.26 (0.015); New Zealand: 9.98 (0.013); Norway 9.87 (0.008); the United States: 10.19 (0.011).

5. See PISA 2015 Technical Report (OECD, 2017 $\left.{ }_{[7]}\right)$ for more details about this index.

6. OECD partners included in the high-income group are the following: Hong Kong (China), Lithuania, Macao (China), Malta, Qatar, Singapore, Chinese Taipei, Trinidad and Tobago, the United Arab Emirates and Uruguay. OECD partners included in the upper-middle-income group are the following: Albania, Algeria, Brazil, Beijing-Shanghai-Jiangsu-Guangdong (China), Bulgaria, Ciudad Autónoma de Buenos Aires (Argentina), Colombia, Costa Rica, Croatia, the Dominican Republic, the Former Yugoslav Republic of Macedonia (FYROM), Lebanon, Montenegro, Peru, Romania, Russia and Thailand. OECD partners included in the lower-middle-income group are the following: Georgia, Indonesia, Jordan, Kosovo, Moldova, Tunisia and Viet Nam.

7. PIAAC collects data on individuals as young as 16 . However, the analysis in this chapter considers only individuals older than 25 at the moment of the survey to ensure that as many respondents as possible have reached their highest level of education. This is consistent with previous studies using a similar methodology (Pfeffer, 2008 $\left.{ }_{[9]}\right)$.

8. See notes at the beginning of this chapter.

9. See the note at the beginning of this chapter.

10. The first round of PIAAC data collection occurred between August 2011 and March 2012 in the following 25 countries: Australia, Austria, Belgium (Flanders), Canada, Cyprus, the Czech Republic, Denmark, England, Estonia, Finland, France, Germany, Ireland, Italy, Japan, Korea, the Netherlands, Northern Ireland, Norway, Poland, the Russian Federation, the Slovak Republic, Spain, Sweden and the United States. The second round of data collection occurred between August 2014 and January 2015 in the following eight countries: Chile, Greece, Israel, Lithuania, New Zealand, Singapore, Slovenia and Turkey.

11. This analysis is based on a measure of educational attainment that considers three response categories (with completing tertiary as highest education level). Results may have been different if different levels or 
kinds of tertiary education had been considered in the analysis, or if educational attainment was measured in terms of years of schooling.

12. Predicted values in Figure 2.16 are based on a regression model that estimates the likelihood of completing tertiary education by parents' education, after accounting for individuals' age cohort (Table 2.25). Having more highly educated parents increases the likelihood of completing tertiary education in all countries, even after accounting for age cohort (Table 2.25). Because predicted values are used only for illustration, the statistical significance of the difference in predicted values was not computed.

\section{References}

Bandura, A. (1997), Self-Efficacy: The Exercise of Control, W.H. Freeman.

Barro, R. and J. Lee (2013), "A new data set of educational attainment in the world, 1950-2010", Journal of Development Economics, Vol. 104, pp. 184-198, http://dx.doi.org/10.1016/J.JDEVECO.2012.10.001.

Baumeister, R. and M. Leary (1995), "The need to belong: Desire for interpersonal attachments as a fundamental human motivation.", Psychological Bulletin, Vol. 117/3, pp. 497-529, http://dx.doi.org/10.1037/0033-2909.117.3.497.

Bills, D. (2003), "Credentials, Signals, and Screens: Explaining the Relationship Between Schooling and Job Assignment", Review of Educational Research, Vol. 73/4, pp. 441-449, http://dx.doi.org/10.3102/00346543073004441.

Borgonovi, F. et al. (2017), "Youth in Transition: How Do Some of The Cohorts Participating in PISA Fare in PIAAC?", OECD Education Working Papers, No. 155, OECD Publishing, Paris, http://dx.doi.org/10.1787/51479ec2-en.

Breen, R. and J. Jonsson (2000), "Analyzing Educational Careers: A Multinomial Transition Model", American Sociological Review, Vol. 65/5, p. 754, http://dx.doi.org/10.2307/2657545.

Breen, R. et al. (2009), "Nonpersistent Inequality in Educational Attainment: Evidence from Eight European Countries", American Journal of Sociology, Vol. 114/5, pp. 1475-1521, http://dx.doi.org/10.1086/595951.

DiPrete, T. and G. Eirich (2006), "Cumulative Advantage as a Mechanism for Inequality: A Review of Theoretical and Empirical Developments", Annual Review of Sociology, Vol. 32/1, pp. 271-297, http://dx.doi.org/10.1146/annurev.soc.32.061604.123127.

Dorius, S. (2013), "The Rise and Fall of Worldwide Education Inequality from 1870 to 2010", Sociology of Education, Vol. 86/2, pp. 158-173, http://dx.doi.org/10.1177/0038040712456558.

Downey, D. and D. Condron (2016), "Fifty Years since the Coleman Report", Sociology of Education, Vol. 89/3, pp. 207-220, http://dx.doi.org/10.1177/0038040716651676.

Entwisle, D., K. Alexander and L. Olson (2005), "First Grade and Educational Attainment by Age 22:

A New Story", American Journal of Sociology, Vol. 110/5, pp. 1458-1502,

http://dx.doi.org/10.1086/428444.

Erikson, R. et al. (2005), "On class differentials in educational attainment.", Proceedings of the National Academy of Sciences of the United States of America, Vol. 102/27, pp. 9730-3, http://dx.doi.org/10.1073/pnas.0502433102. 
Ganzeboom, H. and D. Treiman (2003), "Three Internationally Standardised Measures for Comparative Research on Occupational Status", in Advances in Cross-National Comparison, Springer US, Boston, MA, http://dx.doi.org/10.1007/978-1-4419-9186-7_9.

Gerber, T. and S. Cheung (2008), "Horizontal Stratification in Postsecondary Education: Forms, Explanations, and Implications", Annual Review of Sociology, Vol. 34/1, pp. 299-318, http://dx.doi.org/10.1146/annurev.soc.34.040507.134604.

Goyette, K. (2008), "College for some to college for all: Social background, occupational expectations, and educational expectations over time", Social Science Research, Vol. 37/2, pp. 461-484, http://dx.doi.org/10.1016/I.SSRESEARCH.2008.02.002.

IEA (1997), Mathematics in the Primary School Years: IEA's Third International Mathematics and Science Report, International Association for the Evaluation of Educational Achievement, Boston, https://timssandpirls.bc.edu/timss1995i/MathA.html (accessed on 15 February 2018).

Lucas, S. (2001), "Effectively Maintained Inequality: Education Transitions, Track Mobility, and Social Background Effects", American Journal of Sociology, Vol. 106/6, pp. 1642-1690, http://dx.doi.org/10.1086/321300.

Marks, G. (2010), "Meritocracy, modernization and students' occupational expectations: Crossnational evidence", Research in Social Stratification and Mobility, Vol. 28/3, pp. 275-289, http://dx.doi.org/10.1016//.RSSM.2010.06.002.

Marteleto, L. et al. (2012), "Educational Inequalities among Latin American Adolescents: Continuities and Changes over the 1980s, 1990s and 2000s", Research in Social Stratification and Mobility, Vol. 30/3, pp. 352-375, http://dx.doi.org/10.1016/J.RSSM.2011.12.003.

Ma, X. (2003), "Sense of Belonging to School: Can Schools Make a Difference?", The Journal of Educational Research, Vol. 96/6, pp. 340-349, https://doi.org/10.1080/00220670309596617.

OECD (2017), Education in Chile, Reviews of National Policies for Education, OECD Publishing, Paris, http://dx.doi.org/10.1787/9789264284425-en.

OECD (2017), PISA 2015 Technical Report, OECD, Paris,

http://www.oecd.org/pisa/sitedocument/PISA-2015-technical-report-final.pdf (accessed on 02 August 2018).

OECD (2017), PISA 2015 Results (Volume III): Students' Well-Being, PISA, OECD Publishing, Paris, http://dx.doi.org/10.1787/9789264273856-en.

OECD (2016), Technical Report of the Survey of Adult Skills (PIAAC), OECD, Paris, http://www.oecd.org/skills/piaac/PIAAC Technical Report 2nd Edition Full Report.pdf (accessed on 16 January 2018).

OECD (2016), PISA 2015 Results (Volume I): Excellence and Equity in Education, PISA, OECD Publishing, Paris, http://dx.doi.org/10.1787/9789264266490-en.

OECD (2016), PISA 2015 Results (Volume II): Policies and Practices for Successful Schools, PISA, [15] OECD Publishing, Paris, http://dx.doi.org/10.1787/9789264267510-en.

OECD (2012), Equity and Quality in Education: Supporting Disadvantaged Students and Schools, [16] OECD Publishing, Paris, http://dx.doi.org/10.1787/9789264130852-en.

Pfeffer, F. (2008), "Persistent Inequality in Educational Attainment and its Institutional Context", European Sociological Review, Vol. 24/5, pp. 543-565, http://dx.doi.org/10.1093/esr/jen026. 
Pollard, E. and P. Lee (2003), "Child Well-being: A Systematic Review of the Literature", Social [17] Indicators Research, Vol. 61/1, pp. 59-78, http://dx.doi.org/10.1023/A:1021284215801.

Raftery, A. and M. Hout (1993), "Maximally Maintained Inequality: Expansion, Reform, and [28] Opportunity in Irish Education, 1921-75", Sociology of Education, Vol. 66/1, p. 41, http://dx.doi.org/10.2307/2112784.

Reynolds, J. et al. (2006), "Have Adolescents Become Too Ambitious? High School Seniors' Educational and Occupational Plans, 1976 to 2000", Social Problems, Vol. 53/2, pp. 186-206, http://dx.doi.org/10.1525/sp.2006.53.2.186.

Roemer, J. and A. Trannoy (2015), "Equality of Opportunity", Handbook of Income Distribution, Vol. 2, pp. 217-300, http://dx.doi.org/10.1016/B978-0-444-59428-0.00005-9.

Saha, L. and J. Sikora (2008), "The Career Aspirations and Expectations of School Students: From Individual to Global Effects", Education and Society, Vol. 26/2, pp. 5-22, http://dx.doi.org/10.7459/es/26.2.02.

Shavit, Y. and H. Blossfeld (1993), Persistent Inequality: Changing Educational Attainment in Thirteen Countries, Westview Press, Boulder, CO.

Willms, J. (2006), "Learning divides: ten policy questions about the performance and equity of schools and schooling systems", UIS working paper, No. 5, UNESCO, Montreal, http://unesdoc. unesco.org/Ulis/cgi-bin/ulis.pl?catno=147066\&set=0058C9F12B_0_84\&gp=1\&lin=1\&II=1 (accessed on 24 July 2018).

World Bank (2017), World Bank Country and Lending Groups, https://datahelpdesk.worldbank.org/ knowledgebase/articles/906519-world-bank-country-and-lending-groups (accessed on 08 February 2018). 


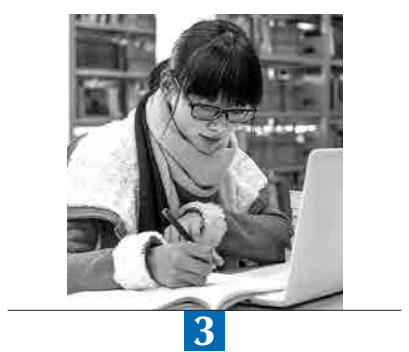

\title{
Academic and socio-emotional resilience among disadvantaged students
}

\begin{abstract}
This chapter examines resilience among socio-economically disadvantaged students. It focuses on two kinds of student resilience: academic and socioemotional. In the first part of the chapter, academic resilience is examined using international, national and "core-skills" perspectives. Student-, school- and system-level characteristics associated with academic resilience are considered. The second part of the chapter examines the incidence of social and emotional resilience across countries, and the relationship between academic and socio-emotional resilience.
\end{abstract}

\begin{abstract}
Notes regarding Cyprus
Note by Turkey: The information in this document with reference to "Cyprus" relates to the southern part of the Island. There is no single authority representing both Turkish and Greek Cypriot people on the Island. Turkey recognises the Turkish Republic of Northern Cyprus (TRNC). Until a lasting and equitable solution is found within the context of the United Nations, Turkey shall preserve its position concerning the "Cyprus issue".

Note by all the European Union Member States of the OECD and the European Union: The Republic of Cyprus is recognized by all members of the United Nations with the exception of Turkey. The information in this document relates to the area under the effective control of the Government of the Republic of Cyprus.
\end{abstract}

\section{A note regarding Israel}

The statistical data for Israel are supplied by and under the responsibility of the relevant Israeli authorities. The use of such data by the OECD is without prejudice to the status of the Golan Heights, East Jerusalem and Israeli settlements in the West Bank under the terms of international law.

\section{A note regarding Lithuania}

Lithuania was not an OECD member at the time of preparation of this publication. Accordingly, Lithuania is shown as a partner country and is not included in the OECD average.

This document, as well as any data and map included herein, are without prejudice to the status of or sovereignty over any territory, to the delimitation of international frontiers and boundaries and to the name of any territory, city or area. 


\section{What the data tell us}

- Some $11 \%$ of socio-economically disadvantaged students across OECD countries are "nationally resilient", meaning that they score in the top quarter of science performance in their own countries. National resilience is more prevalent in countries and economies with greater equity in student achievement. Algeria, Hong Kong (China), Iceland, Kosovo, Macao (China) and Montenegro have the largest shares of nationally resilient students; but top-performing countries and economies, like Singapore and BeijingShanghai-Jiangsu-Guangdong (China), have some of the lowest shares of nationally resilient students.

- On average across OECD countries, 25\% of disadvantaged students are "core-skills resilient", meaning that they score at proficiency Level 3 or above in science, reading and mathematics. This type of academic resilience is more frequently observed in countries with higher average performance. In Hong Kong (China) and Macao (China), more than half of students are core-skills resilient.

- The share of nationally and core-skills resilient students is greater in schools with a better disciplinary climate and among students with a stronger motivation to achieve and who had not skipped classes in the two weeks prior to the PISA test, on average across OECD countries.

- Some $26 \%$ of disadvantaged students and $33 \%$ of advantaged students are satisfied with their life, feel socially integrated at school and do not suffer from test anxiety, on average across OECD countries. Finland, the Netherlands and Switzerland have the largest shares of socially and emotionally resilient disadvantaged students.

- Nationally resilient students are 78\% more likely to be socially and emotionally resilient than disadvantaged students who are not nationally resilient, on average across OECD countries with available data. Core-skills resilient students are $66 \%$ more likely to be socially and emotionally resilient than disadvantaged students who are not core-skills resilient.

Student resilience - students' capacity to overcome barriers and adversities that typically hinder learning processes and outcomes - is a key issue for both equity in education and social mobility. In PISA, resilient students are socio-economically disadvantaged 15-year-olds who beat the odds against them and excel in school. Disadvantaged students who perform well at age 15 tend to continue into higher education and work in skilled jobs later on, as shown in Chapter 5 of this report. Thus, policies and practices that support disadvantaged and resilient students can not only help narrow socio-economic gaps in performance, but also enhance upward social mobility.

While all students face difficulties of one sort or another, socio-economically disadvantaged students tend to be exposed simultaneously to multiple factors that put their learning at risk $\left(\right.$ OECD, 2016 $\left.6_{[1]}\right)$. Disadvantaged students not only have parents with lower levels of education, working in lower-paid and less-prestigious jobs, they are also more likely to have an immigrant 
background, speak at home a language that is different from the one spoken at school, live in rural areas and in single-parent households, had repeated a grade and are enrolled in a vocational track - all of which are associated, in most countries, with lower academic performance. Socioeconomically disadvantaged students are also more likely to have poorer socio-emotional outcomes, such as not feeling that they belong at school, and lacking confidence when they face challenging evaluations and tasks (OECD, 2017 ${ }_{[2]}$ ).

This chapter is based on two innovations in analysing resilience. First, the chapter considers student resilience not only in terms of academic performance, as in previous PISA reports, but also in terms of social and emotional outcomes. This is consistent with the notion that students' psychological and social well-being is an important education outcome in itself.

Second, the chapter distinguishes between different types of academic resilience to capture the notion that resilience goes beyond international excellence in a single subject. Resilience is considered using a national perspective, by comparing disadvantaged students with the best-performing students in their own countries, and also using a core-skills perspective, by considering the achievement of good levels of performance in three cognitive domains.

Findings in this chapter show that top-performing countries have larger shares of disadvantaged students who perform at Level 3 or above in reading, mathematics and science (meaning that they are "core-skills resilient"); but it is countries with greater equity in education that have more disadvantaged students who perform as well as the top performers in their own countries (meaning they are "nationally resilient").

The chapter also shows that students' attitudes and behaviours towards school, as well as the schools they attend, make a difference in their chances of being academically resilient. For example, disadvantaged students who do not skip school and who attend schools with a better disciplinary climate are more likely to be resilient. The chapter also shows that disadvantaged students who are socially and emotionally resilient also tend to do better academically - meaning that helping disadvantaged students develop positive attitudes and behaviours towards themselves and their education can also benefit these students' academic development.

\section{ACADEMIC RESILIENCE}

Academic resilience, as defined in PISA, is the capacity of socio-economically disadvantaged students to achieve higher levels of performance than would be predicted by their family background. In PISA 2015, on average across OECD countries, the mean science score of disadvantaged students was 452 points, 41 points lower than the mean score of all students, and 88 points lower than the mean score of advantaged students (Table 3.1). Although these are large differences, many disadvantaged students perform better than what these average numbers would lead one to expect. How much better? And who are these resilient students? Where do they study? And how do they manage to overcome the odds against them?

\section{Academic resilience in PISA}

In previous PISA reports, academic resilience was usually studied from an international perspective. The level of performance above which socio-economically disadvantaged students 
are considered resilient is the top quarter of performance across all countries and economies participating in PISA, after accounting for students' socio-economic status. ${ }^{1}$ Defining resilience in this way has the virtue of capturing disadvantaged students' capacity to achieve academic excellence against the most competitive international standards.

But academic resilience among socio-economically disadvantaged students goes beyond international excellence. In this chapter, academic resilience among 15-year-olds is examined using two additional perspectives, as summarised in Figure 3.1. These perspectives capture different types or dimensions of academic resilience.

\section{Figure 3.1 - Types of academic resilience in PISA}

\begin{tabular}{|c|c|c|c|}
\hline $\begin{array}{l}\text { Types of } \\
\text { academic } \\
\text { resilience }\end{array}$ & $\begin{array}{l}\text { What are these } \\
\text { students able } \\
\text { to achieve? }\end{array}$ & & How do we measure it? \\
\hline International & $\begin{array}{l}\text { Academic excellence } \\
\text { by international } \\
\text { standards }\end{array}$ & \multirow{3}{*}{$\begin{array}{c}\text { Socio-economically } \\
\text { disadvantaged } \\
\text { students in their } \\
\text { own countries } \\
\text { who score... }\end{array}$} & $\begin{array}{l}\text {...in the top quarter of performance in science } \\
\text { among all students participating in PISA, } \\
\text { after accounting for socio-economic background }\end{array}$ \\
\hline National & $\begin{array}{l}\text { Academic excellence } \\
\text { by national standards }\end{array}$ & & $\begin{array}{l}\text {...in the top quarter of performance in science } \\
\text { among students in their own country }\end{array}$ \\
\hline Core-skills & $\begin{array}{l}\text { Core knowledge } \\
\text { and skills in key } \\
\text { cognitive domains }\end{array}$ & & $\begin{array}{c}\text {...at or above Level } 3 \text { in PISA } \\
\text { in science, reading and mathematics }\end{array}$ \\
\hline
\end{tabular}

Note: Socio-economically disadvantaged students are students in the bottom quarter of the PISA index of economic, social and cultural status (ESCS) in their own country.

An important dimension of academic resilience that is not captured by international comparisons is students' capacity to achieve excellence by national standards. Disadvantaged students who score in the top quarter of their own country in science are considered to be "nationally resilient". Achieving academic excellence by national standards is a positive outcome and a major indication of student resilience in itself, because in every PISA-participating country and economy, disadvantaged students perform significantly worse than students in the top quarter of performance nationally. As shown in Figure 3.2, in every country and economy participating in PISA 2015, the average difference in science performance between disadvantaged students and top-performing students in the country/economy is more than 100 points (except Algeria, where the difference is 97 points); in 43 countries and economies, the average difference is larger than 150 points. 
Figure 3.2 - Socio-economic disadvantage and science performance Mean science score among socio-economically disadvantaged students and national top-performers

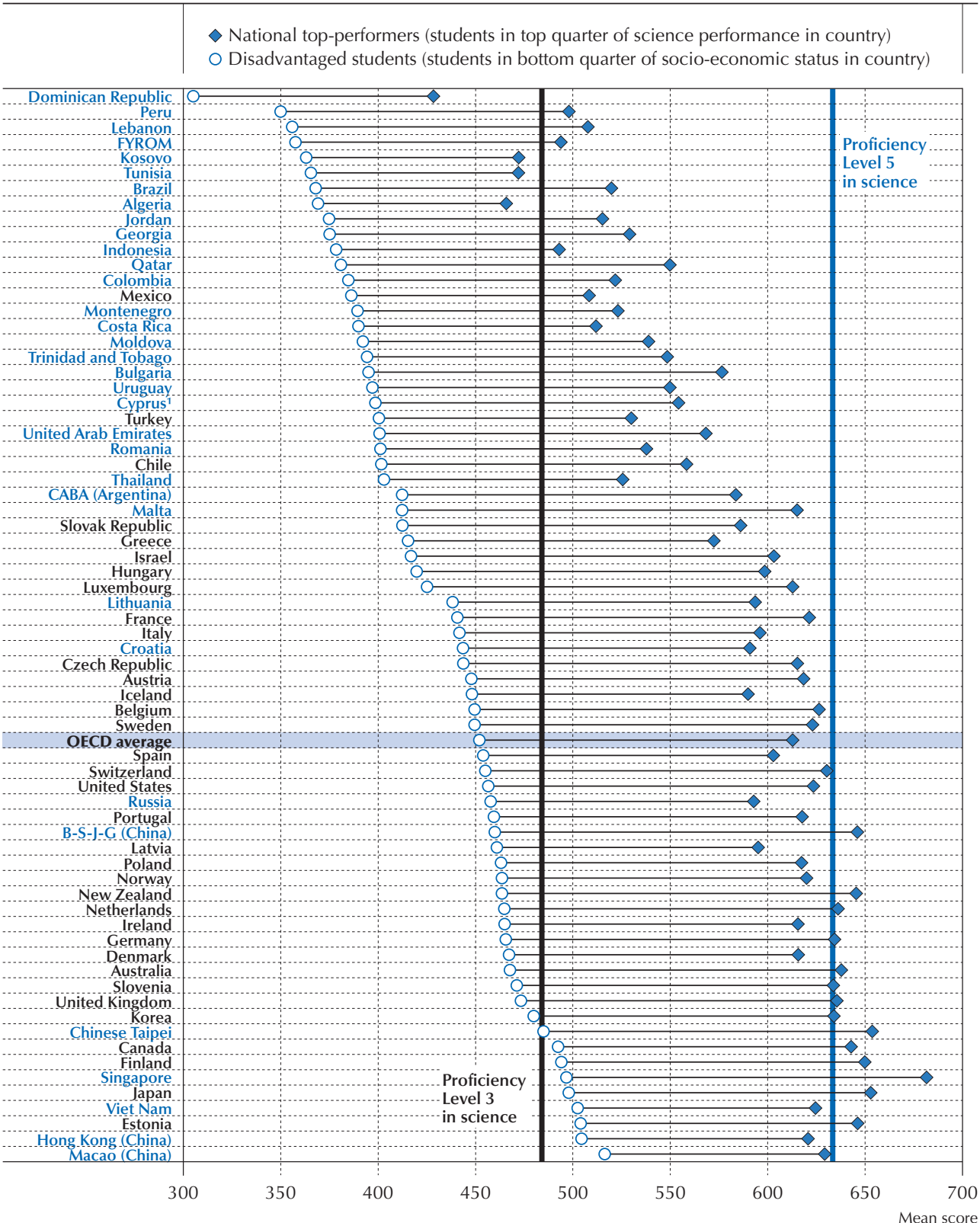

1. See notes at the beginning of this chapter.

Countries and economies are ranked in ascending order of the mean science score of disadvantaged students.

Source: OECD, PISA 2015 Database, Table 3.1.

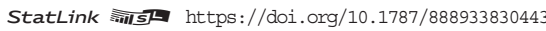


Performing among the top quarter of students in one's own country is not only very difficult for disadvantaged students, it is also an accomplishment that can have a significant positive impact on future success in education and work. As shown in the longitudinal analyses presented in Chapter 5, 15-year-old students who perform as well as their best-performing peers in their own countries are more likely to continue into higher education and obtain better-paid and more prestigious jobs. For disadvantaged students, this means upwards educational and social mobility.

The measure of national resilience is, however, blind to international differences in student performance. For this reason, in countries with higher average performance the threshold or cut-off score for a student to be considered nationally resilient is higher than in countries with lower average performance. In low-performing countries, national resilience can be the first objective for a student to achieve before aiming at international resilience.

The third important perspective on academic resilience considered in this chapter is called "core-skills". The notion of "core-skills resilience" describes the extent to which disadvantaged students achieve certain levels of proficiency in not only one but all three core cognitive domains that PISA assesses. These are the skills students need to participate fully in society (Agasisti et al., $\left.2018_{[3]}\right)$. Socio-economically disadvantaged students who score at Level 3 or above in reading, mathematics and science are considered to be core-skills resilient.

Students at proficiency Level 3 in reading begin to demonstrate the ability to construct the meaning of a text and form a detailed understanding from multiple independent pieces of information. They can work with proportional relationships and engage in basic interpretation and reasoning when solving mathematics problems; and they can handle unfamiliar topics in science. This set of skills goes beyond "baseline" levels of proficiency (Level 2). Level 3 is also, on average across OECD countries, the median proficiency of students in each PISA cognitive domain. Thus core-skills resilient students are in the top 50\% of students participating in PISA.

Note that the core-skills perspective is an "absolute" measure of student resilience, whereas the national perspective is a "relative" measure. The threshold used in the core-skills definition is absolute in the sense that disadvantaged students need to perform at a certain given threshold that is the same for all students. The cut-off point to reach proficiency Level 3 in each subject (484 points in the science assessment, 480 points in the reading assessment and 482 points in the mathematics assessment) does not vary across countries. This provides an identical international standard against which all participating students are evaluated. The national definition uses a relative threshold because the performance level is assessed with reference to the student's own country, and not to the entire pool of students participating in PISA. As a result, nationally resilient students earn higher scores, on average, in high-performing countries than in low-performing countries.

Combining these three perspectives means understanding academic resilience as a dynamic capacity that students can develop and strengthen over time as they progress through their education and, at each point on the way, can consolidate and expand their knowledge and skills. Not even the most gifted students start their education having the advanced skills typically observed among PISA's top-performing students, such as being able to use scientific knowledge as evidence to develop arguments and make life decisions, understand fully and in detail complex texts on unfamiliar topics, or use advanced mathematical thinking and reasoning. 
Instead, students' learning is a process that builds upon previous layers of proficiency, acquired over time, as a result of the education completed in earlier grades.

In all three perspectives on academic resilience considered in this chapter, as in the index of social and emotional resilience examined below, socio-economic disadvantage is defined from a national perspective: disadvantaged students are defined as those in the bottom quarter of the PISA index of economic, social and cultural status (hereafter, ESCS) in the student's own country. In theory, socio-economic disadvantage could also be defined from an international perspective, for example by considering as disadvantaged the students in the bottom quarter of ESCS among all PISA-participating countries. This was not the approach taken in this chapter because a national perspective on socio-economic disadvantage may be more informative for targeted policies aiming to achieve equity within one country or economy than an international or absolute perspective.

Two technical reasons also explain this choice. First, the aim of the analysis is to provide relevant information on student resilience in as many PISA-participating countries and economies as possible. However, wealthier OECD and partner countries have relatively few students in the bottom quarter of international ESCS, thus the analysis would have little relevance for them (Table 3.13). ${ }^{2}$ Second, because of the small sample size in many OECD and partner countries, the statistical power of the estimations in these countries would be diminished. This is not to say that analyses of student resilience using an international definition of socio-economic disadvantage would not be important or possible in countries with larger numbers of students who are considered to be disadvantaged from an international perspective. On the contrary, it is an issue on which future analyses of PISA data might want to focus.

\section{Academic resilience across countries}

Socio-economically disadvantaged students can be resilient in one, two or all three of the ways academic resilience is considered in this chapter, or not at all. On average across OECD countries in 2015, 10\% of disadvantaged students are simultaneously internationally, core-skills and nationally resilient, $13 \%$ are resilient in two ways, and $9 \%$ in only one way. However, about two in three $(68 \%)$ disadvantaged students are not academically resilient in any of the three ways considered here, on average across OECD countries (Table 3.2).

Figure 3.3 shows the percentage of disadvantaged students, across the countries and economies that participated in PISA 2015, who show each of the three types of academic resilience.

The type of academic resilience that varies the most between countries and economies is international resilience. On average across OECD countries, 29\% of disadvantaged students are internationally resilient. Top-performing countries and economies, such as Beijing-ShanghaiJiangsu-Guangdong (China) (hereafter "B-S-J-G [China]"), Estonia, Finland, Hong Kong (China), Japan, Korea, Macao (China), Singapore, Chinese Taipei and Viet Nam have the largest proportions (about $40 \%$ or more, and as much as $76 \%$ in Viet Nam) of internationally resilient students. By contrast, the Dominican Republic, the Former Yugoslav Republic of Macedonia (hereafter "FYROM"), Kosovo, Peru and Tunisia have the smallest proportions (less than 5\%) of disadvantaged students who are internationally resilient. 
Figure 3.3 - International, national and core-skills resilient students in PISA 2015 Percentage of socio-economically disadvantaged students who are academically resilient

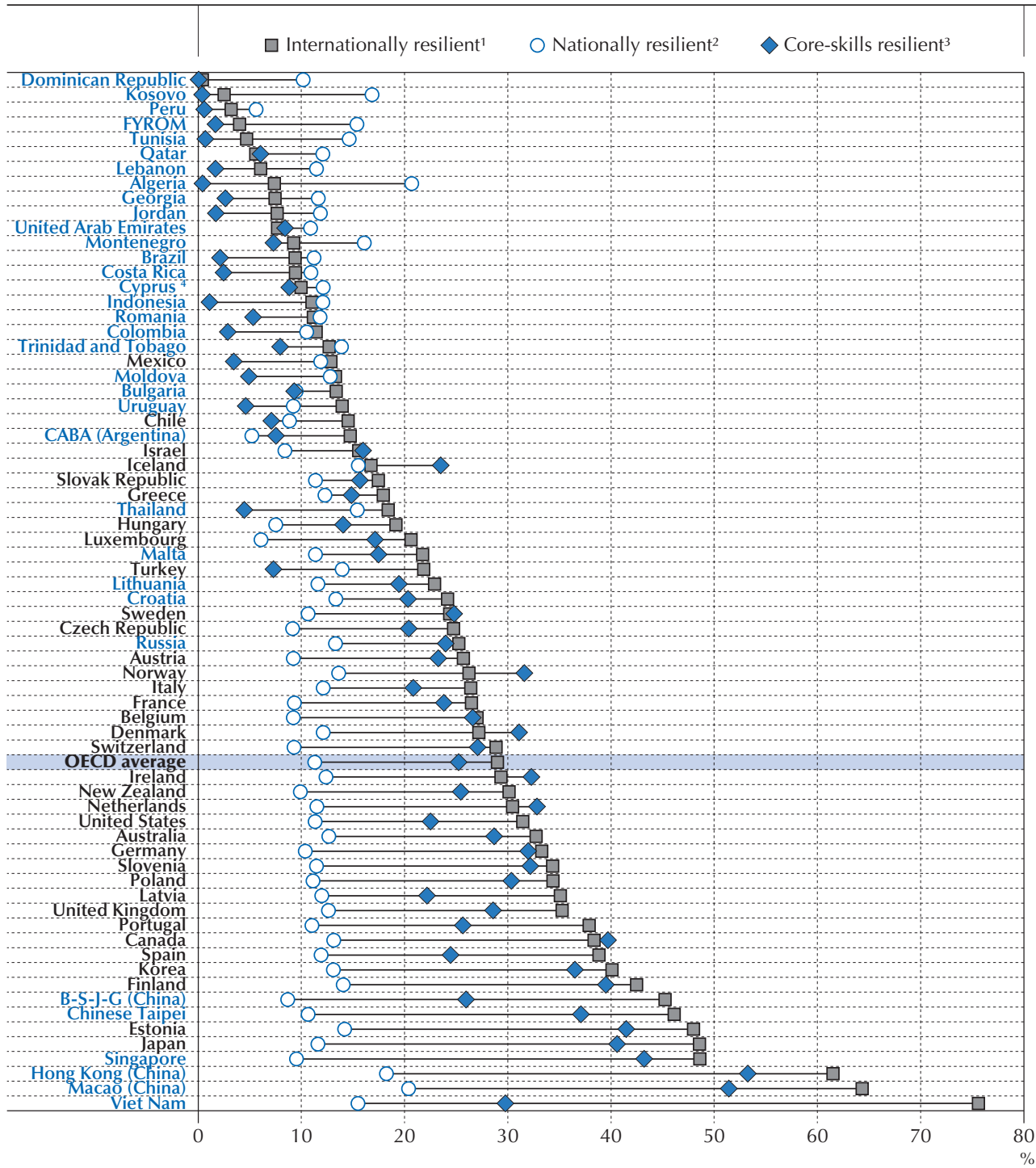

1. Internationally resilient students are disadvantaged students who score in the top quarter of performance in science among all students participating in PISA, after accounting for socio-economic status.

2. Nationally resilient students are disadvantaged students who score in the top quarter of performance in science among students in their own country.

3. Core-skills resilient students are disadvantaged students who score at or above Level 3 in PISA in science, reading and mathematics.

4. See notes at the beginning of this chapter.

Countries and economies are ranked in ascending order of the percentage of students who are internationally resilient.

Source: OECD, PISA 2015 Database, Tables 3.3, 3.5 and 3.7.

StatLink 需s https://doi.org/10.1787/888933830462 
The distribution of core-skills resilience closely resembles that of international resilience (the country-level correlation coefficient between the two is 0.9). On average across OECD countries, $25 \%$ of disadvantaged students reach at least Level 3 in science, reading and mathematics. Canada, Estonia, Finland, Hong Kong (China), Japan, Macao (China) and Singapore, all of them top-performing education systems in PISA, have the largest shares of core-skills resilient students (about $40 \%$ or more, and as much as $53 \%$ in Hong Kong [China]). Algeria, the Dominican Republic, FYROM, Indonesia, Jordan, Kosovo, Lebanon, Peru and Tunisia have the smallest proportion of students (less than $2 \%$ ) who reach Level 3 in all core subjects.

Core-skills resilient students, and also internationally resilient students, are found more frequently in better-performing education systems. As shown in Figure 3.4, the share of core-skills resilient students is strongly related to the education system's average science performance $\left(R^{2}=0.86\right)$. The share of internationally resilient students is also related to the level of performance in science $\left(R^{2}=0.76\right)$.

Figure 3.4 - Science performance and core-skills resilience

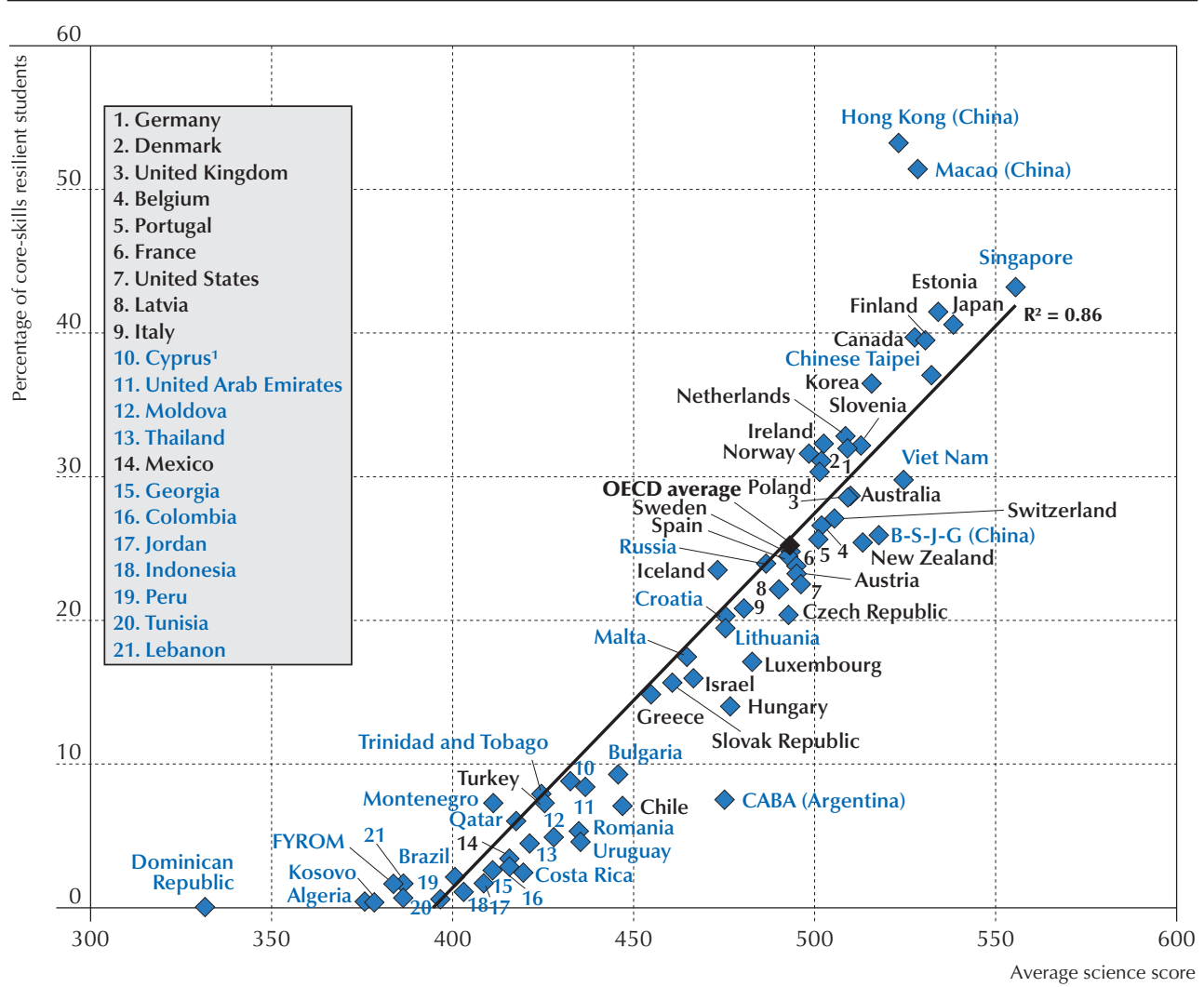

1. See notes at the beginning of this chapter.

Notes: The $\mathrm{R}^{2}$ value indicates the proportion of the variance in core-skills resilience that is accounted for by differences in average science scores between education systems. It is a measure of the strength of the relationship between core-skills resilience and average performance at the country level.

Core-skills resilient students are disadvantaged students who score at or above Level 3 in PISA in science, reading and mathematics. Source: OECD, PISA 2015 Database, Tables 3.1 and 3.5.

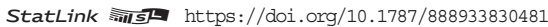


The incidence of national resilience varies much less across countries than the other two kinds of academic resilience. Between $10 \%$ and $20 \%$ of disadvantaged students in nearly all countries and economies that participated in PISA 2015 are nationally resilient. On average across OECD countries, only $11 \%$ of disadvantaged students perform as well as the best-performing students in their own country. In Algeria and Macao (China), some $20 \%$ of disadvantaged students are nationally resilient; in FYROM, Hong Kong (China), Iceland, Kosovo, Montenegro, Thailand and Viet Nam, more than $15 \%$ are. The countries and economies with the smallest shares of nationally resilient students are, in ascending order of magnitude, Ciudad Autónoma de Buenos Aires (Argentina) (hereafter "CABA [Argentina]") (5\%), Peru, Luxembourg, Hungary, Israel, B-S-J-G (China) and Chile (9\%).

What is interesting about national resilience is that, unlike core-skills and international resilience, national resilience is not more frequently observed in top-performing countries than in developing or low-performing countries. The share of nationally resilient students is unrelated to average science performance $\left(R^{2}=0.01\right)$. This is to say that, on average, top-performing countries are not better than low-performing countries in helping their socio-economically disadvantaged students perform as well as their top-performing students.

For example, disadvantaged students in Canada, Japan and Singapore earn higher scores than disadvantaged students in Kosovo, Thailand and Tunisia; but the efforts by the former top-performing countries have not resulted in better outcomes than in the latter low-performing countries in terms of their disadvantaged students performing as well as their top-performing students.

National resilience is instead explained by a different factor: the level of equity in student achievement, as measured by the strength of the socio-economic gradient (see Box 2.1). Figure 3.5 shows that about $75 \%$ of the variation in national resilience between countries and economies can be accounted for by cross-national differences in equity in science performance. Equity accounts for less than $1 \%$ of differences across countries in core-skills resilience and in international resilience. In other words, in countries that find ways to make student performance less dependent on students' socio-economic status, and more on students' own efforts and talents, there are more disadvantaged students who perform as well as their highest-achieving peers in their own country.

These findings underscore the importance of using different perspectives when thinking of policies to promote student resilience. Focusing exclusively on international resilience arguably overestimates the amount of academic resilience in some countries, while it underestimates it in some others. The reason why top-performing countries and economies have much larger shares of core-skills resilient students than low-performing countries is also implicit in Figure 3.2. Socio-economically disadvantaged students perform at higher levels in some countries than in others. However, it would be misleading to simply interpret this finding as meaning that the capacity of disadvantaged students to overcome the barriers and adversities of their background is greater in top-performing than in low-performing countries. In fact, disadvantaged students in top-performing countries are not more likely to perform among the high achievers in their own country (meaning, to be nationally resilient) than are disadvantaged students in low-performing countries.

Policies that focus solely on improving the performance of all students have the potential to improve both advantaged and disadvantaged students' capacity to acquire core skills and excel 
by international standards. But targeted policies that help close the socio-economic gap might be more effective in promoting greater levels of national resilience, and thus potentially greater upward educational and social mobility among disadvantaged students. Thus, both perspectives are important for a nuanced view of the kinds of academic achievements disadvantaged students can accomplish. These perspectives complement, rather than conflict with, each other because many students who achieve excellence by national standards may also be able to achieve excellence in all the core skills by international standards, displaying both international and national resilience at the same time.

Figure 3.5 - Equity in science achievement and national resilience

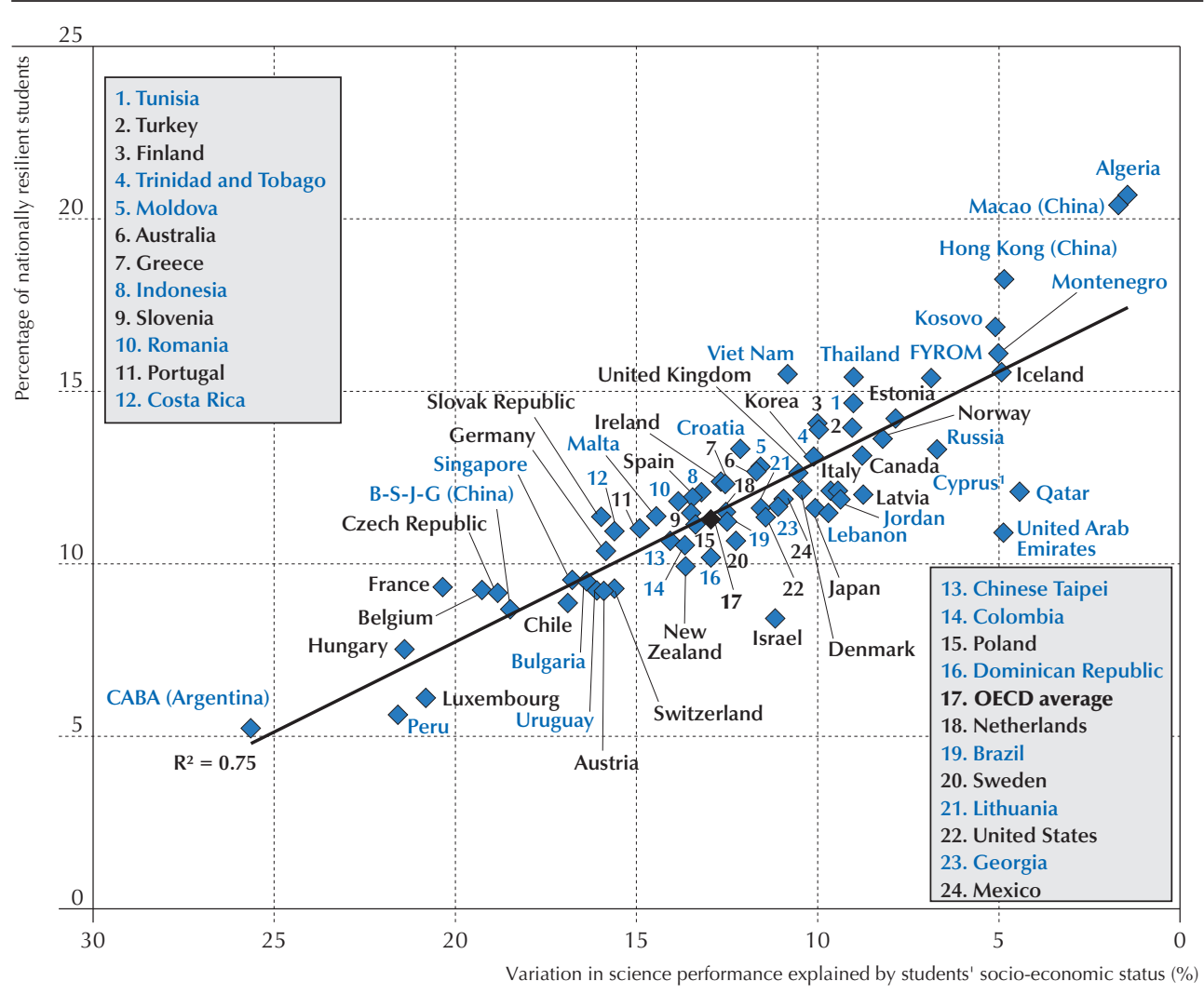

Greater equity

1. See notes at the beginning of this chapter.

Note: The $\mathrm{R}^{2}$ value indicates the proportion of the variance in national resilience that is accounted for by differences in equity in science performance across education systems. It is a measure of the strength of the relationship between national resilience and equity in performance at the country level.

Nationally resilient students are disadvantaged students who score in the top quarter of performance in science among students in their own country.

Source: OECD, PISA 2015 Database, Tables 3.1 and 3.3.

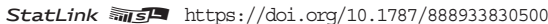


Figure 3.6 groups countries and economies into four categories according to the share of disadvantaged students who are nationally resilient and core-skills resilient. Countries that have large shares of nationally resilient students but low shares of core-skills resilient students, such as Algeria, FYROM, Kosovo, Montenegro and Thailand, are located in the upper-left corner. In these countries, it is important to improve all students' proficiency without widening the gap between disadvantaged and advantaged students. Among countries and economies with a small share of nationally resilient students but a large share of core-skills resilient students, such as Belgium, Germany, Singapore and Chinese Taipei (the opposite quadrant), policies that aim to improve performance among disadvantaged students, while maintaining other students' high scores, would be most suitable. In countries and economies located in the lower-left quadrant, in which both national and core-skills resilience is below the OECD average, improvements in both overall performance and equity are necessary. Countries in this group include CABA (Argentina), Chile, the Czech Republic, Israel, Luxembourg and Peru, among others.

\section{Student and school characteristics related to academic resilience}

On average across OECD countries, academically resilient students are more frequently found in schools that have relatively more advantaged socio-economic profiles and better disciplinary climates. These students display positive behaviours and attitudes towards learning, such as not skipping classes and being highly motivated to earn good grades and succeed in school. They have followed education careers that are typical of students in their own country: they started attending pre-primary education at the national modal age, they had not repeated a grade and they are enrolled in academic programmes. These students also tend to be boys without an immigrant background who live in cities.

These student and school characteristics are related to both types of academic resilience, but some of them are more important for national resilience and others are more important for coreskills resilience. ${ }^{3}$

Figure 3.7 shows differences in the share of nationally resilient students by student and school characteristics. The two school-level variables most frequently associated with national resilience are the school socio-economic profile and the disciplinary climate in school. On average across OECD countries, the share of nationally resilient students is 22 percentage points greater among disadvantaged students who attend an advantaged school (29\%) than among disadvantaged students who attend a disadvantaged school (7\%).

There are several reasons why attending an advantaged school makes such a considerable difference in the performance of disadvantaged students. Advantaged schools tend to concentrate not only a larger proportion of students with more educated and wealthier parents, who tend to be more involved in school and put more pressure on schools to improve their academic achievement, they also have better human and material resources (e.g. qualified teachers, instructional equipment, such as computers or science laboratories) and climates more conducive to learning (OECD, 2013 $[4]$; OECD, 2018 $\left.8_{[5]}\right)$. Some of these dimensions may be not accurately measured by PISA, and others are much more difficult to measure (such as the pedagogical methods used, the quality of the teaching team, etc.). A closer examination of how a school's socio-economic profile is related to equity is provided in Chapter 4. 


\section{Figure 3.6 - National resilience and core-skills resilience}

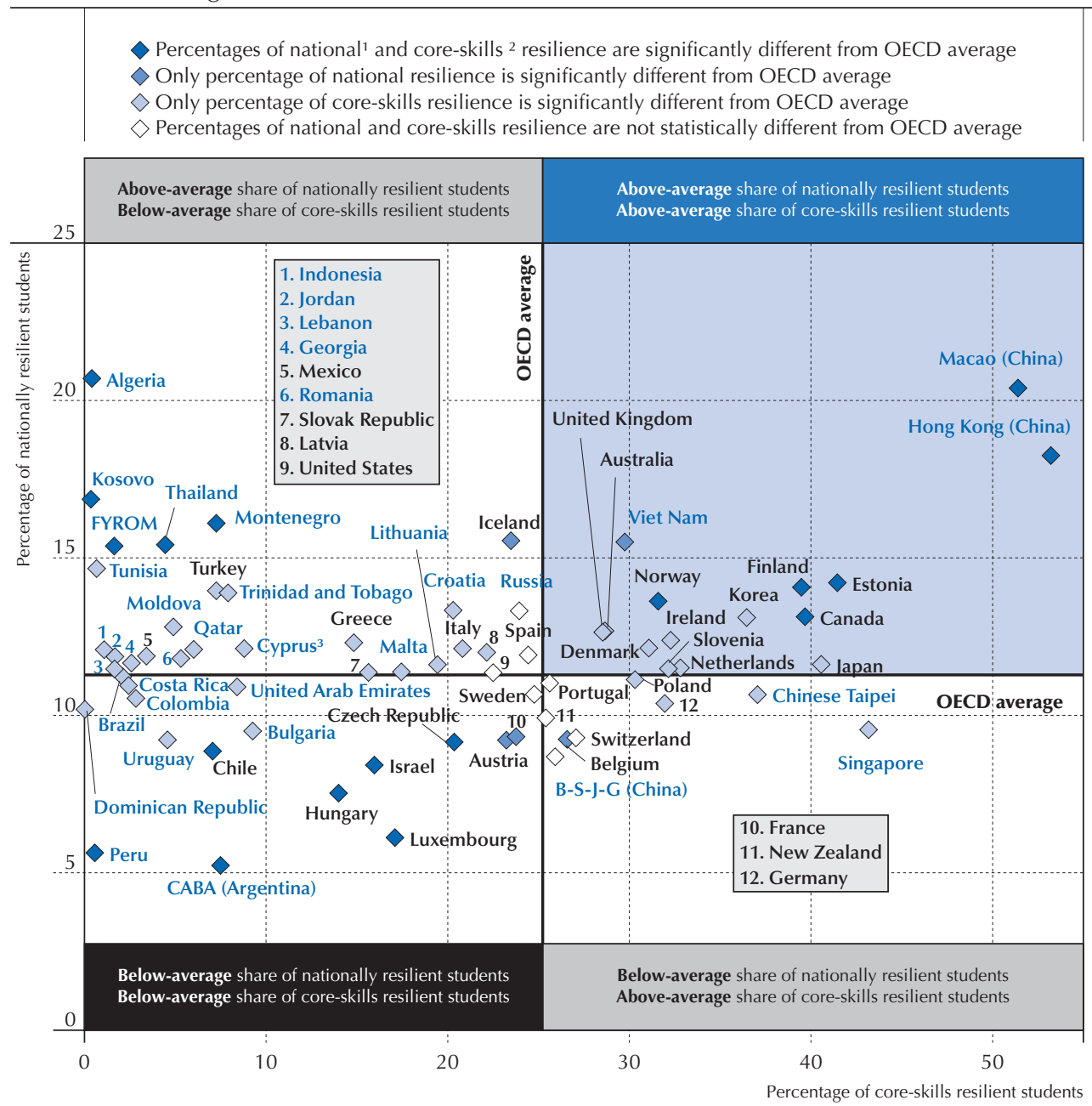

1. Nationally resilient students are disadvantaged students who score in the top quarter of performance in science among students in their own country.

2. Core-skills resilient students are disadvantaged students who score at or above Level 3 in PISA in science, reading and mathematics.

3. See notes at the beginning of this chapter.

Source: OECD, PISA 2015 Database, Tables 3.3 and 3.5.

StatLink 部西 https://doi.org/10.1787/888933830519

Nationally resilient students report more positive attitudes towards learning and school than their disadvantaged peers who are not nationally resilient. Students' motivation to achieve the best they can in school and in their lives in general is one of the attitudes that make a difference. An index of achievement motivation was created for the first time in PISA 2015. This index is based on students' agreement or disagreement with the following statements: "I want top <grades> 
in most or all of my courses"; "I want to be able to select from among the best opportunities available when I graduate"; "I want to be the best, whatever I do"; "I see myself as an ambitious person"; and "I want to be one of the best students in my class".

Figure 3.7 - National resilience and student characteristics Difference in the percentage of students who are nationally resilient, OECD average

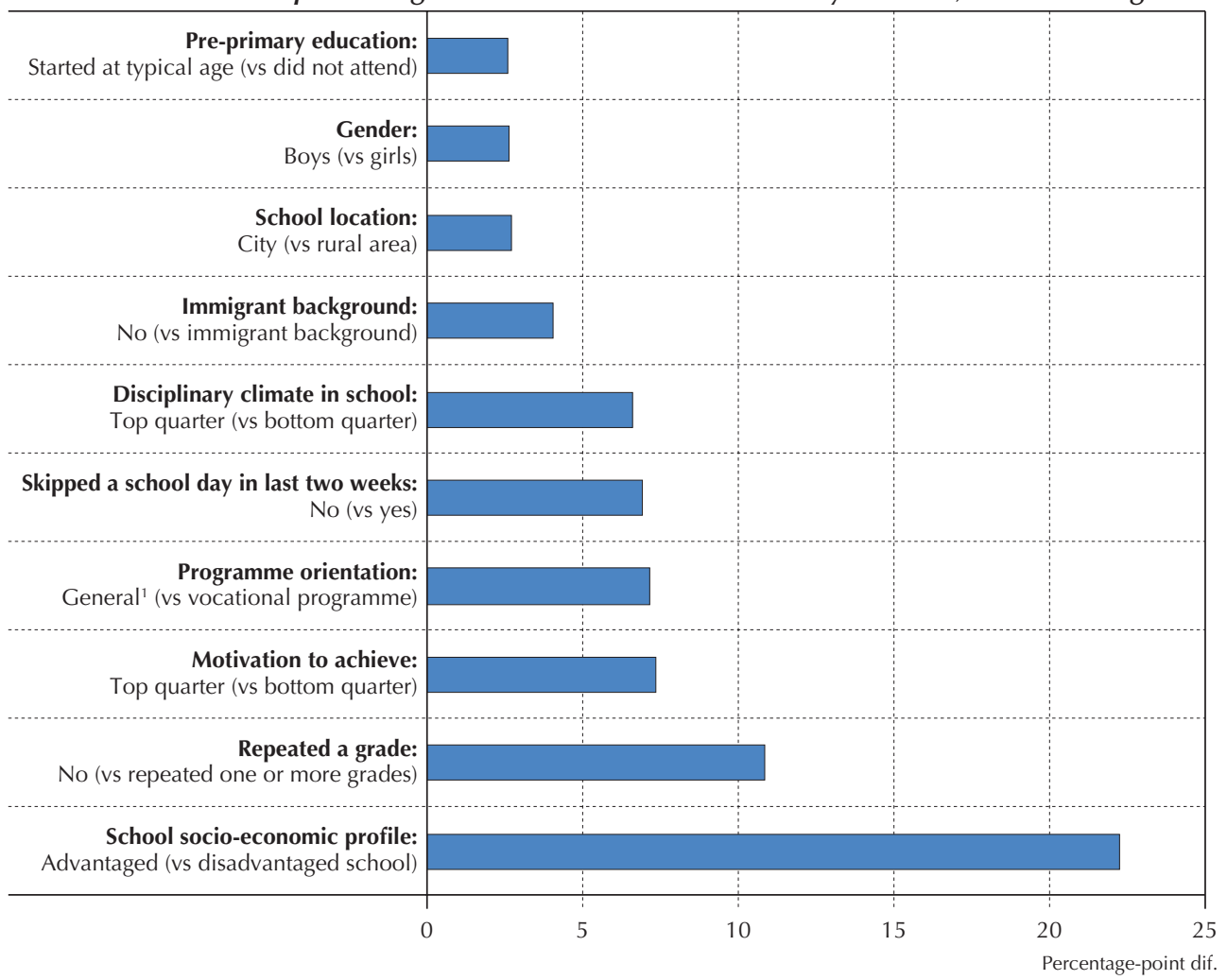

1. General programme orientation includes modular programmes.

Notes: All percentage-point differences are statistically significant.

Nationally resilient students are disadvantaged students who score in the top quarter of performance in science among students in their own country.

Source: OECD, PISA 2015 Database, Tables 3.3 and 3.4.

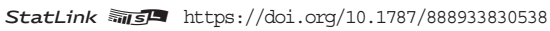

On average across OECD countries, the share of nationally resilient students is 7 percentage points larger among disadvantaged students who are in the top quarter of the index of achievement motivation in their country, compared to their disadvantaged peers in the bottom quarter of achievement motivation ( $16 \%$ of highly motivated students are nationally resilient students and $9 \%$ are among students who reported low motivation to achieve). In Lithuania and the Slovak Republic, the difference in the shares of nationally resilient students between disadvantaged students who are more motivated and those who are less motivated to achieve is larger than 15 percentage points (Table 3.3). 
Disadvantaged students are also more likely to be nationally resilient if they had started attending pre-primary education at the typical (modal) age in their own country. Nationally resilient students had also less frequently repeated a grade, and are more often enrolled in a general academic programme.

As attendance at pre-primary school has increased among recent cohorts of students, performance differences associated with pre-primary education are less about whether or not students had attended and more about when they had started and how long they had stayed (Balladares, Forthcoming $\left.{ }_{[6]}\right) .{ }^{4}$ On average across OECD countries, $12 \%$ of disadvantaged students who had started pre-primary education at their country's typical age are nationally resilient, compared to $10 \%$ of disadvantaged students who had not attended pre-primary education (the difference of 3 percentage points is statistically significant). In Greece, Qatar, the Slovak Republic and Sweden, the difference in shares of nationally resilient students, between students who had attended pre-primary school at the modal age and those who had not attended at all, is about 9 percentage points or larger (Table 3.3).

Figure 3.8 shows differences in core-skills resilience by student and school characteristics.

Whereas motivation is particularly important for nationally resilient students, being truant is associated with large differences in core-skills resilience. On average across OECD countries, the share of core-skills resilient students is 13 percentage points greater among disadvantaged students who had not skipped a day of school in the two weeks prior to the PISA test than among those who had skipped a day. The difference in favour of students who had not skipped a day of school in the two weeks prior to the PISA test is more than 20 percentage points in Japan, Macao (China), the Netherlands and Slovenia, and more than 30 percentage points in Korea, Hong Kong (China) and Chinese Taipei (Table 3.5).

Disciplinary climate at school is also positively associated with core-skills resilience. In PISA 2015, the index of disciplinary climate in science classes was derived from students' responses to how often the following things happen in their school science lessons: "Students don't listen to what the teacher says"; "There is noise and disorder"; "The teacher has to wait a long time for students to quiet down"; "Students cannot work well"; and "Students don't start working for a long time after the lesson begins". On average across OECD countries, the share of core-skills resilient students is 12 percentage points larger among disadvantaged students who attend schools with a better disciplinary climate (the difference between the top and bottom quarters of the disciplinary climate index).

Both truancy and disciplinary climate are related to learning time: students who skip classes lose hours of instruction, as do students in schools with a disruptive climate, where teachers need to use part of their instruction time to quiet classroom noise and disorder. Students' exposure to instruction and opportunities to learn decreases as a result. Core-skills resilience might be more sensitive to differences in the use of time because it requires developing good levels of proficiency in not just one but three different cognitive domains - a wider range of content and subjects than included in national or international resilience, each of which focuses on a single subject.

Unlike national resilience, core-skills resilience is not related to a student's gender. On average across OECD countries, the difference in core-skills resilience between boys and girls is not 
statistically significant. In the case of national resilience, shown in Figure 3.7, boys are more likely to be top-performers in science than girls. This is because performance differences related to gender are domain-specific. On average across OECD countries, boys perform better than girls in science and mathematics, but girls outperform boys in reading. If national resilience had been estimated using reading as the performance domain (instead of science), the gender difference in national resilience would have been the opposite: girls are more likely than boys to be top performers in reading. Thus, because the core-skills perspective considers not only one cognitive domain (as the national and international approaches do), but the three core domains assessed in PISA (science, reading and mathematics), the differences in science performance in favour of boys that are captured by national-resilience metrics are balanced out by the differences in reading performance in favour of girls.

Figure 3.8 - Core-skills resilience and student characteristics

Difference in the percentage of students who are core-skills resilient, OECD average

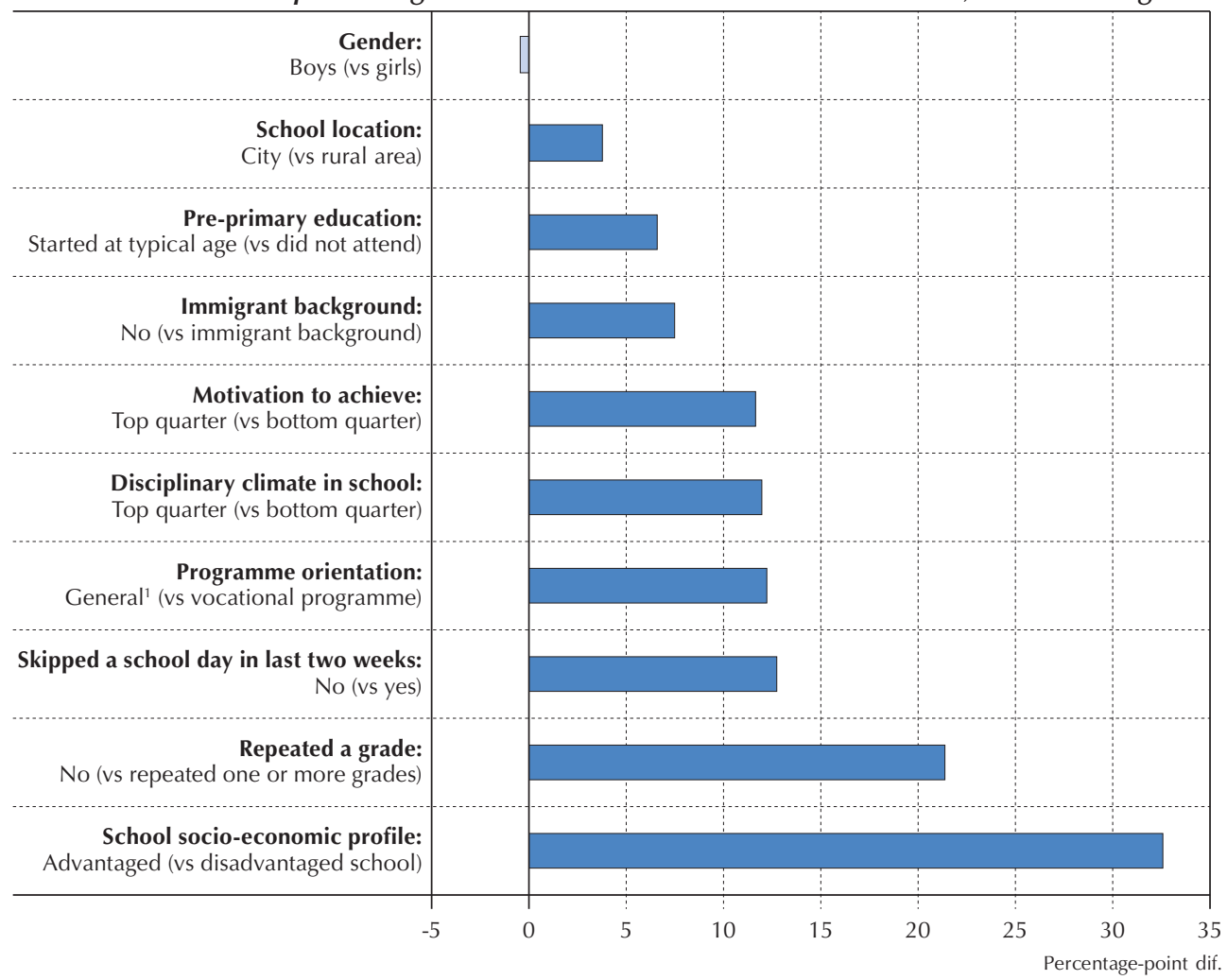

1. General programme orientation includes modular programmes.

Notes: Statistically significant differences are shown in a darker tone.

Core-skills resilient students are disadvantaged students who score at or above Level 3 in PISA in science, reading and mathematics.

Source: OECD, PISA 2015 Database, Tables 3.5 and 3.6.

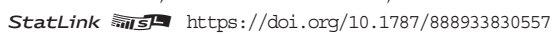




\section{SOCIAL AND EMOTIONAL RESILIENCE}

How is academic resilience related to students' social and emotional well-being? Do academically resilient students pay a price in social isolation or emotional distress for their academic success? Or does social and emotional well-being help disadvantaged students perform better in school? Results in this section suggest that social and emotional resilience tend to be positively related to academic resilience. Thus the two kinds of resilience can be considered mutually reinforcing dimensions of a successful school experience.

The new PISA index of social and emotional resilience captures, in a single measure, various key dimensions of students' well-being (Figure 3.9). ${ }^{5}$ Disadvantaged students are considered to be socially and emotionally resilient if they are satisfied with their life, feel socially integrated at school and do not suffer from test anxiety. Only 48 countries and economies have data corresponding to three items of the PISA 2015 student questionnaire considered in the index of social and emotional resilience.

Figure 3.9 - Index of social and emotional resilience in PISA

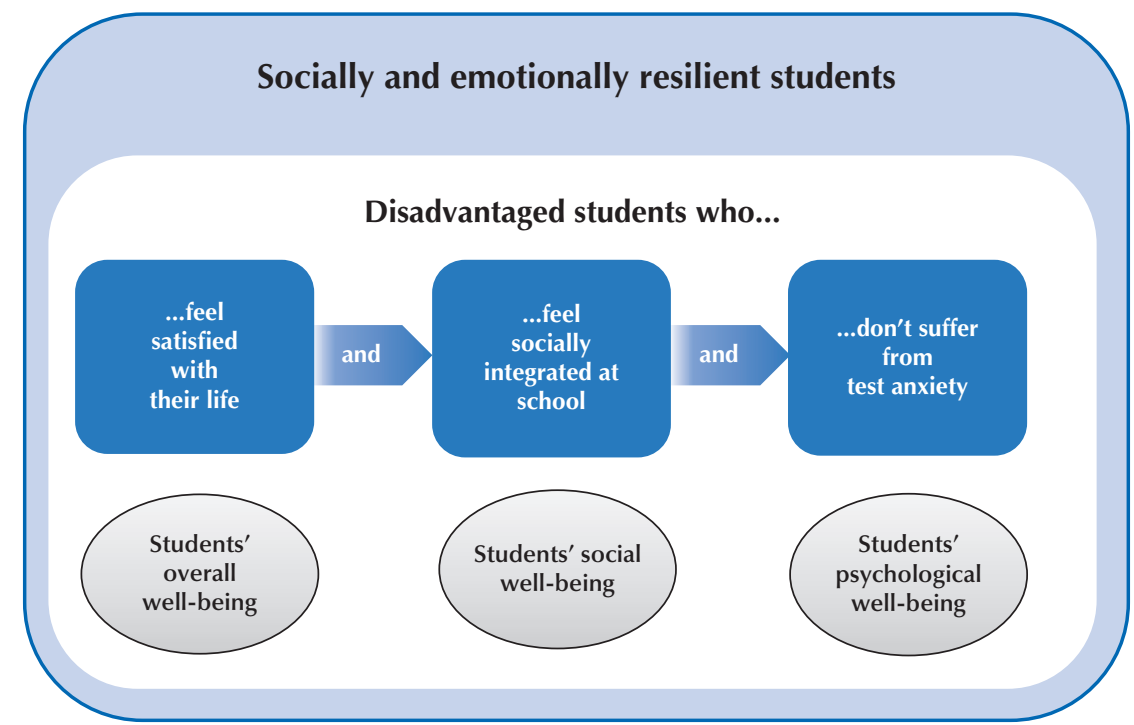

Note: Socio-economically disadvantaged students are students in the bottom quarter of the PISA index of economic, social and cultural status (ESCS).

The first component of social and emotional resilience considered in the index is life satisfaction, a measure of students' overall well-being. In PISA 2015, students were asked: "Overall, how satisfied are you with your life as a whole these days?" Students were requested to assign a number on a scale from zero to ten, with zero meaning "not at all satisfied" and ten meaning "completely satisfied". Students who rated their life with values from 7 to 10 were considered satisfied with their lives. A majority of disadvantaged students reported feeling 
satisfied with their lives. On average across OECD countries, 66\% of disadvantaged students rated their life satisfaction at 7 or higher (Figure 3.10), while $73 \%$ of advantaged students did so (Table $3.9 \mathrm{~b}$ ). The largest proportions ( $80 \%$ or more) of disadvantaged students who so reported are observed in Costa Rica, the Dominican Republic, Mexico and the Netherlands; the smallest proportions (50\% or less) are observed in Hong Kong (China), Korea, Chinese Taipei and Turkey.

The second component of social and emotional resilience considered in the index is social integration at school, a dimension of students' social well-being. Students were asked whether they agreed or disagreed with the following statement: "I feel like an outsider (or left out of things) at school". Students who disagreed with this statement were considered to feel socially integrated at school, and thus to have met the second condition to be considered socially and emotionally resilient. On average across OECD countries, $80 \%$ of disadvantaged students, and $84 \%$ of advantaged students, reported feeling that they belong at school. In Albania, Georgia, Indonesia, the Netherlands, Spain and Viet Nam, at least $90 \%$ of disadvantaged students so reported, but in Bulgaria, the Dominican Republic, Jordan, Lithuania and Turkey, less than 70\% of disadvantaged students so reported.

A lack of test anxiety, another part of students' psychological well-being, is the third component included in the index of social and emotional resilience. Students were asked whether they agreed or disagreed with the following statement: "Even when I am well prepared for a test I feel very anxious". Disadvantaged students who disagreed with the statement were considered not to suffer from text anxiety and thus to have met the third condition to be considered socially and emotionally resilient. On average across OECD countries, $41 \%$ of disadvantaged students and $46 \%$ of advantaged students reported that they do not suffer from test anxiety. The share of disadvantaged students who reported that they do not suffer from test anxiety is largest (more than $60 \%$ ) in the Netherlands and Switzerland, and smallest (less than 20\%) in Brazil, Colombia and Costa Rica.

Thus, socially and emotionally resilient students are disadvantaged students who feel satisfied with their lives, feel well-integrated at school and do not suffer from test anxiety. On average across OECD countries, 26\% of disadvantaged students in PISA 2015 were found to be socially and emotionally resilient, as shown in Figure 3.10. Some 33\% of advantaged students feel satisfied with their lives, feel well-integrated at school and do not suffer from test anxiety, on average across OECD countries. In some European countries, including Croatia, the Czech Republic, Finland, France, Germany, Iceland, Latvia, the Netherlands and Switzerland, the share of socially and emotionally resilient students is among some of the largest $30 \%$ or more) across all countries; but in other European countries, including Bulgaria, Italy, Montenegro, Portugal and the United Kingdom, the share is comparatively small (less than 20\%). In top-performing Asian countries and economies, such as B-S-J-G (China), Hong Kong (China), Japan, Macao (China) and Chinese Taipei, the share is also low (20\% or less), but the Latin American countries of Brazil, Colombia, Costa Rica, the Dominican Republic, Peru and Uruguay have the smallest proportions of socially and emotionally resilient students (less than 15\%). 
Figure 3.10 - Social and emotional resilience, and its components Percentage among socio-economically disadvantaged students

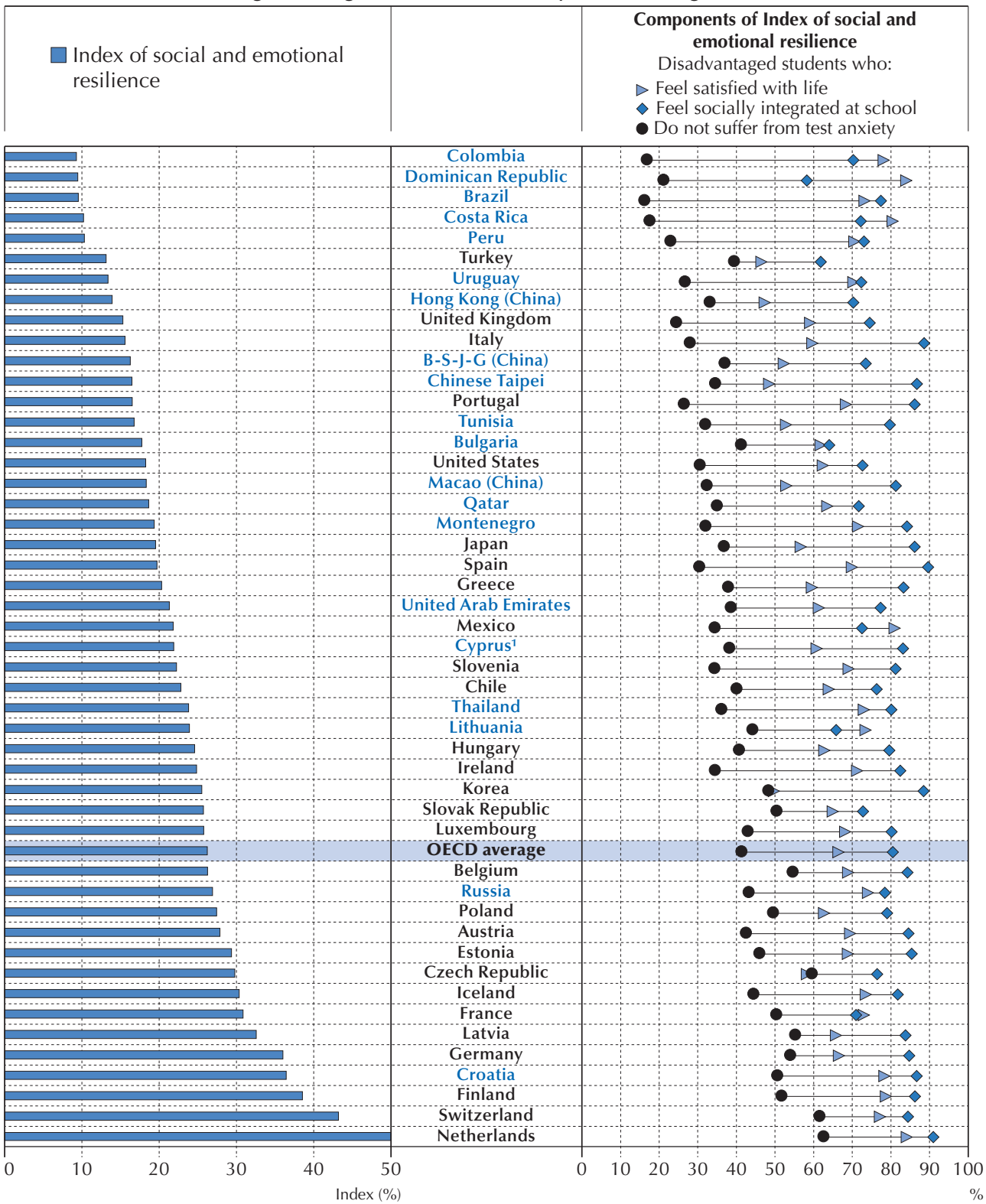

1. See notes at the beginning of this chapter.

Countries and economies are ranked in ascending order of the percentage of students who are socially and emotionally resilient. Source: OECD, PISA 2015 Database, Table 3.9a.

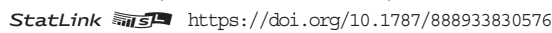




\section{Box 3.1 Are measures of social and emotional well-being internationally comparable?}

A common concern regarding international indicators of social and emotional well-being is that findings can be influenced by culture and response styles, as opposed to reflecting true differences in students' social and emotional well-being (Senik, 2014 ${ }_{[7]}$; Angelini et al., $\left.2014_{[8]}\right)$. One way to allay this concern is to examine whether the data reveal differences between countries with different cultural heritages. If culture and response styles affect students responses to the items included in the index of social and emotional resilience, clear differences between countries, and particularly between countries with different cultural heritages, would be expected. Such cultural differences would also be expected to be reflected by bias in the same direction for both advantaged and disadvantaged students. No clear evidence of cultural bias is observed in the case of the life satisfaction and social integration at school; in both of these variables, levels are relatively high in all countries with available data, as opposed to markedly high or low in some groups of countries. In 44 out of 47 countries and economies with available data, half or more of disadvantaged students rated their life satisfaction at level 7 or above (exceptions are Chinese Taipei, Hong Kong [China] and Turkey, in which the share of students satisfied with their lives was $48 \%$, $47 \%$ and $46 \%$, respectively) (Figure 3.10). Similarly, in almost all countries and economies, more than two-thirds of disadvantaged students reported feeling socially integrated at school (exceptions are Bulgaria [64\% of disadvantaged students so reported], the Dominican Republic [58\%] and Turkey [62\%]) (Table 3.9a). These patterns are corroborated among advantaged students. On the whole, within the same country, advantaged students are more often satisfied with their life and feel socially integrated at school than disadvantaged students, but the magnitude of the gap varies by country (which would not be the case if only cultural differences are reflected) (Table 3.9b).

In the case of test anxiety, cross-national variation is greater, with less than $20 \%$ of students in some countries, and as much as $60 \%$ in others, who reported that they do not suffer from anxiety. Latin American and East Asian countries are the two groups in which a cultural bias in responses might be observed. The five countries with the smallest share of students who do not suffer from test anxiety are all in Latin America, but in Mexico and Chile, the share of such students is more similar to the OECD average than to other Latin American countries. Similarly, East Asian countries tend to have smaller shares of students who do not suffer from test anxiety than the OECD average (in all regions of China and in Japan the share is between $32 \%$ and $39 \%$ among disadvantaged and advantaged students), but in Korea the share is considerably larger (48\% of disadvantaged students and $43 \%$ of advantaged students). No clear pattern is observed in other cultural regions.

Thus, the data provide mixed evidence, at best, that cross-national differences in students' responses are related to differences in culture and response styles. This means that differences in social and emotional well-being, as measured in PISA, might indeed be due to real, absolute differences in students' social and emotional well-being, which supports the decision to establish a common international threshold when defining social and emotional resilience. 


\section{Academic and social and emotional resilience}

Are socially and emotionally resilient students also academically resilient? Figure 3.11 shows that in most countries and economies that participated in PISA 2015, disadvantaged students who are nationally resilient or core-skills resilient are, on average, more likely to be socially and emotionally resilient than their disadvantaged peers who are not academically resilient.

On average across OECD countries with available data, nationally resilient students are $78 \%$ more likely to be socially and emotionally resilient than disadvantaged students who are not nationally resilient. This positive relationship between national resilience, and social and emotional resilience is significant in 30 countries, particularly Belgium and Iceland, where nationally resilient students are around three times more likely than disadvantaged students who are not nationally resilient to also be socially and emotionally resilient.

Similarly, core-skills resilient students are $66 \%$ more likely than disadvantaged students who are not core-skills resilient to be socially and emotionally resilient, on average across OECD countries with available data. This positive relationship between core-skills resilience on the one hand and social and emotional resilience on the other is significant in 28 countries, particularly Brazil and Mexico, where core-skills resilient students are almost three times more likely to be socially and emotionally resilient.

The results of the analysis described in this section illustrate how important it is, particularly for disadvantaged students, to promote balance in the development of academic, and social and emotional outcomes at school. 


\section{Figure 3.11 - Academic resilience, and the likelihood of social and emotional resilience}

Increased likelihood of being socially and emotionally resilient among nationally and core-skills resilient students

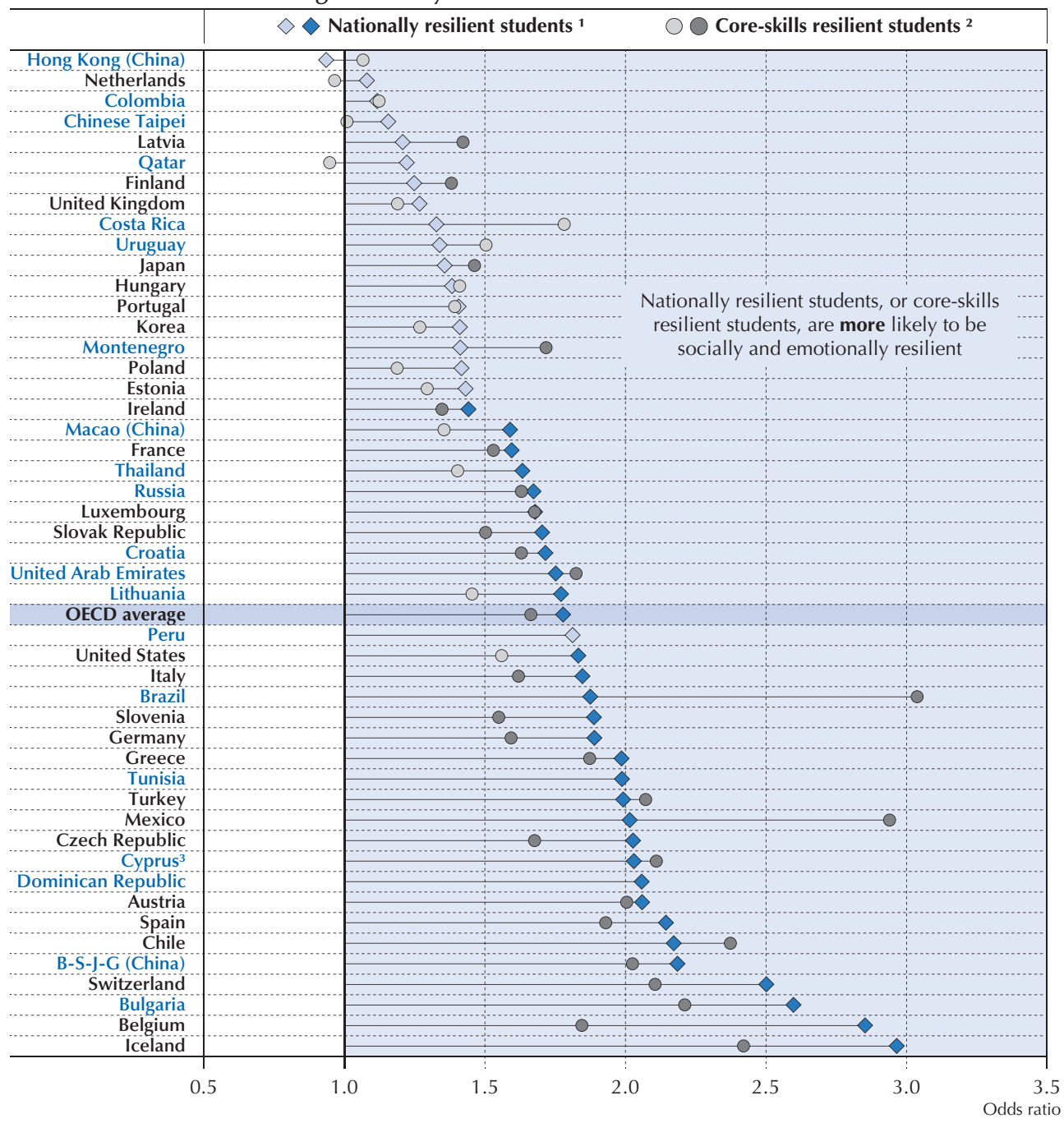

1. Nationally resilient students are disadvantaged students who score in the top quarter of performance in science among students in their own country.

2. Core-skills resilient students are disadvantaged students who score at or above Level 3 in PISA in science, reading and mathematics.

3. See notes at the beginning of this chapter.

Notes: Statistically significant odds ratio are shown in a darker tone.

The Dominican Republic, Peru and Tunisia have too few core-skills resilients in the sample to provide reliable estimates. Countries and economies are ranked in ascending order of the likelihood of nationally resilient students being socially and emotionally resilient, compared with disadvantaged students who are not nationally resilient.

Source: OECD, PISA 2015 Database, Table 3.12.

StatLink 需s https://doi.org/10.1787/888933830595 


\section{Notes}

1. A student is classified as internationally resilient if she or he is in the bottom quarter of the PISA index of economic, social and cultural status (ESCS) in the country/economy of assessment and scores in the top quarter of performance among students from all countries/economies, after accounting for socio-economic status. The procedure for identifying resilient students is as follows. In a first step, a measure of performance adjusted for differences in ESCS across countries is computed through a linear regression of performance on ESCS and a squared transformation of ESCS. This linear regression is not conducted separately by country, but instead by using the pooled sample (meaning that it includes all students participating in PISA) and senate weights (to ensure an equal contribution by each of the countries/economies in the analysis). The results of the regression model are used to predict an expected score for each student, based on her or his ESCS value. Residual scores are the difference between the observed science score (the plausible values) and the expected score. International top performers are defined as those students who are in the top quarter of this adjusted measure (residual scores) among students in all PISA-participating countries and economies. In a second step, the disadvantaged students in each country/economy are defined as those students whose ESCS is in the bottom quarter among students in their country/economy. Resilient students are those students who are socio-economically disadvantaged (their socio-economic status is low relative to other students in their own country) and are international top performers (their performance is high compared to that of all other students in PISA, after accounting for differences in socio-economic status across countries). Therefore, one characteristic of resilient students is that they achieve better performance in PISA than predicted by their socio-economic status.

2. On average across OECD countries, students in the bottom quarter of the PISA index of economic, social and cultural status (ESCS) among all PISA-participating students ("internationally disadvantaged") have a mean ESCS value of -2.02, and students in the bottom quarter of ESCS in their own countries have a mean ESCS value of -1.2 (Table 3.13). This shows that, in OECD countries, students classified as nationally disadvantaged are considerably less disadvantaged, on average, than the smaller group of OECD students who are disadvantaged by international standards.

3. In the following, the focus is mainly on national and core-skills resilience, which are the new concepts of academic resilience (while international resilience has been already studied in previous analyses of PISA 2015 data; see, for instance, OECD, 2016 $\left.{ }_{[9]}\right)$. As suggested in Table 3.2, the distributions of international and core-skills resilience are similar, as they both use an international reference for defining resilience.

4. The typical age is the most common age at entry into pre-primary education, as reported by students. Balladares (forthcoming ${ }_{[6]}$ ) introduced the typical age approach to analyse pre-primary education using PISA data.

5. The index of social and emotional resilience is a simple index that takes the value of one if a student meets four conditions and takes the value of zero otherwise. A student is classified as "socially and emotionally resilient" if she or he meets the following four criteria: (i) the student is in the bottom of the PISA index of economic, social and cultural status (ESCS) in the country/economy of assessment; (ii) the student rated her or his life satisfaction with a value of from 7 to 10 , on a scale from zero to ten, with zero meaning "not at all satisfied" and ten meaning "completely satisfied"; (iii) the student disagreed with the following statement: "I feel like an outsider (or left out of things) at school"; and (iv) the student disagreed with the following statement: "Even when I am well prepared for a test I feel very anxious". 


\section{References}

Agasisti, T. et al. (2018), "Academic resilience: What schools and countries do to help disadvantaged [3] students succeed in PISA", OECD Education Working Papers, No. 167, OECD Publishing, Paris, http://dx.doi.org/10.1787/e22490ac-en.

Angelini, V. et al. (2014), "Do Danes and Italians Rate Life Satisfaction in the Same Way? Using [8] Vignettes to Correct for Individual-Specific Scale Biases", Oxford Bulletin of Economics and Statistics, Vol. 76/5, pp. 643-666, http://dx.doi.org/10.1111/obes.12039.

Balladares, J. (forthcoming), "Attendance matters: Analysis of Early Childhood education and PISA 2015 outcomes in children from low and high socio-economic backgrounds", UCL, Institute of Education.

OECD (2018), Effective Teacher Policies: Insights from PISA, PISA, OECD Publishing, Paris, http://dx.doi.org/10.1787/9789264301603-en.

OECD (2017), PISA 2015 Results (Volume III): Students' Well-Being, PISA, OECD Publishing, Paris, http://dx.doi.org/10.1787/9789264273856-en.

OECD (2016), Low-Performing Students: Why They Fall Behind and How To Help Them Succeed, [1] PISA, OECD Publishing, Paris, http://dx.doi.org/10.1787/9789264250246-en.

OECD (2013), PISA 2012 Results: What Makes Schools Successful (Volume IV): Resources, Policies and Practices, PISA, OECD Publishing, Paris, http://dx.doi.org/10.1787/9789264201156-en.

Senik, C. (2014), "The French unhappiness puzzle: The cultural dimension of happiness", Journal of [7] EConomic Behavior \& Organization, Vol. 106, pp. 379-401, http://dx.doi.org/10.1016/J.JEBO.2014.05.010. 


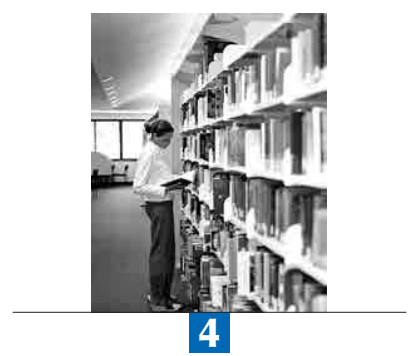

\section{Are disadvantaged students affected by the socio-economic profile of their school?}

This chapter examines the socio-economic segregation of disadvantaged students across schools and changes in this segregation over the past decade. It quantifies the disparities in student performance due to the socio-economic profile of the schools that disadvantaged students attend. The chapter identifies certain school policies and practices, and student behaviours that may mediate the relationship between the socio-economic profile of schools and student performance. It concludes by analysing the relationship between socio-economic diversity in schools and student performance.

\footnotetext{
Notes regarding Cyprus

Note by Turkey: The information in this document with reference to "Cyprus" relates to the southern part of the Island. There is no single authority representing both Turkish and Greek Cypriot people on the Island. Turkey recognises the Turkish Republic of Northern Cyprus (TRNC). Until a lasting and equitable solution is found within the context of the United Nations, Turkey shall preserve its position concerning the "Cyprus issue".

Note by all the European Union Member States of the OECD and the European Union: The Republic of Cyprus is recognized by all members of the United Nations with the exception of Turkey. The information in this document relates to the area under the effective control of the Government of the Republic of Cyprus.
}

\section{A note regarding Israel}

The statistical data for Israel are supplied by and under the responsibility of the relevant Israeli authorities. The use of such data by the OECD is without prejudice to the status of the Golan Heights, East Jerusalem and Israeli settlements in the West Bank under the terms of international law.

\section{A note regarding Lithuania}

Lithuania was not an OECD member at the time of preparation of this publication. Accordingly, Lithuania is shown as a partner country and is not included in the OECD average.

This document, as well as any data and map included herein, are without prejudice to the status of or sovereignty over any territory, to the delimitation of international frontiers and boundaries and to the name of any territory, city or area. 


\section{What the data tell us}

- Countries that participated in the 2015 PISA assessment differ in the degree to which their school systems segregate disadvantaged students into certain schools. On average across OECD countries, in all PISA cycles since 2006, 48\% of disadvantaged students attend disadvantaged schools.

- On average across OECD countries, disadvantaged students who attend advantaged schools score 78 score points higher than their disadvantaged peers who attend disadvantaged schools. However, in Finland, Iceland, Macao (China), Norway and Poland, there is no significant difference in the performance of disadvantaged students related to whether they attend advantaged or disadvantaged schools.

- The level of science-specific resources, the extent to which student behaviour hinders learning, the availability of science competitions, class size, student truancy, the disciplinary climate, and various pedagogical strategies are all potential mediating factors between a school's socio-economic profile and the performance of disadvantaged students.

- On average across OECD countries, students attending more socio-economically diverse schools tend to perform worse than students who attend more homogeneous schools, even after accounting for students' and schools' socio-economic profile. However, at the national level, this relationship is observed in only 18 education systems, while in 46 countries and economies, socio-economic diversity in school is unrelated to student performance. In six countries, students who attend more diverse schools show better science performance.

PISA consistently finds a strong and positive link between a school's socio-economic profile and student performance: socio-economically disadvantaged schools (defined as schools whose socio-economic profile, as measured by the PISA index of economic, social, and cultural status [ESCS], is among the bottom $25 \%$ within their country or economy) usually have lower average performance than those that enrol students of more advantaged socio-economic status (OECD, $\left.2016_{[1]}\right)$. While previous PISA reports have considered this issue by looking at all students, this chapter focuses particularly on disadvantaged students, defined as those among the bottom $25 \%$ of socio-economic status in their country or economy.

How does the performance of a disadvantaged student vary depending on the socio-economic profile of the school that he or she attends? Are these disparities associated with differences in such factors as material resources, teacher qualifications or practices, school climate or student behaviour? And are the relationships stronger in some countries than in others?

Addressing these school disparities with a focus on disadvantaged students is particularly important from the standpoint of equity because disadvantaged students who attend disadvantaged schools face a "double disadvantage". In addition to the disparities in learning opportunities they already face as a result of their family's socio-economic status, they are often confronted with more difficult learning environments that tend to be found in schools with a lower socio-economic profile. Such doubly disadvantaged students are particularly likely to perform poorly in school. Equity in education can be compromised as a result. 
This chapter offers insights into how disadvantaged students can be supported by improving the quality of their schools. It measures whether disadvantaged students in the countries and economies that participated in PISA 2015 are concentrated within certain schools. Specifically, it calculates the proportion of disadvantaged students who are enrolled in a disadvantaged school, and thus who suffer from a double disadvantage. ${ }^{1}$ The chapter then compares the average performance of disadvantaged students who attend schools of different socio-economic profiles. Finally, the chapter considers factors that mediate the relationship between a school's socio-economic profile and the performance of its disadvantaged students. This final analysis offers suggestions for policy makers and educators about what can be done to support disadvantaged students who attend disadvantaged schools.

\section{SOCIO-ECONOMIC SEGREGATION OF DISADVANTAGED STUDENTS IN SCHOOLS}

The PISA 2015 Results (Volume I) (OECD, 2016 ${ }_{[1]}$ ) showed that both student socio-economic status and school socio-economic profile, defined as the average socio-economic status of the students in a school, are strongly associated with student performance. ${ }^{2}$ Students who come from more advantaged backgrounds, and whose classmates are also more advantaged, obtain better scores in the PISA assessment.

Hence, disadvantaged students attending disadvantaged schools are, a priori, doubly disadvantaged as they strive for achievement. Before quantifying the magnitude of this double disadvantage in terms of score points, it is important to quantify the degree to which this double disadvantage exists. To what extent do disadvantaged students have the opportunity to meet and interact with students from different socio-economic backgrounds? Put another way, to what extent are disadvantaged students concentrated in the same schools?

Figure 4.1 shows the proportion of disadvantaged students who are enrolled in disadvantaged schools in PISA 2015. As in previous chapters, disadvantaged students are those who are in the bottom quarter of the PISA index of economic, social and cultural status (ESCS) in their education system; disadvantaged schools are those in the bottom quarter of school-level ESCS in their education system. ${ }^{3}$

On average across OECD countries, 48\% of disadvantaged students attend disadvantaged schools. Among OECD countries, the Nordic countries of Finland, Norway and Sweden are the least socio-economically segregated by this measure: less than $43 \%$ of disadvantaged students attend disadvantaged schools in these three education systems.

The OECD countries where disadvantaged students are the most segregated are Hungary and Mexico, where over 55\% of disadvantaged students are found in disadvantaged schools. In nine other OECD countries - Australia, Belgium, Chile, the Czech Republic, France, Israel, the Slovak Republic, Spain and the United States - over half of all disadvantaged students attend disadvantaged schools.

Large differences in the segregation of disadvantaged students are also observed in partner countries and economies. In all five partner education systems in the Western Balkans Albania, Croatia, the Former Yugoslav Republic of Macedonia (hereafter "FYROM"), Kosovo and Montenegro $-45 \%$ or less of all disadvantaged students are found in disadvantaged schools. However, in the Ciudad Autónoma de Buenos Aires (Argentina) (hereafter "CABA [Argentina]") and Peru, over $60 \%$ of disadvantaged students are found in disadvantaged schools. 


\section{Figure 4.1 - Disadvantaged students in disadvantaged schools} Percentage of disadvantaged students in disadvantaged schools

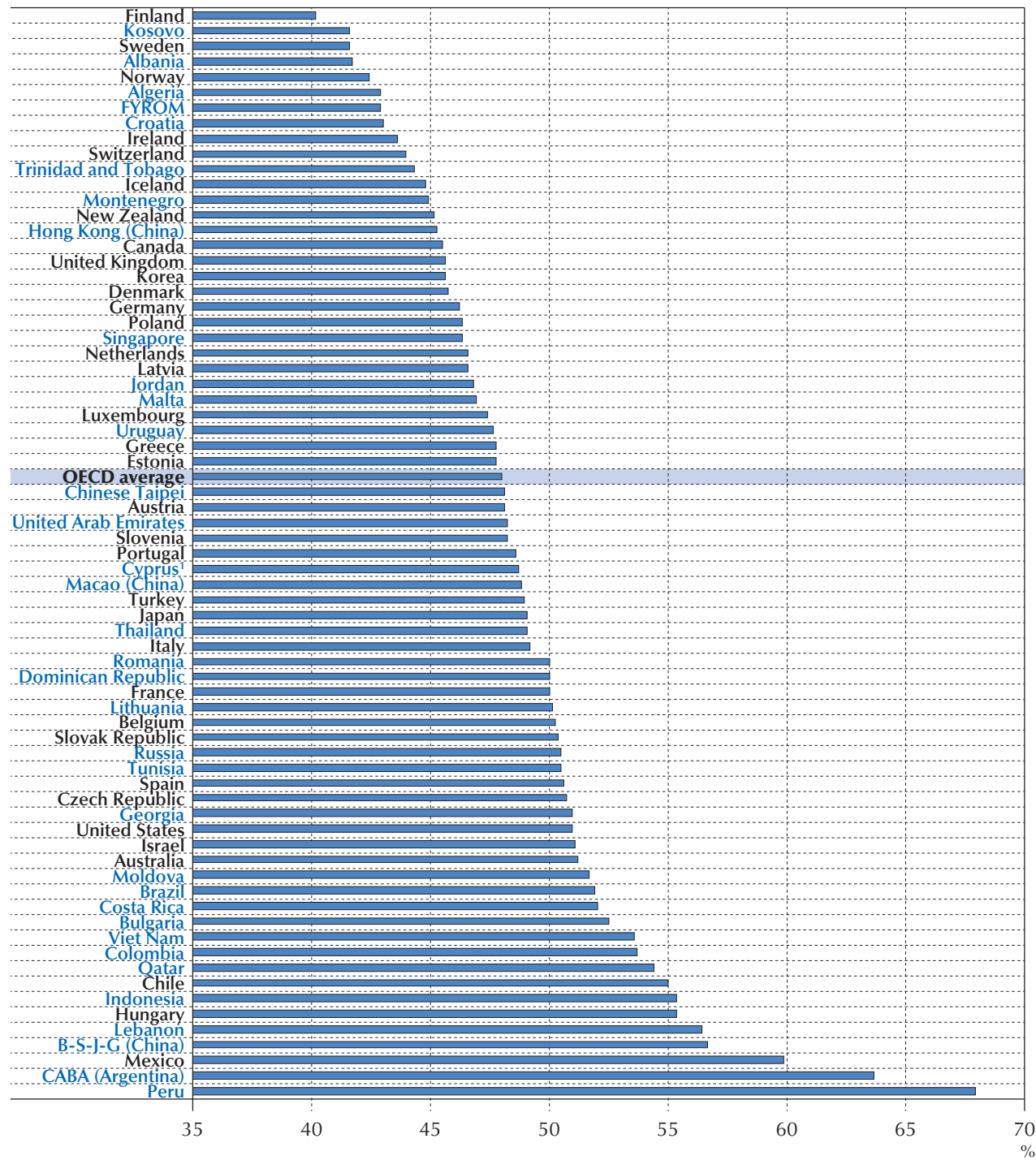

1. See notes at the beginning of this chapter.

Note: Disadvantaged students are those students in the bottom quarter of the national distribution of the PISA index of economic, social and cultural status (ESCS). Disadvantaged schools are schools in the bottom quarter of the national distribution of the school-level ESCS index, which is calculated as the average ESCS index among students in a school. Only schools with at least 10 students with a valid ESCS index were used for this analysis. The national distribution of the schoollevel ESCS index is weighted at the student level.

Countries and economies are ranked in ascending order of the percentage of disadvantaged students found in disadvantaged schools.

Source: OECD, PISA 2015 Database, Table 4.1.

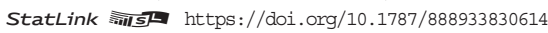


As shown in Figure 4.2, there has been no significant change in the average level of segregation of disadvantaged students, on average across OECD countries, over the past decade. On average across all OECD countries, 48\% of disadvantaged students have been found in disadvantaged schools in every PISA cycle since 2006 (Table 4.1).

\section{Figure 4.2 - Evolution since 2006 of the percentage of disadvantaged students in schools, by school socio-economic profile OECD average}

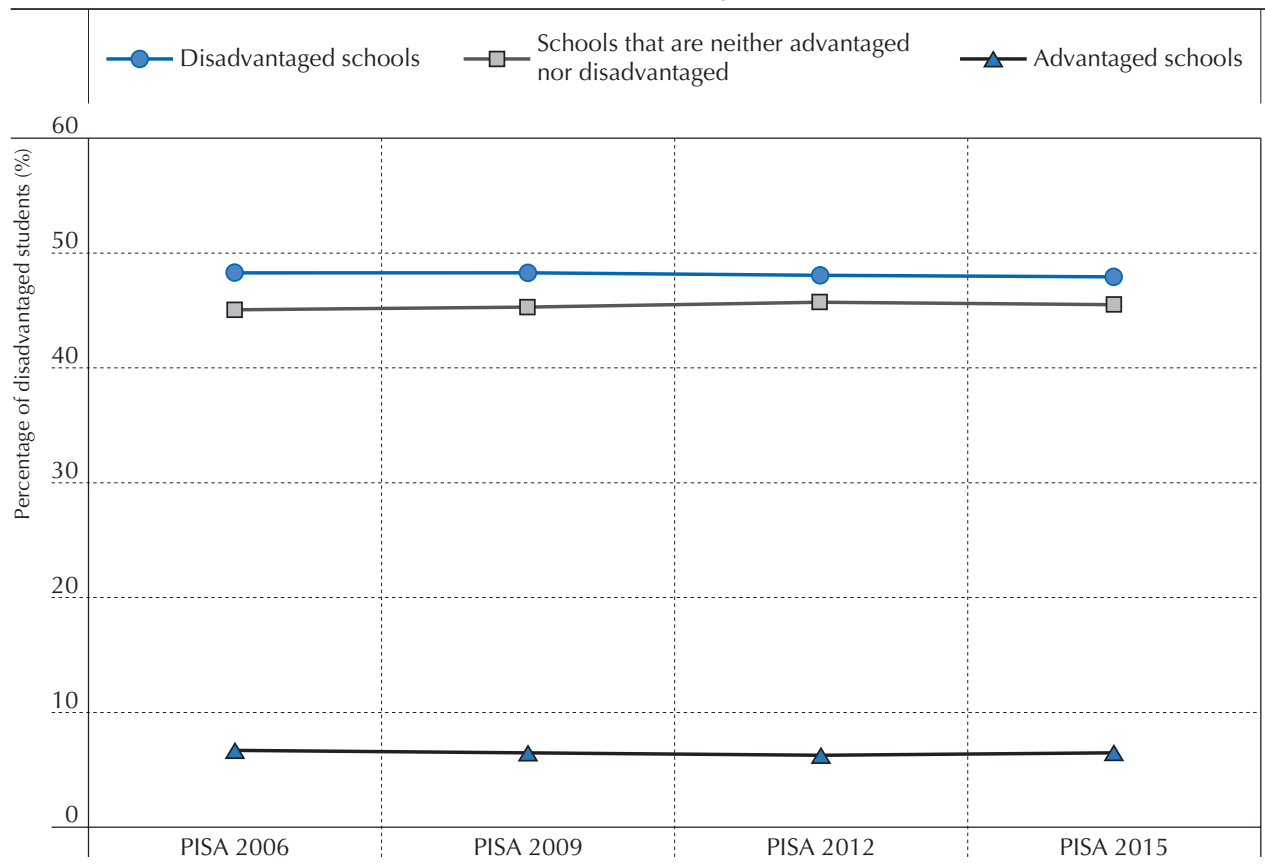

Note: Disadvantaged students are those students in the bottom quarter of the national distribution of the PISA index of economic, social and cultural status (ESCS). Disadvantaged schools are schools in the bottom quarter of the national distribution of the school-level ESCS index, which is calculated as the average ESCS index among students in a school. Advantaged schools are schools in the top quarter of the national distribution of the school-level ESCS index. Only schools with at least 10 students with a valid ESCS index were used for this analysis. The national distribution of the school-level ESCS index is weighted at the student level, so that schools with a larger population carry a greater weight.

Source: OECD, PISA 2006, 2009, 2012 and 2015 Databases, Table 4.1.

StatLink 需西 https://doi.org/10.1787/888933830633

There has also been no significant change in the average level of segregation of disadvantaged students in most PISA-participating education systems. Among OECD countries, the only significant change is observed in Luxembourg, where disadvantaged students have become less segregated in disadvantaged schools since 2006. The opposite trend is observed in Macao (China) and Singapore, where segregation has increased since 2009 (Table 4.1). 
Figure 4.2 also shows that most disadvantaged students who do not attend disadvantaged schools attend socio-economically average schools (which are neither advantaged nor disadvantaged); only a few attend advantaged schools. On average across OECD countries, between $45 \%$ and $46 \%$ of disadvantaged students attended schools with an average socio-economic profile between PISA 2006 and 2015, and only between 6\% and 7\% attended advantaged schools during the same period.

This latter finding is consistent with the observation that on average across OECD countries, disadvantaged schools, as well as schools with an average socio-economic profile, are more socio-economically diverse than advantaged schools (Table 4.4). Disadvantaged students who attend advantaged schools may be those whose parents have actively sought out such schools or those whose performance may have justified attending an academically stronger school, which is likely to be more advantaged. Conversely, advantaged students in disadvantaged schools may be those who are weaker academically and therefore have been sorted into schools with other students who are struggling and who are disproportionately likely to be of lower socio-economic status, or those whose parents are less inclined to seek out enrichment opportunities for their child.

As one quarter of students are, by definition, disadvantaged, and roughly $50 \%$ of disadvantaged students attend disadvantaged schools, roughly one in eight students is doubly disadvantaged by both their student- and school-level socio-economic profiles. The second section of this chapter addresses the size of and possible mechanisms behind the performance gap associated with this double disadvantage.

\section{Why is the segregation of disadvantaged students in schools more frequently observed in some countries than in others?}

Several factors may explain the large variation observed across countries and economies in the level of segregation of disadvantaged students in schools. When assignment to schools is mainly based on the distance between the family's residence and the school (as is the case in the large majority of OECD countries [Musset, $\left.2012_{[2]}\right]$ ), social segregation at school reproduces, at least to some extent, social segregation in the neighbourhood. For example, in some countries in Latin America, metropolitan areas are clearly split into privileged and non-privileged zones (Chmielewski and Savage, 2015 $5_{[3]}$ ), a phenomenon that is manifested in the development of exclusive gated communities (Coy and Pöhler, 2002 ${ }_{[4]}$; Sabatini and Salcedo, 2007 ${ }_{[5]}$ ). This high level of residential segregation is reflected by the position of many Latin American countries at the top end of the spectrum of the proportion of disadvantaged students enrolled in disadvantaged schools (Figure 4.1).

Education policies may also affect the social segregation of disadvantaged students within schools. For instance, segregation is relatively uncommon in most of the Nordic countries. These countries have long championed social inclusion, cohesion and equality, both in schools and in society as a whole (Antikainen, 2006 $6_{[6]}$ ). School systems in these countries have tried to provide equal opportunities to all students by successively breaking down barriers related to geography, socio-economic status, gender and immigrant background (Lie, Linnakylä and Roe, $\left.2003_{[7]}\right)$. 
More generally, how school systems manage academic heterogeneity and how they govern school choice can affect the social composition of schools (Liu et al., 2015 $5_{[8]}$ ). For instance, one may hypothesise that tracking leads to greater socio-economic stratification: after tracking, advantaged children are often over-represented in academic tracks while disadvantaged children are more frequently found in vocational tracks. Moreover, some school choice policies may increase school socio-economic segregation as better-educated and more-motivated parents are more likely to take advantage of these policies. This results in the concentration of advantaged students in what are perceived to be the "best" schools. Such segregation may be amplified if schools are allowed to select students on the basis of either academic and/or financial criteria (for instance, through school fees). Evidence from Chile, for instance, suggests that the rise in private schools funded through voucher programmes has led to an increase in socio-economic segregation in schools because advantaged parents are more likely than disadvantaged parents to choose private government-dependent schools for their children (Schneider, Elacqua and Buckley, 2006 ${ }_{[9]}$; Valenzuela, Bellei and Ríos, 2014 ${ }_{[10]}$; Hsieh and Urquiola, 2006 $\left.{ }_{[11]}\right)$.

However, as suggested in School choice and school vouchers: An OECD perspective (OECD, $\left.2017_{[12]}\right)$, the impact of school choice on segregation can be mitigated. Vouchers for enrolling students in private or charter schools can be targeted to low-income families rather than being offered to all families, and schools can be prevented from "skimming" wealthier and more able students (Altonji, Huang and Taber, 2015 $5_{[13]}$ ). For example, in the Netherlands, school funding partially depends on the socio-economic status and needs of the students, which provides incentives for schools to enrol disadvantaged students. This may partly explain why disadvantaged students are relatively less segregated into certain schools, as these students can be found in significant numbers in all sorts of schools.

\section{HOW THE PERFORMANCE OF DISADVANTAGED STUDENTS MAY BE AFFECTED BY A SCHOOL'S SOCIO-ECONOMIC PROFILE}

The previous section shows that the degree of socio-economic segregation in schools varies across education systems and persists over time. How is this segregation reflected in student performance?

\section{Why does a school's socio-economic profile matter for student performance?}

Many factors may explain why a school's social composition affects, directly or indirectly, the academic performance of children (Thrupp, 1995 ${ }_{[14]}$; Nash, $2003_{[15]}$ ). Empirical evidence suggests that performance deteriorates as the share of low achievers increases, while the proportion of high achievers correlates positively with performance (Hanushek et al., 2003 [16]; Lavy, Silva and Weinhardt, $2012_{[17] ;}$ Burke and Sass, 2013 ${ }_{[18]}$ ). This could be because teachers adjust their style of teaching and their expectations to the type of students in their classes (Liu et al., 2015 ${ }_{[8]}$ ), or because peer pressure and competition may stimulate students to work harder. As disadvantaged students are more likely to perform poorly at school, a larger proportion of disadvantaged students in a school is usually related to a lower likelihood of attending school with top-achieving students. Furthermore, low achievement is often related to disruptive behaviour, such as truancy 
or behaviour that requires teacher attention. A school climate that is not conducive to learning has a potentially detrimental impact on performance (Opdenakker and Damme, $2007_{[19]}$ ).

Teaching conditions are often more challenging in disadvantaged schools, thus these schools may fail to attract and retain the best teachers. The OECD report, Effective Teacher Policies $\left(\right.$ OECD, 2018 $\left.8_{[20]}\right)$, finds that in more than a third of the countries that participated in PISA 2015, teachers in the most disadvantaged schools are less qualified or experienced than those in the most advantaged schools. Even if most countries provide extra financial support to disadvantaged schools, this may not compensate for an initial lack of human resources. Furthermore, in most of the countries and economies that participated in PISA 2015, advantaged schools are better equipped than disadvantaged schools (OECD, 2016 $\left.6_{[21]}\right)$.

All of this suggests that students from the most disadvantaged backgrounds may suffer from a double disadvantage when they are clustered in specific schools. Not only might these students lack the parental support they need, they may also have less stimulating learning conditions than they would have in advantaged schools.

\section{The performance of disadvantaged students and schools' socio-economic profile}

Figure 4.3 shows the performance of students of different socio-economic status who attend schools with different socio-economic profiles. On average across OECD countries, disadvantaged students attending advantaged schools score 78 points higher than those attending disadvantaged schools. Disadvantaged students attending schools of average socio-economic profile (schools that are neither advantaged nor disadvantaged) score 36 points higher than those attending disadvantaged schools. ${ }^{4}$

Among disadvantaged students, disparities in science performance related to their schools' socioeconomic profile vary in magnitude across countries. A school's socio-economic profile matters the most in Belgium, Beijing-Shanghai-Jiangsu-Guangdong (China) (hereafter "B-S-J-G [China]"), Bulgaria, CABA (Argentina), France, Hungary, the Netherlands, the Slovak Republic and Slovenia, where disadvantaged students attending advantaged schools score over 130 points higher than those in disadvantaged schools. By contrast, in Algeria, Estonia, Jordan, Moldova and Sweden, disadvantaged students attending advantaged schools score only between 20 and 40 points higher than those in disadvantaged schools. Most notably, in Finland, Iceland, Macao (China), Norway and Poland, there is no significant difference in the performance of disadvantaged students related to whether they attend advantaged or disadvantaged schools (Table 4.5). This implies that disadvantaged schools in these six countries serve disadvantaged students as well as advantaged schools do. However, such students still suffer from their individual disadvantaged status compared to advantaged students.

Part of the difference in performance between disadvantaged students who attend disadvantaged schools and disadvantaged students who attend advantaged schools is a reflection of the socioeconomic disparities among the students themselves. Indeed, disadvantaged students who attend disadvantaged schools are likely to be more disadvantaged than disadvantaged students 
who attend schools that are not disadvantaged. This could be because of social segregation, as discussed above, or because a school's socio-economic profile is defined as the average socioeconomic status of its students. Lower individual socio-economic status is associated with poorer performance, even before considering the impact of a school's socio-economic profile.

\section{Figure 4.3 - Science performance, by student and school socio-economic profile} $O E C D$ average

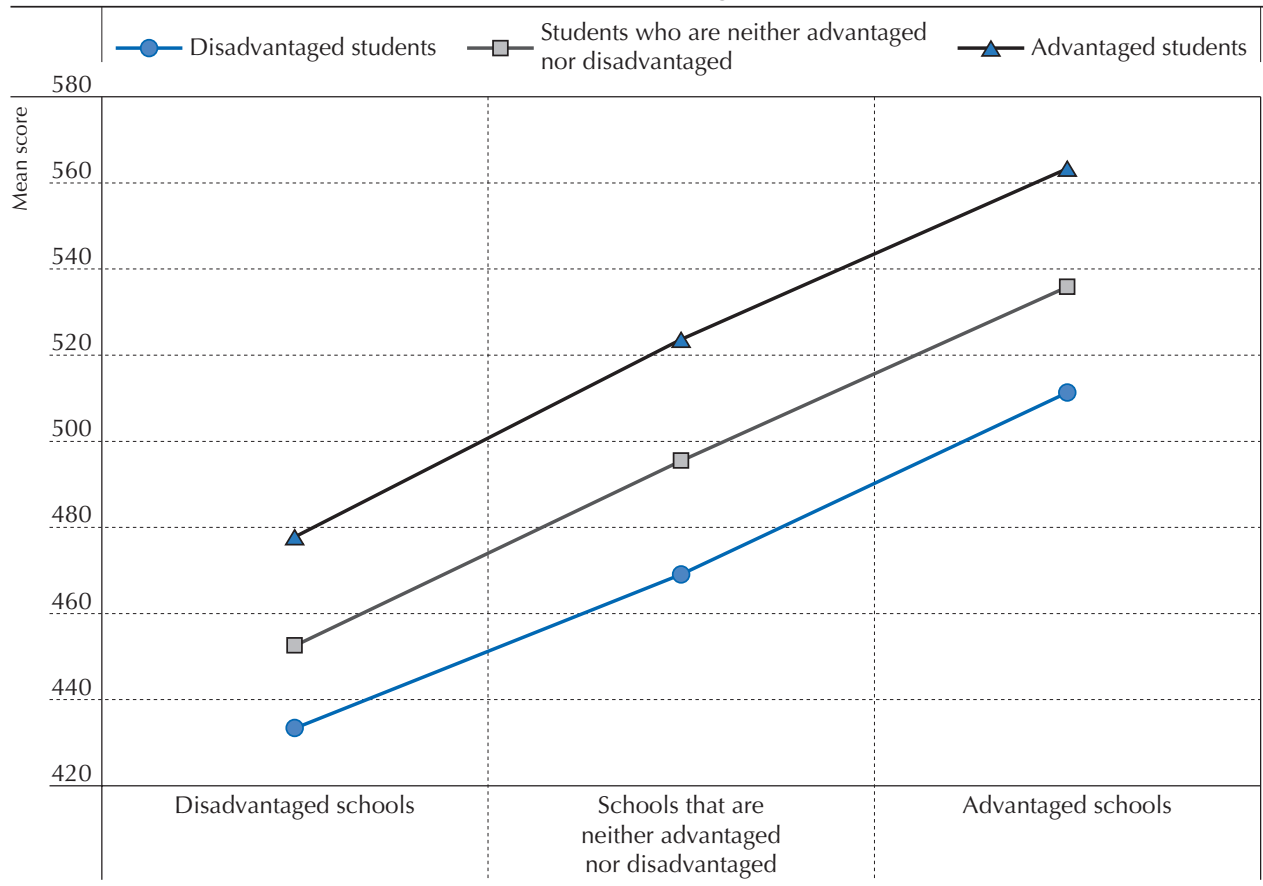

Note: Disadvantaged students are those students in the bottom quarter of the national distribution of the PISA index of economic, social and cultural status (ESCS). Advantaged students are those students in the top quarter of this distribution. Disadvantaged schools are schools in the bottom quarter of the national distribution of the school-level ESCS index, which is calculated as the average ESCS index among students in a school. Advantaged schools are schools in the top quarter of the national distribution of the school-level ESCS index. Only schools with at least 10 students with a valid ESCS index were used for this analysis. The national distribution of the school-level ESCS index is weighted at the student level.

Source: OECD, PISA 2015 Database, Table 4.5.

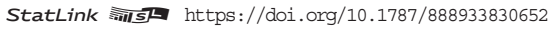

However, as shown in Figure 4.4, on average among disadvantaged students in OECD countries, a one-unit increase in school-level ESCS is associated with a 60 score-point improvement in student performance, even after accounting for students' socio-economic status. ${ }^{5}$ In the Czech Republic, France, Japan, Malta, the Netherlands, Slovenia and Chinese Taipei, each additional unit of school-level ESCS is associated with a more than 100 score-point improvement in performance among disadvantaged students (Table 4.6b). 


\section{Figure 4.4 - Change in student performance associated with school socio-economic profile}

Score-point difference in science among disadvantaged students associated with a one-unit increase in school socio-economic profile, after

accounting for student socio-economic status

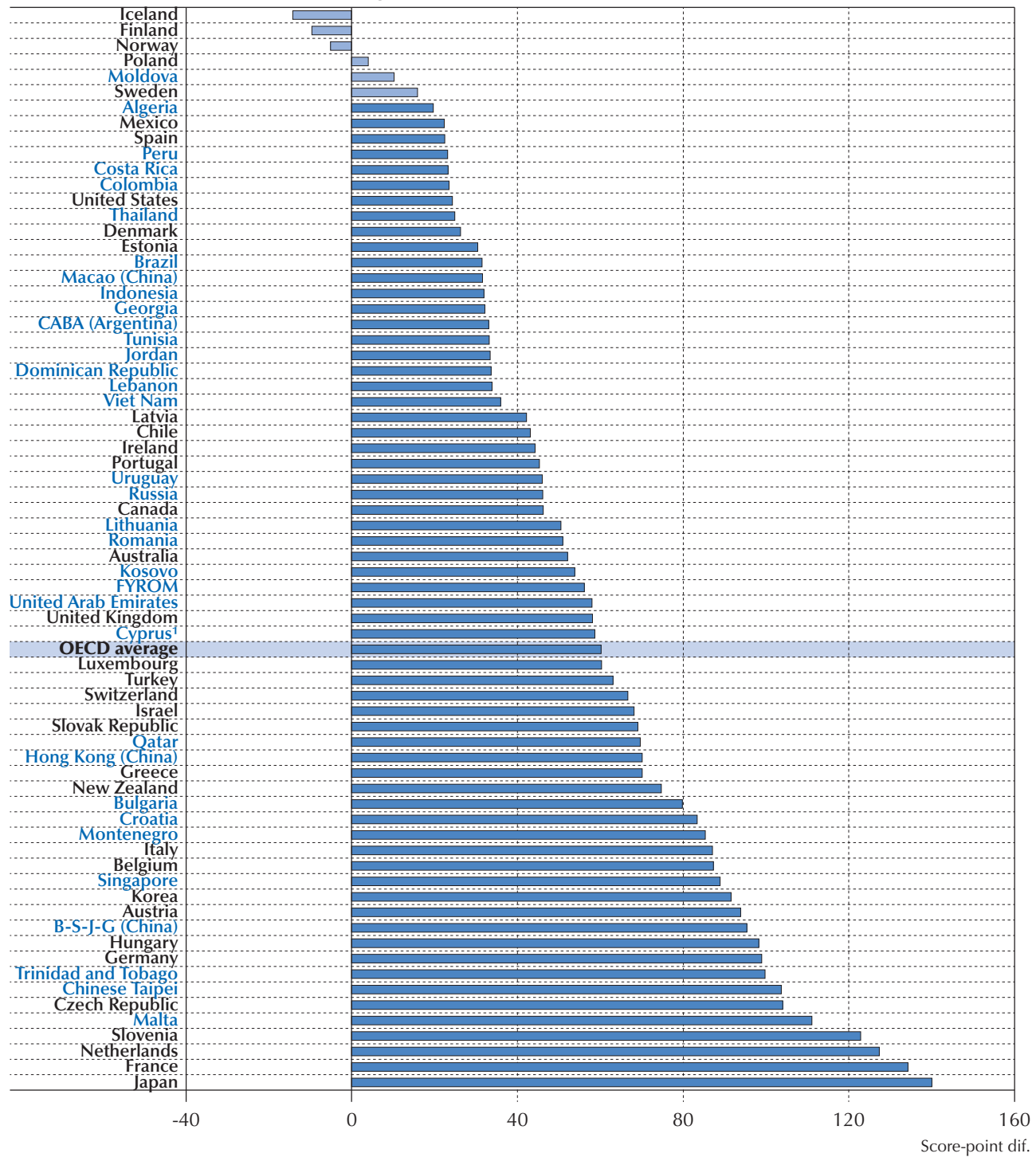

1. See notes at the beginning of this chapter.

Note: Statistically significant score-point differences are shown in a darker tone.

Countries and economies are ranked in ascending order of the change in performance associated with school socio-economic profile.

Source: OECD, PISA 2015 Database, Table 4.6b.

StatLink 光ist https://doi.org/10.1787/888933830671 
The relationship between disadvantaged students' performance and school-level socio-economic profile is significant, even after accounting for students' socio-economic status, in 64 out of the 70 countries and economies that participated in PISA 2015. In Finland, Iceland, Moldova, Norway, Poland and Sweden, there is no significant difference in the performance of disadvantaged students, regardless of whether they attend advantaged or disadvantaged schools, once students' socio-economic status is taken into account.

Student and school socio-economic profiles combined account for about $13 \%$ of the variation in student performance among disadvantaged students, on average across OECD countries (Table 4.6b). The socio-economic profile of schools and students has the strongest relationship with performance in France, Hungary and Slovenia, where over 25\% of the performance variation is so explained. In Algeria, Colombia, Estonia, Macao (China), Poland and Thailand, student and school socio-economic profiles combined explain less than $3 \%$ of the variation in the performance of disadvantaged students (Table 4.6b).

\section{Factors that may mediate the relationship between school socio-economic profile and performance among disadvantaged students}

The literature suggests a variety of reasons why students attending schools with a more advantaged socio-economic profile tend to perform better than their peers attending more disadvantaged schools (Perry and Mcconney, 2010 $0_{[22]}$ ). For example, schools that are more advantaged might provide a better learning environment, whether because of a more favourable disciplinary climate, pedagogical methods or available resources. This type of environment may be more conducive to learning and to achieving better academic outcomes.

PISA 2015 Results (Volume II) (OECD, 2016 $6_{[21]}$ ) identifies factors that are related to student performance and to school socio-economic profile, on average across all students in OECD countries. These factors include school policies and practices, aspects of the school environment, student behaviours and student progress through education. Could these factors mediate the relationship between school socio-economic profile and student performance, particularly for disadvantaged students? As it is not possible to determine causal relationships with PISA data, this section can only provide hypotheses.

As shown in Figure 4.5, four school-level factors - science-specific resources available at school, the availability of science competitions, the extent to which student behaviour hinders student learning (as judged by principals), and average class size - are found to potentially mediate the relationship between school socio-economic profile and the performance of disadvantaged students, on average across OECD countries.

However, mediation at the system level is less commonly observed. Both class size and student behaviour hindering learning are found to be potential mediating factors in only 14 out of 69 education systems. The availability of science competitions is a potential mediating factor in 12 out of 69 education systems, and science-specific resources available at school is a potential mediating factor in just 5 out of 67 education systems. 
Figure $4.5[1 / 2]$ - School policies, practices and characteristics, and the impact of socio-economic status on science performance Disadvantaged students

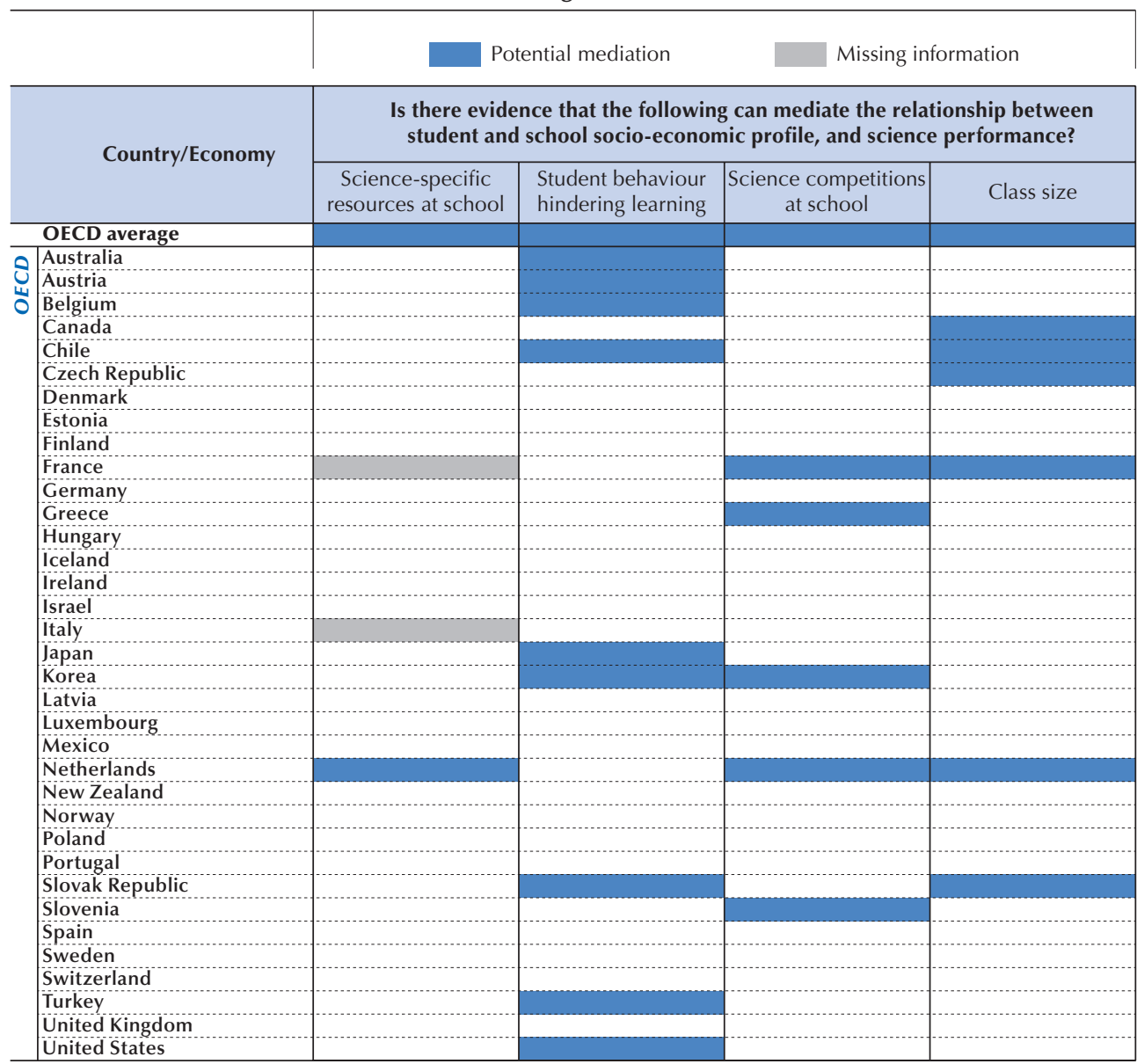

1. See notes at the beginning of this chapter.

Note: These factors were deemed to potentially mediate the relationship between student and school socio-economic profile and student performance if and only if three conditions were fulfilled. First, there must have been a significant relationship between the variable and either student or school socio-economic profile. Second, there must have been a significant relationship between student performance and the variable, after accounting for student and school socio-economic profile. Finally, there must have been a significant change in the relationship between student performance and either student or school socio-economic profile (as measured by regression coefficients) upon the addition of the variable as an explanatory factor in the regression, and this change must have been biased towards zero. In other words, the relationship between student performance and either student or school socio-economic profile must have been significantly smaller in magnitude upon addition of the potentially mediating variable.

Source: OECD, PISA 2015 Database, Tables 4.7a-d.

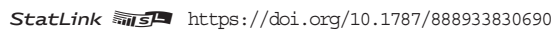


Figure $4.5[2 / 2]$ - School policies, practices and characteristics, and the impact of socio-economic status on science performance Disadvantaged students

\begin{tabular}{|c|c|c|c|c|c|}
\hline & & & ential mediation & Missing inf & ation \\
\hline & \multirow{2}{*}{ Country/Economy } & \multicolumn{4}{|c|}{$\begin{array}{l}\text { Is there evidence that the following can mediate the relationship between } \\
\text { student and school socio-economic profile, and science performance? }\end{array}$} \\
\hline & & $\begin{array}{l}\text { Science-specific } \\
\text { resources at school }\end{array}$ & $\begin{array}{l}\text { Student behaviour } \\
\text { hindering learning }\end{array}$ & $\begin{array}{c}\text { Science competitions } \\
\text { at school }\end{array}$ & Class size \\
\hline \multicolumn{6}{|c|}{ OECD average } \\
\hline \multirow{37}{*}{ 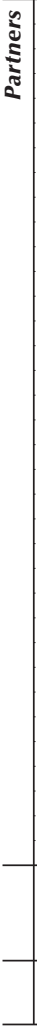 } & Albania & & & & \\
\hline & ÂTgeria & & & & \\
\hline & Brazil & & & & \\
\hline & $\mathrm{B}-\mathrm{S}-\mathrm{J}-\mathrm{G}$ (China) & & & & \\
\hline & Bülgaria & & & & \\
\hline & CABA (Argentina) & & & & \\
\hline & Colombia & & & & \\
\hline & Costa Rica & & & & \\
\hline & Croatia & & & & \\
\hline & Cyprus & & & & \\
\hline & Dominican Republic & & & & \\
\hline & FYROOM & & & & \\
\hline & Georgia & & & & \\
\hline & Hong Kong (China) & & & & \\
\hline & Indonesia & & & & \\
\hline & Jordan & & & & \\
\hline & Kosovo & & & & \\
\hline & Lebanon & & & & \\
\hline & Lithuania & & & & \\
\hline & Macao (China) & & & & \\
\hline & Mälta & & & & \\
\hline & Moldova & & & & \\
\hline & Montenegro & & & & \\
\hline & Peru & & & & \\
\hline & Qatar & & & & \\
\hline & Romania & & & & \\
\hline & Russia & & & & \\
\hline & Singapore & & & & \\
\hline & Chinese Taipei & & & & \\
\hline & Thailand & & & & \\
\hline & Trinidad and Tobago & & & & \\
\hline & Tunisia & & & & \\
\hline & United Arab Emirates & & & & \\
\hline & UUruguay & & & & \\
\hline & Viet Nam & & & & \\
\hline & $\begin{array}{l}\text { Number of countries where } \\
\text { there is a potential mediation } \\
\text { effect due to these variables }\end{array}$ & 5 & 14 & 12 & 14 \\
\hline & $\begin{array}{l}\text { Total number of countries } \\
\text { with available data }\end{array}$ & 67 & 69 & 69 & 69 \\
\hline
\end{tabular}

1. See notes at the beginning of this chapter.

Note: These factors were deemed to potentially mediate the relationship between student and school socio-economic profile and student performance if and only if three conditions were fulfilled. First, there must have been a significant relationship between the variable and either student or school socio-economic profile. Second, there must have been a significant relationship between student performance and the variable, after accounting for student and school socio-economic profile. Finally, there must have been a significant change in the relationship between student performance and either student or school socio-economic profile (as measured by regression coefficients) upon the addition of the variable as an explanatory factor in the regression, and this change must have been biased towards zero. In other words, the relationship between student performance and either student or school socio-economic profile must have been significantly smaller in magnitude upon addition of the potentially mediating variable.

Source: OECD, PISA 2015 Database, Tables 4.7a-d.

StatLink inish https://doi.org/10.1787/888933830690 
Teaching strategies (e.g. teacher-directed science instruction, perceived feedback, adaptive instruction, and enquiry-based science instruction), the student's progress through education (e.g. grade repetition, time spent in science class and attendance at science class), and student behaviour can also mediate the influence of a school's socio-economic profile on the performance of disadvantaged students (Tables 4.8a-k). As shown in Figure 4.6, in 35 out of the 56 education systems for which data are available, skipping an entire day of school - whether by the student him/herself or by his/her classmates - is a potential mediating factor between the school's socio-economic profile and science performance. For example, students from less-advantaged backgrounds attending less-advantaged schools are more likely, on average, to play truant from school, which results in fewer opportunities to learn and lower academic achievement. Skipping some classes is a potential mediating factor in 24 out of the 56 education systems for which data are available, while arriving late for school is a potential mediating factor in 25 of these 56 education systems.

However, there is one caveat: as discussed in PISA 2015 Results (Volume II) (OECD, 2016 ${ }_{[21]}$ ), teachers may adjust their teaching methods depending on their students' abilities. As a result, identifying such teaching strategies as "mediators" may be misleading; it may be student performance that actually mediates the link between a school's socio-economic profile and teaching strategies. This argument could also be made for grade repetition or arriving late for school. Unfortunately, there is no way to distinguish between these possibilities and establish the direction of causality.

\section{The relationship between socio-economic diversity in school and student performance}

How is school-level socio-economic diversity related to performance? This section does not focus exclusively on disadvantaged students because changes in the distribution of disadvantaged students across schools might have implications for the performance of more advantaged students; thus, all students are considered in the analyses below.

A first analysis directly compares students who attend socio-economically diverse schools, as measured by the standard deviation in student-level ESCS within a school. Students who attend schools in the top quarter of the standard deviation of the ESCS index (i.e. the most socioeconomically diverse schools, by this metric) score 34 points lower in the PISA 2015 science assessment than students in the bottom quarter of this index, on average across OECD countries (Table 4.2). This is also true in 45 of the 67 PISA-participating education systems, with gaps of over 100 score points observed in Israel, Qatar, Singapore and the United Arab Emirates. Differences in the other direction - where students in the most socio-economically diverse schools score higher than students in the least diverse schools - are observed only in Turkey and Viet Nam.

Hence, upon first glance, it appears that socio-economic diversity at school, as measured by the standard deviation, is associated with poorer performance. However, greater socio-economic diversity at school is also associated with a less-advantaged school socio-economic profile (i.e. advantaged schools are the least socio-economically diverse) (Table 4.4). Can the performance gap described above therefore be attributed solely to socio-economic diversity in the school? 


\section{Figure $4.6[1 / 2]$ - Student truancy and the impact of socio-economic status on science performance Disadvantaged students}

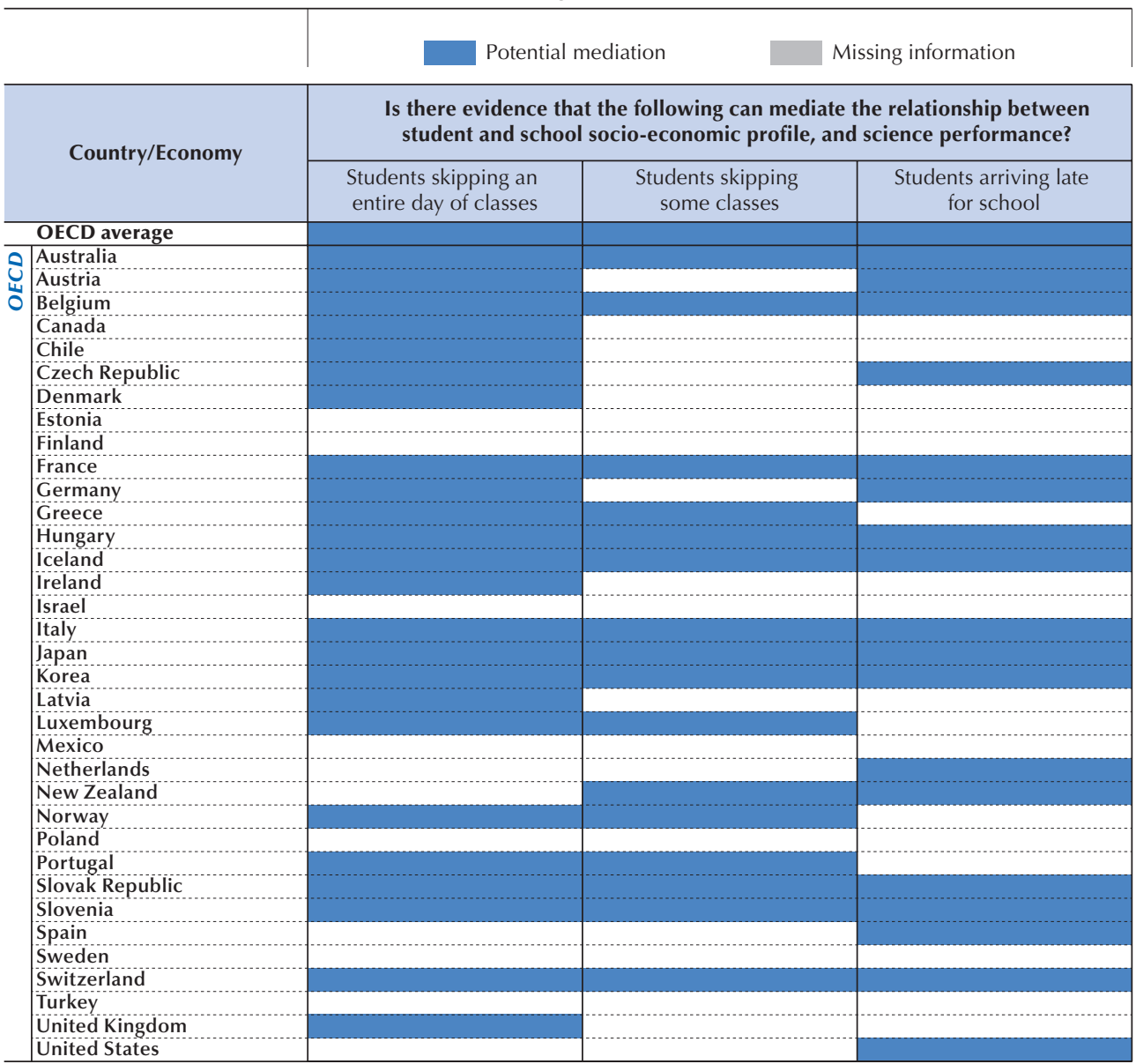

1. See notes at the beginning of this chapter.

Note: These factors were deemed to potentially mediate the relationship between student and school socio-economic profile and student performance if and only if three conditions were fulfilled. First, there must have been a significant relationship between the variable (at either the student or school level) and either student or school socio-economic profile. Second, there must have been a significant relationship between student performance and the variable (at either the student or school level), after accounting for student and school socio-economic profile. Finally, there must have been a significant change in the relationship between student performance and either student or school socio-economic profile (as measured by regression coefficients) upon the addition of the variable (at both the student and school levels) as an explanatory factor in the regression, and this change must have been biased towards zero. In other words, the relationship between student performance and either student or school socio-economic profile must have been significantly smaller in magnitude upon addition of the potentially mediating variable.

Source: OECD, PISA 2015 Database, Tables 4.8a-c.

StatLink ints https://doi.org/10.1787/888933830709 


\section{Figure $4.6[2 / 2]$ - Student truancy and the impact of socio-economic status on science performance Disadvantaged students}

\begin{tabular}{|c|c|c|c|c|}
\hline & & Potent & ation & g information \\
\hline \multirow{2}{*}{\multicolumn{2}{|c|}{ Country/Economy }} & \multicolumn{3}{|c|}{$\begin{array}{l}\text { Is there evidence that the following can mediate the relationship between } \\
\text { student and school socio-economic profile, and science performance? }\end{array}$} \\
\hline & & $\begin{array}{l}\text { Students skipping an } \\
\text { entire day of classes }\end{array}$ & $\begin{array}{l}\text { Students skipping } \\
\text { some classes }\end{array}$ & $\begin{array}{c}\text { Students arriving late } \\
\text { for school }\end{array}$ \\
\hline \multicolumn{5}{|c|}{ OECD average } \\
\hline \multirow{37}{*}{ 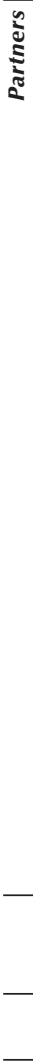 } & Albania & & & \\
\hline & Álgeria & & & \\
\hline & Brazil & & & \\
\hline & $B-S-J-G$ (China) & & & \\
\hline & Bulgaria & & & \\
\hline & CABA (Argentina) & & & \\
\hline & Colombia & & & \\
\hline & Costa Rica & & & \\
\hline & Croatia & & & \\
\hline & Cyprus 1 & & & \\
\hline & Dominican Republic & & & \\
\hline & FYROM & & & \\
\hline & Georgia & & & \\
\hline & Hong Kong (China) & & & \\
\hline & Indonesia & & & \\
\hline & Jordan & & & \\
\hline & Kosovo & & & \\
\hline & Lebanon & & & \\
\hline & Lithuania & & & \\
\hline & Macao (China) & & & \\
\hline & Malta & & & \\
\hline & Moldova & & & \\
\hline & Montenegro & & & \\
\hline & Peru & & & \\
\hline & Qatar & & & \\
\hline & Romania & & & \\
\hline & Russia & & & \\
\hline & Singapore & & & \\
\hline & Chinese Taipei & & & \\
\hline & Thailand & & & \\
\hline & Trinidad and Tobago & & & \\
\hline & Tunisia & & & \\
\hline & United Arab Emirates & & & \\
\hline & Uruguay & & & \\
\hline & Viet Nam & & & \\
\hline & $\begin{array}{l}\text { Number of countries where } \\
\text { there is a potential mediation } \\
\text { effect due to these variables }\end{array}$ & 35 & 24 & 25 \\
\hline & $\begin{array}{l}\text { Total number of countries } \\
\text { with available data }\end{array}$ & 56 & 56 & 56 \\
\hline
\end{tabular}

1. See notes at the beginning of this chapter.

Note: These factors were deemed to potentially mediate the relationship between student and school socio-economic profile and student performance if and only if three conditions were fulfilled. First, there must have been a significant relationship between the variable (at either the student or school level) and either student or school socio-economic profile. Second, there must have been a significant relationship between student performance and the variable (at either the student or school level), after accounting for student and school socio-economic profile. Finally, there must have been a significant change in the relationship between student performance and either student or school socio-economic profile (as measured by regression coefficients) upon the addition of the variable (at both the student and school levels) as an explanatory factor in the regression, and this change must have been biased towards zero. In other words, the relationship between student performance and either student or school socio-economic profile must have been significantly smaller in magnitude upon addition of the potentially mediating variable.

Source: OECD, PISA 2015 Database, Tables 4.8a-c.

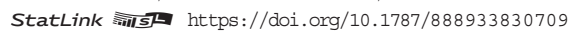


To answer this question, student and school socio-economic profiles were used as controls in a regression of science performance over the school-level variation in socio-economic profile.

On average across OECD countries, students' science scores drop by eight points for every additional unit increase of the school-level standard deviation in socio-economic status, even after accounting for student and school socio-economic profile (Table 4.6a). ${ }^{6}$ As shown in Figure 4.7, socio-economic diversity in school has a negative relationship with student performance in 18 out of the 70 countries and economies that participated in PISA 2015. However, in 46 countries and economies, the school-level standard deviation in ESCS is unrelated to student performance. In the remaining six countries (Kosovo, Luxembourg, Portugal, Trinidad and Tobago, Turkey and the United States), more diverse schools show better science performance, on average, after accounting for student and school socio-economic profile (Table 4.6a). ${ }^{7}$

In summary, on average across OECD countries, attending socio-economically diverse schools is negatively related to science performance, even after accounting for student and school socioeconomic profile. However, this relationship is observed in only a quarter of PISA-participating education systems. 
Figure 4.7 - Socio-economic diversity in school and student performance Relationship between the standard deviation of student socio-economic status in school and student performance

\begin{tabular}{|c|c|c|}
\hline \multicolumn{3}{|c|}{ Student performance... } \\
\hline $\begin{array}{c}\ldots \text { is higher in schools } \\
\text { with greater school- } \\
\text { level diversity }\end{array}$ & $\begin{array}{c}\ldots \text { has no significant } \\
\text { association with school- } \\
\text { level diversity }\end{array}$ & $\begin{array}{c}\ldots \text { is lower in schools } \\
\text { with greater school- } \\
\text { level diversity }\end{array}$ \\
\hline $\begin{array}{l}\text { Kosovo } \\
\text { Luxembourg } \\
\text { Portugal } \\
\text { Trinidad and Tobago } \\
\text { Turkey } \\
\text { United States }\end{array}$ & $\begin{array}{l}\text { Algeria } \\
\text { Australia } \\
\text { Austria } \\
\text { Belgium } \\
\text { Brazil } \\
\text { B-S-J-G (China) } \\
\text { Bulgaria } \\
\text { CABA (Argentina) } \\
\text { Canada } \\
\text { Chile } \\
\text { Colombia } \\
\text { Costa Rica } \\
\text { Croatia } \\
\text { Denmark } \\
\text { Dominican Republic } \\
\text { Estonia } \\
\text { France } \\
\text { Georgia } \\
\text { Greece } \\
\text { Hong Kong (China) } \\
\text { Hungary } \\
\text { Iceland } \\
\text { Indonesia } \\
\text { Ireland } \\
\text { Italy } \\
\text { Japan } \\
\text { Korea } \\
\text { Lebanon } \\
\text { Malta } \\
\text { Mexico } \\
\text { Netherlands } \\
\text { New Zealand } \\
\text { Norway } \\
\text { Romania } \\
\text { Slovak Republic } \\
\text { Slovenia } \\
\text { Spain } \\
\text { Sweden } \\
\text { Switzerland } \\
\text { Chinese Taipei } \\
\text { Thailand } \\
\text { Tunisia } \\
\text { United Kingdom } \\
\text { Uruguay } \\
\text { Viet Nam } \\
\text { tond }\end{array}$ & $\begin{array}{l}\text { Cyprus² }^{2} \\
\text { Czech Republic } \\
\text { Finland } \\
\text { FYROM } \\
\text { Germany } \\
\text { Israel } \\
\text { Jordan } \\
\text { Latvia } \\
\text { Lithuania } \\
\text { Macao (China) } \\
\text { Moldova } \\
\text { Montenegro } \\
\text { Peru } \\
\text { Poland } \\
\text { Qatar } \\
\text { Russia } \\
\text { Singapore } \\
\text { United Arab Emirates }\end{array}$ \\
\hline
\end{tabular}

1. After accounting for student and school socio-economic profile.

2. See notes at the beginning of this chapter.

Source: OECD, PISA 2015 Database, Table 4.6a.

StatLink 部 St https://doi.org/10.1787/888933830728 


\section{Notes}

1. Various indicators have been proposed in the literature to measure segregation at school (Frankel and Volij, $2011_{[23]}$ ), and different indicators may be more relevant for certain analyses (for instance, of the extent to which the socio-economic composition in schools mirrors that of the general population or the extent to which one group is segregated from the rest of the population). The measure used here is related to the interaction indices, such as the isolation or exposure indices, that measure the probability that one type of student interacts with other types of students (Massey and Denton, $1988_{[24]}$ ). As schools with lower ESCS by definition enrol a large share of disadvantaged students, a disadvantaged student in a disadvantaged school is more likely to interact more with students of low socio-economic status.

The proportion of disadvantaged students who attend disadvantaged schools is highly correlated with other measures of socio-economic segregation, including those that do not focus exclusively on disadvantaged students. One of these measures is the PISA index of social inclusion, which is the proportion of the total variance in student socio-economic status in an education system that is found within schools, as opposed to between schools. The coefficient of determination, or $\mathrm{R}^{2}$ value, between the proportion of disadvantaged students who attend disadvantaged schools and the index of social inclusion is 0.77 . This high degree of correlation indicates that this new measure, while focussing on disadvantaged students, is also informative about the segregation of students of all socio-economic backgrounds.

2. In this report, in order to obtain an accurate school-level average of student socio-economic status, only schools where at least 10 students had a valid ESCS index were retained for analysis. This is in contrast to previous PISA reports and the other chapters of this report, where all schools were retained. In a school where only one student has a valid ESCS index, the school-level ESCS would be equivalent to the ESCS index of that one student.

One reason for removing schools with a small number of student-level ESCS measurements is the inherent inaccuracy associated with calculating a mean from a small number of observations. However, the schoollevel mean may also be biased due to the specific way in which PISA samples students. Only 15-year-old students are sampled, and a large school may have a small number of 15-year-old students if such students are not in the modal grade but have been pushed forward or held back. In the former situation, these students are likely to perform better than the average student and therefore be of higher socio-economic status; using their average ESCS index risks overestimating the school's socio-economic profile. The reverse is true if students have been held back.

Robustness analyses show that while the students removed from the analysis generally scored lower than the students who were retained, the relationship between performance and both student- and school-level ESCS generally remained unchanged upon removing schools with fewer than 10 students participating in the PISA assessment.

3. In the most extreme situation, where an education system is completely socio-economically segregated and disadvantaged students attend schools only with other disadvantaged students, $100 \%$ of disadvantaged students would attend disadvantaged schools. At the other extreme, where an education system is completely integrated and disadvantaged (and advantaged) students are equally allocated among all schools, $25 \%$ of disadvantaged students would attend disadvantaged schools. Indeed, in this extreme situation of complete socio-economic integration, there would be no difference between disadvantaged and advantaged schools, as all schools would have an identical school-level ESCS. As disadvantaged schools are defined as comprising $25 \%$ of the total student population, $25 \%$ of disadvantaged students would also be found in disadvantaged schools. By definition, disadvantaged schools have a greater proportion of disadvantaged students than would be expected in the extreme situation where schools are completely integrated.

4. The figure also shows that the difference between doubly disadvantaged students (disadvantaged students attending disadvantaged schools) and doubly advantaged students (advantaged students attending advantaged schools) is 130 points in the PISA 2015 science assessment, on average across OECD countries. Although this comparison is not the focus of the chapter, it shows that there is an even larger disparity in performance between the two socio-economic extremes in education systems. 
5. Without considering student socio-economic status, an increase of one unit in school-level ESCS is associated with an improvement of 66 score points in the PISA 2015 science assessment. The small decrease in the strength of the association after including student-level ESCS as an explanatory variable is due to the positive relationship between student- and school-level ESCS.

6. This gap should be relativised by the fact that the standard deviation of the school-level standard deviation in socio-economic status is 0.14 across OECD countries. Moreover, the average standard deviation of ESCS in the bottom quarter of this index is 0.60 , while that in the top quarter is 0.94 , on average across OECD countries. In other words, a one-unit increase would be an exceptionally large increase when considering actual schools.

7. Another factor that may influence the relationship between student performance and student- and school-level socio-economic profile (including school-level socio-economic diversity) is immigration whether a student has an immigrant background and the proportion of schoolmates who have an immigrant background. Previous PISA reports (such as PISA 2015 Results (Volume I) [OECD, 2016 $\left.6_{[1]}\right]$ ) have shown that students with an immigrant background score below non-immigrant students in most PISA-participating countries, both before and after accounting for socio-economic status. Accounting for immigrant background does not, for the most part, change the results presented in Figure 4.7. The major changes are that student performance in Austria and Macao (China) is observed to be higher in schools with greater school-level socioeconomic diversity; student performance in Malta is observed to be lower in schools with greater schoollevel socio-economic diversity; and student performance in Finland and Germany is no longer significantly associated with school-level socio-economic diversity. On average across OECD countries, however, no significant association between school-level diversity and student performance is observed after accounting for immigrant background.

\section{References}

Altonji, J., C. Huang and C. Taber (2015), "Estimating the Cream Skimming Effect of School Choice", [13] Journal of Political Economy, Vol. 123/2, pp. 266-324, http://dx.doi.org/10.1086/679497.

Antikainen, A. (2006), "In Search of the Nordic Model in Education", Scandinavian Journal of Educational Research, Vol. 50/3, pp. 229-243, http://dx.doi.org/10.1080/00313830600743258.

Burke, M. and T. Sass (2013), "Classroom Peer Effects and Student Achievement", Journal of Labor [18] Economics, Vol. 31/1, pp. 51-82, http://dx.doi.org/10.1086/666653.

Chmielewski, A. and C. Savage (2015), "Socioeconomic Segregation Between Schools in the United States and Latin America, 1970-2012", in McCarthy, G., G. Ingram and S. Moody (eds.), Land and the City, Lincoln Institute of Land Policy, Cambridge, MA, www.lincolninst.edu/publications/ conference-papers/socioeconomic-segregation-between-schools-united-states-latin-america (accessed on 23 March 2018).

Coy, M. and M. Pöhler (2002), "Gated Communities in Latin American Megacities: Case Studies in Brazil and Argentina", Environment and Planning B: Planning and Design, Vol. 29/3, pp. 355-370, http://dx.doi.org/10.1068/b2772x.

Frankel, D. and O. Volij (2011), "Measuring school segregation", Journal of Economic Theory, Vol. 146/1, pp. 1-38, http://dx.doi.org/10.1016/J.JET.2010.10.008.

Hanushek, E. et al. (2003), "Does peer ability affect student achievement?", Journal of Applied Econometrics, Vol. 18/5, pp. 527-544, http://dx.doi.org/10.1002/jae.741. 
Hsieh, C. and M. Urquiola (2006), "The effects of generalized school choice on achievement and stratification: Evidence from Chile's voucher program", Journal of Public Economics, Vol. 90/8-9, pp. 1477-1503, http://dx.doi.org/10.1016/I.JPUBECO.2005.11.002.

Lavy, V., O. Silva and F. Weinhardt (2012), "The Good, the Bad, and the Average: Evidence on Ability Peer Effects in Schools", Journal of Labor Economics, Vol. 30/2, pp. 367-414, http://dx.doi.org/10.1086/663592.

Lie, S., P. Linnakylä and A. Roe (eds.) (2003), Northern Lights on PISA. Unity And Diversity In The Nordic Countries In PISA 2000, Department of Teacher Education and School Development, University of Oslo, www.oecd.org/finland/33684855.pdf (accessed on 23 March 2018).

Liu, H. et al. (2015), "School processes mediate school compositional effects: model specification and estimation", British Educational Research Journal, Vol. 41/3, pp. 423-447, http://dx.doi.org/10.1002/berj.3147.

Massey, D. and N. Denton (1988), "The Dimensions of Residential Segregation", Social Forces, Vol. 67/2, p. 281, http://dx.doi.org/10.2307/2579183.

Musset, P. (2012), "School Choice and Equity: Current Policies in OECD Countries and a Literature Review", OECD Education Working Papers, No. 66, OECD Publishing, Paris, http://dx.doi.org/10.1787/5k9fq23507vc-en.

Nash, R. (2003), "Is the School Composition Effect Real?: A Discussion With Evidence From the UK PISA Data", School Effectiveness and School Improvement, Vol. 14/4, pp. 441-457, http://dx.doi.org/10.1076/sesi.14.4.441.17153.

OECD (2018), Effective Teacher Policies: Insights from PISA, PISA, OECD Publishing, Paris, http://dx.doi.org/10.1787/9789264301603-en.

OECD (2017), School choice and school vouchers: An OECD perspective,

www.oecd.org/education/School-choice-and-school-vouchers-an-OECD-perspective.pdf (accessed on 12 June 2018).

OECD (2016), PISA 2015 Results (Volume I): Excellence and Equity in Education, PISA, OECD Publishing, Paris, http://dx.doi.org/10.1787/9789264266490-en.

OECD (2016), PISA 2015 Results (Volume II): Policies and Practices for Successful Schools, PISA, OECD Publishing, Paris, http://dx.doi.org/10.1787/9789264267510-en.

Opdenakker, M. and J. Damme (2007), "Do school context, student composition and school leadership affect school practice and outcomes in secondary education?", British Educational Research Journal, Vol. 33/2, pp. 179-206, http://dx.doi.org/10.1080/01411920701208233.

Perry, L. and A. Mcconney (2010), "Does the SES of the School Matter? An Examination of Socioeconomic Status and Student Achievement Using PISA 2003", Teachers College Record, Vol. 112/4, pp. 1137-1162, www.tcrecord.org ID Number: 15662.

Sabatini, F. and R. Salcedo (2007), "Gated communities and the poor in Santiago, Chile: Functional and symbolic integration in a context of aggressive capitalist colonization of lower-class areas", Housing Policy Debate, Vol. 18/3, pp. 577-606, http://dx.doi.org/10.1080/10511482.2007.9521612.

Schneider, M., G. Elacqua and J. Buckley (2006), "School choice in Chile: Is it class or the classroom?", Journal of Policy Analysis and Management, Vol. 25/3, pp. 577-601, http://dx.doi.org/10.1002/pam.20192. 
Thrupp, M. (1995), "The School Mix Effect: The history of an enduring problem in educational [14] research, policy and practice", British Journal of Sociology of Education, Vol. 16/2, pp. 183-203, http://dx.doi.org/10.1080/0142569950160204.

Valenzuela, J., C. Bellei and D. Ríos (2014), "Socioeconomic school segregation in a market- [10] oriented educational system. The case of Chile", Journal of Education Policy, Vol. 29/2, pp. 217-241, http://dx.doi.org/10.1080/02680939.2013.806995. 


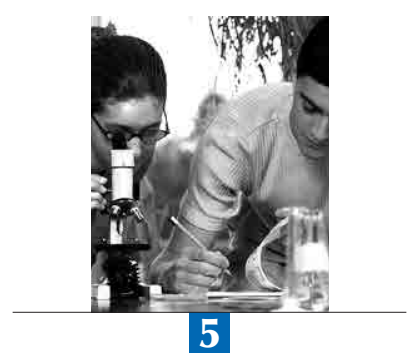

\section{Educational mobility and school-to-work transitions among disadvantaged students}

This chapter uses longitudinal data from five countries (Australia, Canada, Denmark, Switzerland and the United States) to examine the relationship between cognitive competencies at age 15 and educational attainment and early labour market outcomes at age 25 . It also explores different sources of disadvantage, related to a student's home, school and social environment, which contribute to skills gaps during compulsory education and reduce the upward social mobility of children from less-educated families. 


\section{What the data tell us}

- Across the five countries analysed, students with at least one tertiary-educated parent are between 17 and 30 percentage points more likely to complete university than their peers without tertiary-educated parents.

- Students who score in the top quarter in reading are between 38 and 53 percentage points more likely to complete university than students who score in the bottom quarter. Differences in 15-year-olds' reading performance explain between $27 \%$ and $43 \%$ of the difference in university completion rates between students with and those without tertiaryeducated parents. This suggests that reducing the gaps related to socio-economic status in what students learn during compulsory schooling could increase upward educational mobility.

- Across the five countries considered, students with tertiary-educated parents are between 7 and 20 percentage points more likely to be employed in jobs requiring tertiary education at age 25 than students without tertiary-educated parents. Accounting for differences in PISA performance reduces this difference to between 4 and 13 percentage points.

- Lower expectations, less family wealth, concentration in disadvantaged schools, and limited access to cultural activities represent certain characteristics of students from less-educated families that are related to the lower likelihood of completing a university education.

\section{DEFINING SOCIAL AND EDUCATIONAL MOBILITY}

Social mobility refers to a change in the economic or social status of individuals between their childhood and adult life. Children's ability to attain a higher social status than their parents depends on multiple factors, including health, social and cultural capital, education and the evolution of the labour market (Nunn et al., 2007 ${ }_{[1]}$ ). While individual effort can result in upward social mobility, the chances that someone from a disadvantaged background will succeed in life are also bound by where the person lives, and by the social and cultural group to which he or she belongs (Ololube, Onyekwere and Agbor, 2015 [2]; Schaefer, 2005 ${ }_{[3]}$ ).

Inequitable education and career opportunities - shaped by factors such as race, gender or socio-economic status - can create inefficiencies that hinder economic growth, as they lead to significant misallocations of skills and talent (Hsieh et al., 2013 $\left.{ }_{[4]}\right)$.

Because of differences in family and social environments, children begin formal schooling with different levels of skills (Downey, Hippel and Broh, 2004 $4_{[5]}$ ). Schools can play an important role in compensating for these initial inequalities. But education systems that fail to provide equal opportunities to all students can end up reinforcing, rather than helping to reduce, social inequalities that may threaten social cohesion (OECD, 2010 $0_{[6]}$ ). In today's shifting labour market, the gaps between low-qualified and high-qualified workers are expanding: less-educated adults tend to face the highest unemployment and inactivity rates, as well as the lowest and most rapidly 
declining relative wages, on average (OECD, $\left.2017_{[7]}\right)$. That, in turn, can lead to a wide range of social problems, including poverty, poor health and crime (Schoenfeld, $2002_{[8]}$ ).

How successful are today's schools at counterbalancing the forces that perpetuate existing inequalities in society? Some insights into this question can be obtained by analysing the relationship between socio-economic gaps in cognitive outcomes near the end of compulsory schooling - a measure of equity in education - and socio-economic gaps in higher education and labour market outcomes in early adult life. This analysis can be conducted by studying longitudinal data that provide information on the same individuals at different points in time.

This chapter uses longitudinal data from five countries - Australia, Canada, Denmark, Switzerland and the United States (Box 5.1) - to analyse the relationship between performance at school and educational mobility, defined as the likelihood that a student without tertiary-educated parents will complete tertiary education. ${ }^{1}$ The chapter also explores certain dimensions of disadvantage (less family wealth, less cultural capital, negative dispositions towards education, and school segregation) that may help to explain the strong links between parents' education, students' reading proficiency at the end of compulsory schooling, and transitions into higher education and skilled employment.

\section{Box 5.1 Longitudinal country data}

Analyses in this chapter are based on longitudinal data, accessed by the OECD Secretariat in raw form or through collaboration with national researchers, from the following countries (Figure 5.1). ${ }^{2}$

Each of the datasets collects baseline data on nationally representative samples of students when they are 15 years old. The datasets from Australia, Canada, Denmark and Switzerland followed the transition of early PISA cohorts into adulthood, and can therefore shed light on the power of PISA literacy measures to accurately predict social mobility. Nationally representative longitudinal data from the United States, while not based on PISA participants, are also used because the data include measures of literacy proficiency of students around the age of 15, for which a concordance with PISA scores has been developed. While the frequency and timeline of follow-up surveys vary by country, all the datasets collect information on young people when they are approximately 25 years old (the only exception is Denmark, where the analysis in this chapter refers to individuals who are either 26 or 27 years old).

- The data for Denmark is derived from PISA and the Survey of Adult Skills (a product of the OECD Programme for the International Assessment of Adult Competencies [PIAAC]). Participants in the PISA 2000 cycle were tested and interviewed again in the 2012 Survey of Adult Skills (PIAAC).

- Transitions from Education to Employment (TREE1) ${ }^{3}$ surveys the post-secondary education and labour market pathways of students in Switzerland, and is the country's first longitudinal study of this type at the national level. TREE1, the project's first cohort, is based on a sample of students who participated in PISA 2000. The sample was tracked for follow-up surveys annually from 2001 to 2007, and twice more (in 2010 and 2014). 
Figure 5.1 - Description of longitudinal data sets

\begin{tabular}{|c|c|c|c|c|c|}
\cline { 2 - 6 } \multicolumn{1}{c|}{} & Australia & Canada & Denmark & Switzerland & United States \\
\hline $\begin{array}{c}\text { Data source } \\
\text { (surveys) }\end{array}$ & $\begin{array}{c}\text { Longitudinal } \\
\text { Surveys of } \\
\text { Australian } \\
\text { Youth (LSAY) }\end{array}$ & $\begin{array}{c}\text { Youth in } \\
\text { Transition } \\
\text { Survey (YITS) }\end{array}$ & $\begin{array}{c}\text { PISA - PIAAC } \\
\begin{array}{c}\text { Transitions from } \\
\text { Education to } \\
\text { Employment } \\
\text { (TREE1) }\end{array}\end{array}$ & $\begin{array}{c}\text { Educational } \\
\text { Longitudinal } \\
\text { Study of } \\
2002 \text { (ELS) }\end{array}$ \\
\hline $\begin{array}{c}\text { Baseline data collection } \\
\text { Age of students at last } \\
\text { follow-up survey }\end{array}$ & PISA 2003 & PISA 2000 & PISA 2000 & PISA 2000 & ELS 2002 \\
\hline $\begin{array}{c}\text { Access to the data } \\
\text { Data available } \\
\text { upon request }\end{array}$ & $\begin{array}{c}\text { Ell results } \\
\text { Employment } \\
\text { and Social } \\
\text { Development } \\
\text { Canada (ESDC) }\end{array}$ & $\begin{array}{c}\text { Data available } \\
\text { upon request }\end{array}$ & $\begin{array}{c}\text { Data available } \\
\text { upon request }\end{array}$ & $\begin{array}{c}\text { Data available } \\
\text { upon request, } \\
\text { with restrictions } \\
\text { on some }\end{array}$ \\
\hline variables ${ }^{2}$ \\
\hline Sample at last follow-up
\end{tabular}

1. The final survey for Switzerland was conducted in 2014, when participants were 29. However, the previous survey, conducted in 2010, was used for this analysis in order to obtain information on participants at the age of 25. 2. The public access version of the ELS data excludes school identifiers, as well as detailed information on student degree selection, employment, and post-secondary performance.

- The Longitudinal Study of Australian Youth (LSAY) tracks students annually for a period of 10 years as they move from school into further study, work and other destinations. While the first surveys began in 1995, participants have been recruited from Australian schools that have taken part in PISA since 2003 (Y03).

- Canada designed the Youth in Transition Survey (YITS) to examine the patterns of, and influences on, major transitions in young people's lives, particularly with respect to education, training and work. PISA/YITS is a special project that aligned the two survey programmes. The PISA 2000 cohort was selected to participate in YITS, and was surveyed in follow-up interviews every two years through 2010. These data have not been released for public access, so all estimates were obtained through collaboration with national researchers at Employment and Social Development Canada (ESDC), who conducted the analyses on the basis of statistical programmes prepared by the OECD. ${ }^{4}$

- The Educational Longitudinal Study of 2002 (ELS) is the fourth in a series of American school-based longitudinal studies, focusing on the transitions of American youth from secondary school into higher education and the labour market. While the study does not involve PISA participants, it provides nationally representative data and records literacy measures for 15 -year-old students that can be benchmarked to PISA. Follow-up surveys were conducted in 2004, 2006 and 2012/13. The public version of this dataset excludes access to school identifiers, as well as detailed reports of students' degree type, employment and post-secondary transcripts. 


\section{PROGRESSION INTO HIGHER EDUCATION AND PISA PERFORMANCE AT AGE 15}

This chapter focuses on upward educational mobility, defined as the likelihood that a student without tertiary-educated parents attains tertiary education. The percentage of students without a tertiary-educated parent ranges from $26 \%$ in Denmark to $62 \%$ in the United States (Table 5.36). The figures included in this chapter refer to advantaged and disadvantaged students as students with and without a tertiary-educated parent.

Figure 5.2 shows the rates at which students with and those without a tertiary-educated parent pass through various levels of education. In Australia, Canada and the United States, all students are enrolled in a comprehensive programme of secondary education that ends when they are about 18 years old. However, some students in these countries drop out during upper secondary education, as education is compulsory only until the student reaches the age of 16 (Table 5.35).

In Denmark and Switzerland, compulsory secondary education programmes end when students are between 15 and 16 years old. Students in these two countries then decide whether to continue secondary schooling and enter a separate, non-compulsory programme track. This more segmented course of studies may explain why the percentage of students completing secondary education is lower in Denmark and Switzerland than in Australia, Canada and the United States.

Figure 5.2 - Highest level of education completed, by socio-economic status Percentage of advantaged and disadvantaged students who completed each level of education

\begin{tabular}{|c|c|c|c|c|c|c|c|c|}
\hline & \multicolumn{2}{|c|}{ Upper secondary } & \multicolumn{2}{|c|}{$\begin{array}{l}\text { Tertiary vocational } \\
\text { training }\end{array}$} & \multicolumn{2}{|c|}{ University } & \multicolumn{2}{|c|}{$\begin{array}{l}\text { Advanced degree } \\
\text { (completed or } \\
\text { currently enrolled) }\end{array}$} \\
\hline & Adv. & Disadv. & Adv. & Disadv. & Adv. & Disadv. & Adv. & Disadv. \\
\hline & $\%$ & $\%$ & $\%$ & $\%$ & $\%$ & $\%$ & $\%$ & $\%$ \\
\hline Australia & 98 & 96 & 12 & 11 & 50 & 29 & 12 & 6 \\
\hline Canada & 97 & 93 & 36 & 37 & 41 & 24 & 11 & 5 \\
\hline Denmark & 90 & 85 & 20 & 17 & 33 & 14 & 28 & 11 \\
\hline Switzerland & 91 & 84 & 17 & 15 & 28 & 11 & 14 & 5 \\
\hline United States & 97 & 92 & 14 & 21 & 52 & 22 & 12 & 3 \\
\hline
\end{tabular}

Notes: Results based on students' self-reports.

Values with statistically significant differences between advantaged and disadvantaged students are displayed in bold. Advanced degree includes those who have completed or are currently attending a master's or doctoral programme.

Advantaged students are those with at least one tertiary-educated parent; disadvantaged students are those without a tertiaryeducated parent.

Tertiary vocational education refers to tertiary-level (ISCED 5B) vocational training.

Data from Canada did not allow for distinguishing between ISCED 4 and ISCED 5B vocational training, therefore country estimates include both levels of post-secondary vocational education.

Source: OECD, PISA 2000 and PISA 2003 Databases, Tables 5.1, 5.3, 5.5 and 5.37.

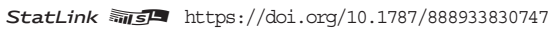


In all countries except Australia, students without tertiary-educated parents are less likely than students with a tertiary-educated parent to complete secondary education. However, when looking at the rates of university completion by age 25, a much larger gap related to parents' education emerges in all countries. Denmark and Switzerland, with more prominent vocational tracks, have lower university completion rates overall. In Denmark, students with tertiaryeducated parents are approximately 19 percentage points more likely than their peers with less-educated parents to complete university; in Switzerland, they are 16 percentage points more likely than their peers with less-educated parents to do so. ${ }^{5}$ Australia, Canada and the United States have higher rates of university completion overall, possibly because these countries do not separate students into academic and vocational tracks at the secondary level, so that students are often less prepared to enter the job market immediately after secondary education (Hanushek, Woessmann and Zhang, $2011_{[9]}$ ). Despite higher rates of university completion among students with less-educated parents, the absolute gaps between advantaged and disadvantaged groups are even larger in these countries, with a nearly 30 percentage-point difference in the United States, a 21 percentage-point difference in Australia, and a 17 percentage-point difference in Canada.

Across all countries, students without tertiary-educated parents are also less likely to pursue an advanced university degree (master's or PhD) than their peers with tertiary-educated parents. In the United States, only $3 \%$ of students without a tertiary-educated parent - compared to $12 \%$ of students with a tertiary-educated parent - are enrolled in or have completed an advanced university degree when they are around 25 years old. For the other countries considered in this chapter, gaps in attainment of advanced degrees range from 5 to 17 percentage points between the two groups of students (Table 5.37).

PISA data show that differences related to socio-economic status in what students have learned and can do with their knowledge are large across all countries (OECD, 2016 $6_{[10]}$ ). To what extent do these learning gaps explain educational mobility? If students score similarly in the PISA reading test, are there still differences between students from more- and less-educated families in how they progress through school after the age of 15 ? These questions are important because they can help identify the potential impact on educational and social mobility of policies that aim to reduce gaps in opportunities to learn during compulsory schooling.

Examining the relationship between university completion and PISA performance reveals significant differences in achievement across quarters of reading performance in all countries (Figure 5.3). In Switzerland, only 1\% of students in the bottom quarter of reading performance, compared to $39 \%$ of students in the top quarter, complete university. In Canada, students in the top quarter of reading performance are 53 percentage points more likely than students in the bottom quarter to earn a university degree. In Australia, Denmark and the United States, differences between these two groups range from 44 to 51 percentage points.

The relationship between 15-year-old students' performance and completion of a tertiary degree holds across different measures of performance and different fields of study in tertiary education. For example, in Denmark, $15 \%$ of students in the top quarter of science performance complete a university degree in mathematics, engineering or science, while only $2 \%$ of students in the bottom quarter of science performance complete such degrees (Table 5.32). Across countries, no large difference in students' choice of field of study at university, based on their parents' 
education, is observed (Table 5.23). Only in Canada are students with tertiary-educated parents more likely than students with less-educated parents to choose to pursue science, mathematics or engineering degrees.

Figure 5.3 - University completion, by quarter of PISA reading performance Percentage of 25-year-old respondents who completed university

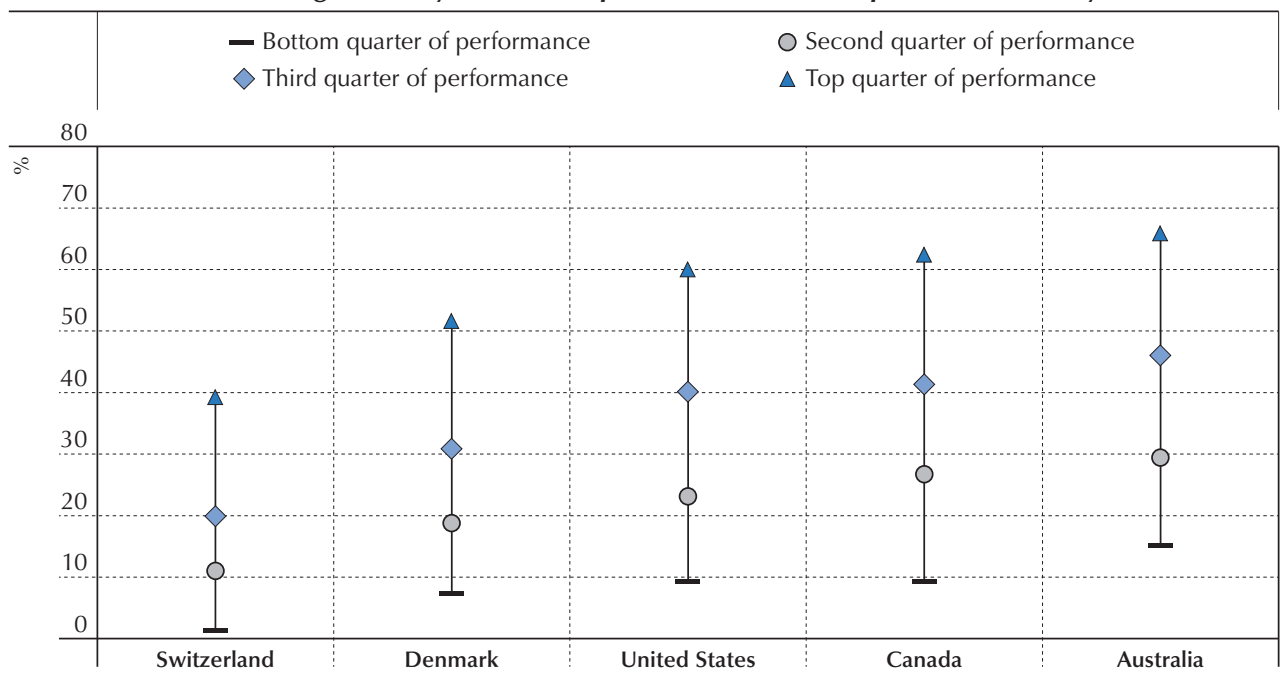

Notes: The difference between the top and the bottom quarters of reading performance is statistically significant in all countries

Quarters of performance are computed for the final sample of each country longitudinal data set.

Countries are ranked in ascending order of the percentage of students in the bottom quarter of reading performance.

Source: OECD, PISA 2000 and PISA 2003 Databases, Table 5.4.

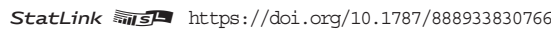

In Figure 5.4, the dark blue bars show the percentage-point difference in university completion rates between 25 -year-old adults with and without tertiary-educated parents. The light blue bars show the difference after accounting for PISA reading performance, meaning the difference observed when comparing students with similar performance in PISA. Across all countries, 15 -year-olds' reading performance explains between $27 \%$ (in the United States) and $43 \%$ (in Denmark) of the gap in university completion rates between students from more- and lesseducated families. This suggests that, while performance around the age of 15 is not a perfect predictor of future education trajectories, the cumulative effect of fewer or lost learning opportunities throughout the initial cycles of schooling is strongly related to students' chances of surpassing their parents' level of education.

The link between performance at 15 and university completion has several possible explanations. One is that students who lag behind their peers in school believe that they do not have the academic skills to do well in higher education. In addition, students from disadvantaged backgrounds tend to be viewed by others as less capable of progressing in education (Croizet and Claire, $1998_{[11]}$ ). Poor grades and difficulties in keeping up with their classmates can reinforce the effects of 
negative social expectations on the students' own perceptions of their capacity to participate in higher education (Owens and Massey, 2011 $1_{[12]}$ ). It is also possible that academic performance among 15-year-old students is not directly related to decisions to pursue higher education; other factors associated with school performance, such as family income, may determine university completion rates. In this case, the observed relationship between performance in PISA and university completion should not be interpreted as causal.

\section{Figure 5.4 - Completed university education at age 25, by PISA reading performance and parents' education \\ Percentage-point difference in university completion between advantaged and disadvantaged students}

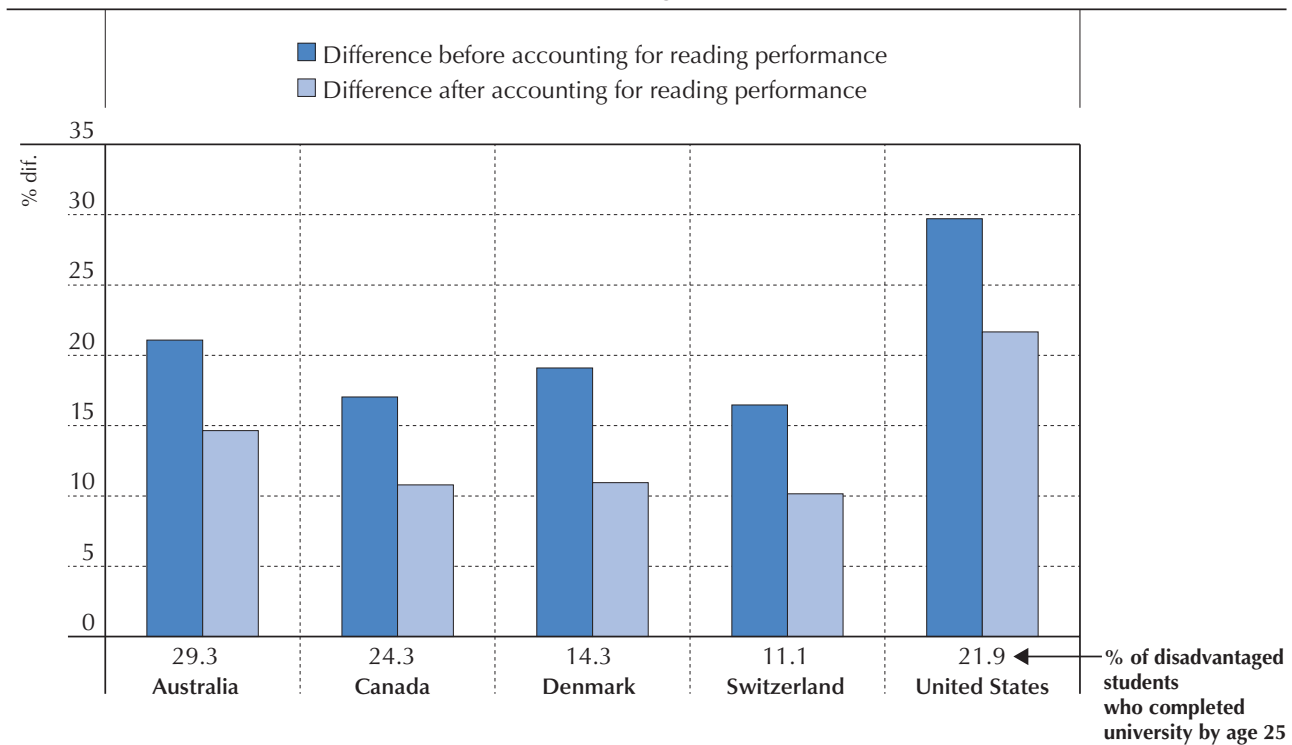

Notes: Results based on students' self-reports.

All percentage-point differences are statistically significant.

Values above the country name represent the percentage of disadvantaged students who completed university by age 25 .

Advantaged students are those with at least one tertiary-educated parent; disadvantaged students are those without a tertiaryeducated parent.

Source: OECD, PISA 2000 and PISA 2003 Databases, Tables 5.3 and 5.4.

StatLink त्राज़ https://doi.org/10.1787/888933830785

Differences across education systems could also influence the relationship between performance at age 15 and attainment of higher education. In both Denmark and Switzerland, upper secondary schools offer multiple tracks that are designed to sort students based on academic ability and preferences. The highest-performing students often enrol in the academic track, while low performers typically continue with technical vocational education. However, access to university education is largely reserved for those who are selected into the academic track at the secondary level. Initial groupings based on performance can thus play a significant role in determining higher educational attainment in these types of systems (Hanushek and Woessmann, 2006 ${ }_{[13]}$ ). 


\section{EARLY CAREER OUTCOMES AND PISA PERFORMANCE}

Students from different socio-economic backgrounds often experience different school-towork transitions. Advantaged students tend to begin working in less-intensive employment, either during secondary or post-secondary education, which gives them greater opportunity to prioritise academic performance and achievement. By contrast, disadvantaged students more commonly begin working at an earlier age and at greater intensity, which may be less conducive to attaining higher educational and career goals over the long term (Mortimer et al., 2008 [14]; OECD, $\left.2017_{[15]}\right)$. Disadvantaged youth are more likely to accept lower-quality employment - in terms of compensation, job security and career development - placing them at higher risk of periods of unemployment and inactivity. Data on early career outcomes in this chapter show marked differences according to parents' level of education.

Figure 5.5 shows that, in four out of five countries, significantly larger shares of students with tertiary-educated parents than students without tertiary-educated parents are enrolled in tertiary studies at the age of 25 , and thus have not necessarily entered the labour market by this time.

Figure 5.5 - Employment status at age 25, by socio-economic background Percentage of advantaged and disadvantaged students, by labour-force status

\begin{tabular}{|c|c|c|c|c|c|c|c|c|c|c|}
\cline { 2 - 12 } & \multicolumn{2}{|c|}{ Studying } & \multicolumn{2}{|c|}{ Working full time } & \multicolumn{2}{c|}{ Working part time } & \multicolumn{2}{c|}{ Unemployed } & \multicolumn{2}{c|}{ NEET } \\
\cline { 2 - 12 } & Adv. & Disadv. & Adv. & Disadv. & Adv. & Disadv. & Adv. & Disadv. & Adv. & Disadv. \\
\cline { 2 - 12 } & $\%$ & $\%$ & $\%$ & $\%$ & $\%$ & $\%$ & $\%$ & $\%$ & $\%$ & $\%$ \\
\hline Australia & $\mathbf{2 0 . 3}$ & $\mathbf{1 3 . 3}$ & 75.1 & 78.2 & 13.5 & 10.2 & 3.2 & 3.5 & 3.9 & 4.1 \\
\hline Canada & $\mathbf{1 7 . 2}$ & $\mathbf{8 . 7}$ & 71.9 & 75.0 & 9.8 & 7.9 & 4.5 & 4.5 & 5.0 & 7.2 \\
\hline Denmark & $\mathbf{2 9 . 8}$ & $\mathbf{1 4 . 6}$ & $\mathbf{6 4 . 1}$ & $\mathbf{7 1 . 7}$ & $\mathbf{1 5 . 9}$ & $\mathbf{8 . 6}$ & 5.4 & 5.0 & $\mathbf{6 . 1}$ & $\mathbf{9 . 2}$ \\
\hline Switzerland & $\mathbf{2 8 . 6}$ & $\mathbf{1 8 . 3}$ & 72.2 & 78.3 & 9.6 & 6.8 & 6.3 & 7.3 & 3.4 & 3.8 \\
\hline United States & 28.0 & 22.1 & 72.6 & 69.4 & 7.4 & 6.5 & 7.9 & 10.9 & 4.0 & 5.7 \\
\hline
\end{tabular}

Notes: Results based on students' self-reports.

Values with statistically significant differences between advantaged and disadvantaged students are displayed in bold. Individuals who are studying can also be considered as working either part or full time, therefore the rows will not add up to $100 \%$.

Individuals are considered to be studying at age 25 if they are enrolled in any tertiary education programme (ISCED 5B or above) at the time of the survey. The definition for Canada includes post-secondary studies (ISCED 4) as well.

Working part time is considered as employed from 1 to 20 hours per week.

Working full time is considered as employed for more than 20 hours per week.

Unemployed is defined as individuals who are not enrolled in education, have no job at the time of the survey, and are actively looking for work.

NEET is defined as individuals who are neither employed nor in education or training, and are not actively looking for work. Advantaged students are those with at least one tertiary-educated parent; disadvantaged students are those without a tertiaryeducated parent.

Source: OECD, PISA 2000 and PISA 2003 Databases, Tables 5.7, 5.13, 5.15, 5.17 and 5.21.

StatLink 需s ht https://doi.org/10.1787/888933830804 
In Denmark, 25-year-olds with less-educated parents are more likely to be in full-time employment, while adults of the same age with tertiary-educated parents are more often employed part time while they continue with their studies. In the other countries, except the United States, similar patterns are observed, but the differences between the two groups are not statistically significant.

In all countries covered in this analysis, most 25-year-olds are either studying or working. In Denmark, larger shares of 25-year-olds with tertiary-educated parents are found in both education and part-time employment, while 25-year-olds with less-educated parents are often more likely to be NEET (neither employed nor in education or training, and not actively looking for work). In other countries, similar patterns are observed for advantaged and disadvantaged 25-year-olds, but the differences are not statistically significant.

In Australia, Canada, Denmark and the United States, 25-year-old women are significantly more likely than men of that age to be NEET. This can be related to the fact that many young women leave the labour market when they have children (OECD, 2017 $\left.{ }_{[16]}\right)$. Similar patterns are observed in Switzerland, but the gender gap is not statistically significant. Only in Australia are firstgeneration immigrants significantly more likely than adults without an immigrant background to be NEET at the age of 25 (Table 5.15).

In Australia and Canada, inactivity, as measured by the NEET rate, is related to 15 -year-olds' literacy proficiency. In Canada, about $4 \%$ of students who were in the top quarter of reading performance when they were 15 are NEET at the age of 25; this is the case for $9 \%$ of students who scored in the bottom quarter of reading performance when they were 15 (Table 5.16). In Australia, $7 \%$ of students who were in the bottom quarter of performance when they were 15 , but only $2 \%$ of students who were in the top quarter of performance are NEET at the age of 25 . Similar relationships are observed in the other countries, but the differences are not statistically significant.

In Australia and the United States, unemployment rates reveal similar patterns. In the United States, $5 \%$ of students who were in the top quarter of PISA reading performance - but $14 \%$ of students in the bottom quarter - are unemployed at the age of 25 (Table 5.18). In Australia, 2\% of students who were in the top quarter of PISA reading performance - but $6 \%$ of students in the bottom quarter - are unemployed at the age of 25. Such patterns are observed in the other countries, but are not statistically significant.

The relationships between performance at school and participation in the labour market suggest that targeting low performance during compulsory schooling may be a way to prevent social exclusion later on, particularly in countries where relatively large shares of young people are inactive or unemployed after leaving school.

When examining the percentages of students in skilled employment (a job requiring tertiary education) by quarters of performance in PISA (Table 5.20), the patterns that emerge are comparable to those concerning university completion in Figure 5.3. In Australia, only $14 \%$ of students who were in the bottom quarter of reading performance end up in skilled employment at the age of 25 , while nearly $50 \%$ of students who were in the top quarter hold a skilled job at that age. In Denmark, students who were in the top quarter of performance at the age of 15 are 47 percentage points more likely than those in the bottom quarter to have a skilled job at 
the age of 25. Differences for the other countries considered in this chapter range from 23 to 25 percentage points. These results imply that performance during secondary school matters not only for later educational attainment, but also in shaping opportunities in the labour market during early adulthood.

Socio-economic segregation in the labour market - by which adults from less-educated families are concentrated in occupations requiring lower academic skills - is an obvious consequence of lower rates of tertiary attainment among disadvantaged students. Across countries, students with less-educated parents are between 7 and 20 percentage points less likely than students with tertiary-educated parents to be working in skilled jobs when they are 25 years old (Figure 5.6).

\section{Figure 5.6 - Skilled employment, by parents' education and PISA reading performance}

\section{Percentage-point difference in skilled employment between} advantaged and disadvantaged students at age 25

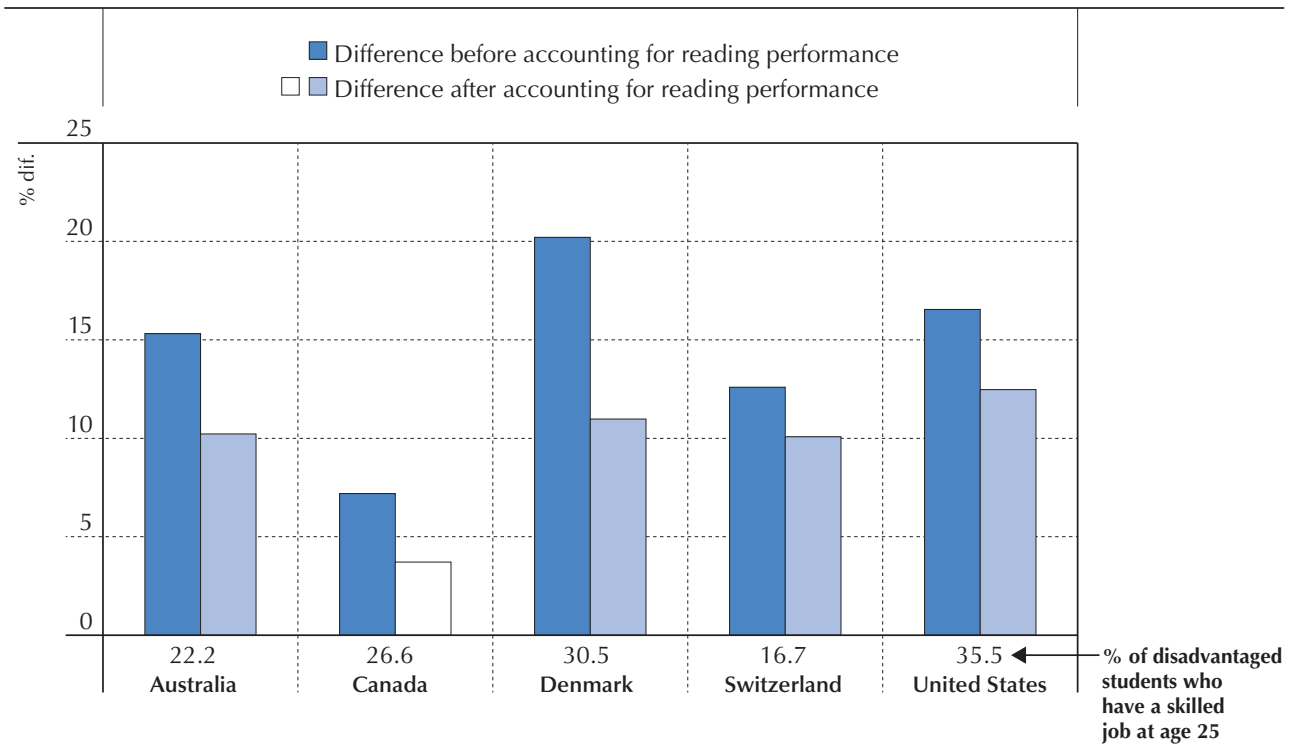

Notes: Results based on students' self-reports.

Statistically significant percentage-point differences after accounting for reading performance are shown in light blue. All percentage-point differences before accounting for reading performance are statistically significant.

Values above the country name represent the percentage of disadvantaged students who work in a skilled job at age 25.

Skilled employment is defined as employment that requires tertiary education, ISCED level 5A or above.

Advantaged students are those with at least one tertiary-educated parent; disadvantaged students are those without a tertiaryeducated parent.

Source: OECD, PISA 2000 and PISA 2003 Databases, Tables 5.19 and 5.20.

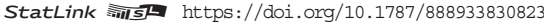

Differences in performance at school between students from more- and less-educated families are associated with differences in access to skilled employment. When comparing students who performed similarly at the age of 15 , the difference between 25 -year-olds with and those 
without tertiary-educated parents in being employed in a skilled job shrinks to between 10 and 12 percentage points in Australia, Denmark, Switzerland and the United States, and is no longer significant in Canada. This suggests that disadvantages in learning opportunities during compulsory education are linked to early career outcomes.

\section{Box 5.2 The Danish case: Linking PISA to PIAAC}

Denmark provides a unique setting in which to study the factors that influence PISA students' chances of success later in life. Denmark conducted the 2011-12 Survey of Adult Skills (a product of the OECD Programme for the International Assessment of Adult Competencies [PIAAC]) among a sample of students who had participated in the PISA 2000 assessment. The Survey of Adult Skills (PIAAC) measures adults' proficiency in three key informationprocessing skills: literacy, numeracy and problem solving in technology-rich environments.

Longitudinal follow-ups of PISA students discussed in this chapter identify strong links between observable factors at age 15 - including cognitive proficiency, background characteristics and attitudes towards schooling - and higher education and labour market outcomes. In Denmark, it is also possible to examine how disparities in cognitive skills related to socio-economic status evolve between the ages of 15 and 26-27 by comparing performance in PISA with performance in the Survey of Adult Skills (PIAAC). While learning disparities between students of different socio-economic, cultural and demographic backgrounds have been extensively analysed in a large body of research (OECD, 2017 ${ }_{[17]}$; Fruehwirth, Navarro and Takahashi, 2016 $[18]$; Montt, 2016 $[19])$, much less is known about the persistence of such differences into early adulthood.

About $31 \%$ of the variation in PIAAC literacy proficiency among 26-year-olds is explained by PISA performance in reading among 15-year-olds (Table 5.39a). There are similar correlations between performance in the PIAAC numeracy assessment and PISA performance in mathematics (Table 5.40a). Around 15\% of the variation in literacy (and 12\% in numeracy) among 26-year-olds is explained by the total number of years of education students have completed. These relationships suggest that the quality of education opportunities, and not just the quantity of education, influences how well citizens are equipped to participate in, and benefit from, increasingly knowledge-based societies.

However, earlier education is only one of the factors that shape individuals' ability to process information and solve cognitive problems as adults. The tasks individuals engage in at work and their life experiences have, in fact, the potential to reshape cognitive capacity, because brains are "plastic" and change dramatically over a lifetime. Furthermore, differences in the attitudes of adolescents and their parents can also play a role in explaining cognitive development beyond the age of compulsory education (Chowdry, Crawford and Goodman, 2011 $1_{[20]}$; Borgonovi et al., 2017 $[21]$. Factors specific to family background, such as parents' education, parents' interest in school, cultural activities, and social communication between parents and students, also influence cognitive outcomes during school years (Borgonovi and Montt, 2012 $2_{[22]}$; OECD, 2017 ${ }_{[15]}$; Kaplan Toren, 2013 ${ }_{[23]}$ ) and possibly beyond. 
Figure 5.7 presents the percentage of variation in numeracy proficiency among 26-yearolds that can be accounted for by students' attitudes towards learning, years of education and family background. Around $14 \%$ of the total variation in adults' proficiency in numeracy, as measured by the PIAAC survey, is explained by attitudes towards learning reported at age 15 (Table 5.40a). Family background explains a similar percentage of the variation in performance (Table 5.40c). Accounting for performance in the PISA mathematics assessment significantly affects the strength of these relationships, suggesting that both family background and attitudes towards learning affect cognitive proficiency at age 26 by shaping learning opportunities early in life, up to age 15. In other words, neither family background nor 15-year-olds' attitudes towards school greatly influence progress in cognitive achievement between the ages of 15 and 26 among students who scored similarly in PISA when they were 15 years old.

\section{Figure 5.7 - Variation in numeracy proficiency explained by student characteristics and educational attainment (Denmark) Percentage of variation in numeracy explained by predictors at age 15 and educational attainment at age 26}

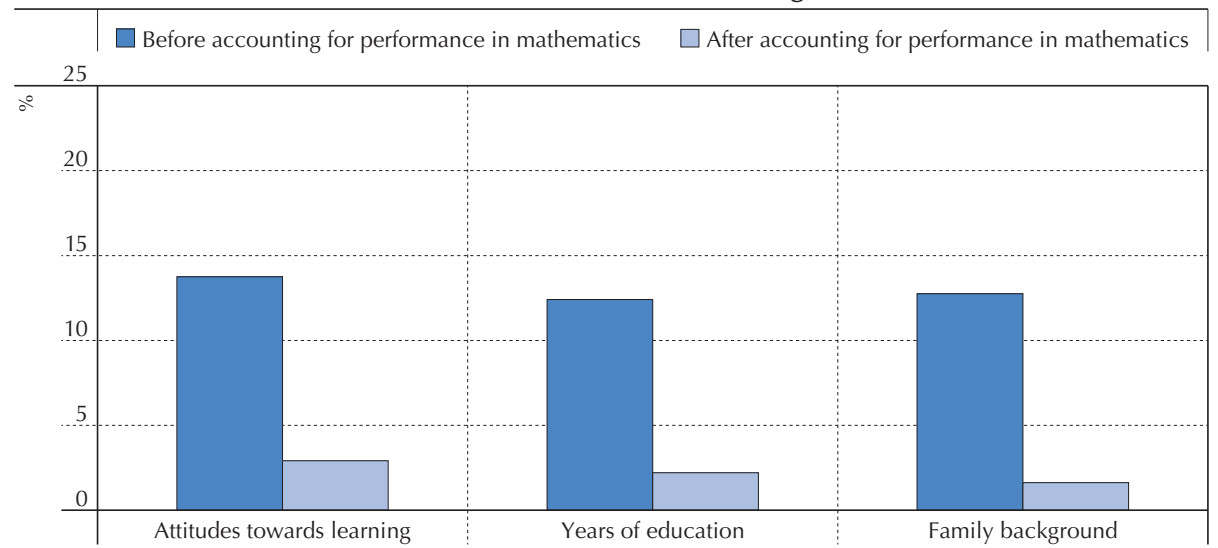

Notes: Results based on students' self-reports.

The results shown by the dark blue bars are obtained from the $\mathrm{R}$ squared of model 1 in Tables $5.40 \mathrm{a}, 5.40 \mathrm{~b}$ and 5.40c.

The results shown by the light blue bars are obtained by subtracting the $\mathrm{R}$ squared of model 2 from the $\mathrm{R}$ squared of model 3 in Tables 5.40a, 5.40b and 5.40c.

Attitudes toward learning include: the index of student self-efficacy, the index of effort and perseverance, the index of interest in reading and the index of engagement in reading.

Family background variables include: the PISA index of economic, social and cultural status, the index of cultural communication, the index of social communication, the percentage of students whose father or mother helps with homework several times per month or more, and the percentage of students who reported that they discuss with their parents how well they are doing in school several times per month or more.

Source: OECD, PISA 2000 Database; PIAAC Database, Tables 5.40a, 5.40b and 5.40c.

StatLink 需政 https://doi.org/10.1787/888933830842 
Figure 5.8 shows that more than half of the gap in literacy proficiency between 26-yearolds with and those without tertiary-educated parents can be accounted for by reading performance at age 15. This suggests that students from less-educated families are not only less likely to perform well during secondary school, but they also face the risk of persistent poor performance and low skills. Only 5\% of the gap is explained by the number of completed years of schooling (Table 5.41). This weaker relationship between educational attainment and cognitive performance in the Survey of Adult Skills (PIAAC) is partly explained by the fact that there is only limited variation in years of schooling in this sample.

\section{Figure 5.8 - Explaining disparities in literacy and numeracy} proficiency in Denmark

Disparities between advantaged and disadvantaged 26-year-olds

$\square$ Percentage explained by
PISA reading performance
$\square$ Percentage explained by
years of schooling
$\square$ Percentage unexplained

Percentage of the difference in PIAAC literacy proficiency explained

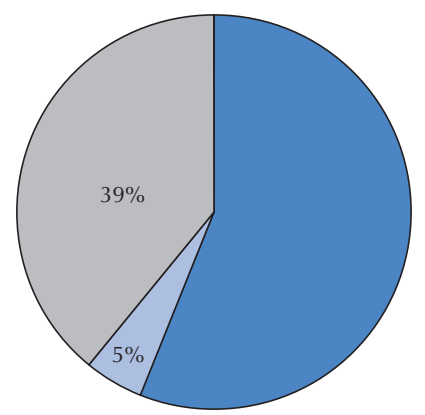

$\square$ Percentage explained by PISA mathematics performance

$\square$ Percentage explained by years of schooling

$\square$ Percentage unexplained

\section{Percentage of the difference in PIAAC} numeracy proficiency explained

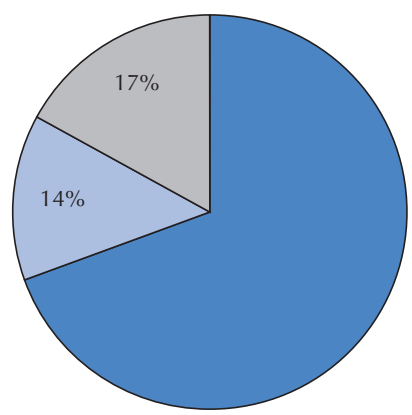

Notes: Results based on students' self-reports.

Advantaged 26-year olds are defined as those whose economic, social, and cultural status (ESCS) is in the top quarter; disadvantaged 26-year olds are defined as those whose economic, social, and cultural status (ESCS) is in the bottom quarter.

Values represent the percentage of the difference between advantaged and disadvantaged 26-year-olds in numeracy and literacy proficiency explained by predictors at age 15 and educational attainment at age 26 .

Source: OECD, PISA 2000 Database; PIAAC Database, Table 5.41.

StatLink ails https://doi.org/10.1787/888933830861

A similar picture emerges when considering proficiency in numeracy. Performance in PISA mathematics explains more than two-thirds of the gap in numeracy proficiency between advantaged and disadvantaged 26-year-olds, a relationship that is even stronger than that between PISA reading performance and literacy proficiency. Interestingly, differences in 
educational attainment account for a larger fraction of the variation in numeracy proficiency than in literacy proficiency. Proficiency in numeracy requires a complex combination of higher-order skills and subject knowledge that is mostly acquired at school, while reading skills can, arguably, be more easily acquired outside of school. This finding suggests that making opportunities to learn mathematics more equitable can have a large impact on adults' capacity to solve problems (OECD, 2016 $6_{[24]}$ ).

Overall, these results for Denmark confirm that students' chances of succeeding later in life are shaped by a multitude of factors. Still, disparities in learning outcomes among 15-yearolds explain a considerable fraction of the variation in proficiency among 26-year-olds, which suggests that lifelong learning opportunities, while important, are no substitute for equitable learning opportunities early in life. Skills beget skills.

\section{UNDERSTANDING THE FORCES BEHIND EDUCATIONAL MOBILITY AND SCHOOL-TO-WORK TRANSITIONS}

The evidence on limited educational mobility in the previous section demands a better understanding of what it means to grow up in a disadvantaged environment. What types of inequities can be observed among 15-year-olds that are associated with their parents' education, and how do these inequities influence higher education and early career outcomes?

The social sphere where disadvantaged students grow up differs in many ways from that enjoyed by more advantaged students (Putnam, 2015 ${ }_{[25]}$ ). Students from disadvantaged families tend to face greater financial constraints and insecurity, live in more fragmented families, enjoy fewer opportunities to participate in cultural activities, and are exposed to less positive messages from their families, teachers and peers about the value of making an effort at school (Snellman et al., 2015 $\left.{ }_{[26]}\right)$. This section explores three dimensions of disadvantage - student attitudes and behaviours, school characteristics and family background - all of which are related to parents' education and can widen a divide in opportunities for social mobility by influencing cognitive and social development at school and beyond.

Understanding why students from less-educated families are less likely to pursue higher education can inform policy design. If environmental differences, rather than individual effort and inherited talent alone, determine education and career outcomes, then there is a case to be made for policy interventions that compensate for inequitable opportunities. To be effective, those interventions should target the sources of inequity. For example, if financial constraints are the main cause of early dropout among talented disadvantaged students, then establishing merit-based scholarship schemes can be an effective way to increase equity in participation in higher education (Belley and Lochner, $\left.2007_{[27]}\right)$. However, if the performance of disadvantaged students suffers due to peer influences, then policies that enable disadvantaged families to move to less-impoverished areas could be more effective than scholarships (Chetty and Hendren, 2015 $5_{[28]}$ ). 


\section{Box 5.3 Can genes predict educational attainment?}

The controversial debate of the role of nature vs. nurture in determining opportunities for success in life has attracted the attention of researchers across multiple fields - from behavioural geneticists and psychologists to sociologists and economists. One side of the argument claims that all people are born with equal capacities to succeed, and that talent is nurtured in specific environments. Others argue that people enter the world with different intellectual abilities, largely determined by genetic inheritance. Empirical evidence falls between these two extremes. Early evidence from behavioural genetics shows that academic potential is, to some extent, inherited, particularly with regard to specific outcome measures, such as adult IQ, which is about $50 \%$ heritable (Plomin et al., $\left.2001_{[29]}\right)$. Some evidence has also established a link between genetic endowments and educational attainment (Behrman and Taubman, 1989 ${ }_{[30]}$; Behrman, Taubman and Wales, $\left.1977_{[31]}\right)$.

Social scientists recently shifted focus to a different method of calculating transmission coefficients from parents to natural children and to adopted children. Such studies have provided estimates of how much of the transmission of education, income or some other outcome takes place even in the absence of a genetic connection between parents and children. A study using data on a large sample of adopted Swedish children concluded that the transmission of earnings and education works strongly through both biological and environmental channels (Bjorklund, Lindahl and Plug, 2004 ${ }_{[32]}$ ). In a subsequent study, data on Korean-American adopted children reveals somewhat less transmission from adoptive parents, yet concludes that both biological and adoptive parents transmit a great deal (Sacerdote, 2011 $1_{[33]}$ ).

While empirical evidence supports a wide range of explanations for the role of genetics in life outcomes, most of these studies make clear that the nurturing environment plays an important role. Given that finding, it would be useful to identify the specific inequities in the environments in which advantaged and disadvantaged students grow up that widen gaps in educational attainment and labour market outcomes, and determine how these different types of inequities interact and accumulate.

\section{Differences in 15-year-old students' attitudes and behaviour}

\section{Students' expectations}

Adolescence is a time when students begin to think seriously about their future, when their aspirations become more closely aligned with their interests, abilities and the opportunities available to them, and when their vision of themselves can be influenced by the peers and adults around them (Beal and Crockett, 2010 $0_{[34]}$; OECD, 2017 ${ }_{[15]}$ ). For this reason, students' aspirations for their future education and career can play a large role in determining their actual achievements (Nurmi, $2013_{[35]}$ ). 
Fewer disadvantaged students either desire or expect to be able to attend university, and they are less likely to see themselves working in high-skilled jobs later in life (Gore et al., 2015 [36]; Gale et al., 2013 $[37])$. Yet high expectations can help disadvantaged students overcome barriers to pursuing higher education. Negative or ambivalent expectations are, instead, often associated with a sense of hopelessness (D'errico, Poggi and Correa, 2011 $1_{[38]}$ ).

PISA data reveal significant differences in the expectations of 15-year-old advantaged and disadvantaged students (Chapter 2). Across the countries examined in this chapter, students with less-educated parents are between 6 and 23 percentage points more likely than students with tertiary-educated parents to expect to work in a skilled job later on in life (Table 5.9).

Longitudinal data allow for verifying the extent to which 15-year-old students hold realistic expectations for their future education and career. Table 5.10 shows that there is a mismatch between expectations and achievement. For example, 27\% of students in Denmark who, at 15, did not expect to work in an occupation that requires tertiary education are, in fact, working in such an occupation when they are about 26 years old. However, in the four countries with available data, people who, as 15-year-old students, had expected to work in a high-skilled job are more likely to be doing so as young adults than those who had not held the same expectations when they were 15 (Figure 5.9). For example, in Australia, 40\% of the 15-year-old students who had expected to work in a high-skilled occupation continue with their studies and are employed in such an occupation when they are 25 years old. By contrast, only 20\% of Australian 15-yearold students who did not see themselves working in a high-skilled job when they were 15 are engaged in such work when they are 25.

The positive relationship between expectations and achievement cannot be interpreted in causal terms, because several other student characteristics can be related to both expectations and progression through school. High-performing students tend to hold high expectations for their education and also have the intellectual capacity to complete higher education. It is possible to take some of these confounding factors into account by restricting the comparisons to students who had achieved the same level of performance at age 15. When comparing students who performed similarly in PISA, the difference between students who had high education expectations and those who had low education expectations in whether they are working in a skilled job at 25 is reduced by around a third in Canada and is no longer significant in Switzerland, but remains substantial in Australia and Denmark (Table 5.10).

At 15, students also seem to have a clear idea of what type of studies and career they would like to pursue. Table 5.12 shows that, in all countries, students who had expected a career in science, mathematics or engineering ${ }^{6}$ at the age of 15 are much more likely to hold this type of job at 25 . This is especially true for boys. Girls, on the other hand, were much less likely than boys to expect a job in science, mathematics or engineering (Table 5.11). These low expectations are realised later on, with fewer women in science careers - even when comparing 15-year-old boys and girls who scored similarly on the PISA science test (Table 5.12).

The fact that differences in expectations related to socio-economic status are associated with subsequent career achievement, even after accounting for school performance, signals that both parents and educators should pay attention to how students think about their future. 
The parents and teachers of more advantaged students tend to have higher expectations for those students, which, in turn, shape the students' own expectations (Buchmann and Dalton, $2002_{[39] ;}$; Sewell et al., 2003 ${ }_{[40]}$ ). Academic and career counselling targeted to disadvantaged students may help these students develop expectations that are better aligned with their academic potential.

Figure 5.9 - Student expectations and skilled employment Percentage-point difference in skilled employment rates at age 25 between those who did and those who did not expect to work in a skilled job when they were 15 years old

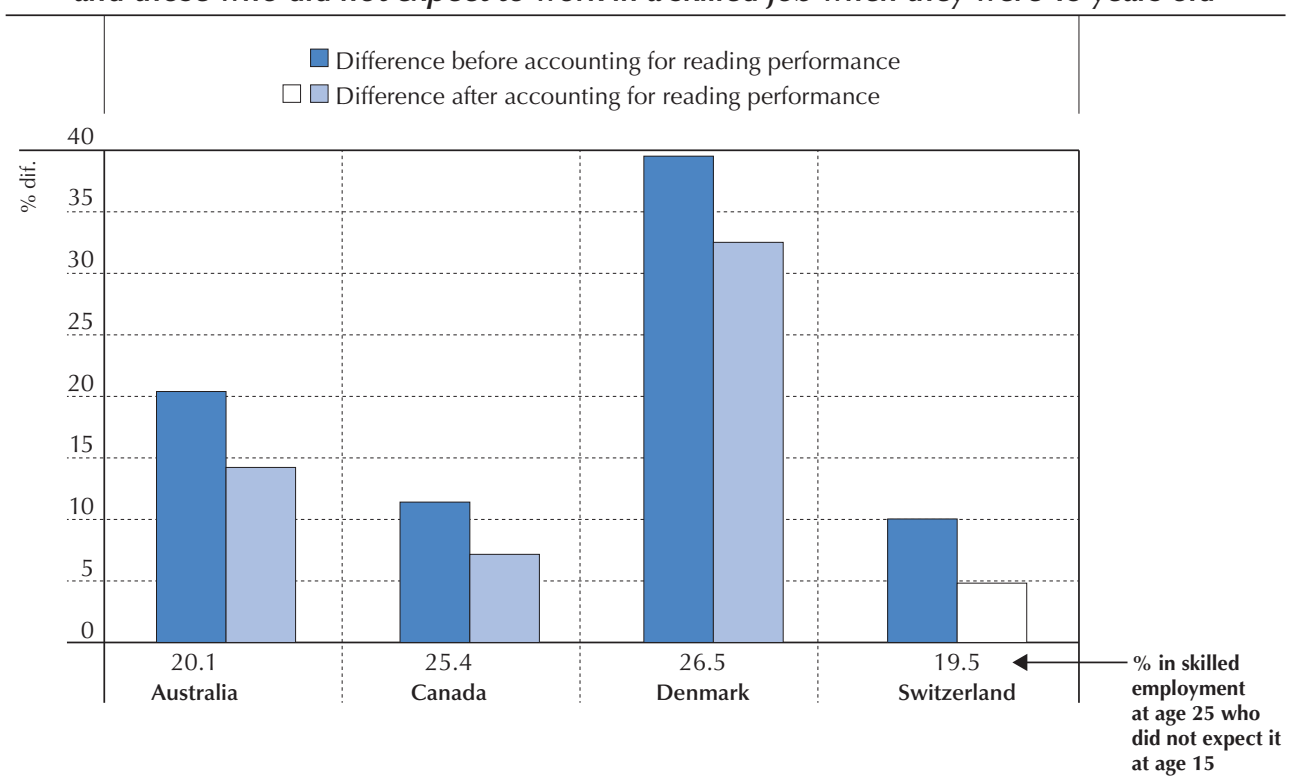

Notes: Results based on students' self-reports.

Statistically significant percentage-point differences after accounting for reading performance are shown in light blue. All percentage-point differences before accounting for reading performance are statistically significant.

Data on career expectations are not available for the United States.

Source: OECD, PISA 2000 and PISA 2003 Databases, Table 5.10.

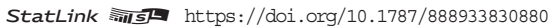

\section{Effort and perseverance}

Individual effort and perseverance have proven to be strong predictors of academic performance and higher levels of educational attainment (Chamorro-Premuzic and Furnham, 2003 [41]; Trapmann et al., 2007 $\left.{ }_{[42]}\right)$. Yet PISA data and other research have revealed significant disparities in effort and perseverance across students of different socio-economic status (OECD, $2013_{[43]}$ ).

It is likely that, with fewer resources and greater constraints, disadvantaged students are more likely to be discouraged. Even if disadvantaged students work hard, their education outcomes may not improve or be rewarded as much as those of other students, so they have less incentive to invest effort in their studies (Deluca and Rosenbaum, 2001 ${ }_{[44]}$ ). 


\section{Figure 5.10 - University completion rates, by effort and perseverance} Percentage-point difference in university completion rates

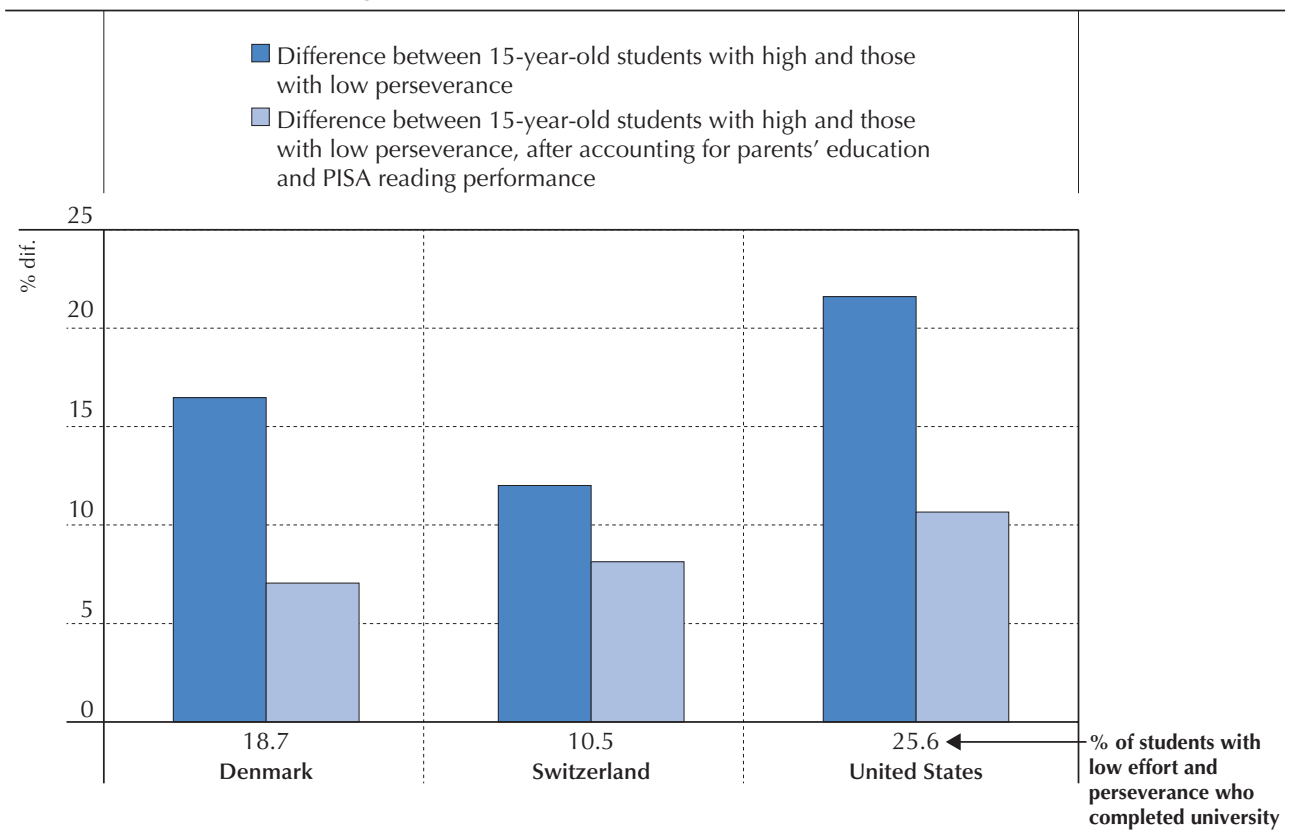

Notes: Results based on students' self-reports.

All percentage-point differences are statistically significant.

Comparable measures for effort and perseverance were not available for Australia or Canada.

Index of effort and perseverance from PISA 2000 survey was used, for Denmark and Switzerland, to identify 15-year-old students within the top and bottom quarters of effort and perseverance. Data from the United States provide a separate but comparable index of effort and perseverance, which was used to identify 15 -year-old students within the top and bottom quarters.

Source: OECD, PISA 2000 and PISA 2003 Databases, Table 5.25.

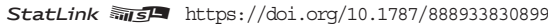

The PISA index of effort and perseverance was derived using students' responses to a series of questions about how they handle difficulty while studying. Students were asked how often they work as hard as possible; they keep working even when the material is difficult; they try to do their best to acquire the knowledge and skills taught; and they put forth their best effort. Students responded to each item in one of four ways, ranging from "almost never" to "almost always".

Students who invest greater effort and perseverance (students in the top quarter of the index of effort and perseverance) are more likely to complete university than students who invest less effort and perseverance (students in the bottom quarter of the index). In Denmark, 35\% of students who had reported high levels of perseverance, but only $19 \%$ of students who had reported low perseverance, had completed university by the age of 25. In Switzerland, 23\% of highly perseverant students versus $11 \%$ of the least-perseverant students completed university; in the United States, $47 \%$ of highly perseverant students versus $26 \%$ of the least-perseverant students completed university by the age of 25 . Even after accounting for parents' education and 
student performance in reading, individual effort and perseverance explain a significant share of the difference in university completion rates across the three countries with available data (Table 5.25).

Other attitudes towards learning are also related to educational achievement. The 2000 round of PISA included an index of perceived self-efficacy, derived from students' responses to a series of questions regarding their level of confidence in their academic abilities. Students were asked to report how often they are certain they can understand the most difficult material in the text; they are confident they can do an excellent job on assignments and tests; and they are certain they can master the skills being taught.

In Denmark and Switzerland, 15-year-old students without tertiary-educated parents reported lower levels of self-efficacy (Table 5.25) than their peers with tertiary-educated parents; and students with low self-efficacy (those who fall within the bottom quarter of the index) during secondary school were less likely to complete university than students with high self-efficacy. Yet, after accounting for PISA reading performance and parents' education, the difference is significantly reduced in Denmark and no longer significant in Switzerland. This suggests that individual attitudes towards learning are strongly linked to academic performance and family characteristics. It is likely that confidence, effort and perseverance are more critical for students with less-educated parents, who often endure greater hardships to achieve the same outcomes as their peers from more advantaged backgrounds.

This evidence complements a growing body of literature that emphasises the importance of developing social skills and positive attitudes, both for cognitive growth and for longer-term labour market and social outcomes (Bowles, Gintis and Osborne, 2001 ${ }_{[45]}$; Heckman, Stixrud and Urzua, 2006 $\left.{ }_{[46]}\right)$. Research has suggested that non-cognitive skills, including attitudes and behaviours, are considerably less malleable at later ages (Cunha and Heckman, 2007 ${ }_{[47]}$ ).

From a policy perspective, this highlights how teachers, schools and institutions can nurture disadvantaged students' attitudes, aspirations and motivations. Teachers can help students develop academic mindsets and learning strategies that cultivate perseverance. Specific initial education and training programmes can help teachers identify and address lack of persistence and poor self-confidence among their students. These initiatives may be particularly relevant for teachers working in schools with large populations of disadvantaged students.

\section{Involvement in cultural activities}

Differences in the social environments surrounding advantaged and disadvantaged students can result not only in different attitudes towards schools but also in a different exposure to intellectually and culturally stimulating experiences. Exposure to the arts, music and other cultural expressions may be a particularly crucial form of socialisation during adolescence, influencing both early performance and attitudes at school, and later educational attainment and career outcomes.

PISA provides two measures for exploring differences in cultural experiences: an index of cultural activity (representing the incidence of 15 -year-old students' participation in various cultural activities over the previous year), and an index of cultural communication (representing parents' engagement with students in cultural activities). 
Research shows that cultural capital is distributed unequally across social classes and education, with the largest share enjoyed by wealthier and more highly educated individuals. Cultural capital is also something that is transmitted from parents to children, and primarily at home rather than in school (Sullivan, 2001 ${ }_{[48]}$ ). Yet exposure to and participation in cultural activities can help students find meaning in what they do at school and appreciate the value of acquiring more education.

\section{Figure 5.11 - University completion rates, by frequency of cultural activity, parents' education and PISA reading performance} Percentage-point difference in university completion rates

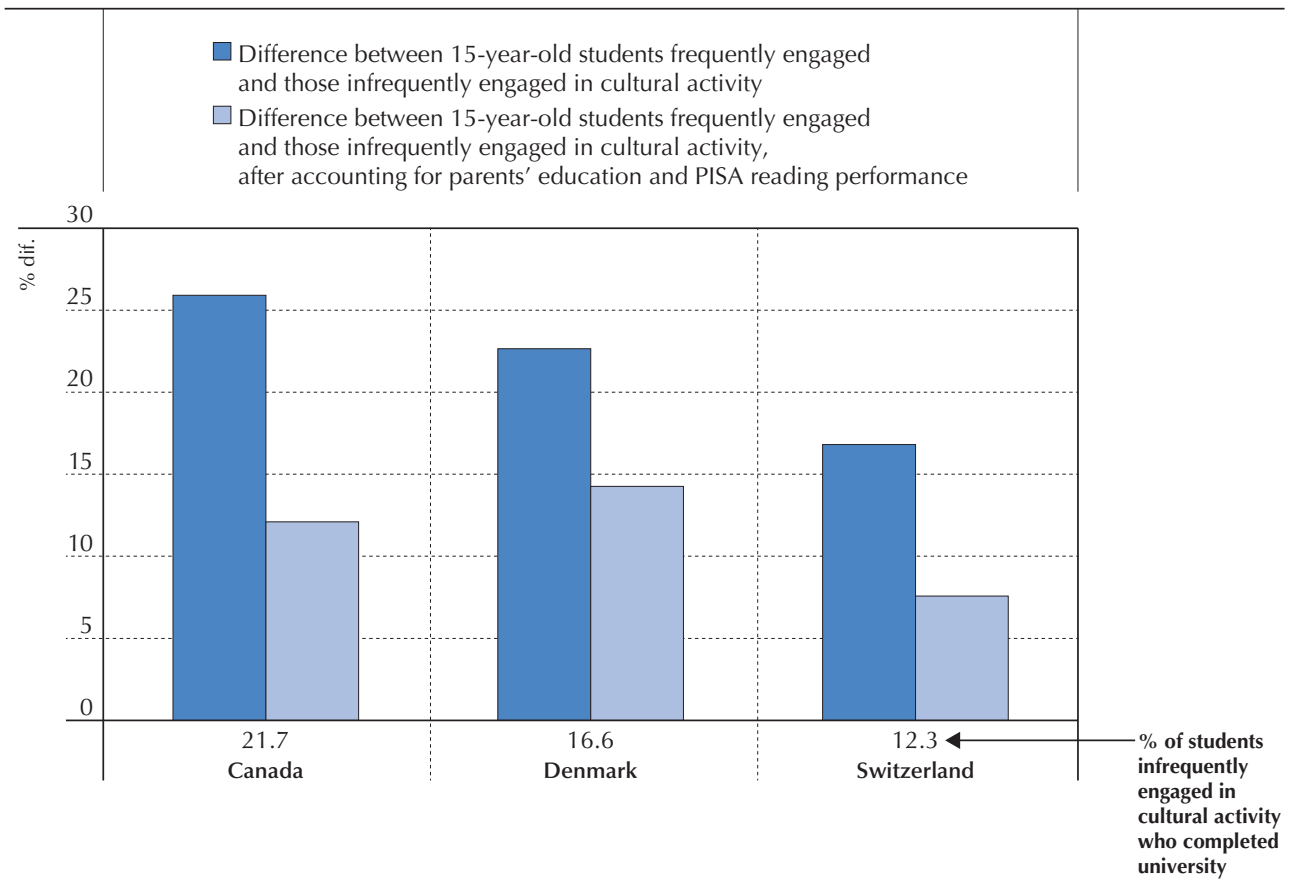

Notes: Results based on students' self-reports.

All percentage-point differences are statistically significant.

Comparable measures for cultural activity were not available for Australia or the United States.

Students engaged in frequent (infrequent) cultural activity are students in the top (bottom) quarter of the index of cultural activity.

Source: OECD, PISA 2000 Database, Table 5.28.

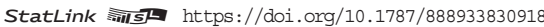

Fifteen-year-old students with tertiary-educated parents are significantly more likely than their peers with less-educated parents to have access to cultural activities (Table 5.28). For example, in Denmark and Switzerland, about one in four children of tertiary-educated parents reported that they had visited a museum or art gallery at least three or four times in the previous year; only one in ten children from less-educated families so reported. In Canada, students in the top quarter 
of the index of cultural activity are 26 percentage points more likely to complete university than students in the bottom quarter of the index. In Denmark, the gap in university completion rates between these two groups is 23 percentage points; in Switzerland, it is 17 percentage points.

When comparing students with similar levels of performance in the PISA reading assessment and whose parents have attained similar levels of education, the magnitude of this difference in university completion in Canada shrinks, but is still large (12 percentage points). In Denmark, the difference falls to 14 percentage points, and in Switzerland, it drops to 8 percentage points.

Tertiary-educated parents are more likely than less-educated parents to engage in cultural activities and conversations with their children (OECD, 2017 $\left.{ }_{[15]}\right)$. For example, in Denmark and Switzerland, about one in two students with tertiary-educated parents reported that they discuss social and political issues with their parents several times per month (Table 5.27). By contrast, only around one in four students with less-educated parents so reported. In Denmark, around $40 \%$ of students who reported frequent cultural exchanges with their parents (those in the top quarter of the index of cultural communication) complete university education; only $14 \%$ of students who rarely engage in this type of communication with their parents (those in the bottom quarter of the index) reach that level of education. In Canada and Switzerland, gaps between these two groups of students range from 13 to 26 percentage points.

After accounting for parents' education and PISA reading performance, gaps in university completion rates fall to 11 percentage points in Canada and 10 percentage points in Denmark, and are no longer significant in Switzerland (Table 5.27).

While not implying a causal relationship, these results suggest that cultural activities may be an additional mechanism through which more-educated families ensure an educational advantage for their children outside of school. Cultural activity can be viewed as yet another factor that explains differences between advantaged and disadvantaged students in socialisation and education opportunities.

\section{Differences in family background}

\section{Family structure}

Both falling marriage rates and increasing divorce rates have contributed to the increase in singleparent families (OECD, 2016 $6_{[24]}$ ). Many studies have documented the challenges confronted by single parents and the disadvantages their children face relative to children raised in two-parent households (Mandara and Murray, 2006 ${ }_{[49]}$ ). Children from single-parent homes tend to score lower on cognitive tests and complete fewer years of school when compared to children from

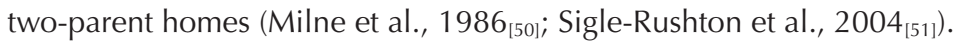

Previous evidence from PISA has shown that family structure is related to performance at school (OECD, 2013 $\left.{ }_{[52]}\right)$. Across OECD countries, the performance gap in the PISA 2012 mathematics assessment between students from single-parent families and those from other types of families was 15 score points - or the equivalent of almost half a year of schooling - before taking socioeconomic status into account. In most countries, single-parent families tend to have lower socioeconomic status than two-parent families (OECD, 2013 $\left.{ }_{[52]}\right)$. After accounting for socio-economic status, the difference in PISA performance is reduced to five score points. 
In Australia, $42 \%$ of students from two-parent families complete university while only $26 \%$ of students from single-parent families attain this level of education (Table 5.33). However, differences in other countries are much smaller, ranging from 7 to 8 percentage points, and are no longer significant after accounting for parents' education and PISA reading performance. This suggests that family structure does not have the same influence on educational achievement in all countries, possibly because of differences in social and economic policies. Moreover, family structure may be related to academic performance up to age 15, but does not necessarily have a significant direct link to later decisions regarding further education and career choice. Yet in Australia, these gaps narrow only modestly when comparing students who perform similarly in PISA and whose parents have similar levels of education. While many single parents are perfectly capable of providing the support their children need to succeed in school and life, some may face difficulties as they act as both the primary care provider and income earner.

School systems and individual schools can consider how and what kinds of parental engagement are to be encouraged among single parents who have limited time to devote to school activities (Pong, Dronkers and Hampden-Thompson, $2003_{[53]}$ ). Given that single parents often struggle with limited time and financial resources, it is particularly important to evaluate the synergies that can be established between education policies and other policies, such as those related to welfare and childcare. It may also be important to identify the different challenges that are faced by mother-only versus father-only households (Nonoyama-Tarumi, $2017_{[54]}$ ) in order for schools to know how best to respond to individual circumstances.

\section{Family wealth}

Parents' low education is often associated with less family wealth. Research in Sweden reveals that inequality in family wealth - even in a comparatively egalitarian context - has profound consequences for the distribution of opportunity across multiple generations (Hällsten and Pfeffer, $\left.2017_{[55]}\right)$. Parents' wealth is strongly associated with a range of outcomes in early adulthood, and these associations are found to be stronger than those related to parents' education in many cases (Karagiannaki, $\left.2012_{[56]}\right)$. Apart from the ability to afford more quality education and educational resources, family wealth also offers a level of security that cannot necessarily be substituted with financial aid for education. Students in wealthier families can focus on the academic, rather than the financial, challenges of higher education, and pay less attention to the short-term opportunity costs of pursuing additional years of schooling (Braga et al., 2017 $[57]$ ).

The PISA index of family wealth was derived from students' reports about the availability of various wealth-related possessions in their home. These questions identified whether a student has a room of his or her own, educational software, Internet access, and a dishwasher; and the number of cellular phones, televisions, computers, cars and bathrooms at home. For the countries with available measures of wealth, high-wealth students (students in the top quarter of the family wealth index) are between 8 and 16 percentage points more likely than low-wealth students (students in the bottom quarter of the family wealth index) to complete university (Figure 5.12). In Switzerland, the difference is no longer significant after accounting for parents' education and performance in the PISA reading assessment. However, these gaps remain substantial in Canada and Denmark, suggesting that wealth can play an important role in both academic performance and educational attainment in certain settings. 
Figure 5.12 - University completion rates, by family wealth

Percentage-point difference in university completion rates

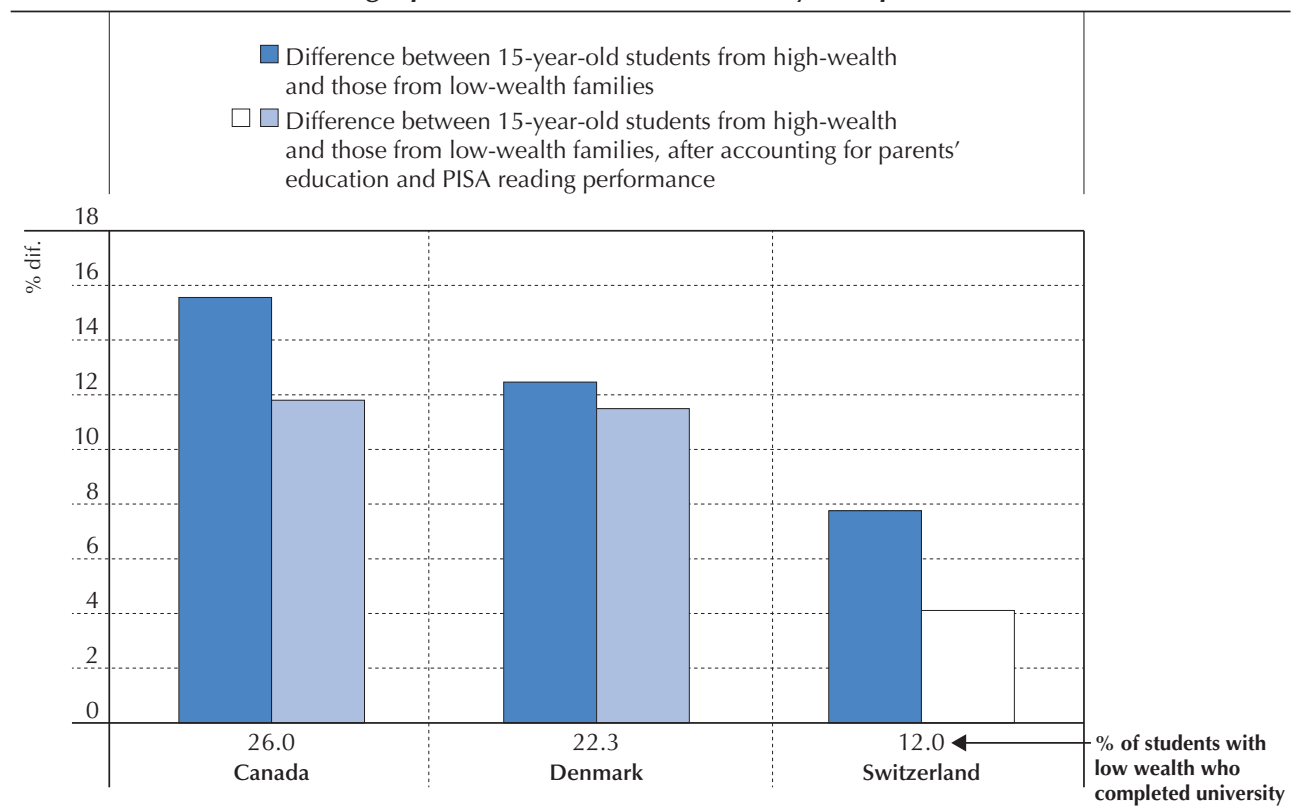

Notes: Results based on students' self-reports.

Statistically significant percentage-point differences after accounting for parents' education and PISA reading performance are shown in light blue.

All percentage-point differences before accounting for parent's education and PISA reading performance are statistically significant. Data for comparable family-wealth indices were not available for Australia or the United States.

Source: OECD, PISA 2000 and PISA 2003 Databases, Table 5.26.

StatLink त्राजा https://doi.org/10.1787/888933830937

Looking at parents' employment status is another way to identify the links between family resources and student outcomes. Students can face significant hardships when their parents are unemployed. They may perform poorly in school, be at risk of repeating a grade, and are less likely to finish secondary education (Mooi-Reci and Bakker, 2015 ${ }_{[58]}$ ). These disadvantages tend to persist beyond the early years of schooling and can influence students' chances of attaining higher levels of education and succeeding in the labour market. In Australia, Canada and Denmark, 15-year-old disadvantaged students are more likely than advantaged students to have unemployed parents (neither parent is employed because of unemployment or inactivity). Later outcomes reveal that 15-year-old students whose parents were unemployed at that time are between 12 and 13 percentage points less likely than students the same age whose parents were employed when their child was 15 to complete university by the age of 25 (Table 5.34). These gaps are no longer significant when comparing outcomes among students with similar PISA reading performance and parents' education.

Inactivity of both parents is relatively rare for this sample of countries (only about 5\%, on average, of the students considered in this chapter); thus it is difficult to estimate its precise 
relationship to student outcomes later in life. In addition, parents' employment status and other family characteristics, such as low family wealth or coming from a single-parent household, are likely to be strongly correlated with performance outcomes observed at age 15 . These indirectly influence later outcomes, and thus explain why certain disparities become insignificant after accounting for student performance. While this analysis provides a preliminary consideration of how family characteristics can influence educational attainment and early career achievement, it cannot fully identify the extent to which gaps in outcomes can be attributed to the direct or indirect effects.

\section{Differences in school characteristics}

\section{School composition}

An important factor behind limited educational mobility is residential segregation, whereby wealth and poverty are concentrated in particular geographic locations and neighbourhoods. Residential segregation is often accompanied by school segregation, where students from lessadvantaged households are more likely both to attend lower-quality schools and be grouped with similarly disadvantaged peers. Schools in poorer neighbourhoods often suffer from limited resources, larger classes, inexperienced teachers and an inability to retain staff - all of which create fewer opportunities for students to excel. Teachers in disadvantaged schools tend to hold low expectations of their students, which reinforce the low expectations that students and their parents may already hold (Sparkes, $\left.1999_{[59]}\right)$. Some researchers (Wodtke, Harding and Elwert, $2011_{[60]}$; Crowder and South, 2011 ${ }_{[61]}$ ) show that the fraction of childhood spent in high-poverty areas is negatively correlated with outcomes such as high school completion. Others (Chetty and Hendren, 2015 $5_{[28]}$ ) have studied more than five million families that relocated and find that living in a poor neighbourhood has adverse effects on children's outcomes.

Figure 5.13 shows that students with tertiary-educated parents who had attended disadvantaged schools (defined as schools where the share of students with tertiary-educated parents is in the bottom quarter of the national distribution) are slightly less likely to complete university than students with tertiary-educated parents who had attended advantaged schools (defined as schools where the share of students with tertiary-educated parents is in the top quarter of the national distribution), although most of these differences are statistically insignificant. This difference is marked in Australia, while it is almost negligible in Denmark.

The socio-economic composition of schools is more strongly related to disadvantaged students' progression through school (Figure 5.14). In Australia, students with less-educated parents who had attended disadvantaged schools are 23 percentage points less likely to complete university than students with less-educated parents who had attended advantaged schools. In Canada, there is a 22 percentage-point difference between the two groups of students; in Switzerland, there is a 15 percentage-point difference.

In Australia, Canada and Denmark, significantly more students with tertiary-educated parents than students without complete university studies after attending disadvantaged secondary schools (Table 5.29). Among advantaged students who had attended disadvantaged schools, between 37\% (Denmark) and 46\% (Australia) complete university by age 25; but only between $15 \%$ (Denmark) and 22\% (Australia) of disadvantaged students who had attended disadvantaged 
schools complete university by 25 . It is possible that, for students with tertiary-educated parents, a number of other beneficial factors, including home environment, financial resources and family support compensate for different school environments. Students of less-educated parents, with fewer family resources and supplemental education opportunities, may be more sensitive to school quality and composition.

Figure 5.13 - University completion rates among advantaged students, by school composition and student performance

Percentage-point difference in university completion rates by age 25 among advantaged 15-year-old students who had attended advantaged schools and those who had attended disadvantaged schools

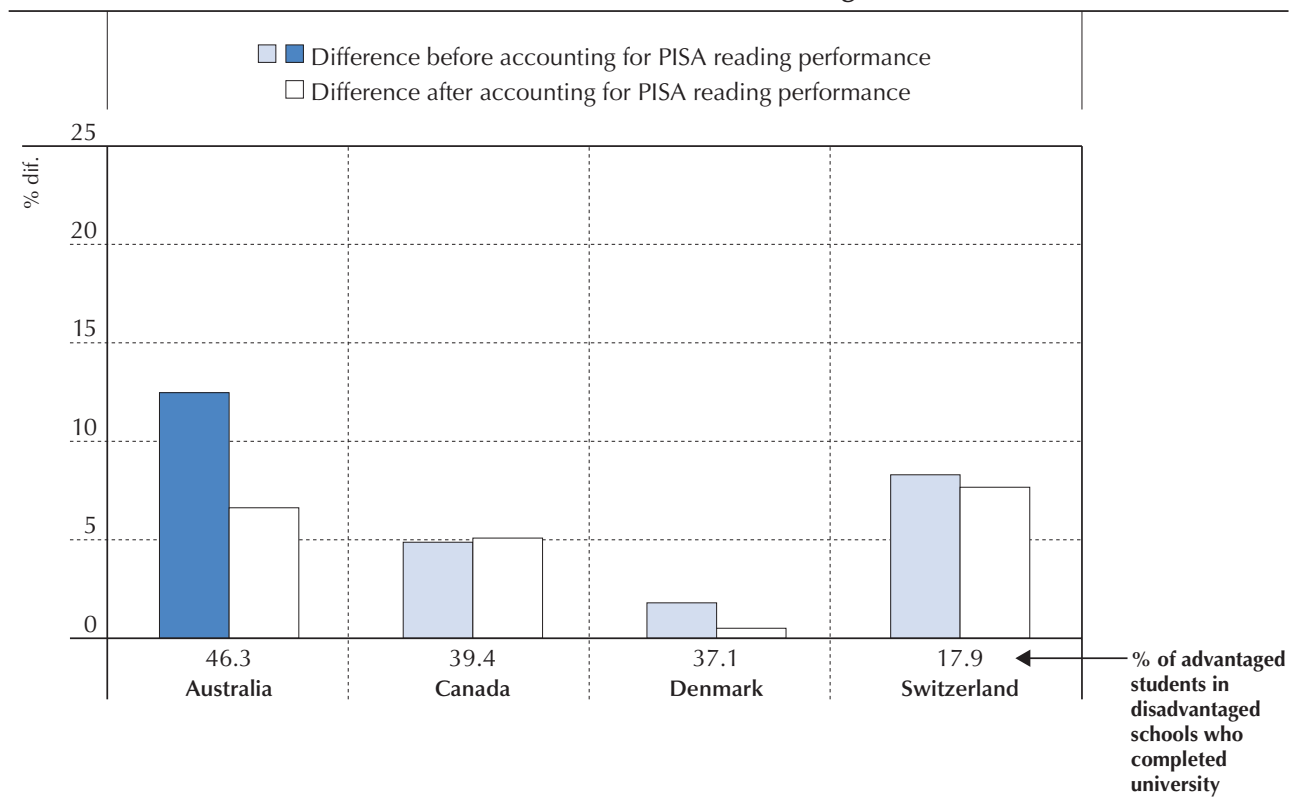

Notes: Results based on students' self-reports.

Statistically significant percentage-point differences before accounting for reading performance are shown in a darker tone. No percentage-point differences after accounting for reading performance are statistically significant.

Comparable school-level data were not available for the United States.

School composition is derived using shares of advantaged and disadvantaged students within each school to identify schools that fall in the top (advantaged) and bottom (disadvantaged) quarters.

Advantaged students are those with at least one tertiary-educated parent; disadvantaged students are those without a tertiaryeducated parent.

Source: OECD, PISA 2000 and PISA 2003 Databases, Table 5.29.

StatLink 需正 https://doi.org/10.1787/888933830956 


\section{Figure 5.14 - University completion rates among disadvantaged students,} by school composition and student performance

Percentage-point difference in university completion rates by age 25 among disadvantaged 15-year-old students who had attended advantaged schools and those who had attended disadvantaged schools

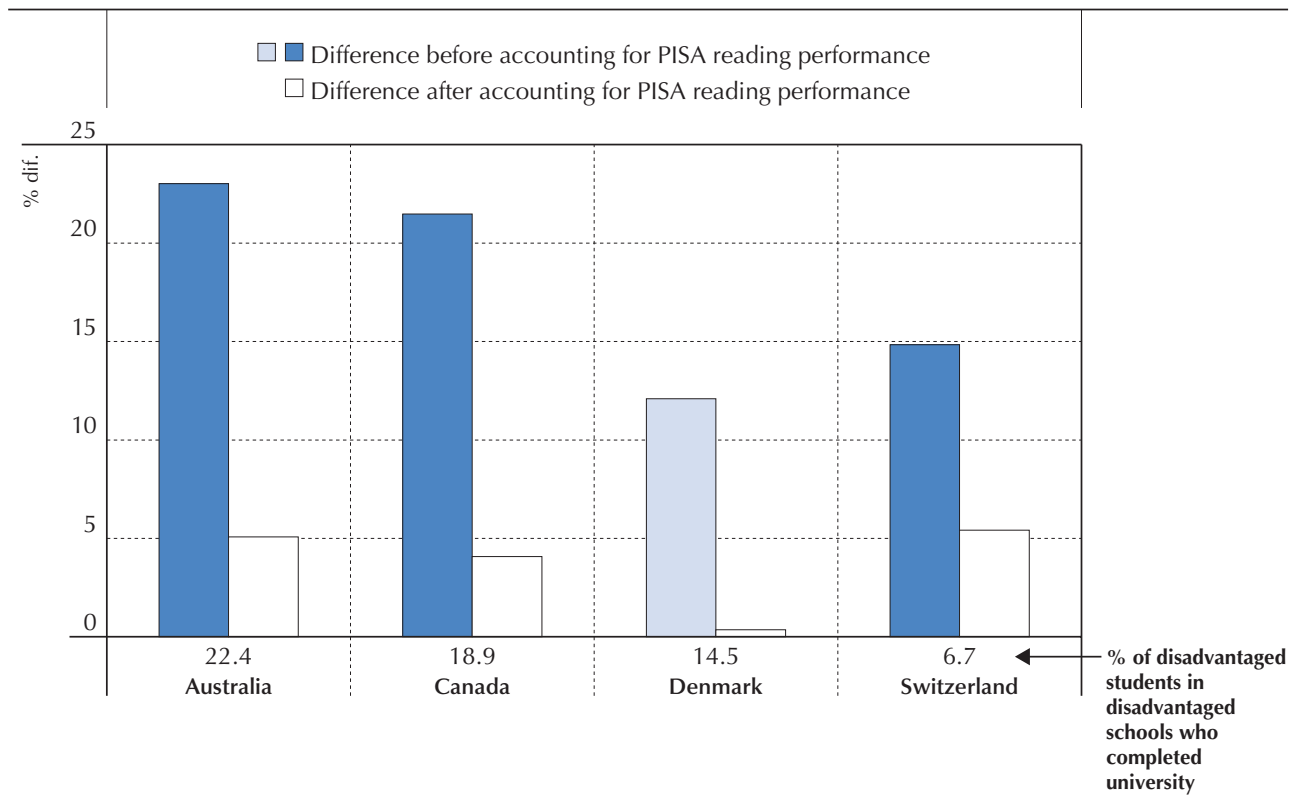

Notes: Results based on students' self-reports.

Statistically significant percentage-point differences before accounting for reading performance are shown in a darker tone. No percentage-point differences after accounting for reading performance are statistically significant.

Comparable school-level data were not available for the United States.

School composition is derived using shares of advantaged and disadvantaged students within each school to identify schools that fall in the top (advantaged) and bottom (disadvantaged) quarters.

Advantaged students are those with at least one tertiary-educated parent; disadvantaged students are those without a tertiaryeducated parent.

Source: OECD, PISA 2000 and PISA 2003 Databases, Table 5.29.

StatLink 吾ISL https://doi.org/10.1787/888933830975

\section{Peer expectations within schools}

At the school level, peer expectations can also have a particularly strong influence both on a student's own expectations and on academic achievement during secondary school (Sacerdote, $\left.2011_{[62]}\right)$. Students from low-income, less-educated households may be especially susceptible to peer influence during adolescence, particularly if these students lack nurturing experiences and mentors outside of school. As previously shown, students' expectations play a key role in influencing later achievement. Peer expectations may influence students' own expectations and thus their educational and social mobility.

In Australia, Denmark and Switzerland, students in advantaged schools are between 13 and 20 percentage points more likely to expect to work in a skilled occupation than students in disadvantaged schools (Table 5.30). These gaps become insignificant, in all countries except 
Switzerland, after accounting for school-level performance in reading. A possible explanation is that school performance reflects a wide range of factors associated with school quality, such as teacher quality, school resources and the learning environment - all of which are likely to affect education expectations within a particular school. Yet in Switzerland, some differences in students' expectations between advantaged and disadvantaged schools are observed even when comparing schools that perform similarly.

Figure 5.15 shows that students who had attended schools with high student expectations (defined as those schools where the percentage of students who expect skilled employment is higher than the country average) are more likely to complete university than students who had attended schools with low student expectations (those schools where the percentage of students who expect skilled employment is lower than the country average). Apart from Denmark, this relationship between peer expectations and university completion remains significant even after accounting for school performance.

Figure 5.15 - University completion rates, by peer expectations and school performance

Percentage-point difference in university completion rates by age 25 between 15-year-old students who had attended schools with high peer expectations and those who had attended schools with low peer expectations of skilled employment

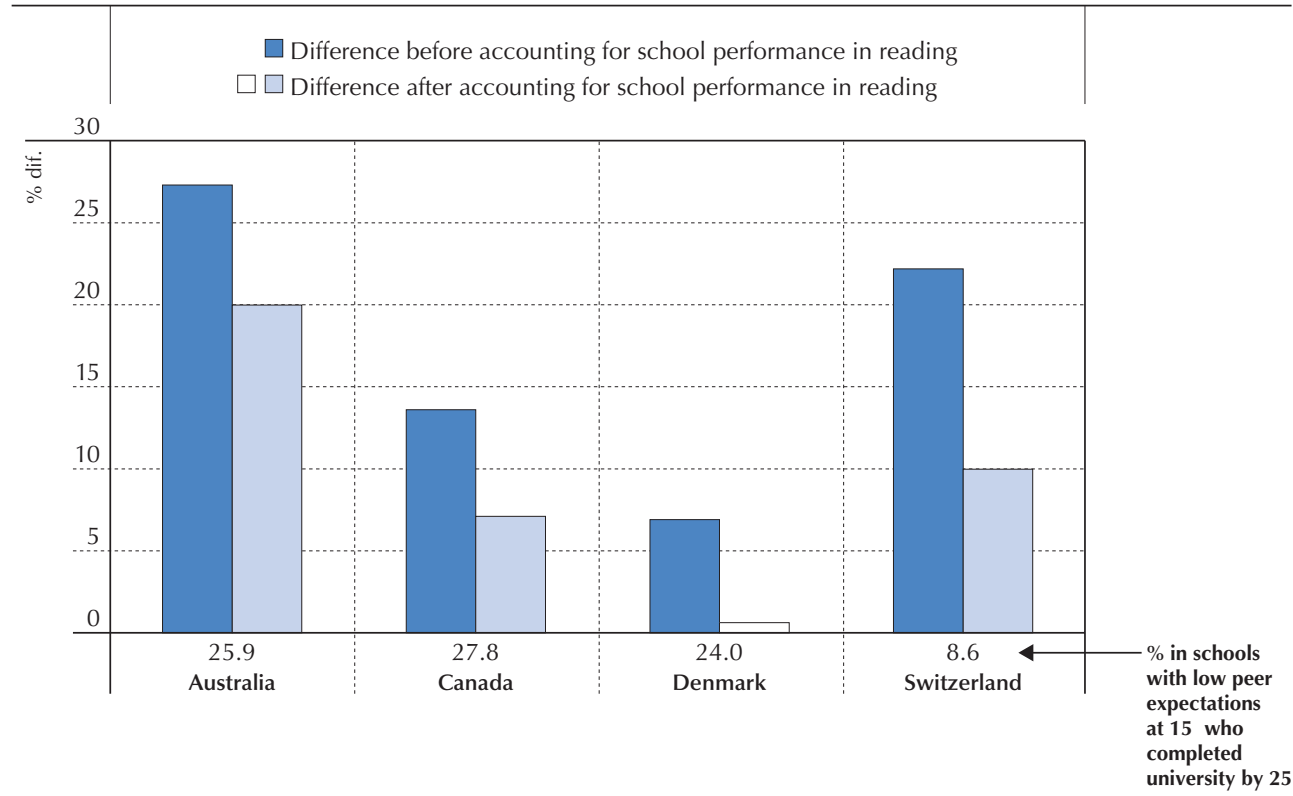

Notes: Results based on students' self-reports.

Statistically significant percentage-point differences after accounting for school performance are shown in light blue.

All percentage-point differences before accounting for school performance are statistically significant.

Comparable school-level data were not available for the United States.

Schools with high (low) expectations are those schools where the percentage of students who expect high-skilled employment is significantly higher (lower) than the country average.

Source: OECD, PISA 2000 and PISA 2003 Databases, Table 5.30.

StatLink त्राजा https://doi.org/10.1787/888933830994 
When students with low expectations are grouped together in the same learning environment, their attitudes towards schooling and perceptions of future potential are reinforced. Research in sociology suggests that aspirations for further education tend to be higher when students attend a school where the average socio-cultural intake is also higher (Dupriez et al., $2012_{[63]}$ ). Though these results do not imply a causal link, they highlight the importance of considering the possible effects of school composition and social stratification on educational mobility.

The analysis of longitudinal data for a limited number of countries reveals that the difficulties disadvantaged students must overcome in order to move up the education ladder are numerous and varied, involving a combination of individual, family, school and even country-level factors. Therefore, it is crucial to identify these factors, and their contribution to the observed gaps in academic performance and educational mobility, in order to design efficient and integrated policies that address the needs of disadvantaged students. Greater efforts to develop longitudinal studies, or to link national and international assessments with administrative records, may prove a worthwhile investment in order to better understand how upward educational mobility works. 


\section{Notes}

1. Upward mobility is one form of mobility to be explored in this analysis. Examining patterns regarding downward mobility and immobility are also possible with these data, but are not the focus of the analysis in this chapter.

2. One weakness of longitudinal data comes from attrition, the discontinued participation of original participants in a longitudinal study. Attrition is problematic for two main reasons. First, attrition reduces the size of the sample, and if the sample becomes too small, this can jeopardise statistical power. Second, if attrition is not random, it can lead to non-response bias. Attrition is not random if certain subgroups of the initial sample are more likely to drop out or not respond to a follow-up survey. If such is the case, this can mean that the sample no longer remains representative of the original population being studied, and thus can affect the validity of statistical findings. Two approaches are typically adopted to deal with this type of missing data: weighting survey responses to re-balance the data or imputing values for the missing information. In this chapter, country- and cycle-specific survey weights are used to correct for non-random attrition that occurred over the course of these longitudinal studies. This method places greater weight on individuals who may be under-represented in the final survey, based on a series of observable characteristics, in order to produce estimates from nationally representative samples.

3. The Swiss panel study TREE (Transitions from Education to Employment) is a social science data infrastructure mainly funded by the Swiss National Science Foundation (SNF) and located at the University of Bern.

4. Canadian results exclude observations from the province of Quebec due to the structural differences in primary and secondary education systems, in comparison to the other provinces in Canada.

5. The estimates in Figure 5.2 are presenting percentage-point differences between advantaged and disadvantaged students. This is not intended to identify the most- and least-equitable countries in this study, but rather highlight the inequities in educational mobility across socio-economic status. Odds ratios or risk ratios are required for comparing countries based on equitable outcomes.

6. In this chapter, STEM jobs are defined as jobs requiring tertiary education in the fields of science, technology, engineering and mathematics; they do not include healthcare-related employment.

\section{References}

Beal, S. and L. Crockett (2010), "Adolescents' Occupational and Educational Aspirations and Expectations: Links to High School Activities and Adult Educational Attainment", Developmental Psychology, Vol. 46/1, pp. 258-265, http://dx.doi.org/10.1037/a0017416.

Behrman, J. and P. Taubman (1989), Is Schooling Mostly in the Genes? Nature-Nurture Decomposition Using Data on Relatives, The University of Chicago Press, http://dx.doi.org/10.2307/1833246.

Behrman, J., P. Taubman and T. Wales (1977), Controlling for and measuring the effects of genetics and family environment in equations for schooling and labor market success. Kinometrics: Determinants of Socioeconomic Success Within and Between Families., North-Holland Pub. Co, https://www.researchgate.net/publication/313444630 Controlling for and measuring the effects of genetics and family environment in equations for schooling and labor market success (accessed on 15 February 2018).

Belley, P. and L. Lochner (2007), "The Changing Role of Family Income and Ability in Determining Educational Achievement", Journal of Human Capital, Vol. 1/1, pp. 37-89, http://dx.doi.org/10.1086/524674. 
Bjorklund, A., M. Lindahl and E. Plug (2004), "Intergenerational Effects in Sweden: What Can We Learn from Adoption Data?", IZA Discussion Paper No. 1194, https://papers.ssrn.com/sol3/papers.cfm?abstract_id=565401 (accessed on 15 February 2018).

Borgonovi, F. and G. Montt (2012), "Parental Involvement in Selected PISA Countries and Economies", OECD Education Working Papers, No. 73, OECD Publishing, Paris, http://dx.doi.org/10.1787/5k990rk0jsij-en.

Borgonovi, F. et al. (2017), "Youth in Transition: How do some of the cohorts participating in PISA fare in PIAAC?", OECD Education Working Papers , No. 155, OECD Publishing, Paris, http://dx.doi.org/10.1787/19939019.

Bowles, S., H. Gintis and M. Osborne (2001), "The Determinants of Earnings: A Behavioral Approach", Journal of Economic Literature, Vol. 39/4, pp. 1137-1176, http://dx.doi.org/10.1257/jel.39.4.1137.

Braga, B. et al. (2017), Wealth Inequality Is a Barrier to Education and Social Mobility, Urban Institute, Washington, DC, http://hdl.voced.edu.au/10707/444950.

Buchmann, C. and B. Dalton (2002), "Interpersonal Influences and Educational Aspirations in 12 Countries: The Importance of Institutional Context", Sociology of Education, Vol. 75/2, pp. 99-122, http://dx.doi.org/10.2307/3090287.

Chamorro-Premuzic, T. and A. Furnham (2003), "Personality traits and academic examination performance", European Journal of Personality, Vol. 17/3, pp. 237-250,

http://dx.doi.org/10.1002/per.473.

Chetty, R. and N. Hendren (2015), "The Effects of Exposure to Better Neighborhoods on Children: New Evidence from the Moving to Opportunity Experiment", NBER Working Paper, No. 21156, http://dx.doi.org/10.3386/w21156.

Chowdry, H., C. Crawford and A. Goodman (2011), "The role of attitudes and behaviours in explaining socio-economic differences in attainment at age 16", Longitudinal and Life Course Studies, Vol. 2/1, pp. 59-76, http://www.llcsjournal.org/index.php/llcs/article/viewFile/141/119 (accessed on 02 March 2018).

Croizet, J. and T. Claire (1998), "Extending the Concept of Stereotype Threat to Social Class: The Intellectual Underperformance of Students From Low Socioeconomic Backgrounds", Personality and Social Psychology Bulletin, Vol. 24/6, pp. 588-594, https://doi.org/10.1177\%2F0146167298246003.

Crowder, K. and S. South (2011), "Spatial and Temporal Dimensions of Neighborhood Effects on High School Graduation", Social Science Research, Vol. 40/1, pp. 87-106, http://dx.doi.org/10.1016/j.ssresearch.2010.04.013.

Cunha, F. and J. Heckman (2007), "The Technology of Skill Formation", American Economic Review, Vol. 97/2, pp. 31-47, http://dx.doi.org/10.1257/aer.97.2.31.

Deluca, S. and J. Rosenbaum (2001), "Individual Agency and the Life Course: Do Low-SES Students Get Less Long-Term Payoff for Their School Efforts?", Sociological Focus, Vol. 34:4, pp. 357-376, https://doi.org/10.1080/00380237.2001.10571208.

D'Errico, F., I. Poggi and L. Correa (2011), "School and life for teenagers. Expectations and hopes in Italy and Brazil", International Journal of Developmental and Educational Psychology, Vol. 1/2, pp. 433-442, www.redalyc.org/articulo.oa?id=349832329036. 
Downey, D., P. Hippel and B. Broh (2004), "Are Schools the Great Equalizer? School and Non-School Sources of Inequality in Cognitive Skills", American Sociological Review, Vol. 69/5, pp. 613-635.

Dupriez, V. et al. (2012), "Social Inequalities of Post-secondary Educational Aspirations: Influence of social background, school composition and institutional context", European Educational Research Journal, Vol. 11/4, pp. 504-519, http://dx.doi.org/10.2304/eerj.2012.11.4.504.

Fruehwirth, J., S. Navarro and Y. Takahashi (2016), "How the Timing of Grade Retention Affects Outcomes: Identification and Estimation of Time-Varying Treatment Effects", Journal of Labor Economics, Vol. 34/4, pp. 979-1021, http://dx.doi.org/10.1086/686262.

Gale, T. et al. (2013), Student Aspirations for Higher Education in Central Queensland: A Survey of Students' Navigational Capacities, Centre for Research in Education Futures and Innovation (CREFI), Deakin University, Melbourne, Australia.

Gore, J. et al. (2015), "Socioeconomic status and the career aspirations of Australian school students: Testing enduring assumptions", Australian Educational Researcher, Vol. 42/2, pp. 155-177, http://dx.doi.org/10.1007/s13384-015-0172-5.

Hällsten, M. and F. Pfeffer (2017), "Grand Advantage: Family Wealth and Grand Children's Educational Achievement in Sweden", American Sociological Review, Vol. 82/2, pp. 328-360, http://dx.doi.org/10.1177/0003122417695791.

Hanushek, E. and L. Woessmann (2006), "Does Educational Tracking Affect Performance and Inequality? Difference-In-Differences Evidence Across Countries", The Economic Journal, Vol. 116/510, pp. C63-C76, https://doi.org/10.1111/j.1468-0297.2006.01076.x.

Hanushek, E., L. Woessmann and L. Zhang (2011), "General Education, Vocational Education, and Labor-Market Outcomes over the Life-Cycle", NBER Working Paper, No. 17504, http://dx.doi.org/10.3386/w17504.

Heckman, J., J. Stixrud and S. Urzua (2006), "The Effects of Cognitive and Noncognitive Abilities on Labor Market Outcomes and Social Behavior", NBER Working Paper, No. 12006, http://dx.doi.org/10.3386/w12006.

Hsieh, C. et al. (2013), "The Allocation of Talent and U.S. Economic Growth", NBER Working Paper, No. 18693, http://dx.doi.org/10.3386/w18693.

Kaplan Toren, N. (2013), "Multiple Dimensions of Parental Involvement and its Links to Young Adolescent Self-Evaluation and Academic Achievement", Psychology in the Schools, Vol. 50/6, pp. 634-649, http://dx.doi.org/10.1002/pits.21698.

Karagiannaki, E. (2012), "The effect of parental wealth on children's outcomes in early adulthood", CASEpaper 164, Centre for Analysis of Social Exclusion, London School of Economics.

Mandara, J. and C. Murray (2006), "Father's Absence and African American Adolescent Drug Use", Journal of Divorce \& Remarriage, Vol. 46/1-2, pp. 1-12, http://dx.doi.org/10.1300//087v46n01_01.

Milne, A. et al. (1986), "Single Parents, Working Mothers, and the Educational Achievement of School Children", Sociology of Education, Vol. 59/3, pp. 125-139, http://dx.doi.org/10.2307/2112335.

Montt, G. (2016), "Are Socioeconomically Integrated Schools Equally Effective for Advantaged and Disadvantaged Students?", Comparative Education Review, Vol. 60/4, pp. 808-832,

http://dx.doi.org/10.1086/688420. 
Mooi-Reci, I. and B. Bakker (2015), "Parental Unemployment: How Much and When Does it Matter for Children's Educational Attainment?", Life Course Centre Working Paper Series, Vol. 2015/03.

Mortimer, J. et al. (2008), "Tracing the Timing of "Career" Acquisition in a Contemporary Youth Cohort", Work and Occupations, Vol. 35/1, pp. 44-84, http://www.ncbi.nlm.nih.gov/pubmed/18542713 (accessed on 14 February 2018).

Nonoyama-Tarumi, Y. (2017), "Educational Achievement of Children From Single-Mother and Single-Father Families: The Case of Japan", Journal of Marriage and Family, Vol. 79, pp. 915-931, http://dx.doi.org/10.1111/jomf.12409.

Nunn, A. et al. (2007), "Factors influencing social mobility", Research Report, No. 450, Department for Work and Pensions, United Kingdom.

Nurmi, J. (2013), "Socialization and Self-Development: Channeling, Selection, Adjustment, and Reflection", in Handbook of Adolescent Psychology, John Wiley \& Sons, Inc., http://dx.doi.org/10.1002/9780471726746.ch4.

OECD (2017), Education at a Glance 2017: OECD Indicators, OECD Publishing, Paris, http://dx.doi.org/10.1787/eag-2017-en.

OECD (2017), Educational Opportunity for All: Overcoming Inequality throughout the Life Course, Educational Research and Innovation, OECD Publishing, Paris, http://dx.doi.org/10.1787/9789264287457-en.

OECD (2017), PISA 2015 Results (Volume III): Students' Well-Being, PISA, OECD Publishing, Paris, http://dx.doi.org/10.1787/9789264273856-en.

OECD (2017), The Pursuit of Gender Equality - An Uphill Battle, OECD Publishing, Paris, http://dx.doi.org/10.1787/9789264281318-en.

OECD (2016), PISA 2015 Results (Volume I): Excellence and Equity in Education, PISA, OECD Publishing, Paris, http://dx.doi.org/10.1787/9789264266490-en.

OECD (2016), Society at a Glance 2016: OECD Social Indicators, OECD Publishing, Paris, http://dx.doi.org/10.1787/9789264261488-en.

OECD (2013), PISA 2012 Results: Excellence through Equity (Volume II): Giving Every Student the Chance to Succeed, PISA, OECD Publishing, Paris, http://dx.doi.org/10.1787/9789264201132-en.

OECD (2013), PISA 2012 Results: Ready to Learn (Volume III): Students' Engagement, Drive and Self-Beliefs, PISA, OECD Publishing, Paris, http://dx.doi.org/10.1787/9789264201170-en.

OECD (2010), Improving Health and Social Cohesion through Education, Educational Research and Innovation, OECD Publishing, Paris, http://dx.doi.org/10.1787/9789264086319-en.

Ololube, N., L. Onyekwere and C. Agbor (2015), "Social Stratification and Mobility: How SocioEconomic Status of Family Affects Children's Educational Development and Management", Education, Vol. 5/4, pp. 111-122, http://dx.doi.org/10.5923/j.edu.20150504.03.

Owens, J. and D. Massey (2011), "Stereotype threat and college academic performance: A latent variables approach", Social Science Research, Vol. 40/1, pp. 150-166,

http://dx.doi.org/10.1016/j.ssresearch.2010.09.010.

Plomin, R. et al. (2001), Behavioral Genetics, Worth Publishers, New York. 
Pong, S., J. Dronkers and G. Hampden-Thompson (2003), "Family policies and children's school achievement in single- versus two-parent families", Journal of Marriage and the Family, Vol. 65/19, pp. 681-699, https://pure.york.ac.uk/portal/en/publications/family-policies-and-childrens-schoolachievement-in-single-versus-twoparent-families(9672f21f-51f8-4cd1-93ba-7539430458d4).html (accessed on 15 February 2018).

Putnam, R. (2015), Our Kids: the American Dream in Crisis, Simon and Schuster, New York, NY.

Sacerdote, B. (2011), "Nature and nurture effects on children's outcomes: What have we learned from studies of twins and adoptees?", Handbook of Social Economics, Vol. 1, pp.1-30, http://dx.doi.org/10.1016/B978-0-444-53187-2.00001-2.

Sacerdote, B. (2011), "Peer Effects in Education: How might they work, how big are they and how much do we know thus Far?", Handbook of the Economics of Education, Vol. 3, pp. 249-277, http://dx.doi.org/10.1016/B978-0-444-53429-3.00004-1.

Schaefer, R. (2005), Sociology, McGraw-Hill, https://books.google.fr/books/about/Sociology.html?id=xYHq2vxl4QAC\&redir_esc=y (accessed on 14 February 2018).

Schoenfeld, A. (2002), "Making Mathematics Work for All Children: Issues of Standards, Testing, and Equity", Educational Researcher, Vol. 31/1, pp. 13-25, https://gse.berkeley.edu/sites/default/files/ users/alan-h.-schoenfeld/Schoenfeld 2002\%20Making\%20Math\%20Work\%20ER.pdf (accessed on 24 July 2018).

Sewell, W. et al. (2003), "As We Age: A Review of the Wisconsin Longitudinal Study, 1957-2001", Research in Social Stratification and Mobility, Vol. 20, pp. 3-111,

http://dx.doi.org/10.1016/S0276-5624(03)20001-9.

Sigle-Rushton, W. et al. (2004), Father Absence and Child Wellbeing: A Critical Review. The future of the family, Russell Sage Foundation, New York, http://eprints.Ise.ac.uk/9589/ (accessed on 15 February 2018).

Snellman, K. et al. (2015), "The Engagement Gap", The ANNALS of the American Academy of Political and Social Science, Vol. 657/1, pp. 194-207, http://dx.doi.org/10.1177/0002716214548398.

Sparkes, J. (1999), "Schools, Education and Social Exclusion", CASEpaper 29, Centre for Analysis of Social Exclusion, London School of Economics,

http://eprints.Ise.ac.uk/6482/1/Schools, Education and Social Exclusion.pdf (accessed on 15 February 2018).

Sullivan, A. (2001), "Cultural Capital and Educational Attainment", Sociology, Vol. 35/04, pp. 893-912, http://dx.doi.org/10.1017/S0038038501008938.

Trapmann, S. et al. (2007), "Meta-Analysis of the Relationship Between the Big Five and Academic Success at University", Zeitschrift für Psychologie / Journal of Psychology, Vol. 215/2, pp. 132-151, http://dx.doi.org/10.1027/0044-3409.215.2.132.

Wodtke, G., D. Harding and F. Elwert (2011), "Neighborhood Effects in Temporal Perspective: The Impact of Long-Term Exposure to Concentrated Disadvantage on High School Graduation", American Sociological Review, Vol. 76/5, pp. 713-736, http://dx.doi.org/10.1177/0003122411420816. 


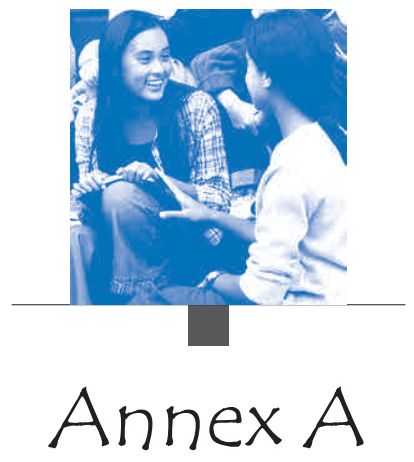

TECHNICAL NOTES ON ANALYSES IN THIS REPORT 


\section{Sources of data}

PISA datasets are the main source of data used in this report. However, in some chapters, additional sources of data are used. Data from the Survey of Adult Skills (PIAAC) (OECD, 2016 $6_{[1]}$ ) are used in Chapters 2 and 5; data from the Barro-Lee Educational Attainment Dataset (Barro and Lee, 2013 ${ }_{[2]}$ ) are used in Chapter 2; and data from the Trends in International Mathematics and Science Study (TIMSS) (IEA, 1997 ${ }_{[3]}$ ) are also used in Chapter 2. Additionally, Chapter 5 uses longitudinal data accessed by the OECD Secretariat, in its raw form or through collaboration with national researchers, from five countries: Australia, Canada, Denmark, Switzerland and the United States. For a detailed description of the longitudinal data used in Chapter 5, see Box 5.1.

\section{Explanation of the PISA indices used in the report}

This section explains the indices derived from the PISA 2015 student and school questionnaires used in this report.

Several PISA measures reflect indices that summarise responses from students, their parents, teachers or school representatives (typically principals) to a series of related questions. The questions were selected from a larger pool of questions on the basis of theoretical considerations and previous research. The PISA 2015 Assessment and Analytical Framework (OECD, 2017 $7_{[4]}$ ) provides an in-depth description of this conceptual framework. Structural equation modelling was used to confirm the theoretically expected behaviour of most indices and to validate their comparability across countries. For this purpose, a model was estimated separately for each country and collectively for all OECD countries. For a detailed description of PISA indices and details on the methods, see the PISA 2015 Technical Report (OECD, 2017 $7_{[5]}$ ).

There are two types of indices used in this volume: simple indices and scale indices. Simple indices are variables that are constructed through the arithmetic transformation or recoding of one or more items in exactly the same way across assessments. Scale indices are variables constructed through the scaling of multiple items. Unless otherwise indicated, the index was scaled using a two-parameter item response model (a generalised partial-credit model was used in the case of items with more than two categories) and values of the index correspond to Warm likelihood estimates (WLE) (Warm, 1985 ${ }_{[6]}$ ). For details on how each scale index was constructed, see the PISA 2015 Technical Report (OECD, 2017 ${ }_{[5]}$ ).

In addition to the simple and scaled indices described in this annex, there are a number of variables from the questionnaires that were used in this volume and correspond to single items not used to construct indices. These non-recoded variables have a prefix of "ST" for items in the student questionnaire, "SC" for items in the school questionnaire, "PA" for items from the parent questionnaire, and "IC" for items from the ICT questionnaire. All the context questionnaires as well as the PISA international database, including all variables, are available through www.oecd.org/pisa.

\section{Student-level simple indices \\ Students' age}

The age of a student (AGE) was calculated as the difference between the year and month of testing and the year and month of the student's birth. Data on students' age were obtained from both the questionnaire (ST003) and student tracking forms. If the month of testing was not known for a particular student, the median month for that country was used in the calculation.

\section{Parents' level of education}

Students' responses to questions ST005, ST006, ST007 and ST008 regarding their parents' education were classified using ISCED 1997 (OECD, 1999 $9_{[11]}$ ). Indices on parents' education were constructed by recoding educational qualifications into the following categories: (0) None, (1) <ISCED level 1> (primary education), (2) <ISCED level 2> (lower secondary), (3) <ISCED level 3B or 3C> (vocational/ 
pre-vocational upper secondary), (4) <ISCED level 3A $>$ (general upper secondary) and $<$ ISCED level 4> (non-tertiary post-secondary), (5) <ISCED level 5B $>$ (vocational tertiary) and (6) $<$ ISCED level 5A $>$ and $<$ ISCED level $6>$ (theoretically-oriented tertiary and post-graduate). Indices with these categories were constructed for each student's mother (MISCED) and father (FISCED). In addition, the index of parents' highest level of education (HISCED) corresponds to the higher ISCED level of either parent. The index of parents' highest level of education was also recorded by the estimated number of years of schooling (PARED). The correspondence between education levels and years of schooling is available in the PISA 2015 Technical Report (OECD, 2017 $\left.7_{[5]}\right)$.

\section{Parents' highest occupational status}

Occupational data for both the student's father and the student's mother were obtained from responses to open-ended questions. The responses were coded to four-digit ISCO (International Standard Classification of Occupations) codes (International Labour Office, 2012 $2_{[7]}$ ) and then mapped to the International Socio-Economic Index of occupational status (ISEI) (Ganzeboom and Treiman, 2003 ${ }_{[8]}$ ). In PISA 2015, as in PISA 2012, the new ISCO codes and ISEI index (2008 version) were used rather than the 1998 versions that had been applied in the previous four cycles of PISA (Ganzeboom and Treiman, $\left.2010_{[9]}\right)$. Three indices were calculated based on this information: father's occupational status (BFMJ2); mother's occupational status (BMMJ1); and the highest occupational status of parents (HISEI), which corresponds to the higher ISEI score of either parent or to the only available parent's ISEI score. For all three indices, higher ISEI scores indicate higher levels of occupational status.

\section{Students' expected occupational status}

In the PISA 2015 student questionnaire, as in the PISA 2006 questionnaire, students were asked: "What kind of job do you expect to have when you are about 30 years old?" This was an open question, meaning that no response categories were provided and students were able to answer freely using their own words. Responses were coded to four-digit ISCO codes and then mapped to the ISEI (International Socio-Economic Index of occupational status) index (Ganzeboom and Treiman, 2010 $0_{[9]}$ ). Higher scores in the ISEI index indicate higher occupational status.

\section{Science-related career expectations}

Science-related career expectations are defined as those career expectations whose realisation requires further engagement with the study of science beyond compulsory education, typically in formal tertiary-education settings. The classification of careers into science-related and non-science-related is based on the four-digit ISCO-08 classification of occupations.

Only professionals (major ISCO group 2) and technicians/associate professionals (major ISCO group 3) were considered to fit the definition of science-related career expectations. In a broad sense, several managerial occupations (major ISCO group 1) are clearly science-related, including research and development managers, hospital managers, construction managers, and other occupations classified under production and specialised services managers (submajor group 13). However, it was considered that when science-related experience and training is an important requirement of a managerial occupation, these are not entry-level jobs, and 15-year-old students with science-related career expectations would not expect to be in such a position at the age of 30 .

Several skilled agriculture, forestry and fishery workers (major ISCO group 6) could also be considered to work in science-related occupations. The United States O*NET OnLine (2016) classification of science, technology, engineering and mathematics (STEM) occupations indeed includes these occupations. These, however, do not typically require formal science-related training or study after compulsory education. On these grounds, only major occupation groups that require ISCO skill levels 3 and 4 were included among science-related career expectations. 
Among professionals and technicians/associate professionals, the boundary between sciencerelated and non-science related occupations is sometimes blurred, and different classifications draw different lines.

The classification used in this report includes four groups of jobs:

1. Science and engineering professionals: All science and engineering professionals (submajor group 21), except product and garment designers (2163) and graphic and multimedia designers (2166).

2. Health professionals: All health professionals in submajor group 22 (e.g. doctors, nurses, veterinarians), with the exception of traditional and complementary medicine professionals (minor group 223).

3. ICT professionals: All information and communication technology professionals (submajor group 25).

4. Science technicians and associate professionals, including:

- physical and engineering science technicians (minor group 311)

- life science technicians and related associate professionals (minor group 314)

- air traffic safety electronic technicians (3155)

- medical and pharmaceutical technicians (minor group 321), except medical and dental prosthetic technicians (3214)

- telecommunications engineering technicians (3522).

For further details about this index, including how this classification compares to existing classifications, see Annex A1 in PISA 2015 Results (Volume I) (OECD, 2016 [10] $)$.

\section{International academic resilience}

The index of international academic resilience is a simple index that takes the value of one if a student meets two conditions and takes the value of zero otherwise. A student is classified as "internationally resilient" if the student is in the bottom quarter of the PISA index of economic, social and cultural status (ESCS) in the country/economy of assessment; and if the student scored in the top quarter of performance in science among all students participating in PISA, after accounting for socio-economic background.

\section{National academic resilience}

The index of national academic resilience is a simple index that takes the value of one if a student meets two conditions and takes the value of zero otherwise. A student is classified as "nationally resilient" if the student is in the bottom quarter of the ESCS index in the country/economy of assessment, and if the student scored in the top quarter of performance in science among students in his or her own country.

\section{Core-skills academic resilience}

The index of core-skills academic resilience is a simple index that takes the value of one if a student meets two conditions and takes the value of zero otherwise. A student is classified as "core-skills resilient" if the student is in the bottom quarter of the ESCS index in the country/economy of assessment, and if the student scored at or above PISA proficiency Level 3 in science, reading and mathematics.

\section{Social and emotional resilience}

The index of social and emotional resilience is a simple index that takes the value of one if a student meets four conditions and takes the value of zero otherwise. A student is classified as "socially and 
emotionally resilient" if she or he meets the following four criteria: i) the student is in the bottom quarter of the ESCS index in the country/economy of assessment; ii) the student rated her or his life satisfaction with a value from seven to ten, on a scale from zero to ten, with zero meaning "not at all satisfied" and ten meaning "completely satisfied" (questionnaire item ST016 was: "Overall, how satisfied are you with your life as a whole these days?"); iii) the student disagreed with the following statement: "I feel like an outsider (or left out of things) at school"; and iv) the student disagreed with the following statement: "Even when I am well prepared for a test I feel very anxious".

\section{Study programme}

PISA collects data on study programmes available to 15 -year-old students in each country. This information is obtained through the student tracking form and the student questionnaire. In the final database, all national programmes are included in a separate derived variable (PROGN) where the first six digits represent the National Centre code, and the last two digits are the nationally specific programme code. All study programmes were classified using the International Standard Classification of Education (ISCED) $\left(\mathrm{OECD}\right.$, 1999 $\left._{[11]}\right)$. The following indices were derived from the data on study programmes:

- Programme level (ISCEDL) indicates whether students were at the lower or upper secondary level (ISCED 2 or ISCED 3).

- Programme designation (ISCEDD) indicates the designation of the study programme ( $\mathrm{A}=$ general programmes designed to give access to the next programme level; $\mathrm{B}=$ programmes designed to give access to vocational studies at the next programme level; $\mathrm{C}=$ programmes designed to give direct access to the labour market; $M=$ modular programmes that combine any or all of these characteristics).

- Programme orientation (ISCEDO) indicates whether the programme's curricular content was general, pre-vocational or vocational.

\section{Immigrant background}

The PISA database contains three country-specific variables relating to the country of birth of the student, their mother and their father (COBN_S, COBN_M, and COBN_F). The items ST019Q01TA, ST019Q01TB and ST019Q01TC were recoded into the following categories: (1) country of birth is the same as the country of assessment and (2) other. The index of immigrant background (IMMIG) was calculated from these variables with the following categories: (0) non-immigrant students (those students who had at least one parent born in the country), and (1) first- and second-generation immigrant students (those born outside the country of assessment and whose parent[s] were also born in another country; and those born in the country of assessment but whose parent[s] were born in another country). Students with missing responses for either the student or for both parents were assigned missing values for this variable.

\section{Student-level scale indices}

\section{PISA index of economic, social and cultural status}

The PISA index of economic, social and cultural status (ESCS) was derived, as in previous cycles, from three variables related to family background: parents' highest level of education (PARED), parents' highest occupational status (HISEI), and home possessions (HOMEPOS), including books in the home. PARED and HISEI are simple indices, described above. HOMEPOS is a proxy measure for family wealth.

For the purpose of computing the PISA index of economic, social and cultural status (ESCS), values for students with missing PARED, HISEI or HOMEPOS were imputed with predicted values plus a 
random component based on a regression on the other two variables. If there were missing data on more than one of the three variables, ESCS was not computed and a missing value was assigned for ESCS.

The PISA index of economic, social and cultural status (ESCS) was derived from a principal component analysis of standardised variables (each variable has an OECD mean of zero and a standard deviation of one), taking the factor scores for the first principal component as measures of this index. All countries and economies (both OECD and partner countries/economies) contributed equally to the principal component analysis, while in previous cycles, the principal component analysis was based on OECD countries only. However, for the purpose of reporting, the ESCS scale was transformed, with zero being the score of an average OECD student and one being the standard deviation across equally weighted OECD countries.

Principal component analysis was also performed for each participating country or economy separately, to determine to what extent the components of the index operate in similar ways across countries and economies.

For more detailed information on how the ESCS was constructed, please refer to the PISA 2015 Technical Report (OECD, 2017 $\left.7_{[5]}\right)$.

\section{Achievement motivation}

The index of achievement motivation (MOTIVAT) was constructed from students' responses to a new question developed for PISA 2015 (ST119). Students were asked to report their agreement ("strongly disagree"; "disagree"; "agree"; or "strongly agree") with the following statements: "I want top grades in most or all of my courses"; "I want to be able to select from among the best opportunities available when I graduate"; "I want to be the best, whatever I do"; "I see myself as an ambitious person"; and "I want to be one of the best students in my class". Higher values indicate that students have greater achievement motivation.

\section{Science self-efficacy}

The index of science self-efficacy (SCIEEFF) was constructed based on a trend question (ST129) that was taken from PISA 2006 (ID in 2006: ST17). Students were asked to rate how well they would perform ("I could do this easily"; "I could do this with a bit of effort"; "I would struggle to do this on my own"; or "I couldn't do this") the following science tasks: recognise the science question that underlies a newspaper report on a health issue; explain why earthquakes occur more frequently in some areas than in others; describe the role of antibiotics in the treatment of disease; identify the science question associated with the disposal of garbage; predict how changes to an environment will affect the survival of certain species; interpret the scientific information provided on the labelling of food items; discuss how new evidence can lead you to change your understanding about the possibility of life on Mars; and identify the better of two explanations for the formation of acid rain. Responses were reverse-coded so that higher values in the index correspond to higher levels of science self-efficacy. The derived variable SCIEEFF was equated to the corresponding scale in the PISA 2006 database, thus allowing for a trend comparison between PISA 2006 and PISA 2015.

\section{Disciplinary climate}

The index of disciplinary climate in science classes (DISCLISCI) was constructed from students' reports on how often ("every lesson"; "most lessons"; "some lessons"; or "never or hardly ever") the following happened in their science lessons (ST097): "students don't listen to what the teacher says"; "there is 
noise and disorder"; "the teacher has to wait a long time for students to quiet down"; "students cannot work well"; and "students don't start working for a long time after the lesson begins".

\section{Index of effort and perseverance (EFFPER)}

The PISA 2000 index of effort and perseverance was derived from students' reports on how often ("almost never"; "sometimes"; "often"; or "almost always") the following statements applied to the student: "when studying, I work as hard as possible"; "when studying, I keep working even if the material is difficult"; "when studying, I try to do my best to acquire the knowledge and skills taught"; and "when studying, I put forth my best effort". Scale scores are standardised Warm estimates where positive values indicate greater frequency and negative values indicate lower frequency of using effort and perseverance as a learning strategy.

\section{Index of cultural communication (CULTCOM)}

The PISA 2000 index of cultural communication was derived from students' reports on the frequency ("never or hardly ever"; "a few times a year"; "about once a month"; "several times a month"; or "several times a week") with which their parents (or guardians) engaged with them in: discussing books, films or television programmes; and listening to classical music. Scale scores are standardised Warm estimates where positive values indicate a greater frequency and negative values indicate a lower frequency of cultural communication.

\section{Index of cultural activities (CULTACTV)}

The PISA 2000 index of cultural activities was derived from students' reports on how often during the preceding year ("never or hardly ever"; "once or twice a year"; "about three or four times a year"; or "more than four times a year") they had: visited a museum or art gallery; attended an opera, ballet or classical symphony concert; or watched live theatre. Scale scores are standardised Warm estimates where positive values indicate a greater frequency and negative values indicate a lower frequency of participating in cultural activities during the year.

\section{Teacher-directed science instruction}

The index of teacher-directed science instruction (TDTEACH) was constructed from students' reports on how often ("never or almost never"; "some lessons"; "many lessons"; or "every lesson or almost every lesson") the following happened in their science lessons (ST103): "the teacher explains scientific ideas"; "a whole class discussion takes place with the teacher"; "the teacher discusses our questions"; and "the teacher demonstrates an idea".

\section{Perceived feedback}

The index of perceived feedback (PERFEED) was constructed from students' reports on how often ("never or almost never"; "some lessons"; "many lessons"; or "every lesson or almost every lesson") the following happened in their science lessons (ST104): "the teacher tells me how I am performing in this course"; "the teacher gives me feedback on my strengths in this <school science> subject"; "the teacher tells me in which areas I can still improve"; "the teacher tells me how I can improve my performance"; and "the teacher advises me on how to reach my learning goals".

\section{Adaptive instruction}

The index of adaptive instruction (ADINST) was constructed from students' reports on how often ("never or almost never"; "some lessons"; "many lessons"; or "every lesson or almost every lesson") the following happened in their science lessons (ST107): "the teacher adapts the lesson to my class's needs and knowledge"; "the teacher provides individual help when a student has difficulties 
understanding a topic or task"; and "the teacher changes the structure of the lesson on a topic that most students find difficult to understand".

\section{Enquiry-based instruction}

The index of enquiry-based instruction (IBTEACH) was constructed from students' reports on how often ("in all lessons"; "in most lessons"; "in some lessons"; or "never or hardly ever") the following happened in their science lessons (ST098): "students are given opportunities to explain their ideas"; "students spend time in the laboratory doing practical experiments"; "students are required to argue about science questions"; "students are asked to draw conclusions from an experiment they have conducted"; "the teacher explains how a <school science $>$ idea can be applied to a number of different phenomena"; "students are allowed to design their own experiments"; "there is a class debate about investigations"; "the teacher clearly explains the relevance of <broad science> concepts to our lives"; and "students are asked to do an investigation to test ideas".

\section{Index of interest in reading (INTREA)}

The PISA 2000 index of interest in reading was derived from students' level of agreement ("disagree"; "disagree somewhat"; "agree somewhat"; or "agree") with the following three statements: "because reading is fun, I wouldn't want to give it up"; "I read in my spare time"; and "when I read, I sometimes get totally absorbed". Scale scores are standardised Warm estimates where positive values indicate higher levels and negative values indicate lower levels of interest in reading.

\section{Index of engagement in reading (JOYREAD)}

The PISA 2000 index of engagement in reading was derived from students' level of agreement ("strongly disagree"; "disagree"; "agree"; or "strongly agree") with the following statements: "I read only if I have to"; "reading is one of my favourite hobbies"; "I like talking about books with other people"; "I find it hard to finish books"; "I feel happy if I receive a book as a present"; "for me, reading is a waste of time"; "I enjoy going to a bookstore or library"; "I read only to get information that I need"; and "I cannot sit still and read for more than a few minutes". Scale scores are standardised Warm estimates where positive values indicate more positive attitudes and negative values indicate less positive attitudes towards reading.

\section{School-level simple indices}

\section{Science-specific resources}

The index of science-specific resources (SCIERES) was constructed using principals' responses to a series of statements about the school science department. It was constructed by summing up principals' answers to the following eight statements in SC059: "compared to other departments, our schools' <school science department> is well equipped"; "if we ever have some extra funding, a big share goes into improvement of our <school science $>$ teaching"; "<school science $>$ teachers are among our best educated staff members"; "compared to similar schools, we have a well-equipped laboratory"; "the material for hands-on activities in <school science> is in good shape"; "we have enough laboratory material that all courses can regularly use it"; "we have extra laboratory staff that helps support <school science> teaching"; and "our school spends extra money on up-to-date $<$ school science $>$ equipment".

\section{Class size}

The average class size (CLSIZE) is derived from one of nine possible categories in question SC003, ranging from "15 students or fewer" to "more than 50 students". 


\section{School-level scale indices \\ Student behaviour hindering learning}

The index of student behaviour hindering learning (STUBEHA) was constructed from school principals' reports on the extent ("not at all"; "very little"; "to some extent"; or "a lot") to which they think that student learning in their schools is hindered by the following phenomena (SC061): student truancy; students skipping classes; students lacking respect for teachers; students using alcohol or illegal drugs; and students intimidating or bullying other students. The responses were combined to create an index such that, across OECD countries, the mean is zero and the standard deviation is one.

\section{References}

Barro, R. and J. Lee (2013), "A new data set of educational attainment in the world, 1950-2010", Journal of Development Economics, Vol. 104, pp. 184-198, http://dx.doi.org/10.1016/J.JDEVECO.2012.10.001.

Ganzeboom, H. and D. Treiman (2010), Occupational Status Measures for the New International Standard Classification of Occupations ISCO-08; With a Discussion of the New Classifications, http://www.harryganzeboom.nl/isol/isol2010c2-ganzeboom.pdf (accessed on 02 August 2018).

Ganzeboom, H. and D. Treiman (2003), "Three Internationally Standardised Measures for Comparative Research on Occupational Status", in Advances in Cross-National Comparison, Springer US, Boston, MA, http://dx.doi.org/10.1007/978-1-4419-9186-7 9.

IEA (1997), Mathematics in the Primary School Years: IEA's Third International Mathematics and Science Report, International Association for the Evaluation of Educational Achievement, Boston, https://timssandpirls.bc.edu/timss1995i/MathA.html (accessed on 02 August 2018).

International Labour Office (2012), International Standard Classification of Occupations, ISCO-08, http://www.ilo.org/public/english/bureau/stat/isco/docs/publication08.pdf (accessed on 02 August 2018).

OECD (2017), PISA 2015 Assessment and Analytical Framework: Science, Reading, Mathematic, Financial Literacy and Collaborative Problem Solving, PISA, OECD Publishing, Paris,

http://dx.doi.org/10.1787/9789264281820-en.

OECD (2017), PISA 2015 Technical Report, OECD, Paris,

http://www.oecd.org/pisa/sitedocument/PISA-2015-technical-report-final.pdf (accessed on

02 August 2018).

OECD (2016), PISA 2015 Results (Volume I): Excellence and Equity in Education, PISA, OECD Publishing, Paris, http://dx.doi.org/10.1787/9789264266490-en.

OECD (2016), The Survey of Adult Skills: Reader's Companion, Second Edition, OECD, Paris, http://dx.doi.org/10.1787/9789264258075-en (accessed on 02 August 2018).

OECD (1999), Classifying Educational Programmes: Manual for ISCED-97 Implementation in OECD Countries, http://www.oecd.org/education/skills-beyond-school/1962350.pdf (accessed on 02 August 2018).

Warm, T. (1985), "Weighted maximum likelihood estimation of ability in item response theory with tests of finite length", Psychometrika, Vol. 54/3, pp.427-450, https://dx.doi.org/10.1007/BF02294627. 



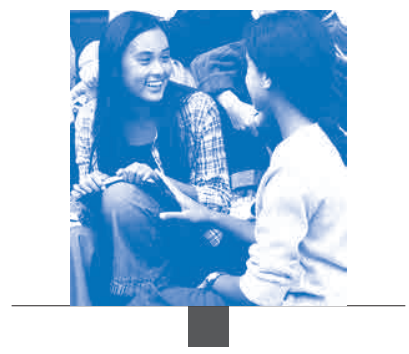

$$
\text { Annex B }
$$

LIST OF TABLES AVAILABLE ON LINE 
The following tables are available in electronic form only.

Chapter 2 How is equity in education changing?

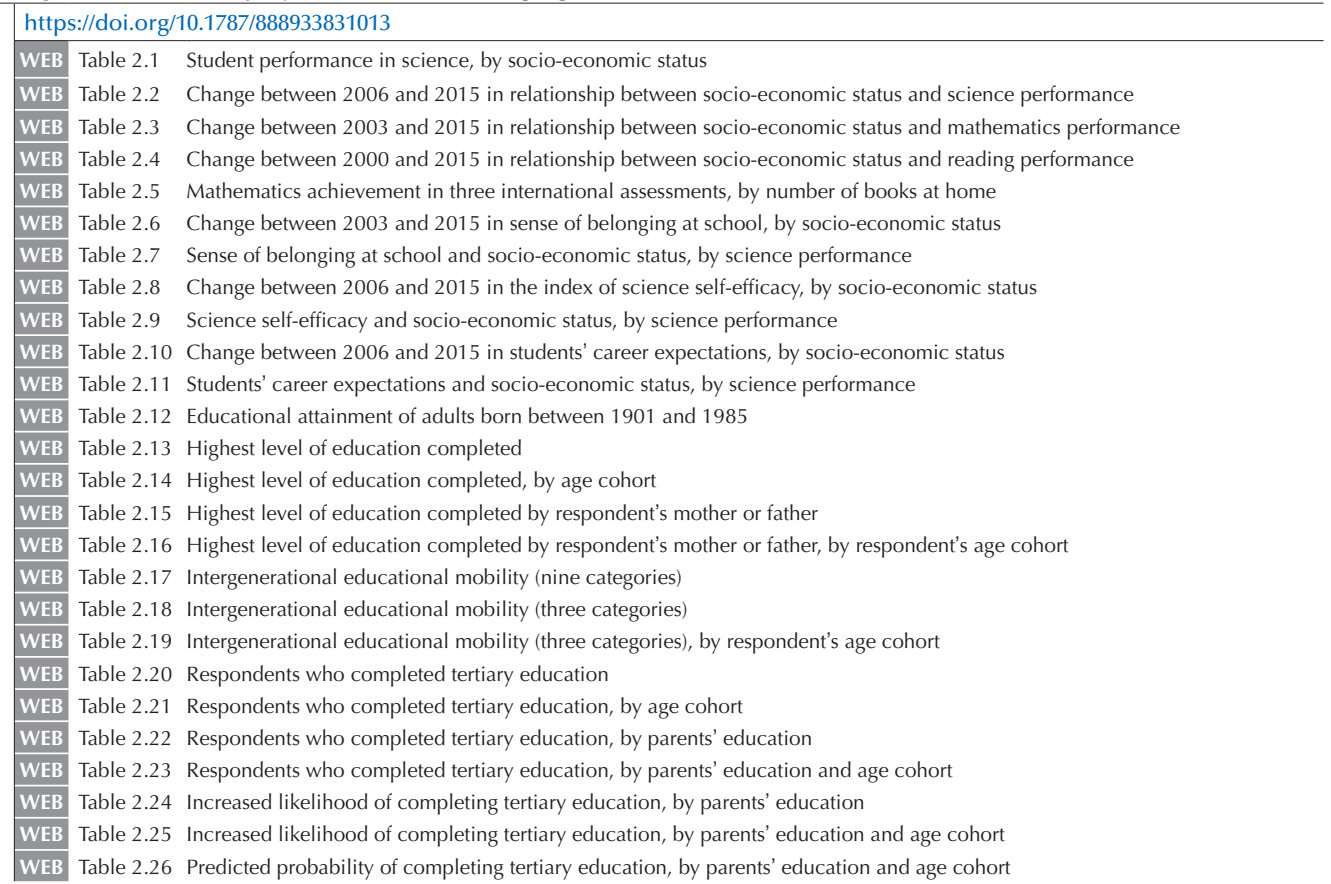

Chapter 3 Academic and socio-emotional resilience among disadvantaged students

\begin{tabular}{|c|c|c|}
\hline \multicolumn{3}{|c|}{ https://doi.org/10.1787/888933831032 } \\
\hline WEB & Table 3.1 & Socio-economic status and science performance \\
\hline WEB & Table 3.2 & Overlapping academic resilience across types \\
\hline WEB & Table 3.3 & Nationally resilient students, by student characteristics \\
\hline WEB & Table 3.4 & Nationally resilient students, by school characteristics \\
\hline WEB & Table 3.5 & Core-skills resilient students, by student characteristics \\
\hline WEB & Table 3.6 & Core-skills resilient students, by school characteristics \\
\hline WEB & Table 3.7 & Internationally resilient students, by student characteristics \\
\hline WEB & Table 3.8 & Internationally resilient students, by school characteristics \\
\hline WEB & Table 3.9a & Index of social and emotional resilience and its components \\
\hline WEB & Table $3.9 \mathrm{~b}$ & Index of social and emotional well-being and its components \\
\hline WEB & Table 3.10 & Social and emotional resilience, and performance in science \\
\hline WEB & Table 3.11 & Social and emotional resilience, and academic resilience \\
\hline WEB & Table 3.12 & Academic resilience, and the likelihood of social and emotional resilience \\
\hline WEB & Table 3.13 & Socio-economically disadvantaged students among all PISA-participating students \\
\hline
\end{tabular}




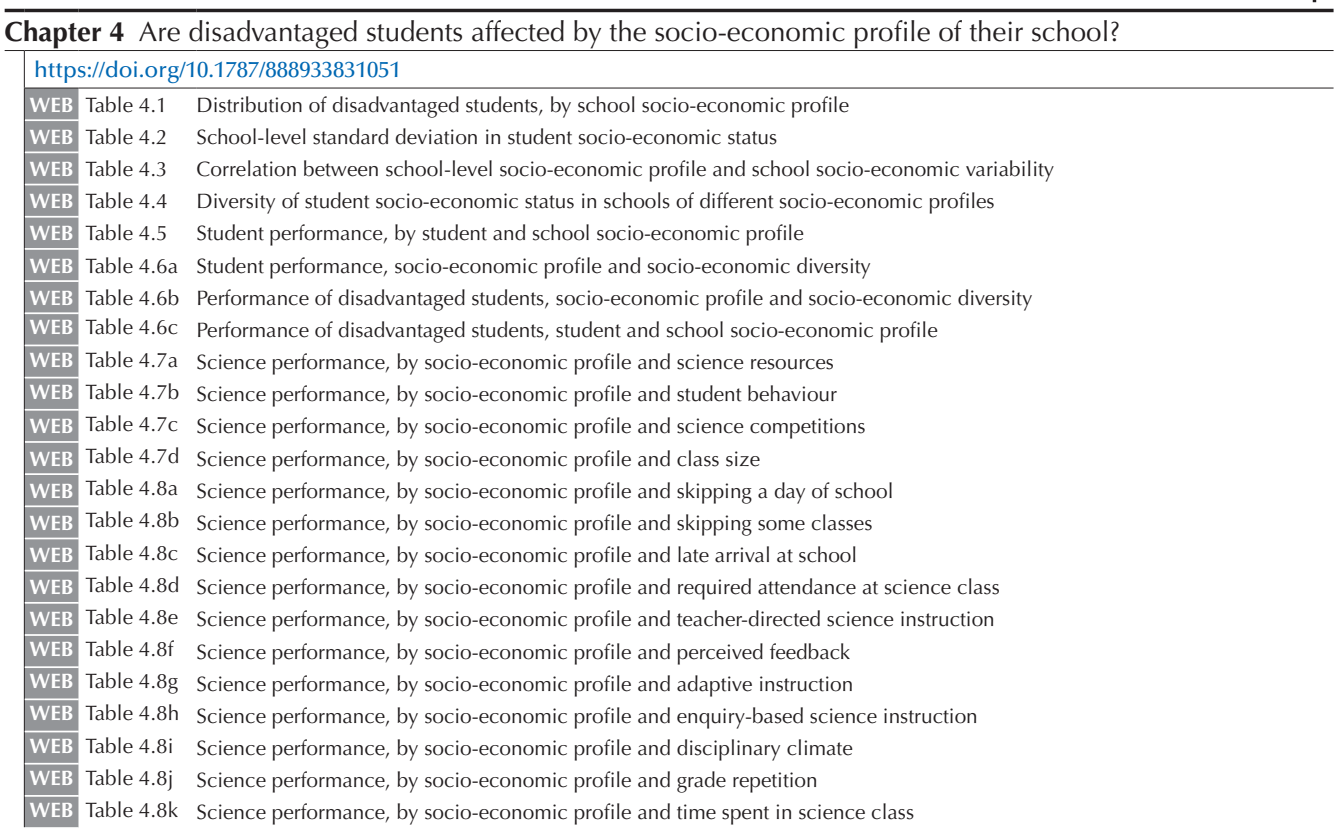

Chapter 5 Educational mobility and school-to-work transitions among disadvantaged students

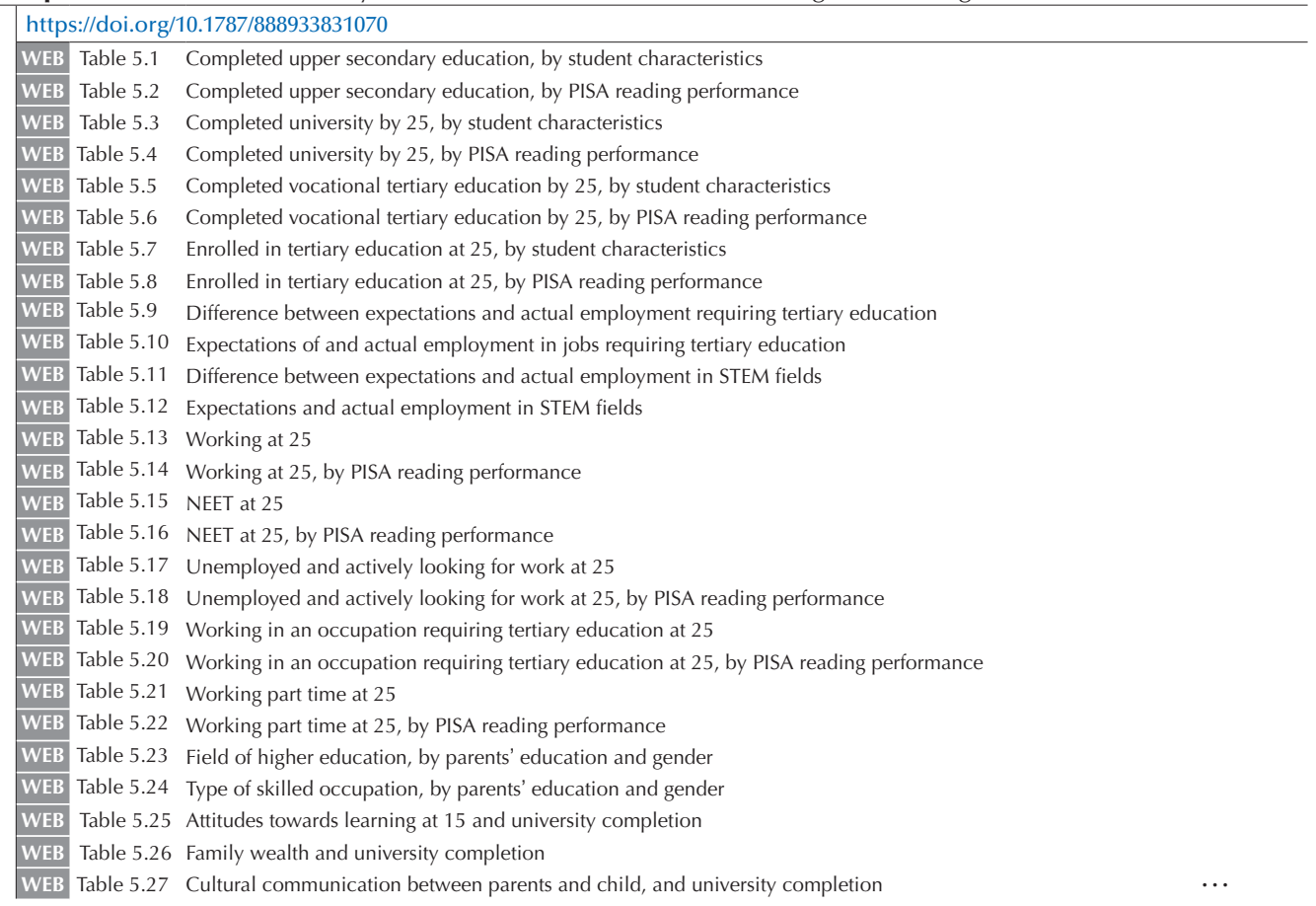


WEB Table 5.28 Fifteen-year-old students' cultural activities and university completion

WEB Table 5.29 Education and early employment outcomes, by school socio-economic profile

WEB Table 5.30 Average education expectations of schoolmates and university completion

WEB Table 5.31 Completed a STEM degree by 25

WEB Table 5.32 Completed a STEM degree at 25, by PISA science performance

WEB Table 5.33 Students from single-parent families and university completion

WEB Table 5.34 Parents' employment at 15 and university completion

WEB Table 5.35 Structure of primary and secondary public education systems, by country

WEB Table 5.36 Shares of advantaged and disadvantaged students

WEB Table 5.37 Completed or enrolled in an advanced degree programme at 25, by student characteristics

WEB Table 5.38 Completed or enrolled in an advanced degree programme at 25, by PISA reading performance

WEB Table 5.39a Literacy proficiency in PIAAC, performance in PISA 2000 and attitudes towards learning (Denmark)

WEB Table 5.39b Literacy proficiency in PIAAC, performance in PISA 2000 and years of education (Denmark)

WEB Table 5.39c Literacy proficiency in PIAAC, performance in PISA 2000 and family background (Denmark)

WEB Table 5.40a Numeracy proficiency in PIAAC, performance in PISA 2000 and attitudes towards learning (Denmark)

WEB Table 5.40b Numeracy proficiency in PIAAC, performance in PISA 2000 and years of education (Denmark)

WEB Table 5.40c Numeracy proficiency in PIAAC, performance in PISA 2000 and family background (Denmark)

WEB Table 5.41 Decomposition of disparities in literacy and numeracy proficiency between advantaged and disadvantaged youth (Denmark) 


\section{ORGANISATION FOR ECONOMIC CO-OPERATION AND DEVELOPMENT}

The OECD is a unique forum where governments work together to address the economic, social and environmental challenges of globalisation. The OECD is also at the forefront of efforts to understand and to help governments respond to new developments and concerns, such as corporate governance, the information economy and the challenges of an ageing population. The Organisation provides a setting where governments can compare policy experiences, seek answers to common problems, identify good practice and work to co-ordinate domestic and international policies.

The OECD member countries are: Australia, Austria, Belgium, Canada, Chile, the Czech Republic, Denmark, Estonia, Finland, France, Germany, Greece, Hungary, Iceland, Ireland, Israel, Italy, Japan, Korea, Latvia, Lithuania, Luxembourg, Mexico, the Netherlands, New Zealand, Norway, Poland, Portugal, the Slovak Republic, Slovenia, Spain, Sweden, Switzerland, Turkey, the United Kingdom and the United States. The European Union takes part in the work of the OECD.

OECD Publishing disseminates widely the results of the Organisation's statistics gathering and research on economic, social and environmental issues, as well as the conventions, guidelines and standards agreed by its members. 


\section{Equity in Education}

\section{BREAKING DOWN BARRIERS TO SOCIAL MOBILITY}

In times of growing economic inequality, improving equity in education becomes more urgent. While some countries and economies that participate in the OECD Programme for International Student Assessment (PISA) have managed to build education systems where socio-economic status makes less of a difference to students' learning and well-being, every country can do more.

Equity in Education: Breaking Down Barriers to Social Mobility shows that high performance and more positive attitudes towards schooling among disadvantaged 15-year-old students are strong predictors of success in higher education and work later on. The report examines how equity in education has evolved over several cycles of the OECD Programme for International Student Assessment (PISA). It identifies the policies and practices that can help disadvantaged students succeed academically and feel more engaged at school.

Using longitudinal data from five countries (Australia, Canada, Denmark, Switzerland, and the United States), the report also describes the links between a student's performance near the end of compulsory education and upward social mobility i.e. attaining a higher level of education or working in a higher-status job than one's parents.

Consult this publication on line at: $\boldsymbol{h t t p : / / d x . d o i . o r g / 1 0 . 1 7 8 7 / 9 7 8 9 2 6 4 0 7 3 2 3 4 - e n}$

This work is published on the OECD iLibrary, which gathers all OECD books, periodicals and statistical databases.

Visit www.oecd-ilibrary.org for more information.

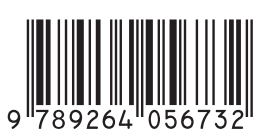

